\title{
Sodium-Bearing Waste Treatment Alternatives Implementation Study
}

Charles M. Barnes

James B. Bosley

Clifford W. Olsen

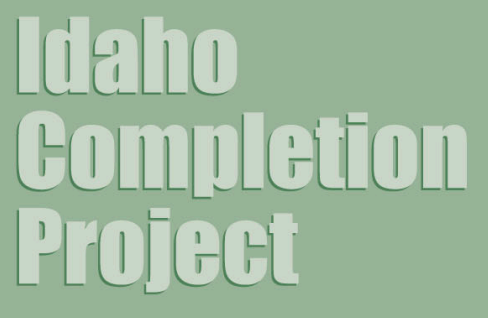

July 2004 


\section{Sodium-Bearing Waste Treatment Alternatives Implementation Study}

Charles M. Barnes

James B. Bosley

Clifford W. Olsen

July 2004

Idaho National Engineering and Environmental Laboratory

Idaho Falls, Idaho 83415

Prepared for the

U.S. Department of Energy

Assistant Secretary for Environmental Management

Under DOE Idaho Operations Office

Contract DE-AC07-99ID13727 
This page intentionally left blank 


\section{SUMMARY}

Radioactive liquid waste has been generated over the last five decades at the Idaho Nuclear Technology and Engineering Center (INTEC), formerly called the Idaho Chemical Processing Plant (ICPP), as a result of nuclear fuel reprocessing activities. From December 1963 until June 2000, the Waste Calcining Facility (WCF; now decommissioned) and the New Waste Calcining Facility (NWCF; presently in a stand-by condition, but undergoing a reversible closure) processed the liquid waste into a granular, solid form. As of February 2004, it is anticipated that approximately 1,000,000 gallons of radioactive liquid and heel solids waste, commonly referred to as sodium-bearing waste (SBW), will remain in storage in the Tank Farm Facility (TFF) at INTEC.

A Settlement Agreement between the U.S. Department of Energy (DOE) and the State of Idaho mandates treatment of the SBW stored at INTEC located within the Idaho National Engineering and Environmental Laboratory (INEEL). One of the requirements of the Settlement Agreement is to complete treatment of SBW by December 31, 2012. Hence, SBW disposition is one of the Idaho Operation Office's (NE-ID) and State of Idaho's top priorities at the INEEL.

The INEEL has been working over the past several years to identify a treatment technology that meets NE-ID and regulatory treatment requirements, including consideration of stakeholder input. Many studies, including the High-Level Waste and Facilities Disposition Environmental Impact Statement, have resulted in the identification of five treatment alternatives that form a short list of the most appropriate technologies for the DOE to select from. The alternatives are (1) calcination with maximum achievable control technology upgrade (CMACT), (2) steam reforming (SR), (3) cesium ion exchange with immobilization (CsIX), (4) direct evaporation (DE), and (5) direct vitrification (DV). Each alternative has undergone some degree of applied technical development and preliminary process design over the past four years.

Additional liquid waste, referred to as Newly Generated Liquid Waste (NGLW) resulting from filter leach operations, equipment and building decontamination activities, Resource Conservation and Recovery Act (RCRA) closure activities, and other operations at INTEC, that is generated after 2005 will be stored in separate tanks from the SBW. The accumulated inventory of NGLW may later be blended with SBW for treatment in a common treatment facility.

The SBW includes some relatively small amounts of undissolved or precipitated solids referred to as tank solids or SBW solids. For treatment alternatives that co-process liquid and solids, the solids would be distributed, prior to treatment, among the SBW storage tanks through a series of waste transfers between tanks. Mixing pumps would be installed in these tanks to keep the solids in suspension. Four of the potential treatment options, all except the CsIX/Immobilization process, would co-process the solids. Solids would be separated from the SBW and treated separately under the CsIX/Immobilization option.

The purpose of this document is to discuss issues related to the implementation of each of the five SBW treatment alternatives and summarize information in three main areas of concern: process/technical, environmental permitting, and schedule. Major implementation options for each treatment alternative are also identified and briefly discussed.

This report may touch upon, but purposely does not address in detail, issues that are programmatic in nature. Examples of these include how the SBW will be classified with respect to the Nuclear Waste Policy Act (NWPA), status of Waste Isolation Pilot Plant (WIPP) permits and waste storage availability, available funding for implementation, stakeholder issues, and State of Idaho Settlement Agreement milestones. 
It is assumed in this report that the SBW would be classified as a transuranic (TRU) waste suitable for disposal at WIPP, located in New Mexico, after appropriate treatment to meet transportation requirements and waste acceptance criteria (WAC). 


\section{CONTENTS}

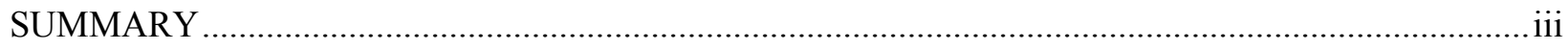

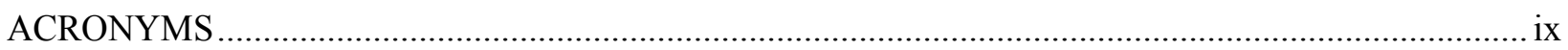

1. CALCINATION WITH MACT UPGRADE (CMACT) …...................................................... 1

1.1 CMACT Physical Systems_-Process/Technical and Related ....................................... 1

1.1.1 CMACT Technical Risks Related To Off-Gas Emissions .................................. 1

1.1.2 CMACT Technical Risks Related To Waste Product Qualification, Characteristics, And Storage ...................................................................... 4

1.1.3 CMACT Risks Related To Feed Uncertainties ................................................. 6

1.1.4 CMACT Risks Related To Use Of And Upgrading The NWCF ....................... 7

1.1.5 CMACT Risks Related to New Treatment Facilities ........................................ 10

1.1.6 CMACT Balance of Plant Requirements, Facility Siting, and Interfaces .......... 11

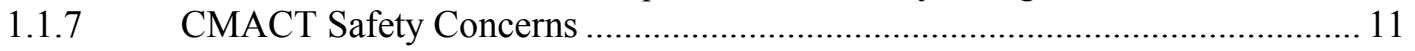

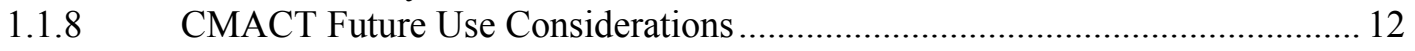

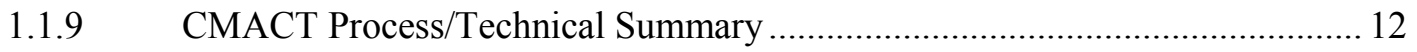

$1.2 \quad$ CMACT Environmental / Regulatory and Related ....................................................... 14

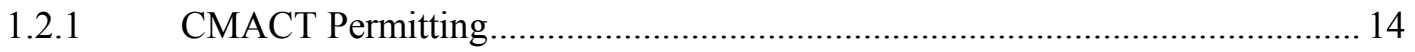

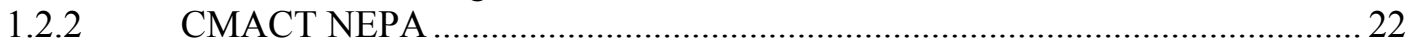

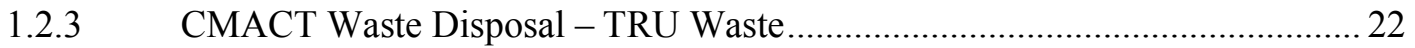

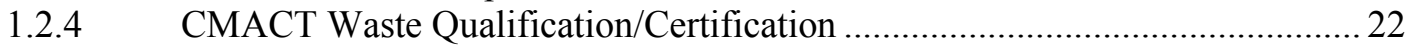

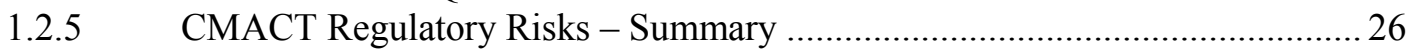

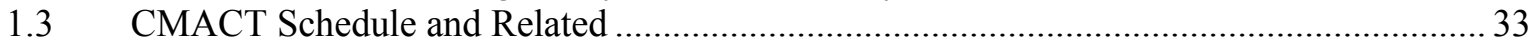

1.3.1 CMACT Capital Project Schedule (February 2005 to September 2010) .......... 33

1.3.2 CMACT Treatment Operations Schedule (October 2010 to November 2014). 39

1.3.3 CMACT Waste Shipment Schedule (April 2011 to May 2016) ......................... 41

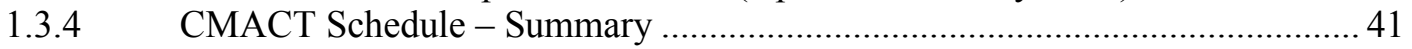

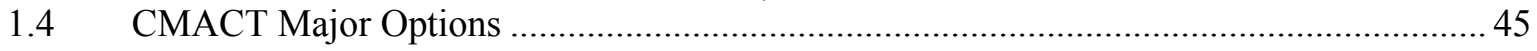

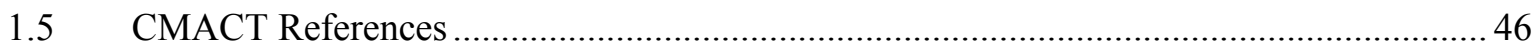

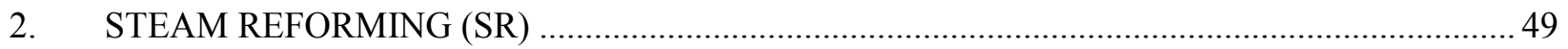

2.1 SR Physical Systems - Process/Technical and Related ................................................. 49

2.1.1 SR Technical Risks Related to Off-Gas Emissions......................................... 49

2.1.2 SR Technical Risks Related to Waste Product Qualification, Characteristics, and Storage .............................................................................................. 51

2.1.3 SR Risks Related to Feed Uncertainties..................................................... 52

2.1.4 SR Risks Related to the Steam Reformer and Reformer Product Packaging.... 53

2.1.5 SR Balance of Plant Requirements, Facility Siting, and Interfaces ................... 54

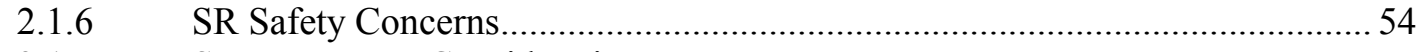

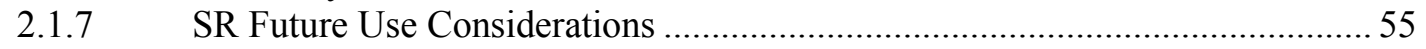

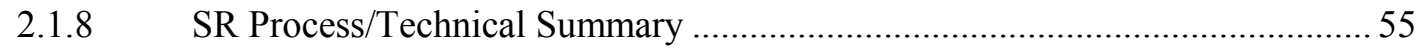

2.2 SR Environmental/Regulatory and Related .............................................................. 57

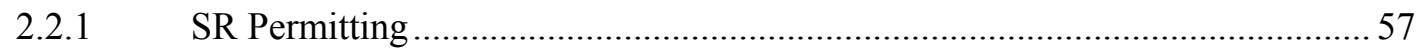




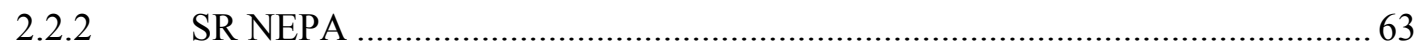

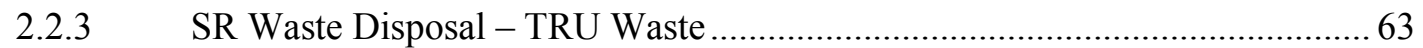

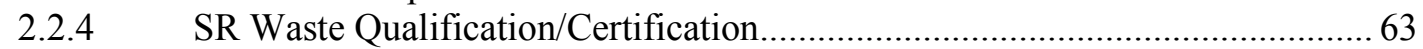

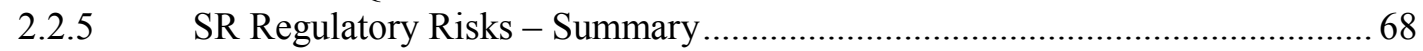

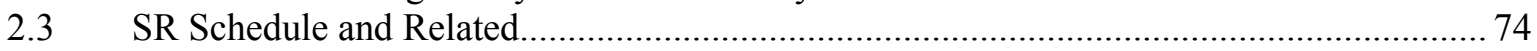

2.3.1 SR Capital Project Schedule (February 2005 to September 2010) .................... 74

2.3.2 SR Treatment Operations Schedule (October 2010 to November 2013) .......... 80

2.3.3 SR Waste Shipment Schedule (April 2011 to December 2013)....................... 80

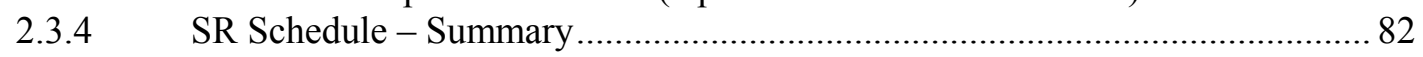

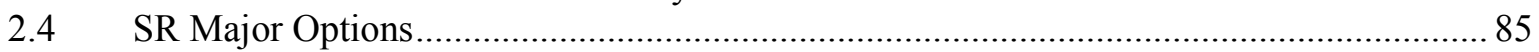

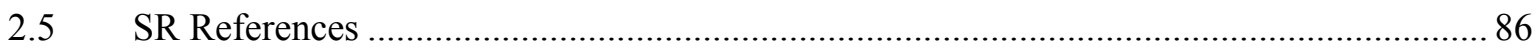

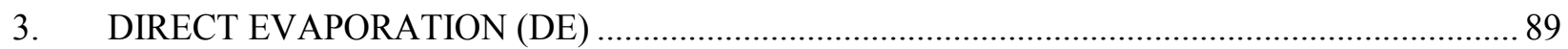

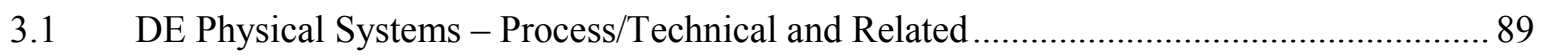

3.1.1 DE Technical Risks Related to Off-Gas and Emissions ................................. 89

3.1.2 DE Technical Risks Related to Waste Product Qualification and Characteristics91

3.1.3 DE Risks Related to Feed Uncertainties and Feed Transfer .............................93

3.1.4 DE Risks Related to the SBW Evaporator Performance...................................99

3.1.5 DE Risks Related to Evaporator Product Packaging....................................... 95

3.1.6 DE Risks Related to Off-gas Treatment............................................................ 95

3.1.7 DE Risks Related to Use of and Upgrade of the LET\&D System ................... 96

3.1.8 DE balance of plant requirements, facility siting, and interfaces......................96

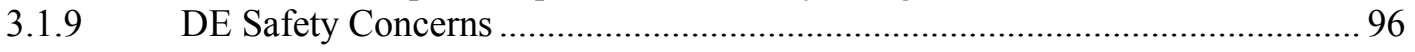

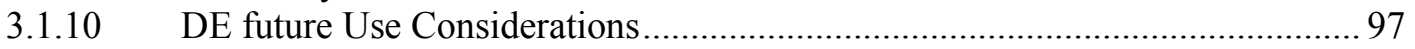

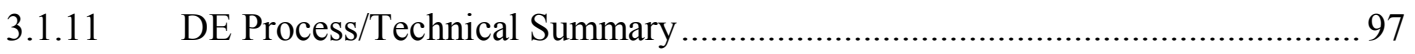

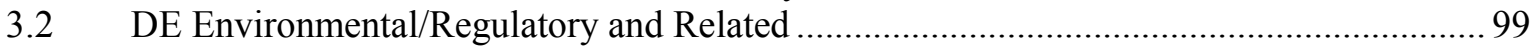

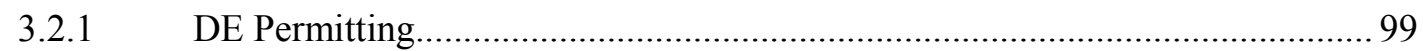

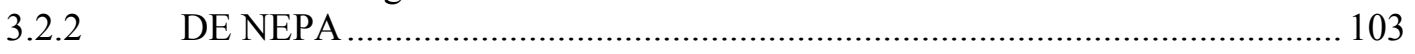

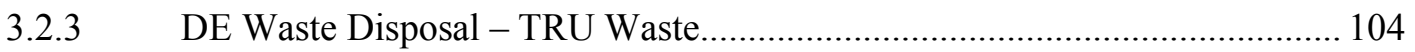

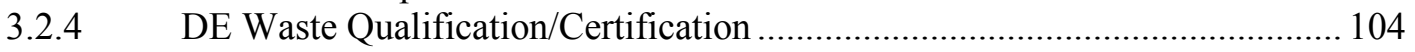

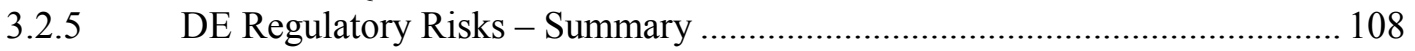

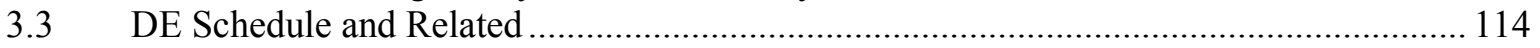

3.3.1 DE Capital Project Schedule (February 2005 to September 2010)................. 114

3.3.2 DE Treatment Operations Schedule (October 2010 to November 2013)........ 118

3.3.3 DE Waste Shipment Schedule (April 2011 to December 2016) ...................... 118

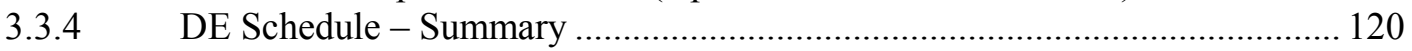

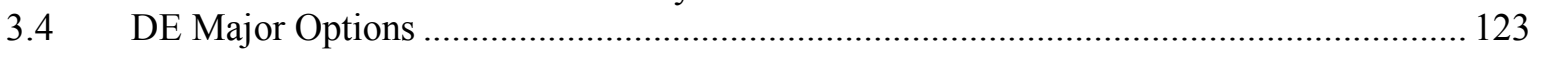

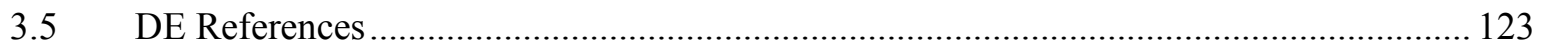

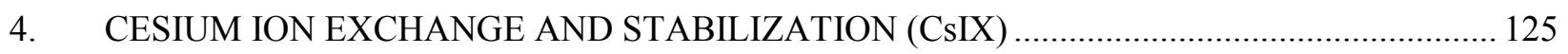

4.1 CsIX Physical Systems - Process/Technical and Related............................................ 125

4.1.1 CsIX Technical Risks Related to Waste Product Qualification, Characteristics, and Storage ........................................................................................... 125

4.1.2 CsIX Risks Related to Feed Uncertainties and Feed Transfer ........................ 127 
4.1.3 CsIX Risks Related to Use of Existing Evaporators and the LET\&D Facility 128

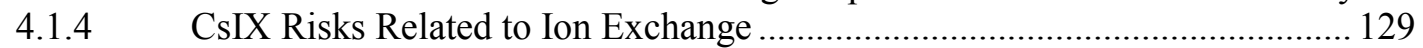

4.1.5 CsIX Risks Related to Grouting.................................................................. 130

4.1.6 CsIX Risks Related to Solids Processing ..................................................... 130

4.1.7 CsIX Balance of Plant Requirements, Facility Siting, and Interfaces.............. 131

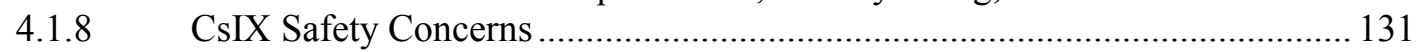

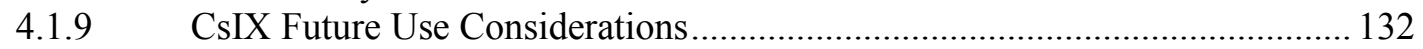

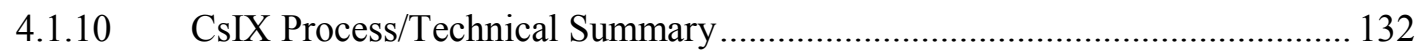

4.2 CsIX - Environmental / Regulatory and Related............................................................ 134

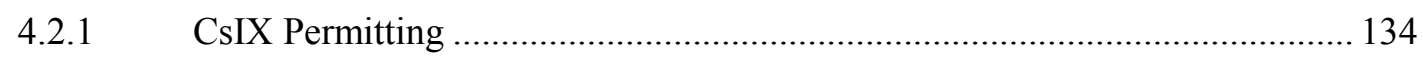

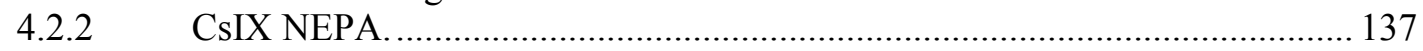

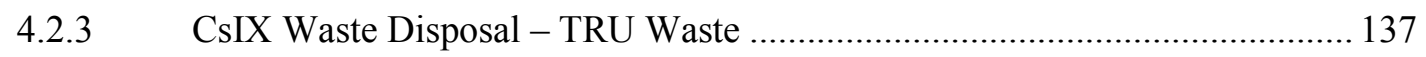

4.2.4 CsIX Waste Qualification / Certification ........................................................ 137

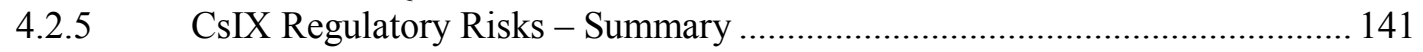

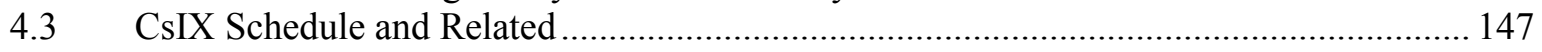

4.3.1 CsIX Capital Project Schedule (February 2005 to September 2010).............. 147

4.3.2 CsIX Treatment Operations Schedule (October 2010 to November 2013) .... 151

4.3.3 CsIX Waste Shipment Schedule (April 2011 to November 2013)................... 152

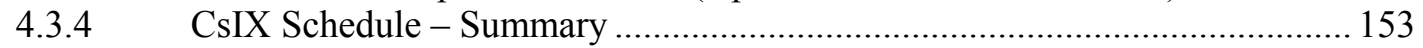

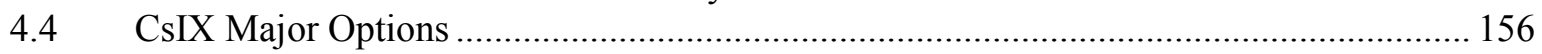

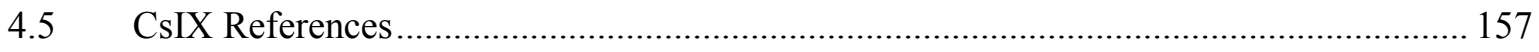

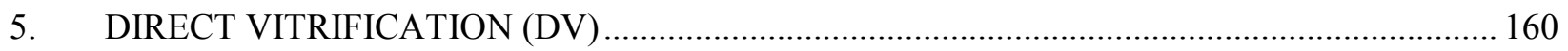

5.1 DV Physical Systems - Process / Technical and Related ........................................... 160

5.1.1 DV Technical Risks Related to Waste Product Qualification, Characteristics, and Storage ............................................................................................... 160

5.1.2 DV Risks Related to Feed Uncertainties and Feed Transfer........................... 163

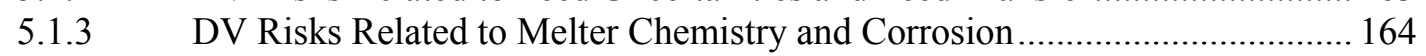

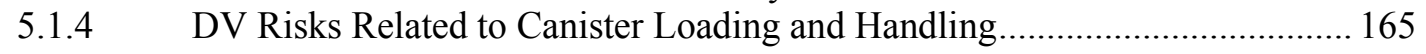

5.1.5 DV Risks Related to Off-Gas Treatment and Emissions ................................ 165

5.1.6 DV Balance of Plant Requirements, Facility Siting, and Interfaces ................ 167

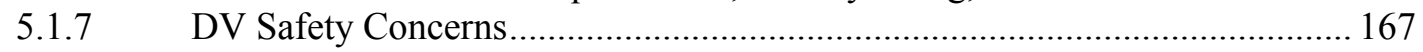

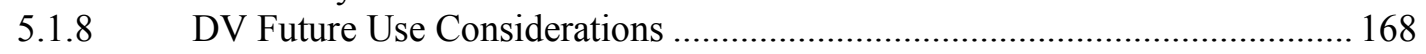

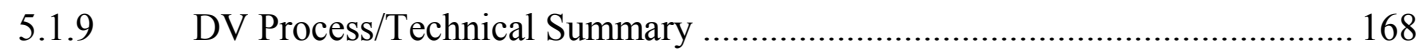

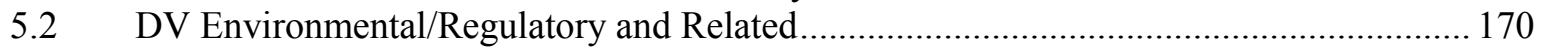

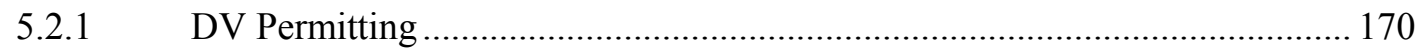

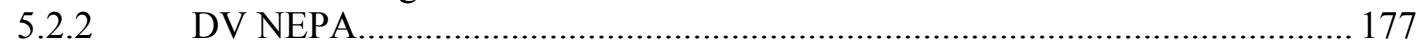

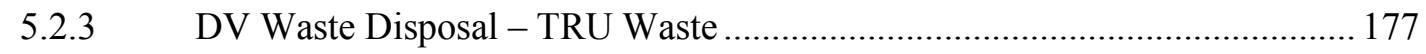

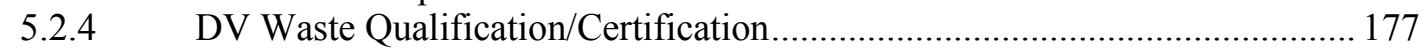

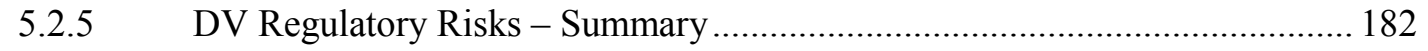

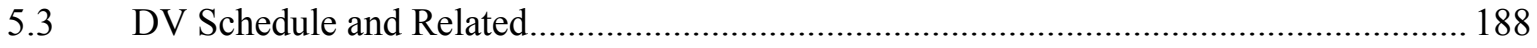

5.3.1 DV Capital Project Schedule (February 2005 to December 2013) ................. 188

5.3.2 DV Treatment Operations Schedule (January 2014 to February 2017).......... 194

5.3.3 DV Waste Shipment Schedule (January 2014 to February 2017).................... 194

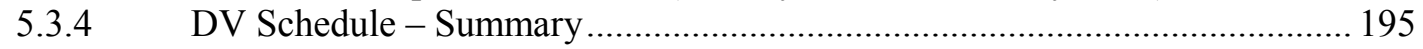

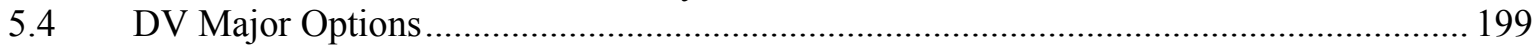


6. ALL ALTERNATIVES - SCHEDULE AND INTERIM STORAGE COMPARISON TABLES201 FIGURES

Figure 1-1. SBW Calcine/MACT block flow diagram: Tank Farm, NWCF, and Calcine Packaging Facility (CPF).

Figure 1-2. SBW Calcine/MACT block flow diagram: MACT Compliance Facility (MCF).................... 3

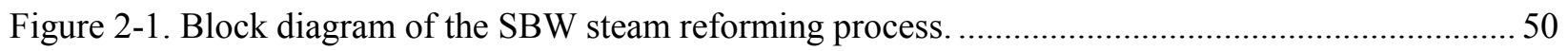

Figure 3-1. SBW direct evaporation (with alkaline scrubber) block flow diagram.............................. 90

Figure 4-1. SBW CsIX/TRU grout block flow diagram. ................................................................ 126

Figure 5-1 Block diagram of the SBW direct vitrification process....................................................... 161

\section{TABLES}

Table 1-1. Calcination System Upgrades - cost and ALARA summary ................................................. 9

Table 1-2. Summary of technical issues and risks - Calcination with MACT Upgrade (CMACT).......... 13

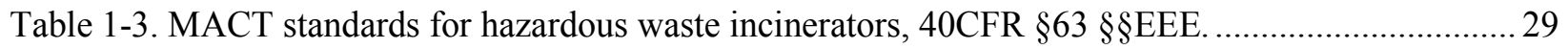

Table 1-4. Important New Source Review (NSR) Values................................................................. 30

Table 2-1. Summary of technical issues and risks - Steam Reforming (SR). ..................................... 55

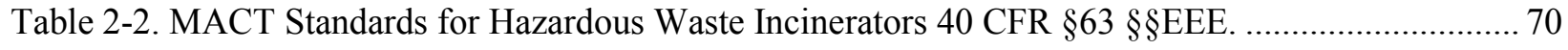

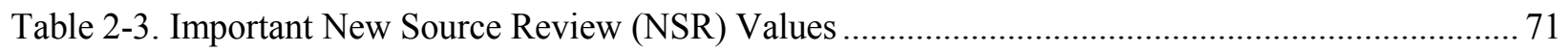

Table 3-1. Summary of technical issues and risks - direct evaporation (DE) . .................................... 97

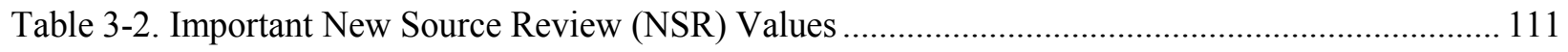

Table 4-1. Summary of technical issues and risks - cesium ion exchange/TRU grout (CsIX).............. 132

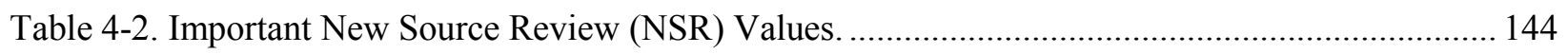

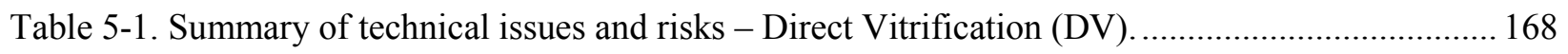

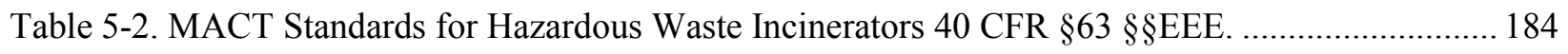

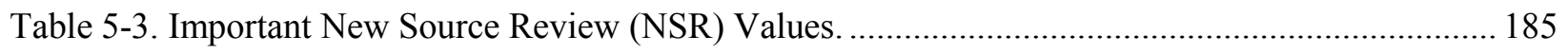

Table 6-1. Schedule Comparisons for the 5 SBW Treatment Alternatives. ........................................... 201

Table 6-2. Interim Storage Comparisons for the 5 SBW Treatment Alternatives................................. 202 


\title{
ACRONYMS
}

\author{
AAR aluminum to alkali mole ratio \\ ALARA as low as reasonably achievable \\ APS Atmospheric Protection System \\ BBWI Bechtel BWXT Idaho, LLC \\ CAA Clean Air Act \\ CBFO (DOE-) Carlsbad Field Office \\ CC construction component \\ CD Critical Decision \\ CEM continuous emission monitor \\ CERCLA Comprehensive Environmental Response, Compensation, and Liability Act \\ CFR code of federal regulations \\ $\mathrm{CH} \quad$ contact-handled \\ CMACT Calcination with MACT Upgrade (SBW treatment alternative) \\ CPF Calcine Packaging Facility \\ CsIX Cesium Ion Exchange (SBW treatment alternative) \\ CSSF Calcine Solids Storage Facility \\ CST crystalline silicotitanate \\ CT cold test \\ DE Direct Evaporation (SBW treatment alternative) \\ DNFSB Defense Nuclear Facilities Safety Board \\ DOE Department of Energy \\ DV Direct Vitrification (SBW treatment alternative) \\ DNFSB Defense Nuclear Facilities Safety Board \\ DWPF Defense Waste Processing Facility \\ EA environmental assessment \\ EDF Engineering Design File \\ EIS Environmental Impact Statement \\ EM-WAPS Environmental Management Waste Acceptance Product Specifications \\ EPA Environmental Protection Agency
}




\begin{tabular}{|c|c|}
\hline ETS & Evaporative Tank System \\
\hline FDSA & Final Documented Safety Analysis \\
\hline $\mathrm{FFA} / \mathrm{CO}$ & Federal Facilities Agreement and Consent Order \\
\hline FY & fiscal year \\
\hline GAC & granulated activated carbon \\
\hline GFE & government furnished equipment \\
\hline HAP & hazardous air pollutant \\
\hline HEME & high efficiency mist eliminator \\
\hline HEPA & high efficiency particulate air (filter) \\
\hline HLLWE & High Level Liquid Waste Evaporator \\
\hline HLW & high-level waste \\
\hline HVAC & heating, ventilation, and air conditioning \\
\hline $\mathrm{HWC}$ & Hazardous Waste Combustion \\
\hline HWFP & hazardous waste facility permit \\
\hline HWMA & Hazardous Waste Management Act \\
\hline $\mathrm{ICDF}$ & Idaho CERCLA Disposal Facility \\
\hline ICPP & Idaho Chemical Processing Plant \\
\hline IDEQ & Idaho Department of Environmental Quality \\
\hline INEEL & Idaho National Engineering and Environmental Laboratory \\
\hline INTEC & Idaho Nuclear Technology and Engineering Center \\
\hline IWVF & Idaho Waste Vitrification Facility \\
\hline LDR & land disposal restrictions \\
\hline LET\&D & Liquid Effluent Treatment and Disposal \\
\hline LWA & Land Withdrawal Act \\
\hline MACT & maximum achievable control technology \\
\hline $\mathrm{MCF}$ & MACT Compliance Facility \\
\hline MTHM & metric ton heavy metal \\
\hline NAA & nonattainment areas \\
\hline NAAQS & national ambient air quality standards \\
\hline NAR & nozzle-air-ratio \\
\hline
\end{tabular}


NE-ID DOE Idaho Operations Office

NEPA National Environmental Policy Act

NESHAPs National Emission Standards for Hazardous Air Pollutants

NGLW newly generated liquid waste

NGR National Geologic Repository

NIC notice of intent to comply

NMED New Mexico Environmental Department

$\mathrm{NO}_{\mathrm{x}} \quad$ nitrogen oxides (gas containing both $\mathrm{NO}$ and $\mathrm{NO}_{2}$ )

NRC Nuclear Regulatory Commission

NSR new source review

NTS Nevada Test Site

NWCF New Waste Calcining Facility

NWPA Nuclear Waste Policy Act

ODS ozone-depleting substances

ORR operational readiness review

P\&IDs process and instrument diagrams

PAL plant wide applicability limits

PDC Project Design Criteria (document)

PDSA Preliminary Documented Safety Analysis

PE professional engineer

PEWE process equipment waste evaporator

PFD process flow diagram

PHA Preliminary Hazards Analysis

PIP Program Implementation Plan

PPE personal protective equipment

PSD prevention of significant deterioration

PTC permit to construct

PTE potential to emit

PTS pneumatic transfer system

RAL Remote Analytical Laboratory 


\begin{tabular}{|c|c|}
\hline RAM & reliability, availability, and maintainability \\
\hline RCRA & Resource Conservation and Recovery Act \\
\hline RH & remote-handled \\
\hline RWMC & Radioactive Waste Management Complex \\
\hline SAR & safety analysis report \\
\hline SBW & sodium-bearing waste \\
\hline SBWT & SBW Treatment (Project) \\
\hline S-GAC & sulfur-impregnated, granulated activated carbon \\
\hline SO & system operations (tests) \\
\hline SOW & Scope of Work \\
\hline SR & Steam Reforming (SBW treatment alternative) \\
\hline SRS & Savannah River Site \\
\hline SSRA & site-specific risk assessment \\
\hline TFR & Technical and Functional Requirements (document) \\
\hline TFF & Tank Farm Facility \\
\hline THOR & thermal organic reduction \\
\hline TRU & transuranic (waste) \\
\hline TSP & total suspended particulate \\
\hline TTT & THOR $^{\text {sm }}$ Treatment Technologies \\
\hline TWBIR & TRU Waste Baseline Inventory Report \\
\hline TWR & ThermoChem Waste Remediation \\
\hline VOC & volatile organic compound \\
\hline WAC & waste acceptance criteria \\
\hline WCF & Waste Calcining Facility \\
\hline WFCP & Waste Form Compliance Plan \\
\hline WFQP & Waste Form Qualification Plan \\
\hline WIPP & Waste Isolation Pilot Plant \\
\hline WIR & waste incidental to reprocessing \\
\hline
\end{tabular}




\section{Sodium-Bearing Waste Treatment Alternatives Implementation Study}

A Settlement Agreement between the U.S. Department of Energy (DOE) and the Sate of Idaho mandates treatment of approximately 1,000,000 gallons of sodium-bearing waste (SBW) at the Idaho Nuclear Technology and Engineering Center (INTEC) at the Idaho National Engineering and Environmental Laboratory (INEEL) by December 31, 2012. This report discusses the issues related to the five treatment alternatives selected for this cleanup: (1) calcination with maximum achievable control technology upgrade (CMACT), (2) steam reforming (SR), (3) cesium ion exchange with immobilization (CsIX), (4) direct evaporation (DE), and (5) direct vitrification (DV).

\section{CALCINATION WITH MACT UPGRADE (CMACT)}

The baseline process scenario for this SBW treatment alternative involves calcination in an upgraded existing calciner system located in the New Waste Calcination Facility, fed from the existing Tank Farm tanks provided with new mixing pumps to suspend and mix the tank solids with the liquid SBW for co-processing; construction of a new MACT Compliance Facility (MCF) for off-gas treatment; and construction of a new Calcine Packaging Facility (CPF) for capturing, cooling, packaging, and providing interim storage of SBW calcine and neutralization, grouting, packaging, and interim storage of calciner scrub solution (see Figures 1-1 and 1-2).

\subsection{CMACT Physical Systems-Process/Technical and Related}

\subsubsection{CMACT Technical Risks Related To Off-Gas Emissions}

The MACT Compliance Facility (MCF) can be designed such that the risk of exceeding any emissions standard is negligibly small. However, for the sake of reducing costs, designs may elect to accept certain risks relative to off-gas treatment.

In the Merrick design (Merrick 2004), gas entering the MCF is first high efficiency particulate air (HEPA) filtered in order to keep the MCF radiologically clean. These filters may be overly conservative and redundant since the calciner off-gas is also HEPA filtered as it exits the NWCF. Removing these HEPA filters carries the risk of increased collection of radioactivity in MCF equipment (some of which will require periodic maintenance) and potential increased emissions of particulate and nonvolatile and semi-volatile metals and radionuclides although the current design shows HEPA filtration as the gas exits the MCF as well.

The concentration of chlorides $\left(\mathrm{HCl} / \mathrm{Cl}_{2}\right)$ in the off-gas is uncertain. Analyses for $\mathrm{HCl}$ and $\mathrm{Cl}_{2}$ in NWCF off-gas samples taken in 1999 and 2000, during operation on SBW feed, showed concentrations below detection limits (10-55 ppm total $\mathrm{Cl}$, dry basis) which brackets the MACT limit of $21 \mathrm{ppmv}$ (Boardman 1999; 2001). Recent pilot test data shows concentrations of $\mathrm{HCl}$ in the off-gas upstream of the GAC bed less than 1 ppm (Boardman 2004), but because scrub solution was not recycled in the pilot test, chlorides in the off-gas from this test can be expected to be much lower than during full-scale operation. The concentration of chlorides in the test scrub solution was lower than expected for NWCF operation by a factor of about 5-10.

In addition to uncertainty in the concentration of $\mathrm{HCl} / \mathrm{Cl}_{2}$ in the off-gas, the removal of $\mathrm{HCl}$ by the granulated activated carbon (GAC) bed is uncertain. Long-term tests with a $6.3 \mathrm{~cm}^{3}$ carbon bed showed negligible $\mathrm{HCl}$ removal (Del Debbio 2003). However, the recent pilot tests, even though the GAC bed feed gas chloride concentration was low, showed increased levels of chloride in the carbon implying removal (Boardman 2004). Removal of chloride by the GAC bed would ensure that chloride emissions are not exceeded, but would require additional carbon. If the carbon beds were sized only for mercury removal, carbon replacement could be required. 


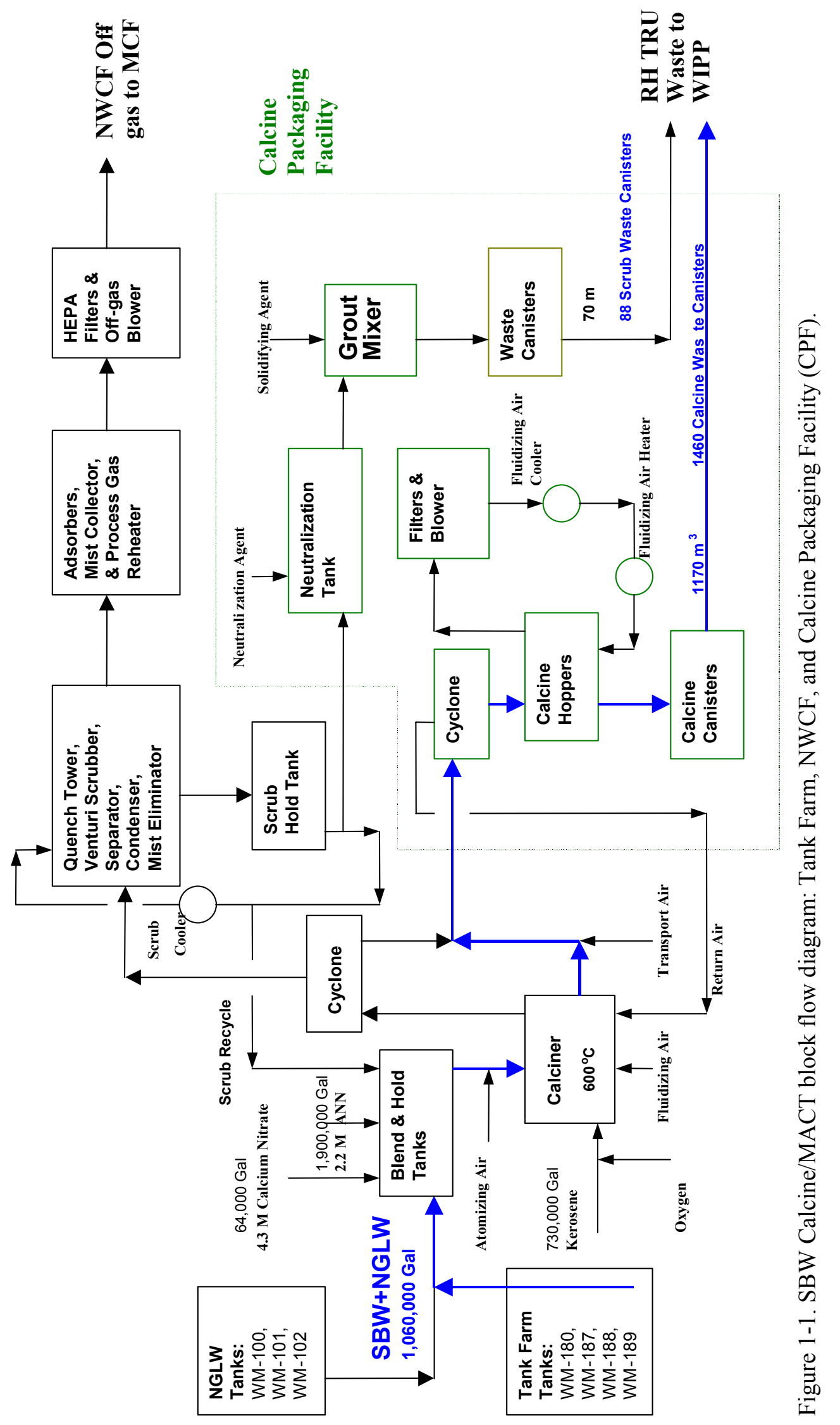



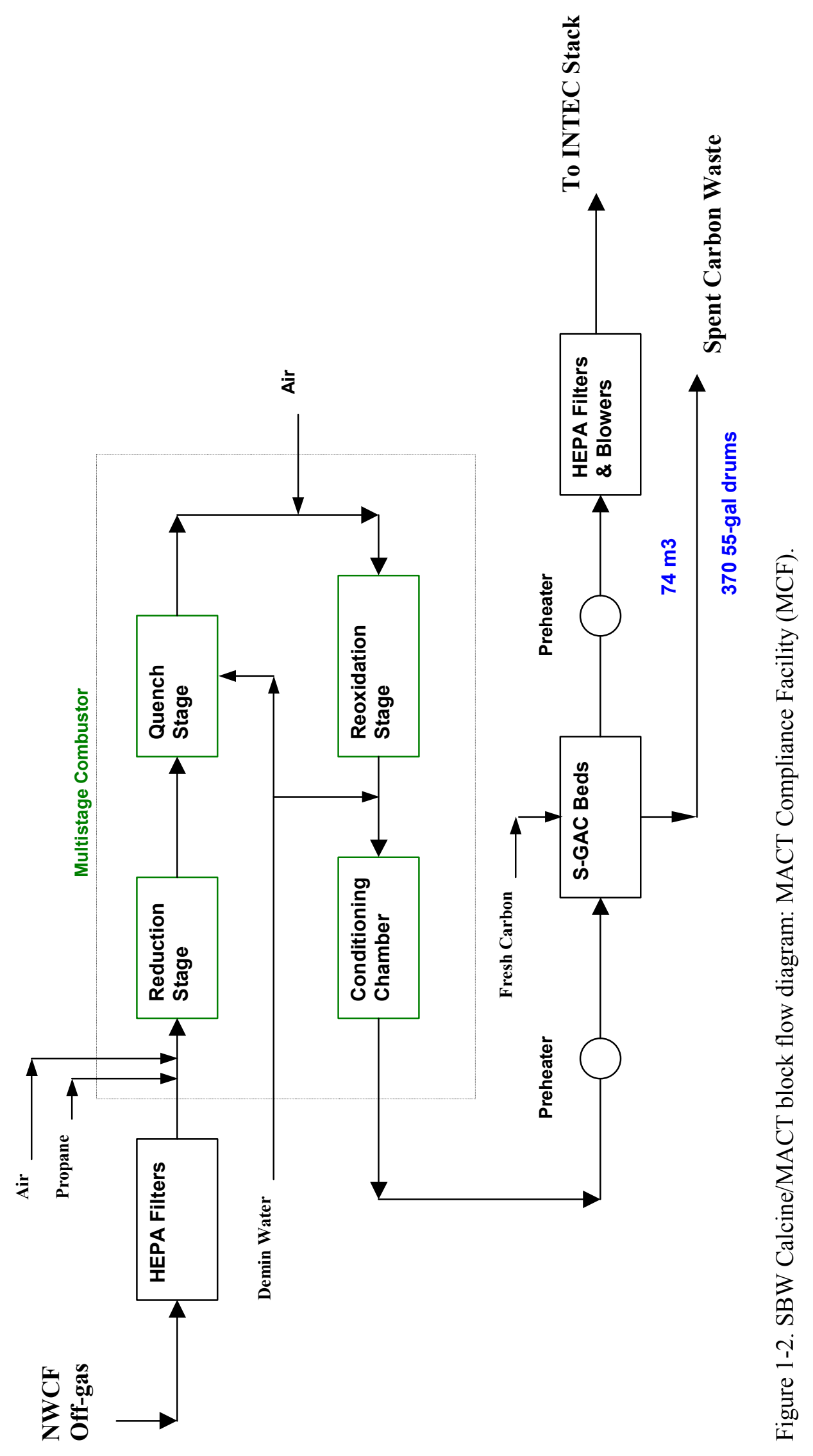
Methods to remove chlorides have been identified and evaluated by Barry O'Brien (O'Brien 2002).

Tests have repeatedly shown that the MACT mercury $(\mathrm{Hg})$ emissions limit can be met by removal of mercury from the off-gas with sulfur-impregnated GAC (Del Debbio 2003; Boardman 2004).

Remaining uncertainties regarding mercury removal relate to sizing the GAC beds and whether to include spare beds, either in parallel or series. One option is to design a single bed to remove all the mercury expected during SBW processes. However, while nearly all mercury will volatilize in the calciner, the exact partitioning of mercury between off-gas and scrub solution is not certain. The maximum mercury loading on the carbon is also uncertain. To allow for these uncertainties as well as the uncertain adsorption of $\mathrm{HCl}$ by the GAC, two beds in parallel could be used so that one could be changed out while the other is still operating. Parallel beds designed for change-out would permit reducing their size compared to one bed sized for no change-out.

Exceeding emission limits due to equipment failure is a risk. Should the staged combustor fail for any reason, the off-gas would be diverted temporarily to the existing atmospheric protection system (APS) and stack, with $\mathrm{CO}, \mathrm{Hg}$, and organics exceeding MACT limits and also releasing $\mathrm{NO}_{\mathrm{x}}$ A GAC-bed temperature excursion could possibly also result in releasing mercury to the atmosphere.

Recent pilot tests (Boardman 2004) have demonstrated that the staged combustor can adequately destroy total hydrocarbons and $\mathrm{CO}$ to below MACT limits, and achieve acceptable levels of $\mathrm{NO}_{\mathrm{x}}$ destruction. No tests have been performed to demonstrate whether the staged combustor will meet the required $99.99 \%$ destruction of principal organic hazardous constituents.

There is also a risk that emissions standards may change. Between now and when the facility comes on line ( 2009), regulations may change that would affect how the plant is designed and operated.

\subsubsection{CMACT Technical Risks Related To Waste Product Qualification, Characteristics, And Storage}

\section{Risks related to waste product qualification have minimal impact provided adequate steps are taken in the design and issues are worked out with waste disposal sites.}

The transuranic (TRU) content of the grouted scrub waste is uncertain. Present mass balances (Barnes 2004) show the TRU-content of grouted scrub waste would be 110-160 $\mathrm{nCi} / \mathrm{g}$. This range is only marginally above the minimum for WIPP disposal of $100 \mathrm{nCi} / \mathrm{g}$. Uncertainties in mass balance assumptions, for example, the rate of buildup of mercury in the scrub, could result in a scrub grout with a TRU-content less than that required for WIPP disposal.

The risk of the grouted scrub waste not qualifying for WIPP disposal due to too low a TRU level is low for two reasons: (1) historical analysis of scrub for other nonvolatile species and (2) the infrequency of purging scrub to the grouting system. The scrub system is purged to the feed tank (referred to as "scrub recycle") to avoid buildup of calcine solids in the scrub. The scrub is purged to the grouting system to avoid excessive buildup of mercury. Purging to the grout system is expected to be required only 3 times over the course of processing all the SBW. Thus there is ample time to sample, analyze, and purge the scrub system only when the TRU content is sufficiently high.

While samples of calciner scrub have not been analyzed for transuranic radionuclides in the past, they have routinely been analyzed for major components of calcine such as aluminum. During the period in 2000 when the NWCF processed SBW using the high temperature $\left(600^{\circ} \mathrm{C}\right)$ flowsheet, the concentration of aluminum in the scrub was usually in the range of 1.4 to 2 molar (Law 2000). Assuming 
the same partitioning of transuranic elements as aluminum would indicate that the scrub, when grouted, would have a TRU content of $250-500 \mathrm{nCi} / \mathrm{g}$.

The TRU-content of NGLW is highly uncertain, and should analysis show a lower content than SBW, it would need to be blended with SBW prior to processing in the calciner to ensure an adequate TRU-content of scrub waste.

The radiolytic hydrogen generation rate from the scrub grout is uncertain. Various waste forms have been suggested for the scrub. If a design utilized a waste form that had a high waste loading, greater than about $50 \%$, the water content of the waste could result in excessive radiolytic hydrogen generation. For the current recommended waste form for the scrub waste, grout, and recommended waste loading, $35 \%$ (Raman 2003), hydrogen generation should not be an issue.

The volume of the grouted scrub waste is uncertain. The volume of grouted scrub waste will be determined by the amount of mercury that is captured by the aqueous scrub system. There is uncertainty both in the partitioning of mercury between scrub and off-gas and the limiting concentration of mercury in the scrub. However, because the scrub is grouted infrequently during SBW processing, additional scrub waste can be processed with very little impact to the treatment facility. Also, the low volume of grout waste produced makes the impact of additional grouted waste small in terms of additional storage space needed for additional waste.

There is uncertainty in the calcine density and volume. In the recent calcination pilot test, the product calcine had a combined fines and product bulk density of $0.95 \mathrm{~g} / \mathrm{cm}^{3}$ during operation at an AAR of 2.25 and $0.90 \mathrm{~g} / \mathrm{cm}^{3}$ at a $1.75 \mathrm{AAR}$ (Boardman 2004, Table 4.3-4). If the full-scale calciner does not achieve the product to fines ratio of the pilot test but instead is close to past runs $(\mathrm{P} / \mathrm{F} \sim 1.0)$, the density of the product calcine would be only $0.68 \mathrm{~g} / \mathrm{cm}^{3}$. Current mass balances (Barnes 2003) assume a density of $1.2 \mathrm{~g} / \mathrm{cm}^{3}$. A lower density product would produce a greater volume of waste requiring a greater interim storage area or an additional processing step to densify the product. The uncertainty of the calcine density is high.

The disposal site and treatment requirements for spent GAC are uncertain. Leach tests of GAC from testing performed in 2002 showed leached mercury concentrations below the RCRA Land Disposal Restriction (LDR) limit of $0.025 \mathrm{mg} /$ liter (Herbst 2002), but similar tests from the long-term mercury removal tests in 2003 showed leach concentrations far in excess of the LDR limit (Del Debbio 2003). In either case, present regulations would require that the spent GAC, classified as a "high mercury" waste, be retorted. The Environmental Protection Agency is considering changes to this requirement (DOE 1999; Hulet 2001). If required, several methods could be used to stabilize the spent GAC waste for disposal. If the spent GAC waste is shown to meet TCLP limits, it could be argued that amalgamation of mercury with the sulfur present in the GAC is adequate immobilization. One stabilization method, Nuclear Fuel Services' DeHg® process, has been used by Envirocare to enable disposal of mercury-containing waste (Envirocare 2001). Thus, it may be possible to ship the spent GAC directly to Envirocare for treatment and disposal. However, no contact has yet been made with any disposal site regarding this waste.

The WIPP Waste Acceptance Criteria (WAC) for remote-handled (RH) has not been issued. WIPP has prepared a draft WAC document for RH waste (WIPP 2002a), but the document is not final or approved. Additional requirements for RH TRU waste are contained in the RH-TRU 72-B Cask Safety Analysis Report (SAR) (WIPP 2002b). Until the RH-WIPP WAC is issued, there will be uncertainty regarding the disposal requirements for calcine and spent scrub. Working closely with WIPP during all phases of the project should mitigate this risk. 


\subsubsection{CMACT Risks Related To Feed Uncertainties}

While uncertainties exist in the composition of the waste feed to the CMACT process, past calcination experience along with certain design features provide confidence that all the SBW and NGLW can be successfully treated by the CMACT process. Mock up testing of the Tank Farm mixing pumps would reduce risks of inadequate tank solids mixing.

Present Tank Farm management plans call for consolidation of all SBW into three tanks, WM-187, WM-188, and WM-189, by the end of CY 2004. Additional waste generated in 2005 would continue to be added to WM-187 and WM-188, and then from 2006 on, segregated in separate, smaller tanks (WM100, WM-101, and WM-102). Waste in one Tank Farm tank, WM-189, was sampled and analyzed in 2002 (Batcheller 2003), and its composition is not expected to change prior to treatment. While changes are expected in the contents and composition of waste in WM-187 and WM-188, waste to be sent to these tanks has been sufficiently well characterized to have high confidence in the predicted compositions for the liquid in these tanks (as documented in Barnes 2004b).

Most of the solids (>85\%) contained in the Tank Farm have been consolidated in Tank WM-187 by tank closure work. The solids in this tank were sampled and analyzed in February 2004. Since solids in Tank WM-187 have not been well mixed, the recent analysis may not be representative of all the solids in the tank. Analysis of solids samples from other tanks that were flushed to WM-187 provide a basis to estimate the range of solids composition in the tank. The uncertainty in the solids composition is not as important to the design as several other issues related to the solids.

The solids must be homogeneously mixed in one or more tanks. Mixing pumps will need to be installed in WM-187 and possibly other tanks in order to (a) characterize the feed for process control and waste qualification purposes and (b) provide a homogeneous feed to treatment using the existing steam jets. The mixing pumps will need to be installed through the existing 12-inch diameter tank risers. The recent CMACT feasibility study (Merrick 2004) and previous studies of mixing pumps (Wood 2002; Morrell 2003) all recommend mock-up testing of the tank mixing pumps to demonstrate performance. Proceeding into construction without demonstration tests of these pumps would risk schedule delays and additional costs should the pumps need to be redesigned and/or additional equipment installed to achieve a known homogeneous liquid/solids feed to the NWCF feed tanks.

A solids blending scheme needs to be defined. A scheme for blending tank solids was defined based on four SBW feed tanks (Wood 2002; Barnes 2003b), but with the recent decision to consolidate SBW into three tanks, a new scheme is needed. Current estimates indicate that if distributed evenly, Tank WM-187 will have between 65 and 120 grams undissolved solids per liter (Barnes 2004b). The higher end of this concentration range risks settling of solids in the transfer lines from the Tank Farm to the NWCF. However, to minimize the effects of solids on the calcination process (potential nozzle plugging, changes in feed chemicals due to high phosphate, changes in operating parameters due to high zirconium, etc.), a lower concentration of solids, constant throughout processing all of the waste, is desirable. Barnes (2004b) suggests two schemes, each involving the installation of mixing pumps in two tanks and lowering the undissolved solids content of the feed to $20-40 \mathrm{~g} /$ liter. Whatever solids blending scheme is proposed, it should ensure that the waste is transferred to the NWCF without solids settling in the transfer lines, minimize the uncertain effects of the tank solids on calciner feed chemical addition and calciner performance, and minimize the effect of the uncertainty in the total amount of solids contained in the Tank Farm tanks.

Incorporation of NGLW into the tank-blending scenario would also eliminate risks due to uncertainties in NGLW volume and composition. The expected total volume of NGLW is small relative to SBW $(\sim 8 \%)$, but planning for separate NGLW calcination would risk not being able to qualify the 
product calcine as well as potentially needing to develop a different set of operating parameters due to differences in its composition compared to SBW. The radionuclide content of future NGLW is highly uncertain, yet if blended with the entire inventory of SBW, the effect of this uncertainty is minimal.

\subsubsection{CMACT Risks Related To Use Of And Upgrading The NWCF}

The NWCF is a 24-year old facility and will be close to 30 years old upon restart for SBW treatment by the CMACT process. Risk of equipment failures is high if significant maintenance and upgrades are not performed prior to treatment.

The design of the NWCF began in 1974; construction took place between October 1976 and October 1980. Cold tests of the NWCF facility began on October 28, 1981, and the first hot feed campaign began September 8, 1982 (Newby 2000). The last NWCF campaign was completed in May 2000. Thus the calciner was operated over a period of nearly 18 years. Some equipment, should it break down, may be difficult to replace with identical items because of its age. Maintenance in various NWCF cells is needed to restart the calciner, and additional upgrades are needed to minimize downtime during future operation.

Eighteen studies have been performed to detail these proposed maintenance upgrades:

Bunnell, P. J., (2003), "NWCF-DCS Upgrade Study - Idaho Tank Farm Project - Calcination with MACT Upgrade SBW Treatment Alternative,” Engineering Design File EDF-3312, Rev. 0, April 10, 2003.

Chien, N., (2003a), "NWCF Fluidizing Air Blowers Replacement - Idaho Tank Farm Project -Calcination with MACT Upgrade SBW Treatment Alternative,” Engineering Design File EDF-3246, Rev. 0, May 13, 2003.

Chien, N., (2003b), "NWCF Offgas Blower Cell Upgrade - Idaho Tank Farm Project - Calcination with MACT Upgrade SBW Treatment Alternative, Engineering Design File EDF-3429, Rev. 0, April 22, 2003.

Craig, D. W., (2003a), "iPPR \#29 NWCF - Liquid Sample Cell Upgrade - Idaho Tank Farm Project Calcination with MACT Upgrade SBW Treatment Alternative," Engineering Design File EDF3258, Rev.0, March 10, 2003.

Craig, D. W., (2003b), "NWCF Return Jet Cubicle Upgrade - Idaho Tank Farm Project - Calcination with MACT Upgrade SBW Treatment Alternative, Engineering Design File EDF-3417, Rev. 0, April 9, 2003.

Craig, D. W., (2003c) "NWCF Embedded Lines - Idaho Tank Farm Project - Calcination with MACT Upgrade SBW Treatment Alternative, Engineering Design File EDF-3555, Rev. 0, April 25, 2003.

Croft, K., W. T. Zollinger, "NWCF Valve Corridor Remote Handling Study - Idaho Tank Farm Project Calcination with MACT Upgrade SBW Treatment Alternative," Engineering Design File, EDF3559, Rev. 0, May 21, 2003.

Faultersack, W., (2003a), "Study \#29 NWCF Fuel Nozzle Study - Idaho Tank Farm Project - Calcination with MACT Upgrade SBW Treatment Alternative,” Engineering Design File EDF-3323, Rev. 0, April 11, 2003. 
Idaho Tank Farm Project - Calcination with MACT Upgrade SBW Treatment Alternative," Engineering Design File EDF-3352, Rev. 0, April 22, 2003.

Hills, S. W., (2003a), "NWCF Out-of-Cell Valves - Idaho Tank Farm Project - Calcination with MACT Upgrade SBW Treatment Alternative," Engineering Design File EDF-3322, Rev. 0, December 2003.

Hills, S. W., (2003b), "NWCF Scrub Cell Upgrade \& HV-208 Acid Transfer to Feed Tanks," Engineering Design File EDF-3326, Rev. 0, December 12, 2003.

Johnson, T. A., (2003), "Evaluation of the NWCF Motor Control Centers - Idaho Tank Farm Project Calcination with MACT Upgrade SBW Treatment Alternative," Engineering Design File EDF3475, Rev. 0, April 22, 2003.

Keller, D. E., (2003), "NWCF HEPA Filter Valve Study - Idaho Tank Farm Project - Calcination with MACT Upgrade SBW Treatment Alternative," Engineering Design File EDF-3244, Rev. 1, May 8, 2003.

Lee, A. E., (2003), "NWCF Calciner Cell Upgrade - Idaho Tank Farm Project - Calcination with MACT Upgrade SBW Treatment Alternative,” Engineering Design File EDF-3238, Rev. 0, May 19, 2003.

McDonald, J. K., (2003a), NWCF HVAC Upgrade- Idaho Tank Farm Project - Calcination with MACT Upgrade SBW Treatment Alternative, Engineering Design File EDF-3565, Rev. 0, April 9, 2003.

McDonald, J. K., (2003b) "NWCF Valve Cubicle Upgrade - Idaho Tank Farm Project - Calcination with MACT Upgrade SBW Treatment Alternative," Engineering Design File EDF-3468, Rev.0, April 22, 2003.

McDonald, J. K., (2003c) "NWCF Calcium Nitrate Addition Room Upgrades - Idaho Tank Farm Project Calcination with MACT Upgrade SBW Treatment Alternative, Engineering Design File EDF3604, Rev. 0, April 30, 2003.

Stacy, D. E., "NWCF Flowmeter Cell Upgrade - Idaho Tank Farm Project - Calcination with MACT Upgrade SBW Treatment Alternative,” Engineering Design File EDF-3541, Rev. 0, May 8, 2003.

Below is a table that summarizes the work that would be necessary to upgrade the calcination system, the dollar and radiation exposure (ALARA) cost of each task, and suggested sequence of performance. 
Table 1-1. Calcination System Upgrades - cost and ALARA summary

\begin{tabular}{|c|c|c|c|c|c|}
\hline $\begin{array}{l}\text { EDF } \\
\text { No. }\end{array}$ & Subject & \begin{tabular}{|c|} 
Type of \\
work \\
(see \\
NOTE 1)
\end{tabular} & Cost, \$ & Construction sequence / ties & \begin{tabular}{|c|} 
ALARA \\
exposure \\
man-Rem
\end{tabular} \\
\hline 3226 & Scrub cell upgrade work & RU & $\$ 556,055$ & with 3555 & 36.0 \\
\hline 3238 & Calciner cell upgrade & $\mathrm{RU}$ & $\$ 3,224,183$ & with MCF \& CPF - share workers & 119.3 \\
\hline 3244 & Valve corridor filter valve upgrade & $\mathrm{RU}$ & $\$ 556,286$ & after 3559 & 26.5 \\
\hline 3246 & $\begin{array}{l}\text { Fluidizing air blowers } \\
\text { replacement }\end{array}$ & RE & $\$ 176,508$ & Independent - any time & - \\
\hline 3258 & Liquid sample cell upgrade & $\mathrm{RU}$ & $\$ 240,000$ & Independent - any time & 10.0 \\
\hline 3312 & DCS upgrade & $\mathrm{CU}$ & $\$ 1,272,037$ & Independent - any time & - \\
\hline 3322 & Out-of-cell valve upgrades & $\mathrm{RE}$ & $\$ 300,000$ & Independent - any time & - \\
\hline 3323 & Fuel nozzle study & $\mathrm{RU}$ & $\$ 547,277$ & Independent - any time & - \\
\hline 3352 & Feed and fuel nozzle upgrades & \multicolumn{3}{|c|}{ DELETE - work scope \& estimate covered in EDF-3323 } & - \\
\hline 3417 & Return jet cubicle upgrade & $\mathrm{RE}$ & $\$ 124,823$ & Independent - any time & 7.9 \\
\hline 3429 & Off-gas blower cell upgrade & $\mathrm{RE}$ & $\$ 490,679$ & before 3238 & 2.0 \\
\hline 3468 & Valve cubicle upgrade & $\mathrm{RU}$ & $\$ 649,455$ & after 3559 & 1.8 \\
\hline 3475 & $\begin{array}{l}\text { Evaluation of motor control } \\
\text { centers }\end{array}$ & CU & $\$ 1,356,631$ & first, with 3565 & - \\
\hline 3541 & Flowmeter cell upgrade & $\mathrm{RU}$ & $\$ 491,165$ & Independent - any time & 16.0 \\
\hline 3555 & Embedded lines & RE & $\$ 1,003,360$ & with 3226 & 32.2 \\
\hline 3559 & Valve corridor remote handling & RE & $\$ 2,506,713$ & first before $3244 \& 3468$ & 16.5 \\
\hline 3565 & NWCF HVAC upgrade & $\mathrm{RE}$ & $\$ 513,487$ & first, with 3475 & - \\
\hline 3604 & $\begin{array}{l}\text { Calcium nitrate addition room } \\
\text { upgrades }\end{array}$ & $\mathrm{RE}$ & $\$ 231,393$ & Independent - any time & - \\
\hline 3646 & NWCF Cyclone Replacement & \multicolumn{4}{|c|}{$\begin{array}{l}\text { DELETE - will not be done due to high ALARA estimate of } \sim 150 \text { man } \\
\text { Rem }\end{array}$} \\
\hline & & & & & \\
\hline & TOTALS & & $\$ 14,240,052$ & & 268.2 \\
\hline & $\perp$ & & & & \\
\hline
\end{tabular}

If calcination using the NWCF were selected to treat SBW the equipment in the NWCF would be thirty years old before processing is complete. Without the replacements and upgrades listed above, process failures are likely, resulting in increased downtime. The above represents a comprehensive list of items known to need maintenance based on past operating history. The age of the facility results in some risk that other items could fail during operation, causing down time for maintenance or replacement. Since meeting the 2012 milestone for treatment of SBW will be challenging, avoiding downtime for maintenance is crucial for success of the project.

Merrick estimated the cost of the above upgrades to be $\$ 15$ million (Merrick 2004). The estimated radiation exposure to perform these upgrades has been estimated to be 268 man-Rem. 


\subsubsection{CMACT Risks Related to New Treatment Facilities}

Upgrading the NWCF with MACT-compliance and calcine packaging facilities will add complexity to the total operation. Some equipment and steps will require mock-up tests to obtain a basis for detailed design.

1.1.5.1 Calcine Packaging Facility. In their feasibility study for the CMACT alternative, Merrick identified mock-up testing of the calcine packaging system equipment as a schedule risk (Merrick 2004). Mock-up testing would add to the project schedule, but not doing mock-up tests would risk longer delays due to failures of packaging equipment. Merrick estimated the cost of the Calcine Packaging Facility at $\$ 227$ million, nearly $70 \%$ of the entire project cost. The high cost of the CPF stems in large part from the remote mechanical operations of packaging calcine and scrub waste while maintaining contamination control.

One major issue in the packaging facility is contamination control - avoiding calcine fines from being released into hot cells while moving canisters in and out of the loading position as well as during filling of canisters. The Merrick feasibility study describes concepts for control of fines during packaging, but recognizes that detailed design will require testing to further define and demonstrate these systems.

Merrick also identified areas of concern regarding the scrub treatment and packaging system that will require additional testing to resolve. These are as follows (from Merrick 2004, Section 3.4.1.2):

- The neutralization of the scrubber liquor needs to be well understood to avoid potential problems with thickening of the neutralized scrub in the tanks and lines. If this proves to be a potential problem, recovery methods and avoidance controls need to be developed.

- $\quad$ The mixing apparatus needs to be piloted. Particular areas of study include the ability of the system to self clean, the ability of the system to feed dry solids only, the reliability of the system, and the ability of the system to provide repeatable results. A failure of the system to perform in any of these areas will have to be resolved with engineering design or alternative systems.

- The discharge of the mixing system into the canister needs to be piloted to ensure plugging, setup, or other problems do not occur.

- $\quad$ The scrub grouting recipe needs to be solidified and certified from a WIPP acceptance standpoint. A determination whether the ability to feed solid absorbent to the bottom and top of a canister for free-liquids capture needs to be completed.

1.1.5.2 MACT Compliance Facility. The staged combustor design is based on technology used in the chemical process industry with hands-on maintenance. In their feasibility study, Merrick cited discussions with the staged combustor vendor indicating that during the SBW processing time, the unit "might need repairs to the reduction furnace refractory and burner tiles plus replacement of selected components such as the quench spray guns and tips, ignition rods, sight glasses and scanner glass" (Merrick 2004, Section 3.3.2.2.3). While the MCF feed contains very low levels of radioactivity, certain volatile radionuclides including tritium and ${ }^{129} \mathrm{I}$ will be present in the off-gas processed by the staged combustor. Modifications needed to the staged combustor for adaptation to radioactive waste processing have yet to be evaluated. These modifications would seek to minimize worker exposure to radioactive materials by reducing maintenance activities consistent with ALARA requirements. Modifications could include alternative refractory materials, modifications of quench spray gun connections, and additional redundant instrumentation. 
Certain MACT requirements are impractical for the MCF and will require evaluations and negotiations with regulators. These include (a) determining a "hazardous waste residence time;" (b) determining operating times for tests prior to the notification of compliance; and (c) negotiating requirements for ALARA, waste feed characterization, waste feed limits, continuous emission monitoring (CEM), and performance testing. The CEM issue is briefly discussed by Merrick (Merrick 2004), and all of these MACT compliance issues are discussed by Soelberg (EDF-3311 2003).

1.1.5.3 Integration of CPF and MCF with NWCF. To minimize the total plant down-time, maintenance will be performed in all treatment facilities - the NWCF, MCF and CPF - during scheduled turnaround times. The design includes emergency capability to route calcine to the existing Calcine Solids Storage Facility (CSSF) should the CPF go down and to discharge off-gas through the existing atmospheric protection system (APS) should the MCF go down. The control systems for each of the treatment facilities will need to be carefully integrated to minimize downtime.

\subsubsection{CMACT Balance of Plant Requirements, Facility Siting, and Interfaces}

To support the MCF, a propane storage and delivery system and a new demineralized water system are required. The propane system includes a 45,000-gallon propane tank, and the demineralized system is designed for generating 60-70 gpm of 1-3 meg ohm water (Merrick 2004). Additional details of these systems can be found in the Merrick CMACT Feasibility Study (Merrick 2004).

Bates (EDF-1794 2004) estimated the rate which samples would be generated by CMACT operation and concluded that the existing analytical facilities (the Remote Analytical Laboratory, INTECCPP-684, or "RAL") would be adequate for this load. A pneumatic transfer system (PTS) is currently in place to transfer samples from NWCF to RAL. Additional systems would be needed to bring samples from the MCF and CPF to RAL if any were to taken there, which is not currently planned.

Based on the Merrick Feasibility Study (2004), the MCF can be situated between the NWCF and the INTEC Main Stack, and the CPF to the east of the NWCF near the existing CSSF bin sets. Thus the tie-in to lines transferring calcine from the NWCF will involve minimal new piping to reach the new $\mathrm{CPF}$, and transferring off-gas exiting the MCF to the stack will require minimal new piping. Additional details regarding facility siting are found in the Merrick Feasibility Study (2004) and siting studies for the MCF and CPF (Lippert 2003a, 2003b).

The NWCF is integrated with numerous other INTEC facilities. This is advantageous for SBW processing; however, it could require keeping certain facilities in use that otherwise could be shut down, decontaminated, and closed. Besides utilities systems, operation of the NWCF would require keeping the PEWE, ETS, and LET\&D facilities operational. A comparatively large volume of waste is generated from maintenance and turnaround of the calciner, which is concentrated in these facilities. Historically, the final concentrate has been returned to the Tank Farm. During SBW treatment, the concentrate could be processed in the calciner. Waste generated from the final decontamination and decommissioning of the calciner would require treatment by a different process.

\subsubsection{CMACT Safety Concerns}

A safety analysis report is available for the NWCF (SAR-103 2001), but similar analyses have not been performed for the MCF or CPF. A criticality assessment concluded that there were no criticality issues associated with calcination of SBW (Nielsen 2003). A hazard categorization for the CMACT alternative concluded the facility would be a moderate hazard due to the quantities of nitric acid used in the NWCF facility (Davis 2003). A hazard identification evaluation for the CMACT alternative classified 
the facility as Hazard Category 2 due to the inventory of radiological material in the NWCF during processing (Durante 2003a).

A systematic hazard evaluation of the NWCF and MCF for treating SBW has also been performed (Durante 2003b). Twenty-one hazards were identified for the NWCF facility. Of these 21, 4 were categorized as "anticipated" and design features identified to prevent or mitigate potential hazardous events. For the MCF, 40 hazards were identified and 34 of these categorized as "anticipated." Appropriate measures would be incorporated into the design to prevent or mitigate events that could result from these hazards. A similar hazards analysis would be preformed for the CPF to ensure adequate safety measures were designed into the $\mathrm{CPF}$.

\subsubsection{CMACT Future Use Considerations}

The CPF could be designed to accommodate high-level waste (HLW) calcine disposition. Additional shielding would be required because the HLW calcine generates a higher radiation field than calcine from SBW. The waste container for HLW calcine would be the same diameter as the WIPP canister, but 15 -ft rather than 10 -ft in length, and would have a different lid design. Design for HLW calcine packaging could affect the siting of the CPF, to optimally tie in to each of the calcine storage facilities as well as receive SBW calcine from the NWCF. The effects on the design of other requirements for HLW calcine disposition, such as processing rate, transport gas handling, and provisions for sampling would need to be considered in the design. The cooling required for SBW calcine would not be required for HLW calcine.

NGLW will continue to be generated after 2012, although at a decreasing rate and possibly with decreasing radioactivity. Current projections indicate an annual generation rate decreasing from 4,400 to 3,100 gallons from 2012 to 2035 . Processing small batches of feed through the calciner is very inefficient, due to the time, fuel, and other utilities used to start up the equipment, and the waste generated upon decontamination after each campaign. The annual NGLW production, if compatible with calcination, could be processed in a few days. Present projections of NGLW composition for the years 2004 to 2012 show significant differences from SBW or past HLW feeds to the calciner. To calcine the NGLW, tests would be needed to demonstrate feed blend recipes.

\subsubsection{CMACT Process/Technical Summary}

The following table presents a summary of the technical risks and issues for the CMACT process. The probability and impact values shown are on a scale of 1 to $10(1=$ low probability or impact $)$ and based on the author's judgment rather than any formal process or group evaluation. A probability of 5 is equivalent to a $50 \%$ chance that the identified risk would occur or uncertainty cause detrimental effects. The "Resolution" column presents a recommendation of how the issue should be resolved, usually either by evaluations during design or testing. 


\subsection{CMACT Environmental / Regulatory and Related}

\subsubsection{CMACT Permitting}

\section{A 24-month permitting schedule, critical path early in the project schedule, appears to be the best that can be achieved.}

The baseline for the SBWT project identifies a 24-month permitting schedule including the Hazardous Waste Management Act (HWMA) and Clean Air Act (CAA) permits. This may be optimistic, since discussions with the State of Idaho, Department of Environmental Quality (IDEQ) in the spring of 2003, indicated that the IDEQ estimated 32 months to permit the SBWT project after receiving the HWMA and CAA permit modifications or applications. The project will need to work with the IDEQ to streamline the permitting schedule. (The 32-month schedule was worked down to 24 months by taking time out of the operating contractor's activities only.)

The CMACT facilities will require CAA permits and HWMA permits. The calciner will require a CAA Title V and PSD permits and will demonstrate that emissions meet the MACT standards for hazardous waste incinerators. The calciner and CPF will need HWMA permits for hazardous waste management activities. The calciner will need a site-specific risk assessment to address hazardous air pollutants (HAPs) and non-HAPs risk to human health and the environment not covered by the MACT, PSD, or Title V emission limits.

EPA recommends hazardous waste combustors provide copies of the facility's notice of intent to comply, compliance performance test plan, and draft Title V permit application to the public at the same time the facility holds the public information meeting prior to submitting the HWMA permit application. In addition, EPA suggests placing copies of the MACT and air permit documents with the HWMA permit application in the facility reading rooms. This will allow the public adequate comment on the facility for both the HWMA and CAA requirements.

The following sections describe the permitting activities necessary for the CMACT treatment alternative.

The CMACT SBW treatment alternative consists of four parts to be permitted and constructed to treat the waste by the end of 2012: (1) the upgrade of approximately 13 liquid transfer pipelines inside of the NWCF building, CPP-659, to meet HWMA standards for secondary containment of pipes.

(2) Construction of the calciner upgrades and the MCF, an off-gas emissions treatment unit to be built between the main stack and the NWCF. The off-gas emission treatment unit would lower the amount and concentration of constituents emitted up the stack to meet MACT standards. (3) Construction of the CPF, which includes waste storage units, to collect and place the calcine in canisters for shipment to WIPP. (4) Installation of mixing pumps in 2 or 3 Tank Farm tanks to produce homogeneous feed to the treatment process and enable solids-liquid co-processing.

1.2.1.1 Upgrade of the Embedded Piping. Piping changes inside the NWCF are required to bring the existing embedded lines into compliance with the requirements in Idaho's HWMA 40 CFR $\S 265.193$ or 40 CFR $\S 264.193$ tank systems. The tank systems and ancillary equipment in the NWCF have interim status or have been included in Volume 14, INTEC Liquid Waste Management System, or Volume 18, HWMA/RCRA Storage and Treatment Permit for INTEC, of the INEEL HWMA permit. There are two paths that can be taken to gain regulatory acceptance of the piping upgrades. (1) Use the interim status modification process in 40 CFR \$272.42, 40 CFR §270.72, and 40 CFR §265.193, and document the upgrades with a P. E. Certification (note: the P.E. Certification can be used if the upgrades are included in the INEEL HWMA permit at a later date) or (2) include the line upgrades in a permit 
application or modification to an existing permit (e.g., modification to Volume 14 for the INTEC Liquid Waste Management System) to include the piping associated with tank systems as required in 40 CFR $\S 270.13,40$ CFR $\S 270.14,40$ CFR $\$ 270.42$, and 40 CFR $\$ 264.193$.

The piping upgrades should be permitted through a Class 1 modification to either interim status or Volume 14 of the INEEL HWMA permit. Equipment replacements or upgrading with functionally equivalent components (e.g. pipes, valves, pumps, conveyors, controls) are defined as Class 1 permit modifications. A Class 1 modification requires a letter notification to the administrator prior to implementing the change.

1.2.1.2 Calciner Permitting. Currently the calciner/off-gas system in the NWCF is managed as an interim status thermal treatment unit (40 CFR $\S 265$ Subpart P). The calciner system is undergoing partial closure by isolating the system from the waste and utility piping. The calciner system as described in the NWCF Calciner System Closure Plan (DOE/ID-10801) is made up of VES-NCC-104, 105, 107, 109, 112, 113, 114, 143-1, and 143-2, HE-NCC-343.1 and 343.2, BLO-NCC-243-1 and 243.2, and associated ancillary equipments. Tanks and equipment shared in common with other treatment and storage process in the NWCF are permitted in Volume 14 or Volume 18 to the INEEL HWMA permit.

For the CMACT treatment alternative, the calciner is subject to CAA permitting for calciner operation and emissions and HWMA permitting for hazardous waste management activities, such as, waste characterization, tank management, public participation, closure, and other operations related to hazardous waste management.

\subsection{Air Permitting-}

1.2.1.2.1.1 MACT Standards-The CMACT SBW treatment alternative would upgrade and replace equipment associated with the calciner/off-gas system in the NWCF and install new emission control equipment in the MCF external to the NWCF to treat the off-gas to MACT standards for hazardous waste incinerators.

The State of Idaho and EPA Region 10 have both stated that, in their opinion, the calciner is a hazardous waste incinerator and the emissions and operations should be permitted under 40 CFR $\S 63$, Subpart EEE National Emission Standards for Hazardous Air Pollutants From Hazardous Waste Combustors. Subpart EEE contains the MACT emission limits and process control requirements for hazardous waste combustors. The State of Idaho and EPA Region 10 have both stated that if the DOE wants to permit the calciner as a miscellaneous thermal treatment unit under the HWMA 40 CFR §264 Subpart X regulations, it would still need to comply with the MACT emission standards for hazardous waste combustion units. DOE has indicated to the State of Idaho that if the calciner was upgraded and used in the future, they would permit it as a new source. (See Table 1-3 at the end of the section which lists the Interim Rule for existing and new source incinerators and proposed Final Rule MACT limits for new source incinerators.)

The project will need to submit several documents to the State of Idaho to comply with the MACT rule. First, the project needs to submit a Notice of Intent to Comply (NIC) to explain how the design for the calciner and off-gas treatment will control emissions, monitor emissions, comply with the emission standards, and minimize waste generation. Second, the project will submit a Compliance Performance Test Plan to explain how the calciner and off-gas treatment will be tested, what emissions will be monitored, what analytical methods will be used, and how the calciner will be operated during the test (time frames, feed rates, spiking, emission control equipment, and emission monitoring equipment). Third, the project will submit a Notice of Compliance to document that the calciner operated below the 
MACT emission limits. Fourth, the project will submit a Title V permit modification to add the emission limits and operating controls necessary to maintain compliance.

Hazardous waste incinerators are required to submit a compliance performance test plan (similar to a RCRA trial burn) with the permit application and complete compliance performance testing to demonstrate that the emission control technologies and emissions from the incinerator will meet the MACT standards. The project can achieve compliance by feed control or emission control technologies or a combination of both. The compliance performance test demonstration will test the process at normal and maximum feed rates and hazardous waste concentrations to develop the operating limits for the treatment process. Compliance performance testing may require spiking the waste with known concentrations of chemicals. In the past, EPA has considered the use of reagent chemical for spiking to be the incineration of un-used commercial chemical products and have added the $\mathrm{P}$ and $\mathrm{U}$ listed hazardous waste numbers to the ash and scrub solution generated during the test. The project needs to work the State of Idaho to select chemicals or surrogates that will not add new hazardous waste numbers to the waste.

The risk is that all of the waste treated after the compliance performance test will be assigned the new hazardous waste numbers due to mixing of the bed material and spent scrub solutions with the SBW in the Tank Farm. This could exclude the waste from disposal at WIPP. This could exclude waste streams from disposal at the National Geologic Repository (NGR), Envirocare, Nevada Test Site (NTS), or Hanford Site without additional work to delist the waste (see discussion in sections 1.2.4.c and 1.2.4.f).

Hazardous waste incinerators permitted under the 40 CFR $\S 63$ standards are exempt from the incinerator permitting requirements for operations and emissions at 40 CFR $\$ 264$ Subpart O (Incinerators) and $\$ 270.62$ (Hazardous Waste Incinerator Permits), except for provision the director determines are necessary to ensure compliance with Subpart $\$ 264.345$ (a) and (c) (releases during startup or shutdown).

It is recommended that the CMACT facilities, including the MCF, be permitted under 40 CFR $\S 63$, Subpart EEE to eliminate dual regulation of operations and emissions. The SWBT project needs to evaluate the proposed final rule limits to determine if the limits for mercury and chlorides can be achieved with the concentration of constituents in SBW and the emission control technology available.

If the chlorine limit cannot be achieved, then the project could establish a site-specific, risk-based limit for total chlorides based on the national exposure standard. The project needs to demonstrate that emission of total chlorides from on-site hazardous waste combustion units result in an exposure to the most exposed individual of a Hazards Index less than or equal to 1.

If the mercury limit cannot be achieved, then DOE should consider asking for a separate category and emission limits for the calciner. The information submitted for DOE thermal treatment units to EPA did not indicate that the DOE units could not meet the MACT standard for new hazardous waste incinerators. The project would need to document why it is not practical to remove mercury below the level required, such that either the technology is not available or the cost to remove additional mercury below the level in the current CMACT design is not beneficial. DOE could use the same approach EPA used in setting the current proposed standards for new hazardous waste incinerators and evaluating if it was practical to achieve lower levels of mercury removal from emissions. EPA used $\$ 18$ million/ton of mercury removed when they evaluated the practicality of removing mercury from emissions below the limit proposed for new sources.

The project should negotiate with the State of Idaho to classify the calciner as an existing source, since the emission limits for existing sources are not as conservative. The project should contract with a 
compliance performance testing contractor early in design to develop NIC, sampling location, testing protocol, and the compliance performance test plan.

The risk is that design changes, emission control and monitoring equipment modifications, or feed rate reductions will be required to meet the MACT standards.

\subsection{Clean Air Act - Existing vs. New Emission Sources-The New}

Source Review (NSR) program is the primary mechanism for preventing facilities from causing or contributing to violations of national ambient air quality standards (NAAQS). NSR applies to what are known as "major" stationary sources, which are defined differently for attainment versus non-attainment areas. The INEEL is in an attainment area adjacent to a wilderness area (Craters of the Moon) and would be a Class 1 attainment area. The NSR program uses the preconstruction permitting process to control the construction of new major sources (and modifications to existing sources). In attainment areas, these preconstruction permits are referred to as prevention of significant deterioration (PSD) permits.

The project needs to determine if the use and changes to the calciner are minor new sources, minor modifications, major new sources, or major modifications in an attainment area.

The calciner was an existing emission source identified in the INEEL Air permit. In 2002, John Pile, BBWI Air Permitting Group, suggested that the calciner could be modified as a minor modification to an existing source with a minimum of permitting required. Since the calciner has been shut down for three years and is undergoing HWMA closure it is doubtful that it will maintain its status as an existing source. The following discusses the issues associated with either an existing or new source status.

1.2.1.2.1.3 Existing Source - PSD Permit-If the calciner system is an existing source and meets the conditions below, then the modifications would not trigger the PSD NSR requirements.

NSR applicability determinations for modification to an existing facility are complicated. Both the baseline emissions and future emissions must be computed to estimate the emission increase and determine whether the increase triggers major NSR. Since the facility is already in operation, the baseline emissions are no longer zero and must be calculated from historical data. EPA has established plantwide applicability limits (PAL) that allow the facility to choose any two-year period in the last 10 years preceding the proposed change to establish a baseline for an existing source's actual emissions.

The upgrade changes planned (excluding the new off-gas treatment equipment to comply with MACT) by the CMACT project to the calciner and existing off-gas systems will be less than $50 \%$ of the capital cost to reconstruct the calciner system. Emissions from the CMACT process would be less than the historical calciner emissions for NOx and CO. The NOx abatement and emission control equipment in the MCF and calciner upgrades could be installed without a new source permit modification and a permit to construct, since there is not an increase in emissions and the cost is $<50 \%$ of the replacement capital cost.

The calciner was included in the permit to construct, December 2003, for nitrogen oxides sources with $472 \mathrm{lbs} / \mathrm{hr}$ NOx emissions, no limit on $\mathrm{CO}, \mathrm{Cl}$, and $\mathrm{Hg}$. The CMACT project would reduce the NOx levels and meet the MACT limits for $\mathrm{CO}, \mathrm{Cl}$, and $\mathrm{Hg}$, resulting in a net decrease in emissions and not trigger the PSD requirements. The cost of the new off-gas treatment equipment is not included when determining whether the changes would cost more than $50 \%$ of the replacement cost (even if they were, it would still be less than $50 \%$ ). 
For the existing source classification the CMACT SBW treatment alternative would submit an "Intent to Construct" with a system description and emission analysis to the State of Idaho Air Program. After construction, the CMACT facility will need to demonstrate with an emission test or as part of the compliance performance test that changes to the calciner and the new off-gas treatment equipment reduced emissions at or below the PSD standards. Following the compliance performance test the State of Idaho would modify the air permit to include the NOx limits for emissions from the calciner. The calciner would be allowed to operate at a feed rate agreed to with the regulators during the time between the compliance performance test and modification of the air permits.

The risk is that the calciner would be required to operate at a reduced feed rate during the compliance performance test data review and the permit modification approval. The biggest risk to the schedule is that the calciner will be considered a new source with additional permitting described below.

NOTE: This existing classification may have been lost, since the calciner has not been operated for over three years and the waste piping has been isolated as part of the HWMA closure process.

1.2.1.2.1.4 New Source - PSD Permit-The calciner will be classified as a new major source unless emissions of pollutants are below the potential to emit 100 tpy of any PSD pollutant or any other source with potential to emit (PTE) of 250 tpy of any PSD pollutant. The calciner will be a major modification to an existing source requiring a PSD permit if any physical or operational change results in a significant net emission increase in a PSD pollutant. (See Table 1-4 at the end of this section.)

For a new major source, NSR applicability is relatively straightforward. Since the facility is not in operation, the baseline emissions are zero, and the emissions impact of the new facility is based on the PTE of all the new emission sources combined. If the new sources meet the applicability thresholds for PSD, the facility must complete the appropriate permit application, review, and approval process. In attainment areas, the applicability threshold is a PTE of 250 tpy, or 100 tpy for certain source types.

The CMACT project should negotiate with the state regulators to classify the calciner as an existing source, since it has operated for the past $20+$ years. Then the equipment replacements and upgrades to the calciner are minor modifications and not subject to PSD permitting. Changes to the calciner would not increase emissions, and the new off-gas treatment unit would reduce emissions below historical levels.

NOTE: The new off-gas treatment equipment in the MCF is not considered when making the cost determination for a major or minor source.

If existing source status is not approved for the calciner, then the project needs to demonstrate that the changes will not increase the emission above the PSD limits for a new source and can be permitted as a minor source.

If the calciner is a new major source then the level of effort and time for permitting increases. The PSD application process requires air monitoring and emission models, stringent pollution controls, estimates of the regional emissions for each hazardous air pollutant, public involvement, and Federal Land Manager involvement near Class 1 attainment areas.

The INEEL needs to consider using PAL by establishing INEEL wide actual emission limits. Then the calciner would be an individual emission unit operating under a plant wide cap. As long as emissions from all sources do not exceed this "actual PAL", physical changes can then be made without triggering PSD permitting. 
1.2.1.2.1.5 Title V Permit-The Title V Air permit application for the INEEL has been submitted to the IDEQ for approval. The IDEQ is reviewing the application and should issue a final permit by May 2005.

The Title V permitting sets forth the comprehensive state air quality operating permits program and emission limits. Sources subject to the operating permit requirements shall have a permit to operate that ensures compliance by the source with all requirements. Of primary interest for SBW are emissions of radionuclides, organics, nitrogen oxides, and the MACT standards. Tables 1-3 and 1-4 at the end of the section identify the list of constituents to be addressed in the permit modification.

At the present time the calciner emissions are included in the permit to construct for nitrogen oxide sources on the INEEL. The permit to construct identifies limits for NOx and radionuclides.

The Title V Air permit identifies the NESHAPs emission limits, process controls, and emission control equipment for each source. New emission sources are added to the Title V permit through a permit to construct and a permit to operate. The permit to construct identifies the potential emissions and controls based on the facility design. The permit to operate is based on emission testing when the source is operating. Emission limits and controls are established for each source based on the emission testing. The emission limits and controls are then added to the Title V Air permit by modifying the permit to include the new source.

The risk is that emissions from the calciner or a combination of the INEEL sources will exceed the NESHAPs limits requiring the calciner to operate at a reduced feed rate. The risk is that NOx emissions cannot be reduced below the visible range and the Federal Land Manager delays or opposes the air permits. The project needs to start early in the design to gather the information necessary to submit applications for the permit to construct, MACT compliance plan, and new source review for PSD.

\subsubsection{HWMA Permits.}

1.2.1.3.1 Calcination System and MACT Compliance Facility-The calciner and related equipment are subject to HWMA permitting. A permit application will cover all permit sections except for MACT air emissions and related operating requirements. The permit application for the calciner will cover tank storage, waste characterization, general facility standards, material handling, risk based emission limits for HAPs and non-HAPs, and operating requirements. Since the calciner is being closed under interim status, it will need to be permitted before construction of the calciner upgrades and MCF can begin.

It is recommended that the calciner be added to Volume 14 of the INEEL HWMA permit, since it shares equipment with other liquid waste management processes in the NWCF building.

1.2.1.3.2 Site-Specific Risk Assessment-A site-specific risk assessment (SSRA) may be required by the IDEQ permit writers if they believe that operation in accordance with the MACT standards alone may not be protective of human health and the environment. The SSRA will focus on the emission rate of HAPs and non-HAPs, stack gas characteristics, meteorological conditions, and exposed populations. There is a high probability that IDEQ will require a risk assessment since they required one for the evaporators permitted in Volume 14. The SBWT project developed a template for a site-specific risk assessment for SBW in 2004.

The risk is that the SSRA may result in additional HWMA permit conditions that affect the feed rate, emission controls, and monitoring emissions. 
1.2.1.3.3 Calcine Packaging Facility-The calcine produced by the CMACT process in the NWCF would be pneumatically transferred to the new Calcine Packaging Facility (CPF). The waste packaging process would collect and store the calcine in hoppers, treat and package scrub solution, package calcine in canisters, and store the canisters pending shipment to WIPP. The calcine storage and packaging units would be subject to the 40 CFR 264 and 270 requirements for miscellaneous units, new tank systems, and container storage. The CPF would be located adjacent to the NWCF and could be added to the INEEL HWMA permit in one of two ways: (1) as a modification to either Volumes 14 or 18, or (2) as a separate volume.

The addition of the CPF will result in less than $25 \%$ increase in the tank capacity and container storage capacity at the facility (INEEL). Therefore, the changes should be a Class 2 modification. It should be possible to submit individual permit modifications for the building, tank systems, and container storage, which should allow the start of construction of the building, floor, walls, roof, and secondary containment, while designs are finalized for tank systems and container storage.

NOTE: The CPF is replacement storage for the waste in the Tank Farm. The net result would be a reduction in storage volume at the INEEL. Tank systems that are used to store or treat hazardous waste that contains no free liquids and are situated inside a building with an impermeable floor are exempt from the secondary containment requirements (40 CFR $\$ 264.190(a))$. Storage areas that store containers holding wastes that do not contain free liquids need not have a containment system (40 CFR $\S 264.175(\mathrm{c}))$.

It is recommended that the $\mathrm{CPF}$, which includes grout treatment, calcine storage, and container storage, be submitted to the State of Idaho as a Class 2 modification to either INEEL HWMA permit Volume 14 or 18 . The calcine storage and canister storage areas are for dry waste with no free liquids, which should simplify the permitting and construction. The tank and container storage areas replace noncompliant storage in the Tank Farm and will not increase waste storage capacity.

If the final design results in significant changes to the CPF then a permit modification would be required (tank size, number of tanks, tank location, cell dimension, etc.). The risk is that changes to the design during final design or construction could result in a permit modification approval before waste could be managed in the CPF and delay the shipments of SBW. It is recommended that the project negotiate with the State of Idaho early in design to determine how design and construction changes will be handled during the application, final design, and construction stages of the project.

1.2.1.4 Mixing Pumps. The mixing pumps would be ancillary equipment to the tank systems in the Tank Farm. The tanks in the Tank Farm have interim status but cannot be permitted since it is not practical to upgrade the secondary containment. Changes to interim status units require the approval of the director as outlined in 40 CFR \$270.72, Changes During Interim Status, and 40 CFR \$270.42, Permit Modification at the Request of the Permittee.

The addition of the mixers to the Tank Farm should be a Class 1 modification under interim status and requires notification of the administrator prior to implementing the change. Adding the pumps would not change the tank's storage capabilities, so the administrator should have little concern with this action.

1.2.1.5 Organic Sample Bias. The IDEQ proposes in Volume 14 to the INEEL HWMA permit to approve the use of a double-needle sampler as an alternative sampling procedure when collecting mixed (hazardous and radioactive) volatile organic and total organic samples from the INTEC Liquid Waste Management System. However, the resulting sample analysis results must not be used in Land Disposal Restriction (LDR) certifications. The appropriateness of the sampling procedure shall be 
confirmed at least three times within the life of the permit by correlation of the analytical results with the permit required off-gas data.

The project should request the use of double needle sampling in the CAA permits and HWMA permit applications. The project should compare sample data from the double needle and simple samplers to show that the organic constituents in the Tank Farm waste are at or near the method detection limits and the sampling method does not affect the results for organics, due to the low concentration in the feed. The project should propose a reduced number of organic analyzes based on the low concentration in the feed. The project should pursue IDEQ approval for use of double-needle samplers for all remote-handled samples, including compliance performance testing, LDR, delisting, and waste characterization samples as required to dispose of waste.

1.2.1.6 Professional Engineer Certifications. CAA permits will not require Professional Engineer (PE) certifications of the design and construction for the changes to the calciner system and new off-gas treatment equipment in the MCF.

HWMA requires PE certification of the design submitted with the permit modification or application and before waste is placed in the tank systems 40 CFR $\$ 264.192$ and 40 CFR $\$ 270.11(d)$. The project should contract with an independent, registered PE early in design for PE support to facilitate certification of the design for the permit application or permit modification.

Due to the dual regulation of hazardous waste combustion units, PE certification of the calciner and MCF may be required as part of the general HWMA permit requirements. The project will need to clarify this issue with the State of Idaho to define specifically what information needs to be included in the HWMA permit and the MACT compliance documents.

1.2.1.7 In-cell Leaks. In-cell leaks from air emission treatment equipment are not specifically addressed in an air permit. They are addressed in the estimated range of emissions from the cell or building. Waste leaked into sumps will need to be removed within 24-hours or secondary containment will be considered primary containment and regulated under the HWMA requirements.

HWMA requires that operation of a leaky tank system be stopped immediately after the leak is detected, waste removed from tank systems with in 24-hours, and waste removed from secondary containment within 24-hours (40 CFR §264.193). The system will have to be repaired before it is used. Depending on the extent of the repairs, a PE certification may be required before resuming operations.

Historically, the piping from the feed tanks to the calciner has had leakage problems during operation. This could be a schedule risk if operations are stopped to repair leaks as they occur. The project should negotiate with the State of Idaho to operate with leaking pumps, pipes, and valves until they can be replaced at scheduled maintenance shutdowns.

1.2.1.8 As-built Drawings. Air permitting does not require as-built drawings of the facility. The air permits require the air emissions from each system, the ranges of the emissions, and a list of equipment.

HWMA permitting requires as-built drawings of the facility, equipment, and piping. A permit application could include between 50 and 100 drawings (40 CFR §270). The project should negotiate with the State of Idaho to add the as-built drawings certified by a PE to the INEEL HWMA permit as a Class 1 modification prior to start of operation. 
Due to the dual regulation of hazardous waste combustion units, as-built drawings of the calciner and MCF may be required as part of the general HWMA permit requirements. The project will need to clarify this issue with the State of Idaho to define specifically what information needs are required for the calciner and MCF in the HWMA permit and the MACT compliance documents.

\subsubsection{CMACT NEPA}

NEPA exposure is low risk and little or no activity should be required here.

The risk of additional NEPA action for the SBWT project is low. The HLW\&FD EIS covered over 120 different alternatives to treat the SBW from no action to vitrification. It does not appear at this time that additional NEPA action would be required for the treatment and storage of SBW.

If required, an environmental assessment (EA) should cover any additional action or process not specifically mentioned in the EIS.

\subsubsection{CMACT Waste Disposal - TRU Waste}

Waste disposal is fairly high risk and is further aggravated by schedule delays.

The CMACT SBW treatment alternative would generate canisters of calcine, canisters of solidified scrub waste, and debris (spent GAC and HEPA filters). The majority of the waste would be remotehandled TRU waste. The WIPP facility is limited to 7,080 $\mathrm{m}^{3}$ of RH-TRU waste by the Land Withdrawal Act (LWA). Hanford, SRS, and INEEL have proposed sending RH-TRU waste not identified in previous estimates. The volume of RH-TRU waste in the DOE complex may exceed the LWA capacity. Disposal is based on first come, first disposed.

The risk to the project is that delays in the schedule caused by permitting, design, construction, and startup could reduce the number of shipments of RH-TRU SBW that WIPP can receive before the capacity authorized in the LWA is exceeded.

\subsubsection{CMACT Waste Qualification/Certification}

\section{Waste qualification/certification is a very high risk area for the project.}

The issues related to waste qualification/certification are: (a) the waste classification through the waste incidental to reprocessing (WIR) determination process, (b) waste acceptance criteria at WIPP, (c) waste acceptance criteria at the National Geologic Repository (NGR), (d) RH-TRU Permits approval, (e) New Mexico Environmental Department (NMED) acceptance of SBW, (f) WIPP waste certification authorization, and $(\mathrm{g})$ acceptance of greater than Class A low-level waste.

a. The Federal District Court in Boise ruled that DOE does not have the authority to classify waste using the WIR determination process in DOE Order 435.1. DOE has appealed the ruling to the U.S. Appeals Court and has asked Congress to clarify DOE's authority under the Nuclear Waste Policy Act.

The risk to the project is that the appeals process drags on for several years and delays treatment of the waste beyond 2012. The project should consider placing the waste in thin metal containers (liners) that could be placed in either the RH-TRU canister or the HLW canister. The treatment alternative would then be neutral to the disposal location. This would unfortunately decrease the net volume per canister and result in increasing the canister count and associated costs for storage, 
transport, handling, and disposal. In addition, if the WIR determination for SBW is disallowed, then classification of the grouted scrub, GAC, and debris would be in question.

b. The State of New Mexico has issued a hazardous waste facility permit (HWFP) to WIPP that covers CH-TRU waste streams. The U.S. Congress in Section 311(b) to the Energy and Water Appropriations Act required WIPP to submit a modification to WIPP's HWFP to limit confirmatory testing of TRU waste containers to radiography or visual inspection. These changes when implemented will significantly reduce the type and number of waste characterization samples required to confirm the acceptable knowledge. The modification was submitted to the State of New Mexico on December 31, 2003. The State of New Mexico is still reviewing the Section 311(b) modification.

The waste acceptance criteria for RH-TRU waste at WIPP are in the process of being established. WIPP and EPA have established requirements for radionuclides with EPA's approval of the RHTRU Waste Characterization Program Implementation Plan for characterization of radionuclides on March 26, 2004. DOE must submit site-specific implementing plans for EPA approval before sites may be authorized to characterize RH-TRU waste for certification and shipment to WIPP. Sites will not be authorized to certify and ship RH-TRU waste to WIPP until EPA conducts an onsite inspection and issues its final authorization. The RH-TRU Waste Characterization PIP requires each site to prepare sampling and analytical plans for characterization of each waste stream and have them approved by the EPA.

The WIPP RH-TRU program has not received approval of the RH-TRU waste modification to the WIPP HWFP. The criteria for hazardous constituents in RH-TRU waste have not been added to the WIPP HWFP. WIPP submitted a Class 3 permit modification for RH-TRU waste to the State of New Mexico in May 2003. The State of New Mexico is still reviewing the modification. WIPP is not ready to receive RH-TRU waste and will require facility modifications and testing prior to receipt of waste.

The risk to the project is starting the design without having all of the waste characterization and certification requirements finalized for either $\mathrm{CH}$ - or RH-TRU wastes resulting in design changes, permit modifications during construction, and delays shipments of waste.

It is recommended that the SBWT project work closely with WIPP and EPA to develop sampling and analysis plans for characterization of the feed. The plans will describe the use of acceptable knowledge for radioisotopes, prohibited items, and dose-to-curie measurements and calculations.

The project should also work with WIPP to include project specific waste characterization procedures for RH-TRU waste in the WIPP HWFP, if required.

c. If the DOE WIR determination process is found to be outside their authority, then SBW containing reprocessing waste and debris contaminated with SBW could be classified as HLW, based on the Nuclear Waste Policy Act. Then SBW and SBW contaminated debris would have to be packaged for disposal at the National Geologic Repository (NGR). The waste acceptance criteria at the NGR are based on an evaluation of the performance of the waste in the package and performance of the waste package in the repository. The only waste form that has been evaluated and approved for HLW disposal is borosilicate glass. Other waste forms such as SBW calcine, scrub system grout, or debris will have to be evaluated case-by-case for acceptability. Failure of the WIR does not mean that the SBW would automatically go to the NGR; and could result in the project generating waste without a disposal path. DOE has a limited capacity available for the disposal of HLW at the NGR, 
if all reprocessing wastes are classified as HLW then the volume of HLW will exceed DOE's allocated capacity requiring long term storage at the INEEL.

The INEEL needs to develop the following technical information to support the acceptance of a waste form for disposal at the NGR. The information needed for the Memorandum of Agreement with the Civilian Radioactive Waste Management System includes the Environmental Management Waste Acceptance Product Specifications (EM-WAPS), Waste Form Compliance Plan (WFCP), Waste Form Qualification Report, and supporting documentation in compliance with the QARD RW-0333P requirements.

1. The chemical composition and waste form projections for the HLW. Information on the chemical composition shall include identification of the speciation of elements and compounds present in concentration greater than $0.5 \%$ by weight in the waste form and an estimate of the uncertainty of these concentrations for the HLW.

2. Information required for determining that the HLW does not exhibit the characteristics of hazardous waste.

3. Estimates of the total facility inventory and individual canister inventory of radionuclides (in curies) that have half-lives longer than 10 years and are or will be present in concentration greater than $0.05 \%$ of the total radioactive inventory. The estimates shall be indexed to the years 2010 and 3110 . The producer shall also report the estimate of the uncertainty in the radionuclide inventories.

4. The time-temperature-transformation diagrams for the HLW and identification of temperature limits (if any) necessary to preserve the properties of the HLW.

5. Identification of the method to be used to ensure consistency of production batches, and any other information necessary to establish post-closure performance of the waste forms (e.g., identification of organic compounds that may be present and estimated quantities). Product consistency test and comparison to the performance of EA benchmark glass.

6. Canister material.

7. Canister dimensions (at the time of acceptance).

8. Canister lifting and handling arrangements.

9. Canister labeling conventions.

10. Information required to assess the canister drop performance including information regarding particulates, pyearophorics, combustibles, explosives, etc. that all may come into play in a Design Basis Earthquake II event. This is likely to be a detailed list, much of which has not yet been determined. This information need will be developed more fully in a future revision of the WASRD.

11. Information required to assess canister criticality, both pre and post closure. This is likely to be a detailed list, much of which has not yet been determined. This information need will be developed more fully in a future revision of the WASRD.

12. Estimated maximum gamma and neutron dose rates at the canister surface. 
13. Projected distribution of canister thermal outputs, including the maximum.

14. Method used to assign individual canister Metric Ton Heavy Metal (MTHM) content for accounting against the repository 70,000 MTHM capacity limit as specified in Section 114d of the Nuclear Waste Policy Act of 1982, as amended.

The SBW waste has been assigned four listed waste codes. The NRG is not permitted as a Subtitle $\mathrm{C}$ hazardous waste landfill therefore the project will need to delist the waste streams before they can be shipped to the NGR. The waste streams cannot exhibit a characteristic of a hazardous waste. In addition to delisting, the SBW must be treated to meet the land disposal restriction standards for hazardous metals before it can be sent to the NGR. Waste form and waste packaging performance assessments and approvals could delay treating the SBW. The NGR will need to request a license change from NRC and EPA to receive waste forms other than borosilicate glass. (See discussion of petition to exclude/delisting petition in Section 1.2.4.f)

d. The WIPP RH-TRU program is not ready to receive RH-TRU waste and will require facility modifications and testing prior to receipt waste.

The WIPP RH-TRU program could present a schedule risk to the project if they do not have a permit and the WIPP receiving facility requires modification resulting in delays to SBW shipments. An additional risk is that the SBWT project could have to modify its design during construction or startup to comply with the requirements in the approved modification for RH-TRU waste to the WIPP HWFP.

e. SBW is not identified in the 1995 TRU Waste Baseline Inventory Report (TWBIR) as a waste destined for disposal at WIPP. SBW is listed as a potential waste stream in the 2004 TWBIR but the SBW source term was not included in the 2004 performance assessment for the Compliance Re-Certification Application to EPA. The State of New Mexico has proposed: 1) to amend the permit for the Waste Isolation Pilot Plant to prohibit the shipment of reclassified high-level waste to the site, 2) to amend WIPP's permit to limit waste for disposal to those wastes identified in the 1995 TWBIR, and 3) legislation to exclude all TRU waste not identified in the 1995 TBWIR. DOE is currently working with the State of New Mexico to resolve these issues.

These proposed restrictions could delay the approval of the RH-TRU Waste Permit Modification and finalization of the RH-TRU waste acceptance requirements in the HWFP. Worst case is that these restrictions prohibit the disposal of SBW at WIPP.

f. The WIPP waste certification authorization process consists of a series of document reviews, assessments, and confirmation audits. DOE-Carlsbad Field Office (CBFO), EPA, and the State of New Mexico Environmental Department (NMED) participate in the process. Waste certification authority is based on the project demonstrating verbatim implementation of the characterization, operating, confirmation, and validation procedures and plans used for characterization and certification of waste shipments.

DOE-CBFO will approve the plans and procedures prior to start of operations and assess implementation during system operation testing. DOE-CBFO and NMED will audit the project during the first six weeks of operations to verify that the operators are trained and hazardous waste management plans and procedures have been implemented as approved. EPA will audit the project to verify that the radioactive waste management plans and procedures are being implemented as approved. Audit findings have to be resolved before waste certification authority is granted. 
NOTE: Changes to approved radioactive and hazardous waste management plans and procedures, equipment, and equipment calibrations that affect waste certification have to be approved by $\mathrm{CBFO}$ prior to implementation of the change. The DOE-CBFO, EPA, and NMED expect verbatim compliance with the approved plans and procedures and conduct quarterly assessments and yearly compliance audits to ensure that plans and procedures are being followed.

The risk to the project is that changes to approved plans and procedures before, during, and after hot startup delay waste shipments. The risk is that waste certification authority approval could be delayed by the time and manpower it takes to correct the audit findings or re-certified waste containers because plans, procedures and equipment calibrations were changed or not followed as approved.

g. Low-level waste generated by the SBWT project is listed hazardous waste and assigned RCRA hazardous waste numbers F001, F002, F005, and U134. At the present time the only disposal site permitted for radioactive and hazardous waste with these hazardous waste numbers is Envirocare. Envirocare is licensed and permitted for low-level Class A radioactive and hazardous waste. For low-level waste streams with INTEC hazardous waste numbers that exceed the radioisotope limits for Class A low-level waste, there are no disposal sites available. If the project generates low-level (non-TRU) waste with activity greater than Class A limits, then it will be a waste without a path for disposal and would require on-site storage.

The Nevada Test Site disposes of radioactive waste from off-site generators. The Hanford site is not permitted to receive radioactive and hazardous mixed waste from off-site generators or wastes with the U134 hazardous waste number. At the INEEL, the Radioactive Waste Management Complex (RWMC) receives radioactive waste and the Idaho CERCLA Disposal Facility (ICDF) receives CERCLA waste. In order, for the project to dispose of waste at either the RWMC, Nevada Test Site, or Hanford Site, the project will need to treat the waste for characteristically hazardous constituents and prepare a delisting petition to remove the hazardous waste number above. In order for the waste to be disposed of at the ICDF the project and waste generated would have to be added to the INEEL CERCLA program under the Federal Facilities Agreements/Consent Order. The proposed treatment option would generate low-level waste in the form of grouted scrub, GAC, PPE, and debris.

To avoid these risks, it is recommended that the SBWT project work with the State of Idaho, Region 10 EPA, and the disposal site state to delist low-level waste generated from this process, since it does not contain the hazard constituents for which it was listed. Delisting petition or a petition to exclude waste from hazardous waste regulation requires approval in the generating state, states through which the waste is transported, and the state in which the waste will be disposed of. There is still the risk that the disposal site state may not accept the delisting for SBW, even if it is approved in Idaho and Region 10.

\subsubsection{CMACT Regulatory Risks - Summary}

\section{WIPP}

- The State of New Mexico delays the approval of the RH-TRU permit modification.

- The State of New Mexico delays the approval of the 311(b) permit modification.

- The State of New Mexico amends the WIPP HWFP to exclude waste classified as TRU using the WIR process. 
- $\quad$ The State of New Mexico amends the WIPP HWFP to exclude waste not listed in the 1995 Transuranic Waste Baseline Inventory Report.

- $\quad$ The EPA or State of New Mexico requires additional sampling and analysis for acceptable knowledge characterization for RH-TRU waste.

- $\quad$ WIPP/EPA/NM do not grant waste certification authority to the project until 180 days after hot start (30 days of production, audit, 4-6 months wait until approval is granted).

- WIPP does not have the manpower or on-site capabilities to support the shipping schedule.

- $\quad$ WIPP does not have 72-B transporters available for the SBWT project to support the shipping schedule.

- WIPP does not have the LWA capacity to receive the RH-TRU SBW.

- $\quad$ NMED continues to require headspace gas analysis for every container in storage.

- $\quad$ NMED continues to require verification sampling and analysis of the waste in containers in addition to acceptable knowledge.

- $\quad$ WIPP approval of changes to equipment and procedures identified during SO testing, readiness review, and hot start up delays waste certification authority or implementation of new procedures.

- $\quad$ Court challenges by the State of New Mexico or stakeholders prevent or delay shipping SBW to WIPP.

- $\quad$ The State of New Mexico passes legislation that prevents or delays shipping SBW to WIPP.

\section{Permitting}

- $\quad$ State of Idaho DEQ cannot support the aggressive permitting modification schedule for start of construction.

- State of Idaho DEQ does not approve a general permit modification to support the start of building construction.

- $\quad$ State of Idaho DEQ does not issue a permit to construct (air) to support the schedule for start of building construction.

- State of Idaho DEQ does not approve the modifications to the HWMA permit in time to support the start of operations.

- State of Idaho DEQ does not issue a permit to operate (air) in time to support the start of operations.

- $\quad$ State of Idaho DEQ and Federal Land Manager, PSD new source review requires additional off gas clean up and delays permit approval.

- $\quad$ State of Idaho DEQ does not cooperate with permitting the high temperature thermal treatment alternatives. 
- $\quad$ The compliance performance testing (trail burn) delays the start of production operations.

- $\quad$ Court challenges by INEEL stakeholders delay or prevent permit modifications needed for the SBW project.

- State of Idaho does not approve the SBW petition to exclude the waste from hazardous waste regulation.

- $\quad$ The disposal site state does not approve the SBW to exclude the waste from hazardous waste regulation.

- $\quad$ Compliance testing to demonstrate compliance with MACT requires the use of chemical spiking that adds new $\mathrm{P}$ and $\mathrm{U}$ listed hazardous waste numbers to the SBW that affect disposal at WIPP, NGR, or low-level waste sites.

\section{DOE O 435.1}

- $\quad$ Federal courts vacate DOE's authority to make WIR determinations.

- $\quad$ Federal courts delay DOE's authority to make WIR determinations.

- $\quad$ Congress does not clarify DOE's authority to make WIR determinations.

- $\quad$ The project generates waste streams without a path to disposal requiring permitting and construction of additional storage capacity.

\section{Safety}

- $\quad$ The Preliminary Documented Safety Analysis (PDSA) is not approved in time to support the schedule for ordering long lead equipment.

- $\quad$ The Final Documented Safety Analysis (FDSA) is not approved in time to support the readiness review schedule.

- $\quad$ Systems operations testing identify problems that delay the hot start up schedule.

- $\quad$ Readiness review process takes additional time to correct findings and delays the hot start up schedule.

- $\quad$ Radioactive Waste Management Authority is not approved in time to support the hot start up schedule causing a delay in WIPP Waste Certification Authority. 
Table 1-3. MACT standards for hazardous waste incinerators, 40CFR $\S 63 \S \S E E E$.

\begin{tabular}{|c|c|c|c|}
\hline Constituent & $\begin{array}{c}\text { Existing Source } \\
\text { Interim Rule }\end{array}$ & $\begin{array}{l}\text { New Source } \\
\text { Interim Rule }\end{array}$ & $\begin{array}{l}\text { New Source } \\
\text { Final Proposed } \\
\text { Rule 4-20-04 }\end{array}$ \\
\hline Dioxins/furans & $<0.20 \mathrm{ng}$ TEQ$/ \mathrm{dscm}$ & $<0.20 \mathrm{ng}$ TEQ$/ \mathrm{dscm}$ & $\begin{array}{l}0.11 \text { for dry APCD or } \\
\mathrm{WHBs}^{1} ; 0.2 \text { for others }\end{array}$ \\
\hline & $\begin{array}{l}<0.40 \mathrm{ng} \mathrm{TEQ} / \mathrm{dscm} \\
\leq 400^{\circ} \mathrm{F}\end{array}$ & & \\
\hline Mercury & $<130 \mu \mathrm{g} / \mathrm{dscm}$ & $<45 \mu \mathrm{g} / \mathrm{dscm}$ & $8 \mu \mathrm{g} / \mathrm{dscm}$ \\
\hline Lead and cadmium & $<240 \mu \mathrm{g} / \mathrm{dscm}$ & $<120 \mu \mathrm{g} / \mathrm{dscm}$ & $6.5 \mu \mathrm{g} / \mathrm{dscm}$ \\
\hline $\begin{array}{l}\text { Arsenic, beryllium, and } \\
\text { chromium }\end{array}$ & $<97 \mu \mathrm{g} / \mathrm{dscm}$ & $<97 \mu \mathrm{g} / \mathrm{dscm}$ & $8.9 \mu \mathrm{g} / \mathrm{dscm}$ \\
\hline Carbon Monoxide & $<100 \mathrm{ppm}$ & $<100 \mathrm{ppm}$ & $\begin{array}{l}100 \text { ppmv (CO) or } 10 \\
\text { ppmv HWC }\end{array}$ \\
\hline $\begin{array}{l}\text { Hydrochloric acid and } \\
\text { chlorine gas }\end{array}$ & $<77 \mathrm{ppm}$ & $<77 \mathrm{ppm}$ & $0.18 \mathrm{ppmv}^{2}$ \\
\hline Particulate Matter & $>34 \mathrm{mg} / \mathrm{dscm}$ & $>34 \mathrm{mg} / \mathrm{dscm}$ & $0.0070 \mathrm{gr} / \mathrm{dscf}^{3}$ \\
\hline
\end{tabular}

NOTES:

(a) Emission limits for existing sources. You must not discharge or cause combustion gases to be emitted into the atmosphere that contain:

(1) For dioxins and furans:

(i) Emissions in excess of $0.20 \mathrm{ng} \mathrm{TEQ} / \mathrm{dscm}$ corrected to 7 percent oxygen; or

(ii) Emissions in excess of $0.40 \mathrm{ng} \mathrm{TEQ} / \mathrm{dscm}$ corrected to 7 percent oxygen provided that the combustion gas temperature at the inlet to the initial particulate matter control device is $400^{\circ} \mathrm{F}$ or lower based on the average of the test run average temperatures. (For purposes of compliance, operation of a wet particulate control device is presumed to meet the $400^{\circ} \mathrm{F}$ or lower requirement);

(2) Mercury in excess of $130 \mu \mathrm{g} / \mathrm{dscm}$ corrected to 7 percent oxygen;

(3) Lead and cadmium in excess of $240 \mu \mathrm{g} / \mathrm{dscm}$, combined emissions, corrected to 7 percent oxygen;

(4) Arsenic, beryllium, and chromium in excess of $97 \mu \mathrm{g} / \mathrm{dscm}$, combined emissions, corrected to 7 percent oxygen;

(5) For carbon monoxide and hydrocarbons, either:

(i) Carbon monoxide in excess of 100 parts per million by volume, over an hourly rolling average (National continuously with a continuous emissions monitoring system), dry basis and corrected to 7 percent oxygen. If you elect to comply with this carbon monoxide standard rather than the hydrocarbon standard under paragraph (a)(5)(ii) of this section, you must also document that, during the destruction and removal efficiency (DRE) test runs or their equivalent as provided by $\S 63.1206(\mathrm{~b})(7)$, hydrocarbons do not exceed 10 parts per million by volume during those runs, over an hourly rolling average (National continuously with a continuous emissions monitoring system), dry basis, corrected to 7 percent oxygen, and reported as propane; or

Hydrocarbons in excess of 10 parts per million by volume, over an hourly rolling average (National continuously with a continuous emissions monitoring system), dry basis, corrected to 7 percent oxygen, and reported as propane;

(6) Hydrochloric acid and chlorine gas in excess of 77 parts per million by volume, combined emissions, expressed as hydrochloric acid equivalents, dry basis and corrected to 7 percent oxygen; and

(7) Particulate matter in excess of $34 \mathrm{mg} / \mathrm{dscm}$ corrected to 7 percent oxygen.

(b) Emission limits for new sources. You must not discharge or cause combustion gases to be emitted into the atmosphere that contain:

(1) Dioxins and furans in excess of $0.20 \mathrm{ng} \mathrm{TEQ} / \mathrm{dscm}$, corrected to 7 percent oxygen;

(2) Mercury in excess of $45 \mu \mathrm{g} / \mathrm{dscm}$ corrected to 7 percent oxygen;

(3) Lead and cadmium in excess of $120 \mu \mathrm{g} / \mathrm{dscm}$, combined emissions, corrected to 7 percent oxygen;

(4) Arsenic, beryllium, and chromium in excess of $97 \mu \mathrm{g} / \mathrm{dscm}$, combined emissions, corrected to 7 percent oxygen;

(5) For carbon monoxide and hydrocarbons, either:

(i) Carbon monoxide in excess of 100 parts per million by volume, over an hourly rolling average (National continuously with a continuous emissions monitoring system), dry basis and corrected to 7 percent oxygen. If you elect to comply with this carbon monoxide standard rather than the hydrocarbon standard under paragraph (b)(5)(ii) of this section, you must also document that, during the destruction and removal efficiency (DRE) test runs or their equivalent as provided by $\S 63.1206(\mathrm{~b})(7)$, hydrocarbons do not exceed 10 parts per million by volume during those runs, over an hourly rolling average (National continuously with a continuous emissions monitoring system), dry basis, corrected to 7 percent oxygen, and reported as propane; or

Hydrocarbons in excess of 10 parts per million by volume, over an hourly rolling average (National continuously with a continuous emissions monitoring system), dry basis, corrected to 7 percent oxygen, and reported as propane;

(6) Hydrochloric acid and chlorine gas in excess of 21 parts per million by volume, combined emissions, expressed as hydrochloric acid equivalents, dry basis and corrected to 7 percent oxygen; and

(7) Particulate matter in excess of $34 \mathrm{mg} / \mathrm{dscm}$ corrected to 7 percent oxygen. 


\begin{tabular}{|c|c|c|c|c|c|c|c|c|c|c|c|c|c|c|c|c|c|}
\hline \multicolumn{2}{|c|}{ 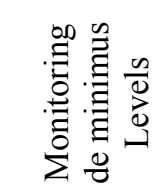 } & $\stackrel{m}{E 0}^{m}$ & $ㅇ$ & i & ๙. & $\sigma$. & $i$ & 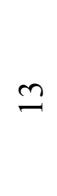 & 1 & $\Xi$ & i & i & 1 & $\stackrel{n}{i n}$ & $\stackrel{n}{a}$ & 1 & 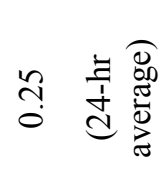 \\
\hline \multicolumn{2}{|c|}{ 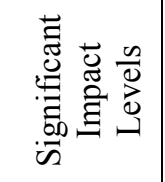 } & ${ }_{0}^{m}$ & $n$ & - & ๙. & $\sigma$. & $\approx$ & $n$ & - & $=$ & 1 & i & \&̊ & \& & $i$ & $i$ & $i$ \\
\hline \multicolumn{2}{|c|}{ 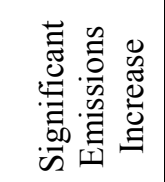 } & 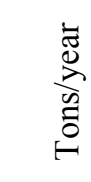 & \multicolumn{2}{|l|}{ 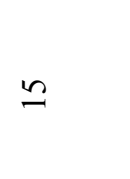 } & \multicolumn{2}{|l|}{ a. } & \multicolumn{3}{|l|}{ f } & \& & \multicolumn{2}{|l|}{ 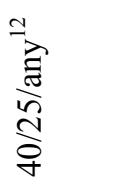 } & 8 & 8 & $\stackrel{0}{0}$ & $\approx$ & $n$ \\
\hline \multirow{3}{*}{ 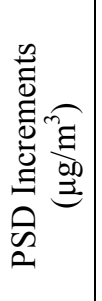 } & \multirow{3}{*}{ 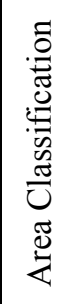 } & $\Xi$ & 8 & $\stackrel{\sim}{m}$ & $\sigma$. & $\sigma$. & \& & $\underset{\infty}{\infty}$ & 우 & in & 1 & 1 & 1 & 1 & 1 & $i$ & $i$ \\
\hline & & $\Xi$ & ి & 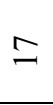 & $\sigma$. & $\sigma$. & $\frac{n}{n}$ & $\bar{a}$ & নి & $\approx$ & i & i & $i$ & $i$ & 1 & 1 & 1 \\
\hline & & $\neg$ & $\infty$ & $\nabla$ & a. & $\sigma$. & $\approx$ & in & $\sim$ & $\tilde{n}$ & 1 & $i$ & 1 & $i$ & 1 & $i$ & 1 \\
\hline \multirow{4}{*}{ 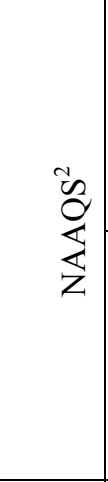 } & \multirow{2}{*}{$\begin{array}{l}\vec{E} \\
\bar{E} \\
\overline{0} \\
0 \\
\tilde{J}\end{array}$} & 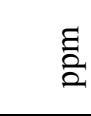 & i & $i$ & i & $i$ & $\tilde{o}$ & 1 & i & $\begin{array}{l}n \\
0 \\
0\end{array}$ & $\frac{1}{0}$ & $\begin{array}{l}\infty \\
\stackrel{0}{0} \\
0\end{array}$ & 1 & $i$ & 1 & i & 1 \\
\hline & & $\sum_{\sum^{0, m}}^{\xi}$ & $\stackrel{n}{n}$ & $\stackrel{i}{n}$ & 6 & $\cong$ & 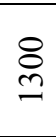 & 1 & 1 & 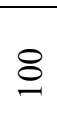 & $\tilde{\approx}$ & $\hat{n}$ & 1 & $i$ & $\stackrel{n}{-}$ & $i$ & $i$ \\
\hline & \multirow{2}{*}{ : } & 总 & 1 & 1 & 1 & i & $i$ & $\stackrel{ \pm}{\overrightarrow{0}}$ & $\stackrel{m}{0}$ & $\begin{array}{l}n \\
\hat{o} \\
0\end{array}$ & $\stackrel{1}{\circ}$ & $\begin{array}{l}\infty \\
0 \\
0\end{array}$ & $\approx$ & $a$ & 1 & $i$ & 1 \\
\hline & & $\stackrel{m}{E D}_{\Xi}^{E}$ & $\stackrel{n}{n}$ & in & $\tilde{6}$ & 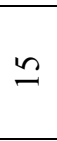 & $i$ & $\stackrel{n}{n}$ & $\infty$ & 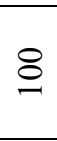 & $\ddot{v}$ & $\hat{n}$ & \begin{tabular}{l}
8 \\
8 \\
\hdashline \\
$\dot{q}$
\end{tabular} & $\begin{array}{l}8 \\
8 \\
0 \\
0\end{array}$ & $\stackrel{n}{=}$ & $i$ & $i$ \\
\hline & & "ే & $\varangle$ & $m$ & U & D & 피 & 피 & I & 工 & 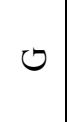 & $I$ & 피 & $\amalg$ & $\neg$ & $i$ & 1 \\
\hline \multicolumn{3}{|c|}{ 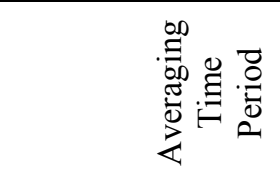 } & 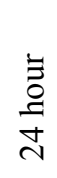 & 鸪 & $\begin{array}{l}\vec{\Xi} \\
\stackrel{\Xi}{ \pm}\end{array}$ & 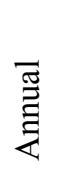 & $\frac{\Xi}{\stackrel{\Xi}{\Xi}}$ & $\begin{array}{l}\vec{\Xi} \\
\stackrel{\Xi}{J}\end{array}$ & $\begin{array}{l}\bar{\Xi} \\
\text { 荌 }\end{array}$ & $\begin{array}{l}\bar{\Xi} \\
\text { 吾 }\end{array}$ & $\stackrel{\Xi}{\Xi}$ & 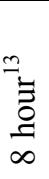 & $\begin{array}{l}\Xi \\
\Xi \\
\Xi\end{array}$ & $\underset{\infty}{\stackrel{\Xi}{0}}$ & 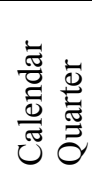 & $i$ & $i$ \\
\hline \multirow{2}{*}{\multicolumn{2}{|c|}{ 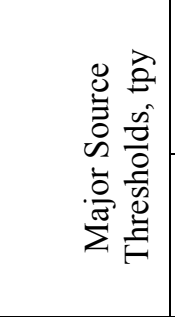 }} & $\sum_{Z}^{+}$ & $\frac{2}{8}$ & & 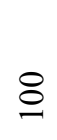 & & 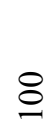 & & & 8 & $\begin{array}{l}\stackrel{\circ}{\circ} \\
\stackrel{n}{8}\end{array}$ & $\begin{array}{l}\overrightarrow{0} \\
\stackrel{0}{\curvearrowright} \\
\end{array}$ & $\begin{array}{l}\stackrel{0}{\circ} \\
\stackrel{8}{8} \\
\text { ¿ }\end{array}$ & & 8 & i & 1 \\
\hline & & $\tilde{\tilde{n}}$ & $\begin{array}{l}8 \\
8 \\
\frac{8}{8} \\
\stackrel{n}{1}\end{array}$ & & $\begin{array}{l}8 \\
\stackrel{0}{\circ} \\
\stackrel{2}{1}\end{array}$ & & $\frac{8}{8}$ & & & 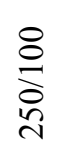 & $\begin{array}{l}8 \\
\stackrel{1}{2} \\
\stackrel{2}{1} \\
\end{array}$ & & $\begin{array}{l}8 \\
\stackrel{2}{8} \\
\stackrel{2}{1}\end{array}$ & & $\begin{array}{l}8 \\
\stackrel{8}{2} \\
\\
\end{array}$ & $\begin{array}{l}8 \\
\stackrel{2}{\circ} \\
\stackrel{2}{7}\end{array}$ & 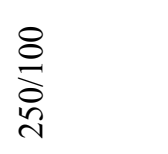 \\
\hline \multicolumn{3}{|c|}{ 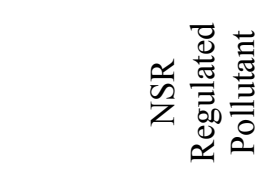 } & $\sum_{i}^{n}$ & & $\sum_{i}^{\infty}$ & & O̊ & & & $\overbrace{Z}^{\top}$ & 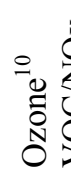 & & O & & 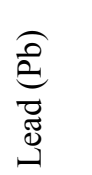 & 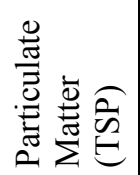 & $\begin{array}{l}\frac{0}{0} \\
\frac{0}{0} \\
\frac{0}{3} \\
\frac{1}{1}\end{array}$ \\
\hline
\end{tabular}




\begin{tabular}{|c|c|c|c|c|c|c|c|c|c|c|c|}
\hline \multicolumn{2}{|c|}{ 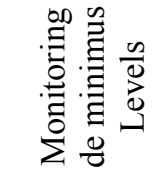 } & $\stackrel{{ }^{m}}{\frac{7}{00}}$ & i & 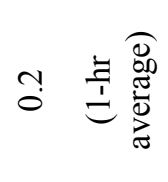 & 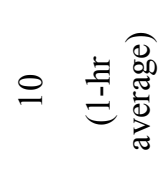 & 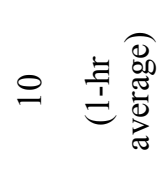 & 1 & i & 1 & i & 1 \\
\hline \multicolumn{2}{|c|}{ 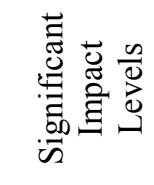 } & ${ }^{m}$ & 1 & i & $i$ & 1 & 1 & i & 1 & 1 & 1 \\
\hline \multicolumn{2}{|c|}{ 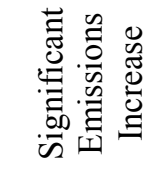 } & 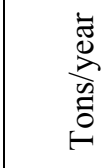 & $r$ & 으 & $\stackrel{0}{ }$ & $\stackrel{0}{ }$ & 穵离 & \& & $\cong$ & $\begin{array}{l}i 0 \\
\frac{1}{x} \\
n \\
m\end{array}$ & in \\
\hline \multirow{3}{*}{ 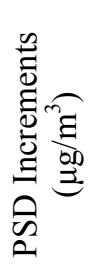 } & \multirow{3}{*}{ 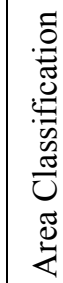 } & $\Xi$ & 1 & $i$ & 1 & $i$ & i & i & i & i & 1 \\
\hline & & $\exists$ & 1 & 1 & 1 & 1 & 1 & i & 1 & 1 & i \\
\hline & & $\neg$ & $i$ & 1 & 1 & 1 & 1 & $i$ & 1 & 1 & 1 \\
\hline \multirow{4}{*}{$\underset{z}{\tilde{z}}$} & \multirow{2}{*}{ 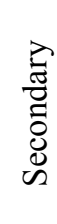 } & 芫 & i & 1 & i & 1 & 1 & i & 1 & i & 1 \\
\hline & & $\sum^{g}$ & $i$ & i & i & 1 & 1 & i & 1 & $i$ & 1 \\
\hline & \multirow{2}{*}{$\underset{\vec{E}}{\stackrel{\vec{E}}{\Xi}}$} & 艺 & 1 & i & i & 1 & 1 & i & 1 & 1 & i \\
\hline & & 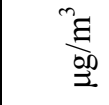 & i & i & i & i & i & i & i & i & i \\
\hline \multirow{2}{*}{\multicolumn{3}{|c|}{ 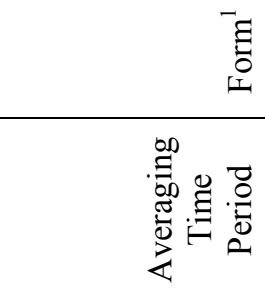 }} & 1 & 1 & $i$ & 1 & 1 & $i$ & 1 & 1 & 1 \\
\hline & & & 1 & 1 & i & 1 & i & i & i & 1 & 1 \\
\hline \multirow{2}{*}{\multicolumn{2}{|c|}{ 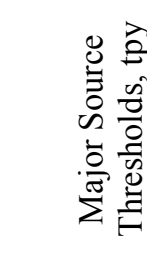 }} & $\stackrel{+}{\rightleftarrows}$ & i & 1 & $i$ & 1 & 1 & $i$ & i & 1 & 1 \\
\hline & & $\tilde{n}$ & $\begin{array}{l}8 \\
\stackrel{8}{2} \\
\vdots \\
i\end{array}$ & $\begin{array}{l}8 \\
\stackrel{8}{8} \\
\vdots \\
i\end{array}$ & $\begin{array}{l}8 \\
\stackrel{8}{8} \\
i \\
i\end{array}$ & 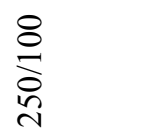 & $\underset{\substack{8 \\
\grave{2}}}{\stackrel{8}{1}}$ & $\begin{array}{l}8 \\
\frac{8}{8} \\
i \\
i\end{array}$ & $\stackrel{8}{\stackrel{8}{8}}$ & $\stackrel{8}{\stackrel{8}{8}}$ & $\underset{\substack{8\\
}}{\stackrel{8}{n}}$ \\
\hline \multicolumn{3}{|c|}{ 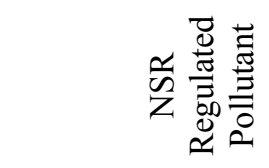 } & 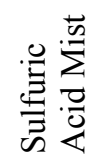 & 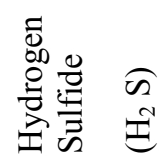 & 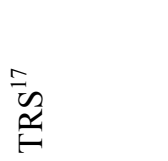 & $\begin{array}{l}\infty \\
\mathscr{N}\end{array}$ & $\frac{\hat{\sigma}}{\hat{0}}$ & 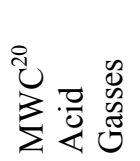 & $\sum_{\sum}^{0} \frac{\pi}{\pi}$ & 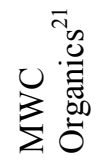 & 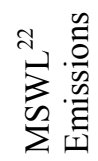 \\
\hline
\end{tabular}


Table 1-2. Summary of technical issues and risks - Calcination with MACT Upgrade (CMACT).

\begin{tabular}{|c|c|c|c|c|}
\hline & Risk or Issue & Probability & Impact & Resolution \\
\hline 1 & MCF HEPA filters may be redundant & 4 & 2 & Design evaluation \\
\hline 2 & $\begin{array}{l}\mathrm{HCl} / \mathrm{Cl}_{2} \text { stack release may exceed } \\
\mathrm{MACT} \text { limit }\end{array}$ & $\begin{array}{l}5 \text { or } 10 \\
\text { (Note } 1)\end{array}$ & 7 & $\begin{array}{l}\text { Design evaluation \& negotiations } \\
\text { with regulators }\end{array}$ \\
\hline 3 & $\begin{array}{l}\text { GAC beds may require change-out due } \\
\text { to } \mathrm{HCl} \text { or saturation }\end{array}$ & 5 & 4 & Design \\
\hline 4 & $\begin{array}{l}\text { GAC bed sizing to ensure } \mathrm{Hg} \text { removal is } \\
\text { uncertain (with the risk of exceeding the } \\
\text { Hg emission limit) }\end{array}$ & $\begin{array}{l}3 \text { or } 10 \\
(\text { Note } 1)\end{array}$ & 8 & $\begin{array}{l}\text { Design, and if more stringent MACT } \\
\text { Hg limit adopted, testing }\end{array}$ \\
\hline 5 & MCF equipment failure & 5 & 4 & $\begin{array}{l}\text { Design and operating/control } \\
\text { procedures }\end{array}$ \\
\hline 6 & Emission standards may change & 8 & 8 & $\begin{array}{l}\text { Design and negotiations with } \\
\text { regulators }\end{array}$ \\
\hline 7 & $\begin{array}{l}\text { Scrub waste TRU content may be less } \\
\text { than } 100 \mathrm{nCi} / \mathrm{g}\end{array}$ & 1 & 10 & $\begin{array}{l}\text { Design with appropriate control } \\
\text { scheme }\end{array}$ \\
\hline 8 & $\begin{array}{l}\text { Scrub waste radiolytic hydrogen } \\
\text { generation is uncertain with potential for } \\
\text { disqualifying waste from WIPP disposal }\end{array}$ & 2 & 10 & $\begin{array}{l}\text { Assign waste code and perform } \\
\text { calculations during design }\end{array}$ \\
\hline 9 & $\begin{array}{l}\text { Volume of grouted scrub waste } \\
\text { uncertain and may exceed estimates }\end{array}$ & 5 & 2 & $\begin{array}{l}\text { Design to include flexibility in scrub } \\
\text { processing capability }\end{array}$ \\
\hline 10 & $\begin{array}{l}\text { Calcine volume could be greater than } \\
\text { expected due to lower calcine density }\end{array}$ & 6 & 6 & $\begin{array}{l}\text { Design evaluation of densification } \\
\text { possibly followed by testing }\end{array}$ \\
\hline 11 & $\begin{array}{l}\text { Stabilization of spent GAC prior to } \\
\text { disposal may be required }\end{array}$ & 5 & 4 & $\begin{array}{l}\text { Negotiation with disposal sites and } \\
\text { regulators; possible testing }\end{array}$ \\
\hline 12 & $\begin{array}{l}\text { Changes could be made in final WIPP } \\
\text { RH WAC }\end{array}$ & 5 & 5 & Design and negotiation with WIPP \\
\hline 13 & $\begin{array}{l}\text { Uncertainties in tank waste solids } \\
\text { composition could affect calcination }\end{array}$ & 2 & 5 & Resolve during startup \\
\hline 14 & $\begin{array}{l}\text { Performance of mix pumps for TFF } \\
\text { tanks uncertain, with risk of varying } \\
\text { solids content in feed }\end{array}$ & 5 & 8 & Mock up testing of mix pumps \\
\hline 15 & $\begin{array}{l}\text { Tank blending scheme has not been } \\
\text { finalized }\end{array}$ & 5 & 5 & Design \\
\hline 16 & $\begin{array}{l}\text { NGLW generation rates and } \\
\text { composition uncertain and could affect } \\
\text { process }\end{array}$ & 3 & 2 & Design \\
\hline 17 & NWCF equipment could fail & 9 & 9 & $\begin{array}{l}\text { Perform upgrades as defined in FY } \\
2003 \text { studies }\end{array}$ \\
\hline 18 & $\begin{array}{l}\text { Basis for design and performance of } \\
\text { calcine packaging equipment uncertain }\end{array}$ & 8 & 10 & Mock up testing of equipment \\
\hline 19 & $\begin{array}{l}\text { Basis for design and performance of } \\
\text { scrub grouting and packaging } \\
\text { equipment uncertain }\end{array}$ & 7 & 8 & Mock up testing of equipment \\
\hline 20 & $\begin{array}{l}\text { Refractory or other components of } \\
\text { staged combustor may need replacement }\end{array}$ & 6 & 4 & $\begin{array}{l}\text { Design evaluations to minimize and } \\
\text { maintenance during turnarounds }\end{array}$ \\
\hline 21 & $\begin{array}{l}\text { Certain MACT requirements impractical } \\
\text { for MCF }\end{array}$ & 9 & 9 & $\begin{array}{l}\text { Design evaluation and negotiation } \\
\text { with regulators }\end{array}$ \\
\hline
\end{tabular}




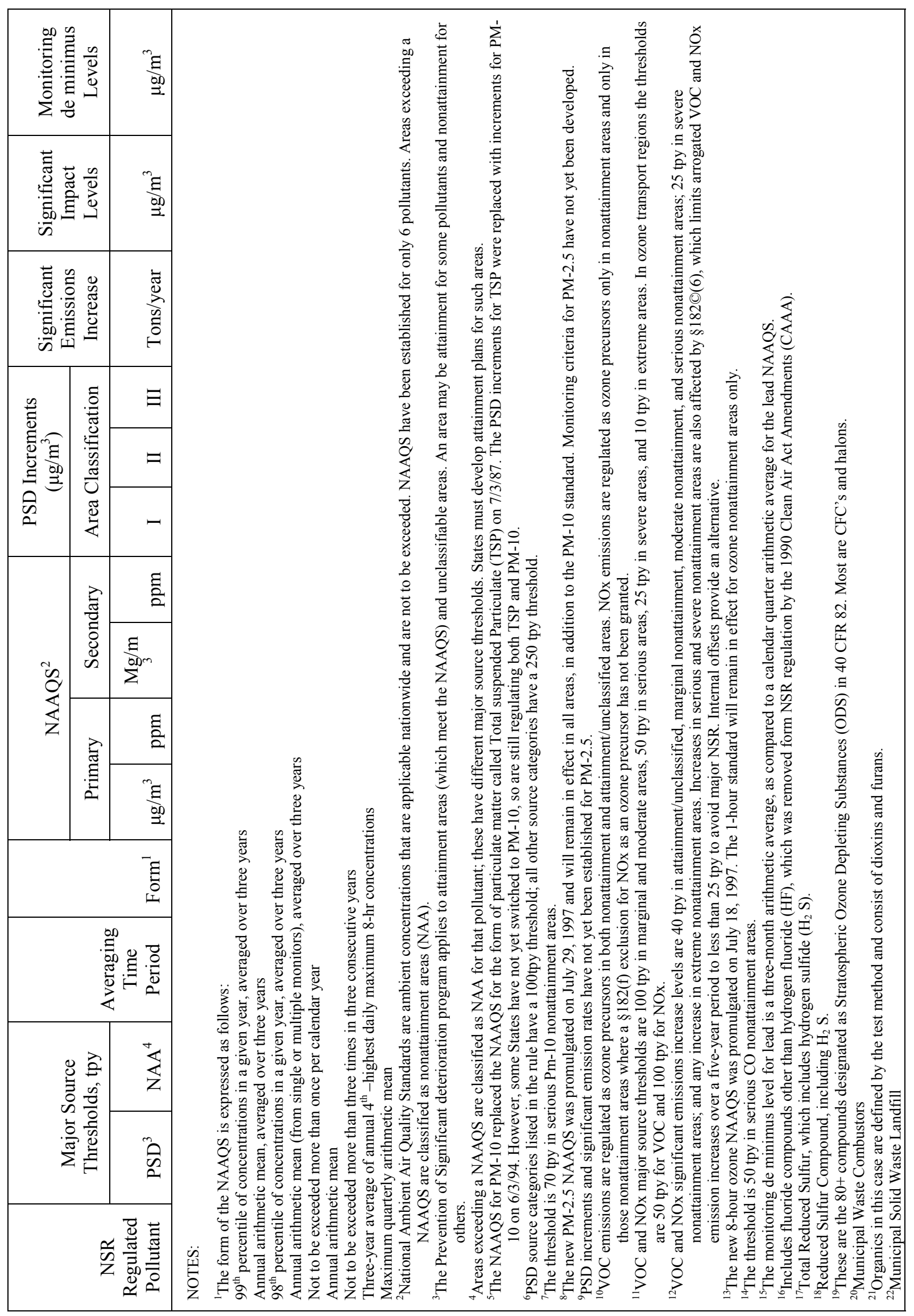




\subsection{CMACT Schedule and Related}

The overall schedule for the CMACT SBW treatment alternative cannot achieve the 2012 milestones (late by at least 23 months) primarily due to throughput limitations of the existing calcination system and the time required to permit and construct the CPF.

\subsubsection{CMACT Capital Project Schedule (February 2005 to September 2010)}

\subsubsection{Preliminary Design (February 2005 to October 2005).}

It will require a very aggressive effort to conclude Preliminary Design by October 2005 in only a nine-month period starting in February 2005 and submit environmental permits in December 2005.

The assumed start for the capital project is February 1, 2005, the first day of the new ICP contractor. It was assumed at the time of the recent CMACT feasibility study (Merrick 2004) that Preliminary (Title I) Design would commence on this date. However, even if government funding and approvals (Critical Decision 0, CD-0, Approve Mission Need, and CD-1, Approve Alternative Selection and Cost Range) were not to be limiting, Preliminary Design cannot start without a design company being in place under contract and design direction documents such as the Scope of Work (SOW), Technical and Functional Requirements document (TFR), and Project Design Criteria (PDC). These documents have not yet been prepared (the treatment alternatives are many and varied and one has not been chosen yet) but could perhaps be developed in the transition period prior to February 1, 2005, or in the month or two immediately following.

An aggressive Preliminary Design (Title I Design) period of nine months is possible but difficult during which the process definition must be finalized and P\&IDs developed. Related to this the following must be done: (1) critical Technical Development test work must be conducted to support process definition; (2) remote mock-up testing must be started and iterate with design to develop and prove the concepts; (3) safety analysis work must be started and proceed through the fundamental assessment stage to define any safety driven requirements to be inputted to the design; and (4) the draft environmental permit applications must be written. Numbers 1 and 2 would be difficult to achieve in such a short time frame and could be schedule limiting or most likely require design work to proceed at risk based on the best concepts and assumptions available. All this must be coordinated to finalize the P\&IDs such that facility design and mechanical layout work can be performed in sufficient detail to support submittal of the RCRA Part B and Air permit applications. This is considered to be a "Title I Plus" design; that is, a level of detail beyond what is normally developed in a Preliminary / Title I Design effort. The following would be required:

\section{HWMA/RCRA Permitting}

\section{Process}

- $\quad$ Final process flow diagrams (PFDs), material and energy balances, and process and instrument diagrams (P\&IDs)

- $\quad$ Process descriptions

- $\quad$ Equipment descriptions

- $\quad$ Operating limits 
- $\quad$ Operating procedures (at least draft).

\section{Building}

- $\quad$ Site location

- $\quad$ Facility layouts

- $\quad$ Floor plan drawings

- $\quad$ Equipment and piping layouts

- $\quad$ Materials of construction used

- $\quad$ Secondary containment details (at least typical).

\section{Waste}

- Characterization of feed waste (SBW in Tank Farm)

- Waste acceptance requirements for the treatment facility

- $\quad$ Process control requirements

- Description of final waste

- Characterization (typical) of final waste

- $\quad$ Sampling and analytical methods used

\section{Air Permitting}

MACT

\section{Air Emission Modeling}

- Identify sources of emission

- Identify constituents of concern

- $\quad$ Model emissions.

\section{Compliance Performance Test Plan or emission testing plans}

- $\quad$ Sampling planned

- Analysis to be performed

- $\quad$ Monitoring equipment to be used

- $\quad$ Surrogate runs planned 
- $\quad$ Spiking to be performed (if any).

\section{NESHAPs}

- $\quad$ Estimated emissions of radionuclides.

PSD

- $\quad$ Estimated NOx emissions

- $\quad$ Estimated visible emissions.

Title V

- $\quad$ Estimate emission of hazardous constituents.

At the end of Preliminary Design, the details of the design would be fed into the environmental permit applications and 60 days later, after final reviews, revisions, and approvals, the complete and fully compliant permit applications would be submitted to the IDEQ for the assumed minimum two year review and approval process (reduced from the 31 months requested by IDEQ by taking time from the contractor's schedule only) before permission would be given to start construction.

Additionally, during Preliminary Design equipment needs will be examined and detailed specifications will be prepared and finalized either at this stage or in the early days of Final Design for equipment that is (1) critical to facility detailed design, (2) needed for the mock-up testing program, or (3) otherwise long-lead and schedule critical. (This equipment is normally referred to as "government furnished equipment," GFE.) Some examples of this are the NOxidizer ${ }^{\circledR}$, the fluidized calcine hoppers and canister loading assembly, the continuous grout mixer and associated assembly, the decon/transfer cart, the canister handling machine, and the tank mixing pumps.

\subsection{Issues Related To Design And Construction Of The Calcine}

Packaging Facility-Advantages could be realized if the CPF was to be designed for both processing newly formed SBW calcine and for receipt and packaging of the existing HLW calcine in the INTEC bin sets. A summary of these benefits to the SBW and HLW programs are significant cost savings and overall schedule savings for HLW with some net detriment to the SBW schedule especially in the design phase. Designing for both SBW and HLW calcine would add to the design and construction complexity and schedule inside the SBW treatment project while having a calcine receipt, packaging, and load-out facility built early would be advantageous for the HLW program and should enable significantly earlier disposition of the HLW calcine.

The following questions and issues need to be addressed before starting design on a dual service Calcine Packaging Facility:

1. The obvious first question is whether or not the INEEL will be successful in obtaining approval for disposal of as-is packaged (no treatment) HLW calcine at the NGR, Yucca Mountain or, if this answer cannot be determined in the short term, if design on the CPF should proceed in any case under this assumption. All of the other following questions depend on the answer to this one.

2. If design were to proceed on the dual use CPF, should it be designed for the 15 -ft canister or the standard 10-ft design? This affects the size and height of the hot cells and storage locations and such things as crane capacities. Hanford has been pursuing approval of the 15-ft canister for HLW 
disposal for several years now, but it has not yet been approved. It should be noted that WIPP will only accept a $10-\mathrm{ft}$ canister.

3. If the CPF were to be designed for dual use, shielding would have to be provided for the worst case HLW calcine instead of the worst case SBW calcine. An analysis of this has already been performed (Rielly, 2003) with the result being that shielding requirements would be $30.1 \mathrm{in}$. of concrete for worst case SBW calcine vs. 36 in. for worst case HLW calcine (15.2 in. vs. 18.2 in. for high density concrete). Thus 3 in. to 6 in. more concrete (20\% additional wall thickness in both cases) would be required for the hottest HLW calcine and the 15-ft canister (SBW calcine was calculated for the $10-\mathrm{ft}$ canister for WIPP).

4. Information is needed on the intended design of the HLW calcine retrieval system so that the interfaces in the CPF could be properly designed - calcine receipt hoppers and filters, transport gas handling and treatment/disposition, etc. as well as the exact location of the CPF on the INTEC plot plan.

5. Both WIPP and Yucca Mountain accept a nominal $2 \mathrm{ft}$ diameter by $10-\mathrm{ft}$ long canister but there are small dimensional differences as well as lid and handling design feature differences. The CPF would have to be designed for both. The canister filling method devised for SBW calcine in the recent CMACT feasibility study (Merrick 2004) would have to be revised or perhaps a different approach taken altogether.

6. The CPF is currently designed with no provision for sampling SBW calcine or scrub solution or its grouted final waste form. This is not needed since both calcine and scrub solution can be sampled in the NWCF and transported to the Remote Analytical Laboratory (RAL) via the existing Pneumatic Transport System (PTS). Would HLW calcine need to be sampled as it is retrieved and received in the CPF? If so, a sampling system would have to be designed (which in turn could affect the approach taken to canister filling) and the PTS extended to get to RAL or a new dedicated lab added onto the $\mathrm{CPF}$ must be provided. These particular changes would not be inexpensive.

All this would not only add to the complexity and schedule of the design effort but these questions would have to be answered early in Preliminary Design so that design concepts could be developed for the environmental permits to be submitted.

It should be noted that Preliminary Design, feeding into the environmental permit applications, and the application review process by Idaho DEQ leading to approval to construct is the first of three critical paths on the project. The second one, discussed later, is construction, testing, and startup of the CPF. The third one, also discussed later, is treatment (calcination) of the SBW which is rate limited by the existing calcination equipment in the NWCF.

\subsubsection{Final Design (November 2005 to July 2007).}

The Final Design schedule does not involve risk nor is it on the critical path. It is dictated by the time required for review and approval of the environmental permits by IDEQ, which will require 24 months after submittal following the completion of Preliminary Design.

Final Design (Title II Design) will start immediately following Preliminary Design in early November 2005. It is assumed that there will be no hold period for CD-2, Approve Performance Baseline (authority to commence Final Design). It is also assumed that an early and partial CD-3 (Approval to Start 
Construction) consent would be given at CD-2 to procure the GFE equipment cited above in the Preliminary Design write-up, which would involve a relatively significant expenditure of capital funds.

All Technical Development test work and remote mock-up testing must be completed by mid-Final Design in order to be factored into the detailed design.

Detailed design would iterate with procurement on GFE items to minimize the overall schedule as well as cost. Design would proceed to the point of preparation of numerous bid packages of equipment specifications and drawings for issuance for competitive bid by either the ICP contractor or his design agency. (The latter is preferred for better communication and control as well as lower cost.) Vendor bids would be received, analyzed, and awarded. Vendor drawings would be produced, reviewed, revised as necessary, and approved after which the equipment layouts and facility designs would be completed by the design agency to reflect these details in the bid packages for general construction. Vendor material purchases, fabrication, testing, and ultimate delivery to the construction site would (or could) be delayed in order to postpone these costs of fabrication without impacting construction as well as to wait until the construction contractor is chosen and on-site to receive delivery of these items. This approach will reduce both costs and schedule by not only initiating early procurement but by providing actual equipment details in the detailed design drawings thus avoiding numerous design related questions and delays during construction.

Final Design, bid, and award of the construction contract (normally a 3-4 month process for a project of this size), and notice to proceed and mobilization of the construction contractor on the site to be poised for the start of construction (approximately 1 month) will all fit within the 26 month permit cycle period (minimum 24 months after submittal plus 2 months after Preliminary Design for final submittal preparation) before authorization to proceed with construction is obtained from IDEQ. Final Design must then, and can without difficulty, be completed by July 31, 2007 over a 21-month time frame. Final Design could be accomplished sooner, but to no net schedule advantage since construction start must wait for the permit review and approval cycle. It would be better for Final Design to be performed over that longer time period so that the design team stays together and a core group can still be kept to support design related questions during construction.

\subsubsection{Construction (January 2008 to September 2009).}

\section{Construction of the Calcine Packaging Facility (CPF) is the second critical path activity on the overall schedule, requiring 21 months if aggressively pursued; 33 months including the testing and readiness review stage leading to hot startup. (NWCF took 71 months, 48 months to construct and 23 months to test and start up.)}

Work to obtain Critical Decision-3, approval to start construction, will begin at the end of Final Design. It is assumed that CD-3 approval will be obtained by July 2007, authorizing the start of the bid and award process. It is also assumed that CD-3 will release and provide funding support for the construction contractor to start procurement for construction. Fabrication of the GFE procurement items mentioned above in the Final Design section will be released at this time and those contracts will be completed by the originating organization (either the design agency or the ICP contractor) and be provided to the construction contractor as GFE for installation. (Schedule analysis will be performed during design and those GFE items that may be schedule limiting, if any, will be released for fabrication earlier during the late stages of Final Design so that no construction delays are encountered due to these items.)

Construction will start in January 2008 (in the middle of winter, not a particularly good time) after approval of the RCRA permit is obtained from IDEQ. Both the CPF and MCF will be started at this time 
as will the majority of the calcination system upgrade work listed in Section 1.1.5. Estimates are that this calciner upgrade work will require 268 man-Rem of radiation exposure. As such, the start of this work must be delayed until the CPF and MCF are started so that construction workers, limited by radiation exposure, can rotate over to the high volume clean work in the $\mathrm{CPF}$ and MCF.

Construction will follow a logical installation sequence from site preparation and required demolition, through earthwork, concrete, steel, piping, to completion of instrumentation and electrical installation and construction component checkout (CC Testing). Schedules from similar construction projects were used as models to develop an activity list and network logic between activities during the CMACT study (Merrick 2004). Activity durations were adjusted based upon resource loading of those activities and took into consideration realistic crew sizes and workspace congestion.

\subsubsection{Testing and Startup (April 2009 to September 2010).} path.

Testing and startup, overlapping with the final stages of construction, are also on the critical

During the late stages of construction, after construction forces have completed rudimentary component testing (CC Testing), the ICP contractor, with support from the design agency as necessary, will perform system operation (SO) tests and cold tests (CT) on the treatment system and its supporting facility and equipment. After this, an in-house readiness review will be performed leading to a formal operational readiness review (ORR) by DOE and others. Usual participants in an ORR are DOE-ID and DOE-HQ and sometimes the Defense Nuclear Facilities Safety Board (DNFSB). However, in this case the following applies: (1) final waste treatment is to be performed using a high temperature thermal process requiring compliance with the new MACT regulations, (2) RCRA waste is being treated and stored and the system is to be fully compliant and Part B permitted, and (3) the intent is to dispose of the treated waste in a major federal repository (WIPP). As such, the Federal EPA, Idaho DEQ, WIPP, and New Mexico Environmental Department will also be involved, at least informally or an audit mode, in the final ORR and hot startup/ "trial burn" and the waste form qualification and process/program validation leading to program certification for the WIPP repository.

Parallel with the final stages of the ORR, Critical Decision-4 and Approval to Start Operations will be conducted and at the conclusion of both, approval will be given for hot startup of the treatment system.

It is planned that pilot scale work, along with process knowledge work such as off-gas modeling, will be performed during the construction phase to qualify the waste form and preliminarily validate the process to the satisfaction of WIPP and the National TRU Waste Management Program. It is through this test work that the waste form will be proven and the "macro-batch" (Tank Farm tank quantities of feed) approach to sampling and characterization, supported by process knowledge, will be validated. (The intent is to physically sample and characterize the feed from the Tank Farm tanks and not the final waste forms or any intermediate treatment streams.) However, the overall process and program validation still must be proven in the full-scale production system using trained operators and procedures.

A "trial burn" using actual hot feed (potentially with the need to add ("spike") certain species to worst case levels) is also required to prove to IDEQ and the Federal EPA that off-gas emissions are acceptably within MACT limits.

Discussions with WIPP in 2002 and 2003 resulted in the baseline premise that WIPP could not and would not certify the SBW treatment process/program and its final waste or authorize shipments until six months after start of hot operations. The SBWT project assumes that, primarily for milestone schedule reasons, waste treatment must continue and final treated waste must be formed, packaged, and stored "at 
risk." It is also assumed that a shutdown will be imposed by WIPP, as is historically the case, if anything, to resolve minor procedural, training, or other "paperwork" problems. (Note that it is also assumed that the final SBW calcine waste product will not have to be physically reworked in any way, not only due to the assumed success of the prior waste form qualification work, but also because little alteration of it could be performed in any case.) It is also expected that, regardless of what might happen with the WIPP program, a shutdown would most likely be required by the environmental regulators to assess the MACT trial burn results (off-gas sample analytical work, some from special samples to be collected only for the trial burn, and analysis of this data and data from process control instrumentation).

The plan is to operate on hot feed for four months and shutdown for two months for the WIPP and RCRA/Air program reviews. It is assumed that at the end of this short shutdown, program certification would be given by WIPP along with approval to make the first shipment from Idaho to New Mexico. It is also assumed that the trial burn review would prove positive and a re-start would be authorized without the need for a second trial burn. Note that historically this is a risky assumption and that at least one repeat of the trial burn may be necessary.

\subsubsection{CMACT Treatment Operations Schedule (October 2010 to November 2014)}

SBW treatment by calcination using the existing calcination system plus new off-gas treatment in the MCF and calcine and scrub solution packaging in the CPF is the third critical path activity on the overall schedule, requiring 4 years. Improvements to a 4 -year operating schedule are possible, but not certain even with added expenditures. And there are risks that even a 4-year schedule can be achieved.

Based on feed blend ratios projected from past NWCF operation, and also on-stream time and throughput data for the NWCF, B. O'Brien (EDF-3212 2002) estimated that 4.0 years would be needed to process all SBW and NGLW. This four-year schedule was predicated on (a) an aluminum to sodium and potassium feed mole ratio (AAR) of 2.25 , (b) a scrub recycle rate of $20 \%$ of the total calciner feed, (c) an average calciner feed rate of $182 \mathrm{gph}$, equivalent to $85 \%$ of the calciner design throughput of $214 \mathrm{gph}$, and (d) three operating periods each having an on-stream efficiency of $73 \%$ with two turnaround periods of 137 days each.

Although based as much as possible on past NWCF operation, this estimate, at the time it was made, contained two significant risks. While $20 \%$ recycle is a valid historical average for scrub recycle, a higher recycle rate was required during high temperature $\left(600^{\circ} \mathrm{C}\right) \mathrm{SBW}$ calcination in 2000 . Based on NWCF operating data from May 2000 (during high temperature SBW calcination), the scrub recycle rate was $22 \%$ of the total feed (Law 2000). The scrub rate needed to be increased to maintain the density of the scrub below a limiting value. This $10 \%$ higher scrub rate (compared to $20 \%$ used by O'Brien) would equate to a $7 \%$ reduction in feed rate or a schedule increase of about three months.

A second risk inherent in the four-year operating schedule is whether successful calcination at an AAR ratio of 2.25 could be achieved. The successful high temperature SBW calcination run in 2000 started with an AAR ratio of about four, operated for most of the run with an AAR between 3.0 and 3.5, and for the last two weeks operated at an AAR of 2.8 and then 2.6 (Law 2000). The 1999 high temperature NWCF run began with an AAR of 2.0. Over the next two weeks the nozzle air ratio and then the oxygen to fuel ratio were changed in attempts to control particle size growth and bed stability, but without success. The AAR was then increased to 4.0 (Wood 2001).

Based on this experience (an AAR of 2.0 is too low, an AAR of 2.6 is acceptable) O'Brien selected an AAR of 2.25. Operating at a more conservative AAR of 2.6 and $22 \%$ recycle would involve minimum risk, but would increase the operating time from the initial 4-year estimate. 
Since O'Brien's study, several other studies and a calciner pilot test have been completed that have focused on, at least in part, reducing the operating schedule. While these studies showed opportunities to reduce the schedule, most would require additional costs.

Doug Stacey (EDF-3291 2003) developed a set of recommendations with the goal of reducing turnaround times from 137 days to 85 days. These recommendations include such efforts as testing and recalibrating all instruments, re-inventorying spare equipment and procuring missing items prior to start up, and fabricating seven different sizes of spare valve loops.

Steve Bates evaluated the schedule reduction achieved by replacement of the present cyclone separator (Bates 2003), and Rick Adams (Adams 2003) estimated the cost of cyclone replacement. By reducing the solids carryover to the scrubber, the scrub recycle rate could be reduced significantly, allowing for an increase in the fresh SBW feed rate. Bates estimated a savings of up to 166 days was possible. However, replacing the cyclone would increase the risk of cyclone plugging which could lead to down time. Also, the effect of a new cyclone on the off-gas treatment pressure profile and potential additional modifications needed to ensure performance of the existing off-gas compressors has not been fully evaluated. And while not quantified, the dose rate workers would receive working in the high radiation cell to change out the cyclone would be substantial.

In January 2004, a pilot calciner test was performed with the goal of demonstrating an AAR of 2.25 and testing lower ratios (Boardman 2004). Tests included 50-hours of run time at an AAR of 2.25 and 50-hours at an AAR of 1.75, using a surrogate for Tank WM-180 waste spiked with additional mercury. Operation was generally very smooth for both test periods, although at the lower AAR, some plugging of feed nozzles was seen.

A product to fines ratio of 5.1 to 1 was determined for the 2.25 AAR test and 2.8 to 1 for the 1.75 AAR test (See Table 4.3-4 of Boardman 2004). If these product-to-fines ratios hold for the full-scale calciner, the recycle rate could be reduced by a factor of two or more, allowing an increased SBW feed rate, even without replacing the cyclone. The product-to-fines ratio observed in a previous pilot test, using an AAR of 3.1, was 0.7, and in the NWCF high temperature test was about 1.0.

While the pilot test showed a lower product to fines ratio, the particle size of the fines was lower than previous pilot tests (an average size of $12 \mu \mathrm{m}$ compared to $45 \mu \mathrm{m}$ for a INTEC 15 -cm pilot-plant test) (Boardman 2004). Lower particle size fines would result in lower cyclone removal efficiencies, more carryover of fines to the scrub, and higher scrub recycle rates.

Based on the 2004 pilot test results and the other studies of schedule reduction, Barry O'Brien recalculated a matrix of total operating time, depending on which improvements were implemented (see Table 5.2-1 of Boardman 2004). These operating times vary from 2.6 to 3.8 years. Further improvements could also be made by reducing turnaround times.

Whether the recent calciner test results can be replicated in the NWCF calciner is subject to uncertainty for two reasons. The pilot calciner is approximately $1 / 100^{\text {th }}$ the scale of the full-scale calciner and operates in a slugging fluidization regime rather that the bubbling mode typical of the NWCF calciner and large fluidized beds. Secondly, the feed used in the tests was WM-180 waste simulant. Recent changes in Tank Farm management will result in the further concentration of Tank WM-180 waste by evaporation and then sending this waste to Tank WM-187, which contains accumulated undissolved solids from receiving heels of six other tanks. Higher concentrations of certain species, whether due to evaporation or the undissolved solids, may require AAR ratios higher than the 1.75 successfully used in the pilot test. 


\subsubsection{CMACT Waste Shipment Schedule (April 2011 to May 2016)}

\section{Remote handled (RH) waste shipments are receipt rate limited at WIPP and cannot keep pace with treatment nor be completed by the 2012 milestone.}

Idaho's SBW treatment production rate exceeds WIPP's receipt rate, even for the CMACT treatment alternative, which, being rate limited itself by throughput in the existing calcination system, is the "slowest" of the SBW treatment alternatives. This would result in net accumulation that drives the need for lag storage in Idaho and is a direct function of the treatment rate. Significant lag storage would be required as described as follows.

SBW treatment by calcination would produce about $1460 \mathrm{RH}$ canisters with dose rates of 20$60 \mathrm{R} / \mathrm{hr}$ on contact. The treatment generation rate would be 1.4 canisters per day or 9.9 canisters per week (7 day week at 24 hour per day operation). The WIPP overall RH receipt rate/capacity is 12 canisters per week over a 50-week year; one canister per cask and one cask per truck shipment. This receipt rate is physically limited by the receipt, off-loading, and handling system on the surface at WIPP and not by transportation or placement in the repository.

WIPP committed to DOE-ID in 2003 to take 6 RH canisters per week (300 per year) in the 2009 to 2012 time frame. RH capacity currently claimed by others in this time period is three canisters per week such that $75 \%$ of the total is currently claimed while Idaho claims half of that total. The difference between the generation rate in Idaho and the take-away rate by WIPP is 3.9 canisters per week resulting in net accumulation. With the assumption (validated by WIPP) that shipments would not be authorized until six months after start of hot operations and the need to continue to treat and generate waste at risk, primarily to minimize schedule, calculations have been done that show that net peak accumulation is about 500 canisters or about one third of the 1548 canister total (1460 calcine and 88 scrub grout). (See Merrick 2004, Appendix D7 in Volume 3.) It would take an additional 18 months, until May 31, 2016, to complete shipment of this accumulated inventory to WIPP with a project start date of February 1, 2005, and an end of treatment date of November 30, 2014. This further aggravates the twin goals of SBW treatment (missed by 23 months) as well as shipment and off-site disposal (missed by 41 months) by the end of 2012.

\subsubsection{CMACT Schedule - Summary}

The 2012 milestone schedule cannot be achieved with the calcination SBW treatment alternative using the existing calciner. Schedule risks have been identified and include:

- $\quad$ Beginning Preliminary (Title I) Design activities on February 1, 2005. Any delay releasing this work will impact project completion.

- An environmental permitting timeframe of 24 months, especially in light of opposition to thermal treatment by various stakeholders.

- DOE funding, reviews, and approvals. The schedule assumes funding will be available in a timely manner and will not impact design, procurement, or construction.

- Technical development (process testing) as this information iterates with detailed design.

- $\quad$ Mock-up testing of calcine packaging system equipment as this information iterates with detailed design. 
- $\quad$ GFE procurement as it feeds into mock-up testing and design.

- $\quad$ Testing, operational readiness reviews (ORRs), startup, WIPP certification, and Trial Burn.

- $\quad$ Treatment over a four-year period.

In addition to the risks listed above, normal risks associated with a project of this size and complexity can be expected including availability of skilled craftsmen, weather impacts, working in contaminated areas, and timely delivery of equipment and materials. 


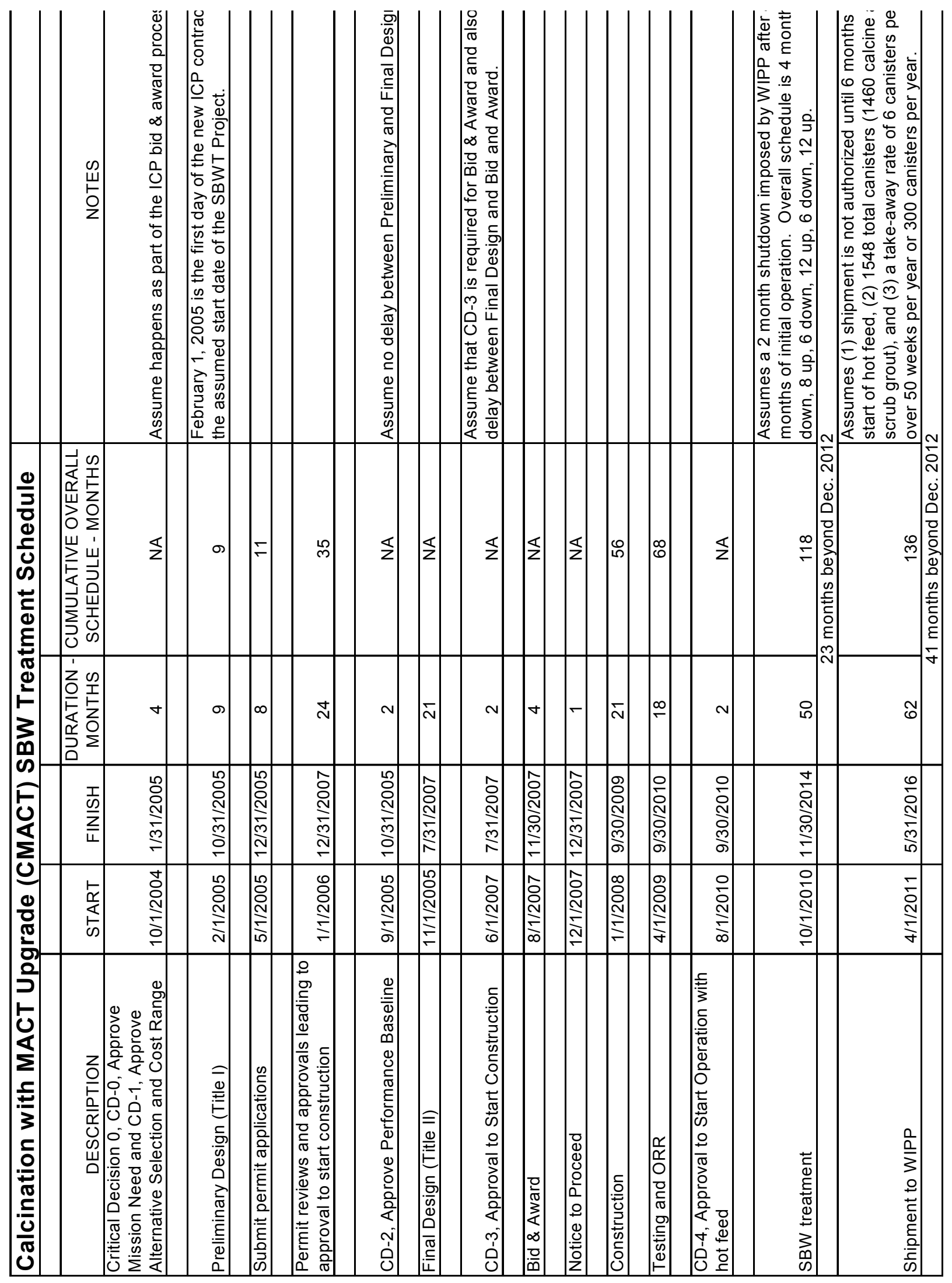




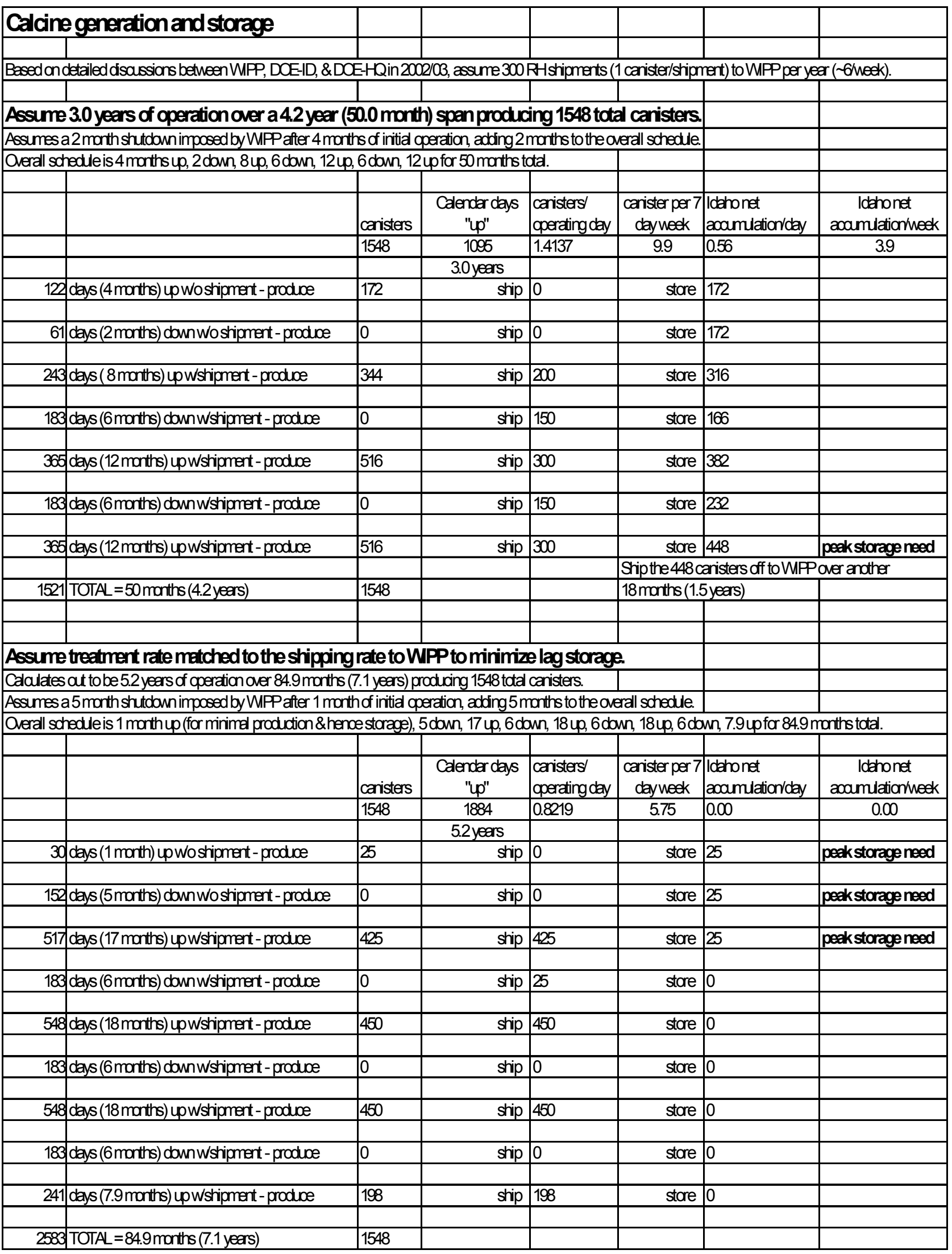




\subsection{CMACT Major Options}

1. In an attempt to meet the 2012 milestone, the Calcine Packaging Facility (CPF) could be eliminated and the SBW calcine could be sent to bulk storage in Bins Sets 7 or 6 and 7. Bin Set 7, currently unused and uncontaminated, could hold the entire volume of SBW calcine if isolation from the existing HLW calcine was wanted. (Isolation would allow "straddling" the WIR issue; if a favorable decision were to be made at a later date that SBW is not HLW, independent retrieval and packaging of SBW calcine for WIPP and HLW calcine for the NGR would be possible.) Otherwise Bin Set 6 could not hold all of the SBW calcine (only 35-50\%) thus necessitating the use of Bin Set 7 in any case not involving packaging or shipment.

This option would result in significant near term cost savings of $\sim \$ 200 \mathrm{M}$ (the cost of the CPF with a scrub treatment system added back); $60 \%$ of the total estimated cost for this SBW treatment alternative. The technical risk would be significantly reduced by considerable simplification of the overall treatment system. It also would result in schedule savings of $\sim 10-14$ months, which however, is still 6-10 months past the 2012 milestone. This option also would not place the SBW waste into a final packaged, shippable state thus deferring these costs to a future date. Also, contaminating Bin Set 7 would incur additional defferred costs of \$20-25 M in 2004 dollars for a retrieval system (differential cost per bin set) and \$10-12 M in 2004 dollars for its ultimate $\mathrm{D} \& \mathrm{D} /$ closure. If this option were to be chosen it might be beneficial for the retrieval system for Bin Set 7 to be designed and installed before it is contaminated to minimize future costs and radiation exposure. This option would also require a scrub treatment system to be installed elsewhere perhaps inside an NWCF cell at an approximate cost of \$20M.

2. An option within the baseline concept (i.e., including the CPF) would be to start treatment of the SBW before the CPF is complete. Environmental permitting, mostly concerned with the off-gas treatment system design, is the critical path at the front end of the project, while CPF construction is the critical path for the remainder of the schedule. Design, construction, and permitting of the CPF could be de-coupled from the rest of the project - the MCF, calciner system upgrades, and Tank Farm mixer installation. The MCF schedule could be pushed aggressively (design and permit submittal for the MCF alone could be done faster than for the full project) in order to get SBW treatment started as soon as possible. The newly formed SBW calcine could be sent to Bin Set 6 for up to $1 \frac{1}{2}$ years while construction and testing of the CPF is completed. (A layer of dolomite or other inert could be put into Bin Set 6 in an attempt to separate SBW calcine from HLW calcine for future selective retrieval although that might not be necessary since SBW was calcined by itself in the last campaign in 2000 and that is the last layer sitting in Bin Set 6 at present.) SBW calcine would stop being sent to Bin Set 6 once it was full or when the CPF is ready for use to package out SBW calcine for disposal at WIPP. In this plan Bin Set 7 would not be used or contaminated so as not to trigger those costs. There are no significant cost impacts to this approach. It could be more or less depending on how efficiently staffing was to be utilized between the two separate projects. The main advantage is schedule savings of $\sim 10$ months. However, again this is still not enough to make the 2012 milestone, missing by 10 months, especially with a February 2005 project start date. There would also be some additional deferred costs, unquantifiable at this time, for different handling and packaging (WIPP canister vs. Yucca canister) of SBW calcine upon retrieval at a later date. This also assumes that the calcine (HLW and SBW) would be retrieved from the bins and that there would be little or no differential cost to retrieving the SBW calcine from Bin Set 6. A potential issue is questions about the effectiveness of the SBW / HLW calcine buffer layer (if applied) and the ability to selectively retrieve these layers of calcine at a later date which is dependent on the condition of the calcine in the bins (agglomerated to any extent or not) and the methods used for retrieval. 
3. A second option within the baseline concept would be to slow down treatment to match the RH receipt/disposal rate at WIPP in order to minimize the size of lag storage in Idaho or eliminate it all together. In conjunction with this, a decision could be made not to proceed with treatment while WIPP reviews the overall process/program prior to authorizing initial shipment. This would additionally save the assumed four months of lag storage of waste produced "at risk" in the early stage of treatment. The two steps combined would save approximately $\$ 30 \mathrm{M}$ in capital project costs but add 41 months to the schedule, well beyond 2012 .

\subsection{CMACT References}

Adams, R. D., (2003), "NWCF Upgrades - Cyclone Replacement," INEEL Interoffice Memorandum (to Steve Bates), RDA-21-03, June 3, 2003.

Barnes C. M., A. L. Olson, D. D. Taylor, (2004a), Sodium-Bearing Waste Treatment Technology Evaluation Report, INEEL/EXT-04-01692, February 2004.

Barnes C. M., C. B. Millet, (2004b), Feed Composition for the Sodium-Bearing Waste Treatment Process, INEEL/EXT-2000-01378, Revision 4, June 2004.

Barnes C. M., S. K. Janikowski, C. B. Millet, (2003b), Feed Composition for the Sodium-Bearing Waste Treatment Process, INEEL/EXT-2000-01378, Revision 3, September 2003.

Barnes C. M., R. A. Wood, B. H. O'Brien, (2003a), "Calcination with MACT Upgrade Process Design," Engineering Design File EDF-3387, April 22, 2003.

Batcheller, D. D. Taylor, V. J. Johnson, (2003), Characterization of Tank WM-189 Sodium-Bearing Waste at the Idaho Nuclear Technology and Engineering Center, INEEL/EXT-02-01171 Rev. 1, July 2003.

Bates, S. O., (2004), "Calcination With MACT Upgrade - Sampling Strategy and Logistics of Treatment of SBW,” Engineering Design File EDF-1794, January 16, 2004.

Bates, S. O., (2003), "NWCF Cyclone Replacement Options For Calcination With MACT Upgrade SBW Treatment Alternative," Engineering Design File EDF-3646, May 8, 2003.

Boardman, R. D., B. H. O’Brien, N. R. Soelberg, S. O. Bates, R. A. Wood, and C. St. Michael, (2004), High Temperature Calcination - MACT Upgrade Pilot Plant Tests, INEEL/EXT-04-01625, February, 2004.

Boardman, R. D., L. J. Young, N. R. Soelberg, and L. A. Matejka, (2001), "NWCF Calciner Emissions Inventory - Final Report for Phase IV Testing,” INEEL/EXT/01-00260, February 2001.

Boardman, R. D., L. J. Young, N. R. Soelberg, M. L. Abbott, and D.V. Croson, (1999), Summary of NWCF Calciner Emissions Inventory Data, INEEL/EXT-99-1190, November 1999.

Davis, P. R., "Hazard Categorization of Calcination with Maximum Achievable Control Technology (MACT) Upgrade SBW Treatment Alternative,” Engineering Design File EDF-3360, January 9, 2003. 
Del Debbio, J. A., T. L. Watson, J. B. Heintzelman, (2003), Long-Term Performance of SulfurImpregnated, Granulated Activated Carbon (GAC) for Mercury Removal From NWCF Off-Gas, INEEL/EXT-03-01102, September, 2003.

DOE, (1999) “Advance Notice of Proposed Rulemaking; Potential Revisions to the Land Disposal Restrictions Mercury Treatment Standards,” United State Government Memorandum, June 7, 1999.

Durante, R., P. R. Davis, E. P. Wagner, (2003a), Hazard Identification Document for the Calcination with Maximum Achievable Control Technology Upgrade - SBW Treatment Alternative, INEEL/INT03-00573, September, 2003.

Durante, R., (2003b), Preliminary Hazard Evaluation for the Calcination with Maximum Achievable Control Technology Upgrade - SBW Treatment Alternative, INEEL/INT-03-00321, June 2003.

Envirocare, (2001), "Envirocare Successfully Treats NFS Mercury Waste," http://envirocareutah.com/pages/ecnews/ec_successfully_NFS.html.

Herbst, A. K., J. A. Del Debbio, R. J. Kirkham, B. A. Scholes, T. L. Watson, (2002), Idaho Nuclear Engineering Center Sodium-Bearing Waste Treatment Research and Development FY-2002 Status Report, INEEL/EXT-02-00985, September, 2002.

Hulet, G. A., V. C. Maio, M. I. Morris, "Demonstrations to Support Change to the $>260$ ppm Mercury Treatment Regulations," WM'01 Conference, February 25-March 1, Arizona.

Law, J., (2000), Operation of the New Waste Calciner at $600^{\circ} \mathrm{C}$, INEEL/EXT-2000-01263, September 2000.

Lippert, R. F., (2003a), "MACT Facility Siting Study - Idaho Tank Farm Project - Calcination with MACT Upgrade SBW Treatment Alternative," Engineering Design File EDF-3316, April 23, 2003.

Lippert, R. F., (2003b), “Calcine Packaging Facility Siting Study - Idaho Tank Farm Project Calcination with MACT Upgrade SBW Treatment Alternative," Engineering Design File EDF3317, April 23, 2003.

Merrick \& Company, (2004), Calcination with MACT Upgrade Feasibility Study Report, Project No. 10014501-01, January 23, 2004.

Morrell, D. K., "Mixing Pumps for Homogenizing TFF-SBW Liquids and Solids - Calcination with MACT Upgrade SBW Treatment Alternative,” Engineering Design File EDF-3307, April 24, 2003.

Nielsen, J. W., "Criticality Concerns Associated with Calcination of the Sodium Bearing Waste at the INTEC," Engineering Design File EDF-3514, April 28, 2003.

Newby, B. J., B. H. O’Brien, (2000), Summary of Waste Calcination At the Idaho Nuclear Technology and Engineering Center, INEEL/EXT-2000-01206, October, 2000.

O’Brien, B. H., (2002) "Calciner Throughput Evaluation for Calcination with MACT Upgrade SBW Treatment Alternative," Engineering Design File EDF-3212, December 5, 2002. 
O’Brien, B. H., (2003), "Off-gas Chloride Control for the Calciner MACT Compliance Facility," Engineering Design File EDF-2205, April 3, 2003.

Raman, S. V., A. K. Herbst, B. A. Scholes, S. H. Hinckley, and R. D. Colby, (2003) Solidification of Simulated Liquid Effluents Originating form Sodium-Bearing Waste at the Idaho Nuclear Technology and Engineering Center, INEEL/Ext-03-01096, September 2003.

Rielly, P. S. (2003), "Shielding Analysis for Calcine (Sodium Bearing Waste and CFFS 1) Storage Canisters”, Engineering Design File EDF-3577, April 28, 2003.

SAR-103, Safety Analysis Report for the New Waste Calcining Facility, November 29, 2001.

Soelberg, N. R., "MACT Compliance for the 'Calcination with MACT Upgrade' Alternative," Engineering Design File EDF-3311, September 26, 2003.

Stacey, D. E., (2003), "Study \#3b Calciner Throughput Evaluation - Idaho Tank Farm Project Calcination with MACT Upgrade SBW Treatment Alternative," Engineering Design File EDF3291, April 28, 2003.

WIPP, (2002a), Remote-Handled TRU Waste Acceptance Criteria for the Waste Isolation Pilot Plant, DOE/WIPP-02-3123, draft, June 2002.

WIPP, (2002b), Safety Analysis Report for the RH-TRU 72-B Waste Shipping Package, November 2002, http://www.wipp.carlsbad.nm.us/library/RHsar/rhsar/rhsartoc.pdf.

Wood, R. A., (2002), "Heel Solids Processing Evaluation for the SBW Treatment Project - Calcination with MACT Upgrade Alternative,” Engineering Design File EDF-3049, December 4, 2002.

Wood, R. A., (2001), NWCF High-Temperature Calcination Trial Summary, INEEL/EXT-01-00851, July 2001. 


\section{STEAM REFORMING (SR)}

The baseline process scenario for this SBW treatment alternative involves design and construction of a new steam reforming treatment system fed from the existing Tank Farm tanks provided with new mixing pumps to suspend and mix the tank solids with the liquid SBW for co-processing (see Figure 2-1). It involves a new off-gas treatment system close-coupled to the fluidized bed, and construction of a new steam reforming waste product packaging system for capture, cooling, packaging, and interim storage of the SR waste product and neutralization, grouting, packaging, and interim storage of steam reforming scrub solution all located in one common new facility.

\subsection{SR Physical Systems - Process/Technical and Related}

Demonstration tests of two variations of steam reforming for processing SBW were performed in 2003 (Marshall 2003a; Marshall 2003b; Marshall 2003c; Soelberg 2004a; Soelberg 2004b). The following discussion is most applicable to treatment processes similar in unit operations to those of the demonstration tests.

\subsubsection{SR Technical Risks Related to Off-Gas Emissions}

It is likely an off-gas treatment system can be designed that will adequately remove contaminants from the reformer off-gas. However, without further testing, present uncertainties in off-gas treatment requirements would result in oversized or unnecessary equipment adding to the cost of the system.

Pilot tests (Soelberg 2004a) have provided information on the concentrations of most contaminants in the reformer off-gas, and shown that major contaminants $\left(\mathrm{CO}, \mathrm{H}_{2}\right.$, organics, $\left.\mathrm{Hg}\right)$ can be removed to emissions standards. However, while pilot-tests have provided information regarding the steam reformer off-gas, uncertainties remain; and without further testing, off-gas treatment requirements could not be finalized. Further optimization of reformer operating conditions would also affect the off-gas composition and possibly change off-gas treatment requirements. For example, the test data shows minimal $(<0.5 \%)$ removal of mercury from the off-gas by water scrubbing. In a full-scale facility, unlike the test scheme, a portion of the scrub solution would be recycled to the reformer. The degree of buildup of mercury in the scrub, and whether mercury would need to be removed from the scrub, are uncertain. Also, the uncertainty in the partitioning of mercury between scrub and off-gas could result in either oversizing or undersizing the downstream GAC beds.

The amount and speciation of organics in the off-gas, and the effects the organics will have on treatment operations, are uncertain. Organics captured in the scrub system could affect the grout formulation required to solidify scrub waste. Organics not removed by the scrubbing steps would need to be destroyed in an oxidation step, or they would saturate the GAC bed and result in mercury emissions exceeding the MACT limit. No tests have been performed to demonstrate whether the oxidizer will meet the required $99.99 \%$ destruction of principal organic hazardous constituents.

It is uncertain whether or not a scrub waste product would be generated. The pilot plant data shows high retention of halides in the reformer solids $(99 \% \mathrm{Cl}, 94 \% \mathrm{~F}$ for the Phase 2 TTT tests, see Table 5.4-3 of Soelberg 2004a). However, mass balance closure for the test data was poor $(122 \% \mathrm{Cl}$ recovery, $51 \% \mathrm{~F}$ recovery). If retention of halides in the solids remains high even with purging the scrub system to the reformer, the scrub waste product could be eliminated. 
The fate of radioactive iodine is uncertain. The radioactive iodine present in SBW could be the major dose contributor in the stack gas. The partitioning of iodine between reformer solids, scrub solution, GAC beds, and stack release is unknown.

There is a risk that emissions standards may change. Between now and when the facility comes on line ( 2009), regulations may change that would affect how the plant is designed and operated.

Certain MACT requirements are impractical for the treatment facility and will require evaluations and negotiations with regulators. These include (a) determining a "hazardous waste residence time," (b) determining operating times for tests prior to the notification of compliance, and (c) negotiating requirements for ALARA, waste feed characterization, waste feed limits, continuous emission monitoring (CEM), and performance testing. These MACT compliance issues are discussed relative to the CMACT process by Soelberg (2003), but are equally applicable to steam reforming.

\subsubsection{SR Technical Risks Related to Waste Product Qualification, Characteristics, and Storage}

\section{Additional testing is needed to resolve uncertainties in the types, volumes, and properties of wastes produced to ensure that these wastes can be disposed.}

There is uncertainty in the reformer product density and volume and methods to handle the product fines. The reformer fines product is very airy and light with a low bulk density $\left(\sim 0.3 \mathrm{~g} / \mathrm{cm}^{3}\right)$. Handling such a product could be problematic due to the tendency to form air-born particulate containing both high activity fission products and alpha-emitting radionuclides. Present mass balances assume densification of the reformer product, but no testing or demonstrations of densification have been performed. Thus the reformer waste product density, and hence also the volume of product are uncertain.

The need for, volume, and properties of the scrub waste are uncertain. Based on SBW steam reforming test results (Marshall 2003a; Marshall 2003b; Marshall 2003c; Soelberg 2004a; Soelberg $2004 b$ ), it is unclear whether or not a scrub waste would be produced. Longer tests with scrub recycle are needed to determine if any species build up in the scrub would require purging to a separate waste.

If a scrub waste needs to be produced, its classification is highly uncertain. The scrub waste classification and ultimate treatment and handling will be dependent on accumulated constituents and their concentrations including: (1) transuranic radionuclides, (2) non-transuranic radionuclides including cesium, strontium, and others which will be primarily responsible for the specific activity associated with the waste; and (3) hazardous constituents, believed to be primarily mercury, but lead, cadmium, chromium, and others may also be included. To ensure that this waste can be disposed, these properties must be known.

The radiolytic hydrogen generation rate from the reformer product and the scrub grout wastes are uncertain. The WIPP RH-TRU 72-B Cask Safety Analysis Report requires that hydrogen concentration in all void spaces within a 72-B shipping cask be less than 5 vol\% (WIPP 2002). The reformer product may contain a significant amount of hydrocarbons that would generate hydrogen via radiolysis during waste storage. Organics may also be captured by the scrubbing system and be present in significant concentrations in the grouted scrub waste. These hydrocarbons in the waste products would undergo radiolytic decomposition and generate hydrogen during storage. However, the rate of hydrogen generation is unknown.

The disposal site and treatment requirements for spent GAC are uncertain. Leach tests of GAC from testing performed in 2002 showed leached mercury concentrations below the RCRA Land Disposal 
Restriction (LDR) limit of $0.025 \mathrm{mg} /$ liter (Herbst 2002), but similar tests from long-term tests in 2003 showed leach concentrations far in excess of the LDR limit (Del Debbio 2003). In either case, present regulations would require that the spent GAC, classified as a "high mercury" waste, be retorted. The Environmental Protection Agency is considering changes to this requirement (DOE 1999; Hulet 2001). Several methods could be used to stabilize the spent GAC waste for disposal, if needed. However, if the spent GAC waste is shown to meet TCLP limits, it could be argued that amalgamation of mercury with the sulfur present in the GAC is adequate immobilization. One stabilization method, Nuclear Fuel Services' DeHg® process, has been used by Envirocare to enable disposal of mercury-containing waste (Envirocare 2001). Thus, it may be possible to ship the spent GAC directly to Envirocare for treatment and disposal. However, no contact has yet been made with any disposal site regarding this waste.

The Waste Isolation Pilot Plant (WIPP) Waste Acceptance Criteria (WAC) for RH has not been issued. The WIPP has prepared a draft WAC document for RH waste (WIPP 2002b), but the document is not final. Additional requirements for RH TRU waste are contained in the RH-TRU 72-B Cask Safety Analysis Report (SAR) (WIPP 2002a). Until the RH-WIPP WAC is issued, there will be uncertainty regarding the disposal requirements for the reformer product. Working closely with WIPP during all phases of the project should mitigate this risk.

\subsubsection{SR Risks Related to Feed Uncertainties}

\section{The steam reforming process can be designed to handle uncertainties in tank waste compositions. Mock up testing of Tank Farm mixing pumps would reduce risks of inadequate tank solids mixing.}

Present Tank Farm management plans call for consolidation of all SBW into three tanksWM-187, WM-188, and WM-189- by the end of CY 2004. Additional waste generated in 2005 would continue to be added to WM-187 and WM-188, and then, from 2006 on, segregated in separate, smaller tanks (WM-2002 (Batcheller 2003), and its composition is not expected to change prior to treatment. While changes are expected in the contents and composition of waste in WM-187 and WM-188, waste to be sent to these tanks has been sufficiently well characterized to have high confidence in the predicted compositions for the liquid in these tanks (as documented in Barnes 2004b).

Most of the solids ( $>85 \%$ ) contained in the Tank Farm have been consolidated in Tank WM-187 by tank closure work. The solids in this tank were sampled and analyzed in February 2004. Since solids in Tank WM-187 have not been well mixed, the recent analysis may not be representative of all the solids in the tank. Analysis of solids samples from other tanks that were flushed to WM-187 provide a basis to estimate the range of solids composition in the tank. The difference between present compositions of tank solids and what the future well-mixed tank solids composition will be is not expected to have an impact on the design and only a minor effect, if any, on reformer operating conditions. Uncertainty in the solids composition is less important to the design than ensuring the solids are well mixed.

The solids must be homogeneously mixed in one or more tanks. Mixing pumps will need to be installed in WM-187 and possibly other tanks in order to characterize the feed for process control and waste qualification purposes and provide a homogeneous feed to treatment using the existing steam jets. The mixing pumps will need to be installed through the existing 12-inch diameter tank risers. The recent CMACT feasibility study (Merrick 2004) and previous studies of mixing pumps (Wood 2002: Morrell 2003) all recommend mock-up testing of the tank mixing pumps to demonstrate performance. Proceeding into construction without demonstration tests of these pumps would risk schedule delays and additional costs should the pumps need to be redesigned and/or additional equipment installed to achieve a known homogeneous liquid/solids feed to the steam reforming facility. 
A solids blending scheme needs to be defined. A scheme for blending tank solids was defined based on four SBW feed tanks (Wood 2002; Barnes 2003), but with the recent decision to consolidate SBW into three tanks, a new scheme is needed. Current estimates indicate that, if distributed evenly, Tank WM-187 will have between 65 and 120 grams undissolved solids per liter (Barnes 2004b). The higher end of this concentration range risks settling of solids in the transfer lines from the Tank Farm to the steam reforming facility. But to minimize the effects of solids on the reformer process (feed nozzle plugging, denitration reactions, interactions with the organic feed additive, etc.) a lower concentration of solids, constant throughout processing all of the waste, is desirable. Barnes (2004b) suggests two schemes, each involving the installation of mixing pumps in two tanks and lowering the undissolved solids content of the feed to 20-40 g/liter. Whatever solids blending scheme is proposed, it should ensure that the waste is transferred to the reformer process without solids settling in the transfer lines, minimize the uncertain effects of the tank solids on reformer chemistry, and minimize the effect of the uncertainty in the total amount of solids contained in the Tank Farm tanks.

Incorporation of NGLW into the tank-blending scenario would also eliminate risks due to uncertainties in NGLW volume and composition. The expected total volume of NGLW is small relative to SBW ( $\sim 8 \%)$, but planning for separate NGLW steam reforming would risk not being able to qualify the product as well as potentially needing to develop a different set of operating parameters due to differences in its composition compared to SBW. The radionuclide content of future NGLW is highly uncertain, yet if blended with the entire inventory of SBW, the effect of this uncertainty is minimal.

\subsubsection{SR Risks Related to the Steam Reformer and Reformer Product Packaging}

\section{Steam reforming is a relatively complex operation involving multiple treatment steps. Additional pilot and mock-up testing is needed to reduce risks in the performance of the reformer and product packaging systems.}

Steam reformer operating conditions have not been thoroughly worked out for SBW treatment. A major operational requirement implementing the steam reforming technology is to be able to control the dynamics of bed particle growth and attrition so that the growth of particles from the input of solids in the feed is balanced by diminution through friction, collision, fracturing, and spallation. In addition, the total volume of the bed must be maintained within specified limits through elutriation of fines and/or withdrawal of bed product from the vessel. Finally, the bed must not be prone to agglomeration. When these criteria are satisfied the bed remains fluidized throughout operation and the bed particle size distribution eventually becomes static or mildly oscillatory within static limits. Under these conditions the bed is described as "stable". Such a stable condition was not demonstrated during the FY 2003 or 2004 pilot-scale tests. Rather, a fairly broad spectrum of particle sizes was observed during most of the tests, and bed agglomeration occurred during most, if not all, of the tests. Thus, a major outstanding uncertainty is whether or not a stable bed can be achieved and maintained through extended operating periods.

Liquid fed to the steam reformer is atomized by a pressurized gas stream. The intensity of the atomization is characterized by the ratio of the standardized volumetric flow rates of gas and liquid (nozzle-air-ratio [NAR]). The NAR value influences the bed dynamics through its impact on particle attrition and will almost certainly require adjustment in the search for a set of conditions that ensure a stable bed.

The rate at which one or more organics are added to the feed and/or reformer represents a compromise between maximizing $\mathrm{NO}_{\mathrm{x}}$ destruction and minimizing unburned carbon and hydrocarbons in the steam reformer product. Multiple organics and feed rates were tested in FY 2003 (Marshall 2003a; Marshall 2003b; Marshall 2003c; Soelberg 2004a; Soelberg 2004b), and while these tests resulting in acceptable parameters, further optimization could be performed. 
Different organic materials, including sucrose and isopropyl alcohol, can be used as reductants in the steam reformer process. When sucrose is added to SBW it has been found that, after an induction period of several hours, a reaction takes place as indicated by effervescence of the combined solution. This is accompanied by formation of solids and a slight drop in solution density. If the sucrose/SBW reaction is deemed unacceptable or problematic, a mixer designed to minimize this reaction could be used. For example, a stirred tank with a short residence time or an in-line mixer with sucrose charged as a liquid syearup could be used.

As reformer operating parameters are determined, performance parameters needed for detailed design will change. These include the product to fines ratio that will affect the design of the fines handling system, the off-gas composition that affects the design of the off-gas treatment system, and feed requirements (gases, chemicals, etc.) that affect the design of feed systems.

Design and mock-up testing of the packaging system is needed. In their feasibility study for the CMACT alternative, Merrick identified mock up testing of the calcine packaging system equipment as a schedule risk (Merrick 2004). The packaging system for steam reformer product is expected to be of similar complexity, if not more so, due to the increased percentage of fines involved. Mock-up testing would add to the project schedule, but not doing mock up tests would risk longer delays due to failures of packaging equipment. The high cost of waste packaging, as reflected in the cost estimate for the Calcine Packaging Facility ( $\$ 227$ million) underscores the need for a demonstrated reformer product packaging system design.

\subsubsection{SR Balance of Plant Requirements, Facility Siting, and Interfaces}

Oxygen would be required as a feed to the oxidizer and, depending on the process, possibly also to the reformer. Other process gases such as nitrogen or carbon dioxide would also be required.

Fuel, such as propane, would be needed to heat the oxidizer to its operating temperature.

A steam boiler, fired by fuel oil or another fuel would also be needed to generate steam for the reformer. ${ }^{a}$ A new water treatment system would be required to supply boiler feed water.

Normal electrical power would be supplied from an existing INEEL substation.

The SBW Steam Reforming Feasibility Study (Williams 2002) recommended that a siting study be performed to review the impacts of this facility on site utilities and the surrounding infrastructure. Tentatively the facility was located in the northeast corner of INTEC, providing an optimal transfer route from the Tank Farm waste tanks (Williams 2002). This is not optimal, however, for off-gas discharge out the main INTEC stack or for sharing of a packaging facility with HLW calcine (discussed below).

\subsubsection{SR Safety Concerns}

No hazards analysis or safety analysis has been performed specifically for the steam reforming process, although a Preliminary Hazard Assessment (PHA) of various SBW treatment options was completed, including steam reforming (Stoller 2003). In the PHA, 23 potential hazardous events were identified for the steam reforming process, and for some events, design and administrative preventive and mitigative features were also identified. Hazardous events included radiological releases, toxic chemical exposure, over-pressurization of solids waste containers, a fire in the steam boiler area and various natural

\footnotetext{
a. A steam generator would not be required for the TWR process.
} 
phenomena. It was noted in the PHA that the evaluation of steam reforming was incomplete because the reformer reductant had not been identified at that time.

A systematic hazard evaluation of the NWCF and MCF for treating SBW has been performed (Durante 2003), and many hazards identified for the NWCF/MCF would apply to the steam reforming process. Twenty-one hazards were identified for the NWCF facility. All but four would apply to steam reforming, and these four would be replaced by hazards associated with the organic feed additives and steam boiler of the steam reforming process. For the MCF, 40 hazards were identified and 34 of these categorized as "anticipated." Many of these would apply to the steam reforming off-gas treatment system. Appropriate measures would be incorporated into the design to prevent or mitigate events that could result from these hazards.

\subsubsection{SR Future Use Considerations}

The steam reforming product packaging system could be designed to accommodate high-level waste (HLW) calcine disposition. Additional shielding would be required because the HLW calcine generates a higher radiation field than would SBW steam reformer product. The waste container for HLW calcine would be the same diameter as the WIPP canister, but $15-\mathrm{ft}$ rather than $10-\mathrm{ft}$ in length, and would have a different lid design. Design for HLW calcine packaging could affect the siting of the SBW treatment facility, to optimally tie in to each of the calcine storage facilities as well as the Tank Farm. The effects on the design of other requirements for HLW calcine disposition, such as processing rate, transport gas handling, and provisions for sampling would need to be considered in the design.

NGLW will continue to be generated after 2012, although at a decreasing rate and possibly with decreasing radioactivity. Current projections indicate an annual generation rate decreasing from 4400 to 3100 gallons from 2012 to 2035 . Processing small batches of feed through a steam reformer would be very inefficient, due to the time, fuel and other utilities used to start up the equipment, and the waste generated upon decontamination. The annual NGLW production, if compatible with steam reforming, could be processed in a few days. Present projections of NGLW composition for the years 2004-2012 show significant differences from SBW. To process the NGLW, tests would likely be needed to demonstrate feed additive rates and reformer operating parameters.

\subsubsection{SR Process/Technical Summary}

Table 2-1 presents a summary of the technical risks and issues for the steam reforming process. The probability and impact values shown are on a scale of 1 to $10(1=$ low probability or impact $)$ and based on the author's judgment rather than any formal process or group evaluation. A probability of 5 is equivalent to a $50 \%$ chance that the identified risk would occur or uncertainty cause detrimental effects. The "Resolution" column presents a recommendation on how the issue should be resolved, usually either by evaluations during design or testing.

Table 2-1. Summary of technical issues and risks - Steam Reforming (SR).

\begin{tabular}{|l|l|l|l|l|}
\hline 1 & \multicolumn{1}{|c|}{ Risk or Issue } & Probability & \multicolumn{1}{c|}{ Impact } & \multicolumn{1}{c|}{ Resolution } \\
\hline $\begin{array}{l}\text { Because contaminant concentrations in the off- } \\
\text { gas are uncertain, off-gas treatment equipment } \\
\text { included in the process may be unnecessary or } \\
\text { oversized or emissions limits may be exceeded }\end{array}$ & 7 & 7 & $\begin{array}{l}\text { Design evaluations may be able } \\
\text { to reduce the impact of this } \\
\text { uncertainty but integrated } \\
\text { system testing would be needed } \\
\text { to resolve this issue }\end{array}$ \\
\hline
\end{tabular}




\begin{tabular}{|c|c|c|c|c|}
\hline & Risk or Issue & Probability & Impact & Resolution \\
\hline 2 & $\begin{array}{l}\text { The uncertainty in the build up of halides, } \\
\text { organics, radionuclides and hazardous metals in } \\
\text { the scrub results in an inadequate design basis } \\
\text { for the scrub treatment system and selection of } \\
\text { a disposal site }\end{array}$ & 6 & 10 & $\begin{array}{l}\text { Long term tests of reformer/off- } \\
\text { gas treatment systems that } \\
\text { include scrub recycle; possibly } \\
\text { followed by hydrogen } \\
\text { generation tests of the grouted } \\
\text { scrub }\end{array}$ \\
\hline 3 & $\begin{array}{l}\text { The required destruction efficiency of principle } \\
\text { organic hazardous constituents in the oxidizer } \\
\text { has not been demonstrated }\end{array}$ & 5 & 7 & Reformer and oxidizer tests \\
\hline 4 & $\begin{array}{l}\text { The partitioning of radioactive iodine in the } \\
\text { reformer and off-gas treatment system is } \\
\text { uncertain, risking unacceptable emissions or } \\
\text { GAC waste not meeting WAC }\end{array}$ & 5 & 10 & $\begin{array}{l}\text { Tests of reformer and off-gas } \\
\text { treatment system that include } \\
\text { iodine as a feed component }\end{array}$ \\
\hline 5 & Emission standards may change & 8 & 8 & $\begin{array}{l}\text { Design and negotiations with } \\
\text { regulators }\end{array}$ \\
\hline 6 & $\begin{array}{l}\text { Certain MACT requirements are impractical for } \\
\text { the steam reformer }\end{array}$ & 9 & 9 & $\begin{array}{l}\text { Design evaluation and } \\
\text { negotiation with regulators }\end{array}$ \\
\hline 7 & $\begin{array}{l}\text { The density and volume or reformer waste are } \\
\text { uncertain risking a higher than anticipated final } \\
\text { waste volume }\end{array}$ & 5 & 8 & $\begin{array}{l}\text { Testing of densification } \\
\text { methods }\end{array}$ \\
\hline 8 & $\begin{array}{l}\text { The low density reformer waste may create } \\
\text { handling problems }\end{array}$ & 6 & 7 & $\begin{array}{l}\text { Mock up testing of packaging } \\
\text { equipment }\end{array}$ \\
\hline 9 & $\begin{array}{l}\text { The basis for design and performance of } \\
\text { reformer product packaging equipment is } \\
\text { uncertain }\end{array}$ & 8 & 10 & $\begin{array}{l}\text { Mock up testing of packaging } \\
\text { equipment }\end{array}$ \\
\hline 10 & $\begin{array}{l}\text { Stabilization of spent GAC prior to disposal } \\
\text { may be required }\end{array}$ & 5 & 4 & $\begin{array}{l}\text { Negotiation with disposal sites } \\
\text { and regulators; possible testing }\end{array}$ \\
\hline 11 & $\begin{array}{l}\text { Changes could be made in final WIPP RH } \\
\text { WAC }\end{array}$ & 5 & 5 & $\begin{array}{l}\text { Design and negotiation with } \\
\text { WIPP }\end{array}$ \\
\hline 12 & $\begin{array}{l}\text { Uncertainties in tank waste solids composition } \\
\text { could affect reformer design or operation }\end{array}$ & 2 & 5 & $\begin{array}{l}\text { Design, with final resolution } \\
\text { during startup }\end{array}$ \\
\hline 13 & $\begin{array}{l}\text { Performance of mix pumps for TFF tanks } \\
\text { uncertain, with risk of varying solids content in } \\
\text { feed }\end{array}$ & 5 & 8 & Mock up testing of mix pumps \\
\hline 14 & Tank blending scheme has not been finalized & 5 & 5 & Design \\
\hline 15 & $\begin{array}{l}\text { NGLW generation rates and composition } \\
\text { uncertain and could affect process }\end{array}$ & 3 & 2 & Design \\
\hline 16 & $\begin{array}{l}\text { Operating conditions that achieve reformer bed } \\
\text { stability have not been achieved in pilot tests, } \\
\text { risking operating schedule delays }\end{array}$ & 7 & 9 & Pilot testing \\
\hline 17 & $\begin{array}{l}\text { The type and rate of organics fed to the } \\
\text { reformer has not been optimized }\end{array}$ & 4 & 4 & $\begin{array}{l}\text { Design studies that may require } \\
\text { testing to validate } \\
\text { recommendations }\end{array}$ \\
\hline 18 & $\begin{array}{l}\text { There are uncertainties in the control of } \\
\text { potential reaction in the SBW/reductant mix } \\
\text { tank resulting in possible safety issues }\end{array}$ & 5 & 6 & $\begin{array}{l}\text { Design and possible testing, } \\
\text { once reductant has been } \\
\text { selected }\end{array}$ \\
\hline
\end{tabular}




\subsection{SR Environmental/Regulatory and Related}

\subsubsection{SR Permitting}

\section{A 24-month permitting schedule, critical path early in the project schedule, appears to be the best that can be achieved.}

The baseline for the SBWT project identifies a 24-month permitting schedule, including the Hazardous Waste Management Act (HWMA) and Clean Air Act (CAA) permits. This may be optimistic, since discussions with the State of Idaho, Department of Environmental Quality (IDEQ) in the spring of 2003 indicated that the IDEQ estimated 32-months to permit the SBWT project after receiving the HWMA and CAA permit modifications or applications. The project will need to work with the IDEQ to streamline the permitting schedule. (The 32-month schedule was worked down to 24 months by taking time out of the operating contractor's activities only.)

The steam reforming facilities will require CAA permits and HWMA permits. The steam reformer unit will require a CAA Title V and PSD permits and demonstrate that emissions meet the MACT standards for hazardous waste incinerators. The steam reformer unit and product packaging facility (PPF) will need HWMA permits for hazardous waste management activities. The steam reformer unit will need a site-specific risk assessment to address hazardous air pollutants (HAPs) and non-HAPs risk to human health and the environment not covered by the MACT, PSD, or Title V emission limits.

EPA recommends hazardous waste combustors provide copies of the facility's notice of intent to comply (NIC), compliance performance test plan, and draft Title V permit modification to the public at the same time the facility holds the public information meeting prior to submitting the HWMA permit application. In addition, EPA suggests placing copies of the MACT and air permit documents with the HWMA permit application in the facility reading rooms. This will allow the public adequate comment on the facility for both the HWMA and CAA requirements

The following sections describe the permitting activities necessary for the steam reforming treatment alternative.

The Steam Reforming SBW treatment alternative consists of four parts to be permitted and constructed to treat the waste by the end of 2012: (1) Construction of the steam reforming treatment unit including a MACT compliant facility (MCF), off-gas treatment system. (The Steam Reforming process and MACT compliant off-gas treatment system would lower the amount and concentration of constituents emitted up the stack to meet MACT, PSD, and Title V Standards). (2) Construction of the SR Product Packaging Facility (PPF) to collect, store and package the steam reforming product in canisters for shipment to WIPP. (3) Installation of mixing pumps in 2 or 3 Tank Farm tanks to produce homogeneous feed to the treatment process and enable solids-liquid co-processing. (4) Construction of a boiler to supply steam to the Steam Reforming treatment process. (The boiler is subject to PSD and Title V Standards for emissions.)

2.2.1. SR Treatment System Permitting. The steam reforming treatment unit will generate emissions similar to a hazardous waste incinerator unit and will be required to meet the MACT emission limits and HWMA and CAA permitting processes. The steam reforming treatment unit, off-gas treatment system, and boiler emissions and operations will be permitted under the Clean Air Act, NESHAPS, PSD, and Title $\mathrm{V}$. The steam reformer unit and MCF will require a HWMA permit for hazardous waste management activities, such as, waste characterization, tank management, public participation, closure, and other operation related to hazardous waste management. The steam reforming product storage tanks, grout treatment, product packaging, and container storage will be permitted under the Hazardous Waste 
Management Act. Tanks and equipment in the NWCF or PEWE that will provide support to the Steam Reforming process are permitted in Volume 14 or Volume 18 to the INEEL HWMA Permit.

\subsection{Air Permitting-}

2.2.1.1.1 MACT Standards-The steam reforming SBW treatment alternative would construct a new facility to house the stream reforming treatment unit and MCF to house the off-gas treatment system. The emission control equipment would treat the off-gas to Maximum Achievable Control Technology (MACT) standards.

The State of Idaho and EPA Region 10 have both stated that, in their opinion, the steam reforming treatment system is similar to a hazardous waste incinerator and the emissions and operations should be permitted under 40 CFR §63, Subpart EEE National Emission Standards for Hazardous Air Pollutants From Hazardous Waste Combustors. Subpart EEE contains the MACT emission limits and process control requirements for hazardous waste incinerators. (See Table 2-2 at the end of the section which lists the Interim Rule for existing and new source incinerators and proposed Final Rule MACT limits for new source incinerators.)

The project will need to submit several documents to the State of Idaho to comply with the MACT Rule. First, the project needs to submit a NIC to explain how the design for steam reforming unit and offgas treatment will control emissions, monitor emissions, comply with the emission standards, and minimize waste generation. Second, the project will submit a Compliance Performance Test Plan to explain how the steam reforming unit will be tested, what emissions will be monitored, what analytical methods will be used, and how the unit will be operated during the test (time frames, feed rates, spiking, emission control equipment, and emission monitoring equipment). Third, the project will submit a Notice of Compliance to document that the steam reformer operated below the MACT emission limits. Fourth, the project will submit a Title $\mathrm{V}$ permit modification to add the emission limits and operating controls necessary to maintain compliance.

Hazardous waste incinerators are required to submit a compliance performance test (similar to a RCRA trial burn) plan with the permit application and complete compliance performance testing to demonstrate that the emission control technologies and emissions from the incinerator will meet the MACT standards. The project can achieve compliance by feed control or emission control technologies or a combination of both. The compliance performance test demonstration will test the process at normal and maximum feed rates and hazardous waste concentrations to develop the operating limits for the treatment process. Compliance performance testing may require spiking the waste with know concentration of chemicals. In the past, EPA has considered the use of reagent chemical for spiking to be the incineration of un-used commercial chemical products and have added the $\mathrm{P}$ and $\mathrm{U}$ listed hazardous waste numbers to the ash and scrub solution generated during the test. The project needs to work with the State of Idaho to select chemicals or surrogates that will not add new hazardous waste numbers to the waste.

The risk is that all of the waste treated after the compliance performance test will be assigned the new hazardous waste numbers due to mixing of the bed material and spent scrub solutions with the SBW in the tank farm. This could exclude the waste from disposal at WIPP. This could exclude waste streams from disposal at the National Geologic Repository (NGR), Envirocare, Nevada Test Site (NTS) or Hanford Site without addition work to delist the waste (see discussion in sections 2.2.4c and 2.2.4f).

Hazardous waste incinerators permitted under the 40 CFR $\S 63$ standards are exempt from the incinerator permitting requirements for operations and emissions at 40 CFR $\$ 264$ Subpart O (Incinerators) and $\$ 270.62$ (Hazardous Waste Incinerator Permits), except for provision the Director 
determines are necessary to ensure compliance with subpart §264.345(a) and (c) (releases during startup or shutdown).

It is recommended that the steam reforming facility, including the off-gas treatment system, be permitted under 40 CFR $\S 63$, Subpart EEE to eliminate dual regulation of operations and emissions. The SBWT project needs to evaluate the proposed final rule limits to determine if the limits for mercury and chlorides can be achieved, with the concentration of constituents in SBW and the emission control technology available.

If the chlorine limit cannot be achieved, then the project could establish a site-specific risk based limit for total chlorides based on the national exposure standard. The project needs to demonstrate that emissions of total chlorides from on-site hazardous waste combustion units results in an exposure to the most exposed individual of a Hazards Index less than or equal to 1.

If the mercury limit cannot be achieved, then DOE should consider asking for a separate category and emission limits for the steam reformer unit. The information submitted for DOE thermal treatment units to EPA did not indicate that they could not meet the MACT standards for new hazardous waste incinerators. The project would need to document why it is not practical to remove mercury below the level required, either the technology is not available or the cost to remove additional mercury below the level in the current steam reforming design is not beneficial. DOE could use the same approach EPA used in setting the current proposed standards for new hazardous waste incinerators and evaluating if it was practical to achieve lower levels of mercury removal from emissions. EPA used \$18 million/ton of mercury removed when they evaluated the practicality of removing mercury from emissions below the limit proposed for new sources.

The risk is that design changes, emission control and monitoring equipment modifications or feed rate reductions will be required to meet the MACT Standards. The project should contract with a compliance performance test contractor early in design to develop NIC, sampling location, testing protocol, and the compliance performance plan.

\subsection{Clean Air Act - New Emission Sources-The steam reforming} treatment option has two units that would be classified as new sources and require New Source reviews, the steam reforming unit and the new boiler.

The New Source Review (NSR) program is the primary mechanism for preventing facilities from causing or contributing to violations of national ambient air quality standards (NAAQS). NSR applies to what are known as "major" stationary sources, which are defined differently for attainment versus nonattainment areas. The INEEL is in an attainment area adjacent to a wilderness area (Craters of the Moon) and would be a Class 1 attainment area. The NSR program uses the pre-construction permitting process to control the construction of new major sources (and modifications to existing sources). In attainment areas, these pre-construction permits are referred to as prevention of significant deterioration (PSD) permits.

The project needs to determine if the emissions from the steam reforming unit and boiler are minor new sources or major new sources in an attainment area.

The steam reforming unit or boiler will be classified as a new major source unless emissions of pollutants are below the potential to emit 100 tpy of any PSD pollutant or any other source with potential to emit (PTE) of 250 tpy of any PSD pollutant. (See Table 2-3 at the end of this section.)

For a new major source, NSR applicability is relatively straightforward. Since the facility is not in operation, the baseline emissions are zero, and the emissions impact of the new facility is based on the 
PTE of all the new emission sources combined. If the new sources meet the applicability thresholds for PSD, the facility must complete the appropriate permit application, review, and approval process. In attainment areas, the applicability threshold is a PTE of 250 tpy, or 100 tpy for certain source types.

The PSD application process requires air monitoring and emission models, stringent pollution controls, estimate of the regional emissions for each hazardous air pollutant, public involvement, and Federal Land Manager involvement near Class 1 attainment areas.

2.2.1.1.3 Title V Permit-The Title V Air Permit application for the INEEL has been submitted to the State of Idaho Department of Environmental Quality (IDEQ) for approval. The IDEQ is still reviewing the application and should issue a final permit by May 2005.

The Title V permitting sets forth the comprehensive State air quality operating permits program and emission limits. Sources subject to the operating permit requirements shall have a permit to operate that assures compliance by the source with all requirements. Of primary interest for SBW are emissions of radionuclides, organics, nitrogen oxides and the MACT Standards. Tables 2-2 and 2-3 at the end of the section identify the list of constituents to be addressed in the permit modification.

The Title V Air Permit identifies the NESHAP's emission limits, process controls, and emission control equipment for each source. New emission sources are added to the Title V permit through a permit to construct and a permit to operate. The permit to construct identifies the potential emissions and controls based on the facility design. The permit to operate is based on emissions testing when the source is operating. Emission limits and controls are established for each source based on the emission testing. The emission limits and controls are then added to the Title V Air Permit by modifying the permit to include the new sources.

The risk is that emissions from the steam reforming unit and boiler or a combination of the INEEL sources will exceed the NESHAP's limits requiring additional off-gas treatment or operate at reduced feed to meet the emission limits. The risk is that NOx emissions cannot be reduced below the visible range and the Federal Land Manager delays or opposes the air permits. The project needs to start early in the design to gather the information necessary to submit applications for the permit to construct, MACT compliance plan, and new source review for PSD.

\subsubsection{HWMA Permit.}

2.2.1.2.1 Steam Reforming Unit and MACT Compliance Facility-The steam reforming unit and related equipment in the MCF are subject to HWMA permitting. A permit application will cover all permit section except for MACT air emissions and related operating requirements. The permit application for the steam reforming unit will cover tank storage, waste characterization, general facility standards, material handling, risk based emission limits for HAPs and non-HAPs, and operating requirements. A permit is required before construction can begin on the steam reforming unit or the MCF.

It is recommended that the steam reforming unit be added to Volume 14 of the INEEL permit with the other liquid waste treatment equipment.

2.2.1.2.2 Site-Specific Risk Assessment-A site-specific risk assessment may be required by the IDEQ permit writers, if they believe that operation in accordance with the MACT standards alone may not be protective of human health and the environment. The SSRA will focus on the emission rate of HAPs and non-HAPs, stack gas characteristics, meteorological conditions, and exposed populations. There is a high probability that IDEQ will require a risk assessment, since they required one 
for the evaporators permitted in Volume 14. The SBWT project developed a template for a site-specific risk assessment for SBW in 2004.

The risk to the project is that the SSRA may result in additional HWMA permit conditions that affect the feed rate, emission controls, and monitoring of emissions.

2.2.1.2.3 Steam Reforming Product Packaging Facility—The steam reforming product produced would be pneumatically transferred to the Product Packaging Facility (PPF). The processes in the PPF would collect and store the SR product in hoppers, treat and package scrub solution, package the product and scrub grout in canisters, and store the canisters pending shipment to WIPP. The steam reforming product storage and packaging units would be subject to the 40 CFR 264 and 270 requirements for miscellaneous units, new tank systems, and container storage. The PPF would be located adjacent to the steam reforming facilities and could be added to the INEEL HWMA permit in one of two ways: (1) as a modification to either Volumes 14 or 18, or (2) as a separate volume.

The addition of the PPF will result in less than $25 \%$ increase in the tank capacity and container storage capacity at the facility (INEEL). Therefore, the changes should be a Class 2 modification. It should be possible to submit individual permit modifications for the building, tank systems, and container storage, which should allow the start of construction of the building, floor, walls, roof, and secondary containment, while designs are finalized for tank systems and container storage.

NOTE: The steam reforming PPF is replacement storage for the waste in the Tank Farm. The net result would be a reduction in storage volume at the INEEL. Tank systems that are used to store or treat hazardous waste which contain no free liquids and are situated inside a building with an impermeable floor are exempt from the secondary containment requirements, 40 CFR §264.190(a). Storage areas that store containers holding wastes that do not contain free liquids need not have a containment system (40 CFR $\S 264.175(\mathrm{c})$ ).

It is recommended that PPF, which includes the grout treatment, steam reforming product storage, and container storage be submitted to the State of Idaho as a Class 2 modification to either INEEL HWMA Permit Volume 14 or 18. The steam reforming product storage and canister storage areas are for dry waste with no free liquids, which should simplify the permitting and construction. The tank and container storage areas replace non-compliant storage in the Tank Farm and will not increase waste storage capacity.

If the final design results in significant changes to the PPF then a permit modification would be required (e.g., tank size, number of tanks, tank location, cell dimension, etc.). The risk is that changes to the design during final design or construction could result in a permit modification approval before waste could be managed in the PPF and delay the shipments of SBW. It is recommended that the project negotiate with the State of Idaho early in design to determine how design and construction changes will be handled during the application, final design, and construction stages of the project.

2.2.1.3 Mixing Pumps. The mixing pumps would be ancillary equipment to the tank systems in the Tank Farm. The tanks in the Tank Farm have interim status, but cannot be permitted since it is not practical to upgrade the secondary containment. Changes to interim status units require the approval of the director as outlined in 40 CFR $\$ 270.72$, Changes During Interim Status and 40 CFR $\$ 270.42$, Permit Modification at the Request of the Permittee.

The addition of the mixers to the Tank Farm should be a Class 1 modification under interim status and require notification of the administrator prior to implementing the change. Adding the pumps would 
not change to the tank's storage capabilities, so the administrator should have little concern with this action.

2.2.1.4 Organic Sample Bias. The IDEQ proposes in Volume 14 to the INEEL HWMA Permit to approve the use of a double-needle sampler as an alternative sampling procedure when collecting mixed (hazardous and radioactive) volatile organic and total organic samples from the INTEC Liquid Waste Management System. However, the resulting sample analysis results must not be used in Land Disposal Restriction (LDR) certifications. The appropriateness of the sampling procedure shall be confirmed, at least three times within the life of the permit by correlation of the analytical results with the permit required off-gas data.

The project should request the use of double needle sampling in the CAA permits and HWMA permit applications. The project should compare sample data from the double needle and simple samplers to show that the organic constituents in the Tank Farm waste are at or near the method detection limits and the sampling method does not affect the results for organics, due to the low concentration in the feed. The project should propose a reduced number of organic analyzes based on the low concentration in the feed. The project should pursue IDEQ approval for use of double-needle samplers for all remote-handled samples, including compliance performance testing, LDR, delisting, and waste characterization samples as required to dispose of waste.

2.2.1.5 Professional Engineer (PE) Certifications. CAA permits will not require PE Certifications of the design and construction for the stream reforming unit, MCF off-gas treatment system, or the boiler.

HWMA requires PE certification of the design submitted with the permit modification or application and before waste is placed in the tank systems 40 CFR $\$ 264.192$ and 40 CFR $\$ 270.11(d)$. PE certification would be required for, grout treatment, steam reforming product storage, and container storage facilities. The project should contract with an independent, registered PE early in design for PE support to facilitate certification of the design for the permit application or permit modification.

Due to the dual regulation of hazardous waste combustion units, P.E. Certification of the steam reforming unit and MCF may be required as part of the general HWMA permit requirements. The project will need to clarify this issue with the State of Idaho to define specifically what information needs are required for the steam reforming unit and MCF in the HWMA permit and the MACT compliance documents.

2.2.1.6 In-cell Leaks. In-cell leaks from air emission treatment equipment are not specifically addressed in an air permit. They are addressed in the estimated range of emissions from the cell or building. Waste leaked into sumps will need to be removed within 24-hours or secondary containment will be considered primary containment and would be regulated under the HWMA requirements.

HWMA requires that operation of a leaky tank system be stopped immediately after the leak is detected, waste be removed from tank systems with in 24-hours, and waste be removed from secondary containment within 24-hours (40 CFR \$264.193). The system will have to be repaired before it is used. Depending on the extent of the repairs, a PE certification may be required before resuming operations.

Historically, the piping from the feed tanks to the calciner has had leakage problems during operation. The steam reforming piping may have similar problems due to thermal expansion and contraction and could be a schedule risk if operations are stopped to repair leaks as they occur. The project should negotiate with the State of Idaho to operate with leaking pumps, pipes and valves until they can be replaced at scheduled maintenance shutdowns. 
2.2.1.7 As-built Drawings. Air permitting does not require as-built drawings of the facility. The air permits require the air emissions from each system, the ranges of the emissions, and a list of equipment.

HWMA permitting requires as-built drawings of the facility, equipment, and piping. A permit application could include between 50 and 100 drawings (40 CFR §270). The project should negotiate with the State of Idaho to add the as-built drawings certified by a PE to the INEEL HWMA Permit as a Class 1 modification prior to start of operation.

Due to the dual regulation of hazardous waste combustion units, as-built drawings of the steam reforming unit and MCF may be required as part of the general HWMA permit requirements. The project will need to clarify this issue with the State of Idaho to define specifically what information needs are required for the steam reforming unit and MCF in the HWMA permit and the MACT compliance documents.

\subsubsection{SR NEPA}

NEPA exposure is low risk and little or no activity should be required here.

The risk of additional NEPA action for the SBWT project is low. The HLW\&FD EIS covered over 120 different alternatives to treat the SBW from no action to vitrification. It does not appear at this time that additional NEPA action would be required for the treatment and storage of SBW.

If required, an environmental assessment (EA) should cover any additional action or process not specifically mention in the EIS.

\subsubsection{SR Waste Disposal - TRU Waste}

\section{Waste disposal is fairly high risk and is further aggravated by schedule delays.}

The Steam Reforming treatment alternative would generate canisters of SR product, canisters of solidified scrub waste, and debris (spent GAC and HEPA filters). The majority of the waste would be RH-TRU waste. The WIPP facility is limited to $7080 \mathrm{~m}^{3}$ of RH-TRU waste by the Land Withdrawal Act (LWA). Hanford, SRS, and INEEL have proposed sending RH-TRU waste not identified in previous estimates. The volume of RH-TRU waste in the DOE complex may exceed the LWA capacity. Disposal is based on first come, first disposed.

The risk to the project is that delays in the schedule caused by permitting, design, construction, and startup could reduce the number of shipments of RH-TRU SBW that WIPP can receive before the capacity authorized in the LWA is exceeded.

\subsubsection{SR Waste Qualification/Certification}

\section{Waste qualification/certification is a very high risk area for the Project.}

The issues related to waste qualification/certification are: (a) the waste classification through the WIR determination process, (b) waste acceptance criteria at WIPP, (c) waste acceptance criteria at the National Geologic Repository (NGR), (d) RH-TRU Permits approval, (e) New Mexico Environmental Department (NMED) acceptance of SBW (f) WIPP Waste Certification Authorization, and (g) acceptance of greater than Class A low- level waste. 
a. The Federal District Court in Boise ruled that DOE does not have the authority to classify waste using the waste incidental to reprocessing (WIR) determination process in DOE Order 435.1. DOE has appealed the ruling to the U.S. Appeals Court and has asked Congress to clarify DOE's authority under the Nuclear Waste Policy Act.

The risk to the project is that the appeals process drags on for several years and delays treatment of the waste beyond 2012. The project should consider placing the waste in thin metal containers (liners) that could be placed in either the RH-TRU canister or the HLW canister. The treatment alternative would then be neutral to the disposal location. This would unfortunately decrease the net volume per canister and result in increasing the canister count and associated costs for storage, transport, handling, and disposal. In addition, if the WIR determination for SBW is disallowed, then classification of the grouted scrub, GAC and debris would be in question.

b. The State of New Mexico has issued a hazardous waste facility permit (HWFP) to WIPP that covers CH-TRU waste streams. The U.S. Congress in Section 311(b) to the Energy and Water Appropriations Act required WIPP to submit a modification to WIPP's HWFP to limit confirmatory testing of TRU waste containers to radiography or visual inspection. These changes when implemented will significantly reduce the type and number of waste characterization samples required to confirm the acceptable knowledge. The modification was submitted to the State of New Mexico on December 31, 2003. The State of New Mexico is still reviewing the Section 311(b) modification.

The WAC for RH-TRU waste at WIPP are in the process of being established. WIPP and EPA have established requirements for radionuclides with EPA's approval of the RH-TRU Waste Characterization Program Implementation Plan for characterization of radionuclides on March 26, 2004. DOE must submit site-specific implementing plans for EPA approval before sites may be authorized to characterize RH-TRU waste for certification and shipment to WIPP. Sites will not be authorized to certify and ship RH-TRU waste to WIPP until EPA conducts an onsite inspection and issues its final authorization. The RH-TRU Waste Characterization PIP requires each site to prepare sampling and analytical plans for characterization of each waste stream have them approved by the EPA.

The WIPP RH-TRU Program has not received approval of the RH-TRU waste modification to the WIPP HWFP. The criteria for hazardous constituents in RH-TRU waste have not been added to the WIPP HWFP. WIPP submitted a Class 3 permit modification for RH-TRU waste to the State of New Mexico in May 2003. The State of New Mexico is still reviewing the modification. WIPP is not ready to receive RH-TRU waste and will require facility modifications and testing prior to receipt of waste.

The risk to the project is starting the design without having all of the waste characterization and certification requirements finalized for either $\mathrm{CH}$ - or RH-TRU wastes resulting in design changes, permit modifications during construction, and delays in shipment of waste.

It is recommended that the SBWT project work closely with WIPP and EPA to develop sampling and analysis plans for characterization of the feed. The plans will describe the use of acceptable knowledge for radioisotopes, prohibited items, and dose-to-curie measurements and calculations.

The project should also work with WIPP to include project-specific waste characterization procedures for RH-TRU waste in the WIPP HWFP, if required. 
c. If the DOE WIR determination process is found to be outside their authority, then SBW, containing reprocessing waste and debris contaminated with SBW could be classified as HLW, based on the Nuclear Waste Policy Act. Then SBW and SBW contaminated debris would have to be packaged for disposal the National Geologic Repository (NGR). The waste acceptance criteria at the NGR are based on an evaluation of the performance of the waste in the package and performance of the waste package in the repository. The only waste form that has been evaluated and approved for HLW disposal is borosilicate glass.

Other waste forms such as steam reformed solids, scrub system grout, or debris will have to be evaluated on a case-by-case for acceptability. Failure of the WIR does not mean that the SBW would automatically go to the NGR and could result in the project generating waste without a disposal path. DOE has a limited capacity available for the disposal of HLW at the NGR, if all reprocessing wastes are classified as HLW, then the volume of HLW will exceed DOE's allocated capacity requiring long term storage at the INEEL.

The INEEL needs to develop the following list of technical information to support the acceptance of a waste form for disposal at the NGR. The INEEL will need the information for the Memorandum of Agreement with the Civilian Radioactive Waste Management System that will include the Environmental Management Waste Acceptance Product Specifications (EM-WAPS), Waste Form Compliance Plan (WFCP), Waste Form Qualification Report, and supporting documentation an comply with the QARD RW-0333P requirements.

1. The chemical composition and waste form projections for the HLW. Information on the chemical composition shall include identification of the speciation of elements and compounds present in concentration greater than 0.5 percent by weight in the waste form and an estimate of the uncertainty of these concentrations for the HLW.

2. Information required for determining that the HLW does not exhibit the characteristics of hazardous waste.

3. Estimates of the total facility inventory and individual canister inventory of radionuclides (in curies) that have half-lives longer than 10 years and are or will be present in concentration greater than 0.05 percent of the total radioactive inventory. The estimates shall be indexed to the years 2010 and 3110 . The producer shall also report the estimate of the uncertainty in the radionuclide inventories.

4. The Time-Temperature-Transformation diagrams for the HLW and identification of temperature limits (if any) necessary to preserve the properties of the HLW.

5. Identification of the method to be used to ensure consistency of production batches, and any other information necessary to establish post-closure performance of the waste forms (e.g., identification of organic compounds that may be present and estimated quantities). Product consistency test and comparison to the performance of EA benchmark glass.

6. Canister material

7. Canister dimensions (at the time of acceptance)

8. Canister lifting and handling arrangements

9. Canister labeling conventions 
10. Information required to assess the canister drop performance including information regarding particulates, pyearophorics, combustibles, explosives, etc. that all may come into play in a Design Basis Earthquake II event. This is likely to be a detailed list, much of which has not yet been determined. This information need will be developed more fully in a future revision of the WASRD.

11. Information required to assess canister criticality, both pre and post closure. This is likely to be a detailed list, much of which has not yet been determined. This information need will be developed more fully in a future revision of the WASRD.

12. Estimated maximum gamma and neutron dose rates at the canister surface.

13. Projected distribution of canister thermal outputs, including the maximum.

14. Method used to assign individual canister Metric Ton Heavy Metal (MTHM) content for accounting against the repository 70,000 MTHM capacity limit as specified in Section 114d of the nuclear Waste Policy Act of 1982, as amended.

The SBW waste has been assigned four listed waste codes. The NRG is not permitted as a Subtitle $\mathrm{C}$ hazardous waste landfill therefore the project will need to delist the waste streams before they can be shipped to the NGR. The waste streams cannot exhibit a characteristic of a hazardous waste. In addition to delisting, the SBW must be treated to meet the land disposal restriction standards for hazardous metals, before it could be sent to the NGR. Waste form and waste packaging performance assessments and approvals could delay treating the SBW. The NGR will need to request a license change from the NRC and EPA to receive waste forms other than borosilicate glass. (See discussion of petition to exclude/delisting petition in Section 2.2.4f.)

d. The WIPP RH-TRU program is not ready to receive RH-TRU waste and will require facility modifications and testing prior to receipt waste.

The WIPP RH-TRU program could present a schedule risk to the project if they do not have a permit and the WIPP receiving facility requires modification, resulting in a delay to SBW shipments. An additional risk is that the SBWT project could have to modify its' design during construction or startup to comply with the requirements in the approved modification for RH-TRU waste to the WIPP HWFP.

e. SBW is not identified in the 1995 TRU Waste Baseline Inventory Report (TBWIR) as a waste destined for disposal at WIPP. SBW is listed as a potential waste stream in the 2004 TWBIR and the SBW source term has not been included in the 2004 performance assessment for the Compliance Re-Certification Application to EPA. The State of New Mexico has proposed 1) to amend the state's permit for the Waste Isolation Pilot Plant to prohibit the shipment of reclassified high-level waste to the site and 2) to amend WIPP's permit to limit waste for disposal to those wastes identified in the 1995 TRU Waste Baseline Inventory Report, and 3) legislation to exclude all TRU waste not in the 1995 TWBIR. DOE is currently working the issue with the State of New Mexico to resolve these issues.

These proposed restrictions could delay the approval of the RH-TRU Waste Permit Modification and finalization of the RH-TRU waste acceptance requirements in the HWFP. The worst case scenario is that these restrictions would prohibit the disposal of SBW at WIPP. 
f. The WIPP waste certification authorization process consists of a series of document reviews, assessments, and confirmation audits. DOE-Carlsbad Field Office (CBFO), EPA and the State of New Mexico Environmental Department (NMED) participate in the process. Waste certification authority is based on the project demonstrating verbatim implementation of the characterization, operating, confirmation and validation procedures and plans used for characterization and certification of waste shipments.

DOE-CBFO will approve the plans and procedures prior to start of operations and assess implementation during system operation testing. DOE-CBFO and NMED will audit the project during the first 6 weeks of operations to verify that the operators are trained and hazardous waste management plans and procedures have been implemented as approved. EPA will audit the project to verify that the radioactive waste management plans and procedures are being implemented as approved. Audit findings have to be resolved before waste certification authority is granted.

NOTE: Changes to approved radioactive and hazardous waste management plans and procedures, equipment, and equipment calibrations that affect waste certification have to be approved by $\mathrm{CBFO}$ prior to implementation of the change. The DOE-CBFO, EPA, and NMED expect verbatim compliance with the approved plans and procedures and conduct quarterly assessments and yearly compliance audits to ensure the plans and procedures are being followed.

The risk to the project is that changes to approved plans and procedures before, during, and after hot startup delay waste shipments. The risk is that waste certification authority approval could be delayed by the time and manpower it takes to correct the audit findings or re-certified waste containers because plans, procedures, and equipment calibrations were changed or not followed as approved.

g. Low-level waste generated by the SBWT project is listed as hazardous waste and assigned RCRA hazardous waste numbers F001, F002, F005 and U134. At the present time the only disposal site permitted for radioactive and hazardous waste with these hazardous waste numbers is Envirocare. Envirocare is licensed and permitted for low-level Class A radioactive and hazardous waste. For low-level waste streams, with INTEC hazardous waste numbers, that exceed the radioisotope limits for Class A low-level waste, there are no disposal sites available. If the project generates low-level (non-TRU) waste with activity greater than Class A limits, then it will be a waste without a path for disposal and would require on-site storage.

The Nevada Test Site disposes of radioactive only waste from off-site generators. The Hanford site is not permitted to receive radioactive and hazardous mixed waste from off-site generators or wastes with the U134 hazardous waste number. At the INEEL, the Radioactive Waste Management complex (RWMC) receives radioactive waste and the Idaho CERCLA Disposal Site (ICDF) receives CERCLA waste. In order, for the project to dispose of waste at either the RWMC, Nevada Test Site or Hanford Site the project will need to treat the waste for characteristically hazardous constituents and prepare a delisting petition to remove the hazardous waste number above. In order for the waste to be disposed of at the ICDF the project and waste generated would have to be added to the INEEL CERCLA Program under the Federal facilities Agreement/Consent Order. The proposed treatment option would generate low-level waste in the form of grouted scrub, GAC, PPE, and debris.

To avoid these risks, it is recommended that the project work with the State of Idaho, Region 10 EPA, and the disposal site state to delist low-level waste generated from this process, since it does not contain the hazard constituents for which it was listed. Delisting petition or a petition to exclude waste from hazardous waste regulation requires approval in the generating state, states 
through which the waste is transported, and the state in which the waste will be disposed of. There is still the risk that the disposal site state may not accept the delisting for SBW even if it is approved in Idaho and Region 10.

\subsubsection{SR Regulatory Risks - Summary}

\section{WIPP}

- $\quad$ The State of New Mexico delays the approval of the RH-TRU permit modification

- The State of New Mexico delays the approval of the 311(b) permit modification

- $\quad$ The State of New Mexico amends the WIPP HWFP to exclude waste classified as TRU using the WIR process

- $\quad$ The State of New Mexico amends the WIPP HWFP to exclude waste not listed in the 1995 Transuranic Waste Baseline Inventory Report

- $\quad$ The EPA or State of New Mexico requires additional sampling and analysis for acceptable knowledge characterization for RH-TRU waste

- $\quad$ WIPP/EPA/NM do not grant waste certification authority to the project until 180 days after hot start (30 days of production, audit, 4-6 months wait until approval is granted)

- WIPP does not have the manpower or on-site capabilities to support the shipping schedule

- $\quad$ WIPP does not have 72-B transporters available for the SBWT project to support the shipping schedule

- $\quad$ WIPP does not have the LWA capacity to receive the RH-TRU SBW

- $\quad$ NMED continues to require headspace gas analysis for every container in storage

- $\quad$ NMED continues to require verification sampling and analysis of the waste in containers in addition to acceptable knowledge

- WIPP approval of changes to equipment and procedures identified during SO testing, readiness review, and hot start up delays waste certification authority or implementation of new procedures

- Court challenges by the State of New Mexico or stakeholders prevent or delay shipping waste to WIPP

- $\quad$ The State of New Mexico passes legislation that prevents or delays shipping SBW to WIPP.

\section{Permitting}

- $\quad$ State of Idaho DEQ cannot support the aggressive permitting modification schedule for start of construction

- $\quad$ State of Idaho DEQ does not approve a general permit modification to support the start of building construction 
- $\quad$ State of Idaho DEQ does not issue a permit to construct (air) to support the schedule for start of building construction

- $\quad$ State of Idaho DEQ does not approve the modifications to the HWMA permit in time to support the start of operations

- $\quad$ State of Idaho DEQ does not issue a permit to operate (air) in time to support the start of operations

- $\quad$ State of Idaho DEQ and Federal Land Manager, PSD new source review requires additional off gas clean up and delays permit approval

- $\quad$ State of Idaho DEQ does not cooperate with permitting the high temperature thermal treatment alternatives

- $\quad$ The compliance performance testing (trail burn) delays the start of production operations

- $\quad$ Court challenges by INEEL stakeholders delay or prevent permit modifications needed for the SBW project

- State of Idaho does not approve the SBW petition to exclude the waste from hazardous waste regulation

- $\quad$ The disposal site state does not approve the SBW petition to exclude the waste from hazardous waste regulation

- $\quad$ Compliance testing to demonstrate compliance with MACT requires the use of chemical spiking that adds new $\mathrm{P}$ and $\mathrm{U}$ listed waste hazardous waste numbers to the SBW that affect disposal at WIPP, NGR or low-level waste sites.

\section{DOE O 435.1}

- $\quad$ Federal courts vacate DOE's authority to make WIR determinations

- $\quad$ Federal courts delay DOE's authority to make WIR determinations

- $\quad$ Congress does not clarify DOE's authority to make WIR determinations

- $\quad$ The project generates waste streams without a path to disposal requiring permitting and construction of additional storage capacity.

\section{Safety}

- $\quad$ PDSA is not approved in time to support the schedule for ordering long lead equipment

- $\quad$ FDSA is not approved in time to support the readiness review schedule

- $\quad$ Systems operations testing identify problems that delay the hot start up schedule

- $\quad$ Readiness review process takes additional time to correct findings and delays the hot start up schedule

- $\quad$ Radioactive Waste Management Authority is not approved in time to support the hot start up schedule causing a delay in WIPP Waste Certification Authority. 
Table 2-2. MACT Standards for Hazardous Waste Incinerators 40 CFR $\S 63 \S \S E E E$.

\begin{tabular}{|c|c|c|c|}
\hline Constituent & $\begin{array}{l}\text { Existing Source }^{\mathrm{a}} \\
\text { Interim Rule }\end{array}$ & $\begin{array}{l}\text { New Source } \\
\text { Interim Rule }\end{array}$ & $\begin{array}{c}\text { New Source }{ }^{\mathrm{c}} \text { Final } \\
\text { Proposed Rule 4-20-04 }\end{array}$ \\
\hline Dioxins/furans & $<0.20 \mathrm{ng} \mathrm{TEQ} / \mathrm{dscm}$ & $<0.20 \mathrm{ng} \mathrm{TEQ} / \mathrm{dscm}$ & $\begin{array}{l}0.11 \text { for dry APCD or } \\
\mathrm{WHBs}^{1} ; 0.2 \text { for others }\end{array}$ \\
\hline & $<0.40 \mathrm{ng} \mathrm{TEQ} / \mathrm{dscm} \leq 400^{\circ} \mathrm{F}$ & & \\
\hline Mercury & $<130 \mu \mathrm{g} / \mathrm{dscm}$ & $<45 \mu \mathrm{g} / \mathrm{dscm}$ & $8 \mu \mathrm{g} / \mathrm{dscm}$ \\
\hline Lead and cadmium & $<240 \mu \mathrm{g} / \mathrm{dscm}$ & $<120 \mu \mathrm{g} / \mathrm{dscm}$ & $6.5 \mu \mathrm{g} / \mathrm{dscm}$ \\
\hline $\begin{array}{l}\text { Arsenic, beryllium, and } \\
\text { chromium }\end{array}$ & $<97 \mu \mathrm{g} / \mathrm{dscm}$ & $<97 \mu \mathrm{g} / \mathrm{dscm}$ & $8.9 \mu \mathrm{g} / \mathrm{dscm}$ \\
\hline Carbon Monoxide & $<100 \mathrm{ppm}$ & $<100 \mathrm{ppm}$ & $\begin{array}{l}100 \text { ppmv (CO) or } 10 \\
\text { ppmv HWC }\end{array}$ \\
\hline $\begin{array}{l}\text { Hydrochloric acid and } \\
\text { chlorine gas }\end{array}$ & $<77 \mathrm{ppm}$ & $<77 \mathrm{ppm}$ & $0.18 \mathrm{ppmv}^{2}$ \\
\hline Particulate Matter & $>34 \mathrm{mg} / \mathrm{dscm}$ & $>34 \mathrm{mg} / \mathrm{dscm}$ & $0.0070 \mathrm{gr} / \mathrm{dscf}^{3}$ \\
\hline
\end{tabular}

NOTES:

(a) Emission limits for existing sources. You must not discharge or cause combustion gases to be emitted into the atmosphere that contain:

(1) For dioxins and furans:

(i) Emissions in excess of $0.20 \mathrm{ng} \mathrm{TEQ} / \mathrm{dscm}$ corrected to 7 percent oxygen; or

(ii) Emissions in excess of $0.40 \mathrm{ng} \mathrm{TEQ} / \mathrm{dscm}$ corrected to 7 percent oxygen provided that the combustion gas temperature at the inlet to the initial particulate matter control device is $400^{\circ} \mathrm{F}$ or lower based on the average of the test run average temperatures. (For purposes of compliance, operation of a wet particulate control device is presumed to meet the $400^{\circ} \mathrm{F}$ or lower requirement);

(2) Mercury in excess of $130 \mu \mathrm{g} / \mathrm{dscm}$ corrected to 7 percent oxygen;

(3) Lead and cadmium in excess of $240 \mu \mathrm{g} / \mathrm{dscm}$, combined emissions, corrected to 7 percent oxygen;

(4) Arsenic, beryllium, and chromium in excess of $97 \mu \mathrm{g} / \mathrm{dscm}$, combined emissions, corrected to 7 percent oxygen;

(5) For carbon monoxide and hydrocarbons, either:

(i) Carbon monoxide in excess of 100 parts per million by volume, over an hourly rolling average (National continuously with a continuous emissions monitoring system), dry basis and corrected to 7 percent oxygen. If you elect to comply with this carbon monoxide standard rather than the hydrocarbon standard under paragraph (a)(5)(ii) of this section, you must also document that, during the destruction and removal efficiency (DRE) test runs or their equivalent as provided by $\$ 63.1206(\mathrm{~b})(7)$, hydrocarbons do not exceed 10 parts per million by volume during those runs, over an hourly rolling average (National continuously with a continuous emissions monitoring system), dry basis, corrected to 7 percent oxygen, and reported as propane; or

(ii)

Hydrocarbons in excess of 10 parts per million by volume, over an hourly rolling average (National continuously with a continuous emissions monitoring system), dry basis, corrected to 7 percent oxygen, and reported as propane;

(6) Hydrochloric acid and chlorine gas in excess of 77 parts per million by volume, combined emissions, expressed as hydrochloric acid equivalents, dry basis and corrected to 7 percent oxygen; and

(7) Particulate matter in excess of $34 \mathrm{mg} / \mathrm{dscm}$ corrected to 7 percent oxygen.

(b) Emission limits for new sources. You must not discharge or cause combustion gases to be emitted into the atmosphere that contain:

(1) Dioxins and furans in excess of $0.20 \mathrm{ng} \mathrm{TEQ} / \mathrm{dscm}$, corrected to 7 percent oxygen;

(2) Mercury in excess of $45 \mu \mathrm{g} / \mathrm{dscm}$ corrected to 7 percent oxygen;

(3) Lead and cadmium in excess of $120 \mu \mathrm{g} / \mathrm{dscm}$, combined emissions, corrected to 7 percent oxygen;

(4) Arsenic, beryllium, and chromium in excess of $97 \mu \mathrm{g} / \mathrm{dscm}$, combined emissions, corrected to 7 percent oxygen;

(5) For carbon monoxide and hydrocarbons, either:

(i) Carbon monoxide in excess of 100 parts per million by volume, over an hourly rolling average (National continuously with a continuous emissions monitoring system), dry basis and corrected to 7 percent oxygen. If you elect to comply with this carbon monoxide standard rather than the hydrocarbon standard under paragraph (b)(5)(ii) of this section, you must also document that, during the destruction and removal efficiency (DRE) test runs or their equivalent as provided by $\$ 63.1206(\mathrm{~b})(7)$, hydrocarbons do not exceed 10 parts per million by volume during those runs, over an hourly rolling average (National continuously with a continuous emissions monitoring system), dry basis, corrected to 7 percent oxygen, and reported as propane; or

(ii) Hydrocarbons in excess of 10 parts per million by volume, over an hourly rolling average (National continuously with a continuous emissions monitoring system), dry basis, corrected to 7 percent oxygen, and reported as propane;

(6) Hydrochloric acid and chlorine gas in excess of 21 parts per million by volume, combined emissions, expressed as hydrochloric acid equivalents, dry basis and corrected to 7 percent oxygen; and (7) Particulate matter in excess of $34 \mathrm{mg} / \mathrm{dscm}$ corrected to 7 percent oxygen. 


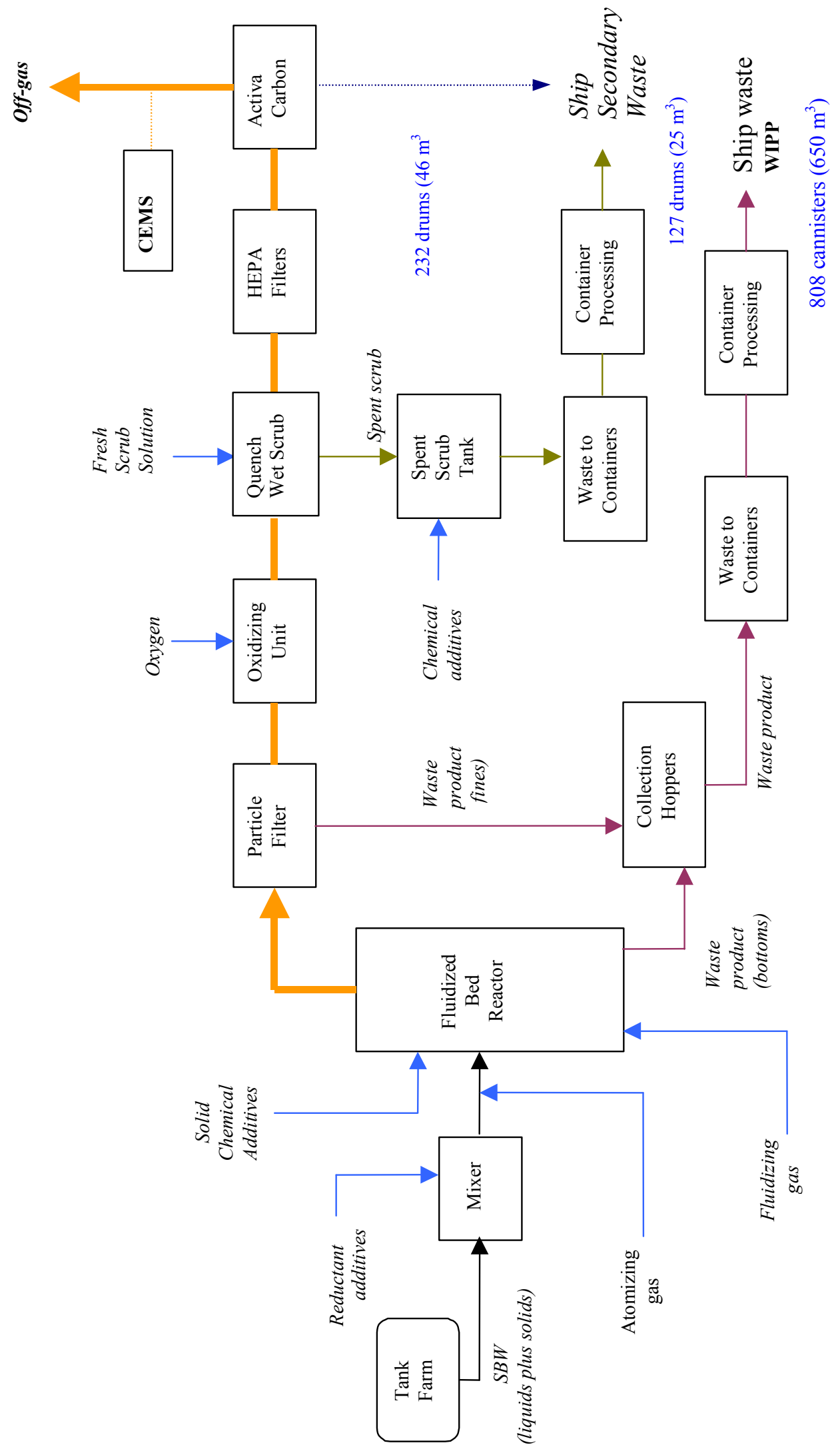

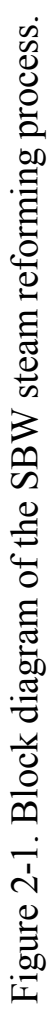




\begin{tabular}{|c|c|c|c|c|c|c|c|c|c|c|c|c|c|c|c|c|c|c|}
\hline \multicolumn{2}{|c|}{ 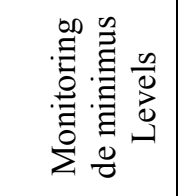 } & 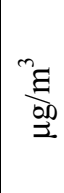 & 으 & 1 & o. & $\sigma$. & $\mathrm{i}$ & $\cong \quad 1$ & \pm & $i$ & 1 & 1 & $\frac{n}{n}=$ & $\overrightarrow{0}$ & i & 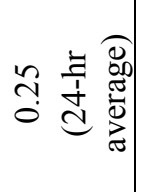 & 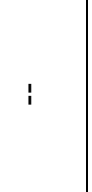 & 늘 \\
\hline \multicolumn{2}{|c|}{ 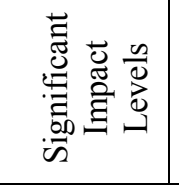 } & 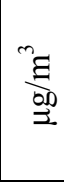 & $n$ & - & o. & $a \cdot \mid a^{4}$ & $\approx$. & $n-$ & $=$ & 1 & 1 & ڤ્ટે & $\begin{array}{l}8 \\
i n\end{array}$ & I & 1 & 1 & 1 & 1 \\
\hline \multicolumn{2}{|c|}{ 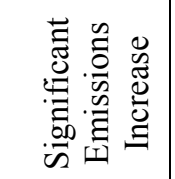 } & 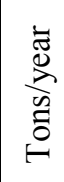 & \multicolumn{2}{|l|}{$\cong$} & a. & & \multicolumn{2}{|l|}{ \& } & 우 & \multicolumn{2}{|c|}{ 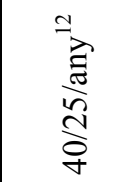 } & 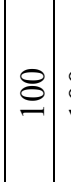 & 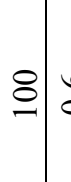 & $\begin{array}{l}0 \\
\stackrel{0}{0}\end{array}$ & $\approx$ & $m$ & $r$ & $\stackrel{0}{ }$ \\
\hline \multirow{3}{*}{ 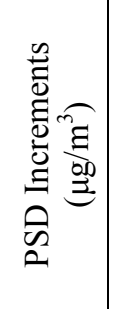 } & \multirow{3}{*}{ 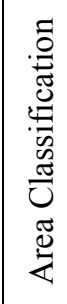 } & $\Xi$ & 8 & m & a. & c. $\mid$ & ¿ & $\begin{array}{ccc}\infty & \text { P } \\
\infty & \end{array}$ & in & $i$ & 1 & $\mathrm{i}$ & $i$ & 1 & 1 & 1 & i & 1 \\
\hline & & $=$ & ஓ) & I & a. & $a \cdot \mid \frac{3}{4}$ & $\frac{N}{n}$ & $\bar{\sigma}$ & $\approx$ & $\mathrm{i}$ & i & $i$ & 1 & 1 & 1 & 1 & $i$ & 1 \\
\hline & & $\neg$ & $\infty$ & $\nabla$ & a. & a. ${ }^{2}$ & $\approx$ & $n d$ & $\tilde{n}$ & 1 & 1 & $\mathrm{i}$ & $\mathrm{i}$ & 1 & $i$ & $i$ & 1 & 1 \\
\hline \multirow{4}{*}{$\sum_{z}^{2}$} & \multirow{2}{*}{ 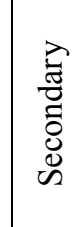 } & 额 & 1 & 1 & 1 & 13 & 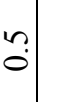 & $\mathrm{i}$ & $\tilde{n}$ & $\stackrel{7}{0}$ & 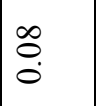 & $i$ & 1 & $i$ & 1 & 1 & $i$ & 1 \\
\hline & & ${ }^{m} \xi$ & $\stackrel{ }{n}$ & 오 & 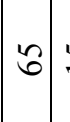 & $\sim$ & \begin{tabular}{l}
8 \\
\hdashline \\
-2
\end{tabular} & $i$ & 8 & $\left|\begin{array}{c}n \\
\tilde{N}\end{array}\right|$ & $n$ & $i$ & $i$ & $\because$ & 1 & 1 & i & 1 \\
\hline & \multirow{2}{*}{ 莺 } & 苑 & $i$ & $i$ & $i$ & $\mathrm{i}$ & $i$ & $\begin{array}{cc} \pm \\
\\
\end{array}$ & $\mid \begin{array}{l}n \\
\tilde{n} \\
0 \\
0\end{array}$ & $\stackrel{7}{0}$ & $\stackrel{\infty}{\infty}$ & $\approx$ & $a$ & 1 & $i$ & i & i & $i$ \\
\hline & & $\stackrel{m}{E}^{m}$ & $\stackrel{n}{-1}$ & in & $\tilde{6}:$ & 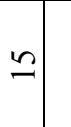 & 13 & 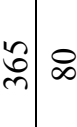 & 8 & $\begin{array}{l}n \\
\tilde{n}\end{array}$ & $n$ & $\begin{array}{l}8 \\
\vdots \\
\dot{q} \\
\dot{q}\end{array}$ & $\begin{array}{ll}8 \\
8 \\
0 \\
0\end{array}$ & $\stackrel{n}{n}$ & i & i & i & 1 \\
\hline \multicolumn{3}{|c|}{${ }^{-}$E } & $\varangle$ & 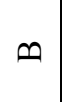 & 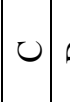 & 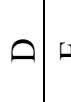 & 工 & 工思 & 工 & 0 & $I$ & 工1 & 디 & - & i & i & i & i \\
\hline \multicolumn{3}{|c|}{ 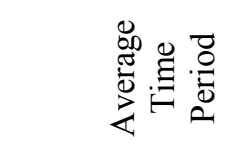 } & 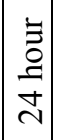 & 吾 & 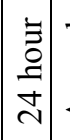 & 胥 & $\begin{array}{l}\bar{z} \\
\vdots \\
m\end{array}$ & \begin{tabular}{l}
$\vec{\Xi}$ \\
吾 \\
\multirow{2}{*}{}
\end{tabular} & 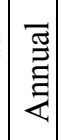 & 音 & 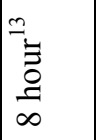 & 章 & 章 & 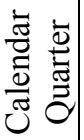 & i & i & i & i \\
\hline \multirow{2}{*}{\multicolumn{2}{|c|}{ 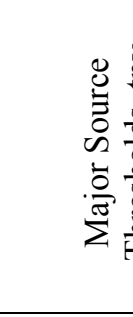 }} & $\stackrel{+}{\longleftarrow}$ & 童 & & \& & & \multicolumn{2}{|c|}{ ○ } & 8 & \multicolumn{2}{|c|}{8} & $\begin{array}{l} \pm \\
0 \\
0 \\
8 \\
0\end{array}$ & & ¿ & $i$ & 1 & 1 & 1 \\
\hline & & के & $\begin{array}{l}8 \\
8 \\
\vdots \\
\vdots \\
i n\end{array}$ & & $\begin{array}{l}8 \\
\stackrel{8}{2} \\
\stackrel{2}{1}\end{array}$ & & \multicolumn{2}{|c|}{ 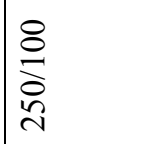 } & $\mid \begin{array}{l}8 \\
\frac{8}{2} \\
\vdots \\
\end{array}$ & \multicolumn{2}{|l|}{ 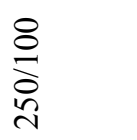 } & $\begin{array}{l}8 \\
\stackrel{8}{8} \\
\infty \\
i 1\end{array}$ & & 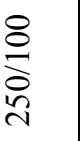 & $\begin{array}{l}8 \\
\stackrel{8}{8} \\
\curvearrowleft \\
i\end{array}$ & $\begin{array}{l}8 \\
\stackrel{8}{8} \\
i n \\
i 1\end{array}$ & 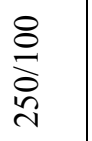 & $\begin{array}{l}8 \\
\stackrel{8}{8} \\
ٌ \\
\end{array}$ \\
\hline \multicolumn{3}{|c|}{ 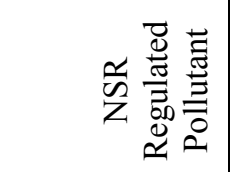 } & $\sum_{1}^{3}$ & & $\sum_{i}^{i}$ & & రీ & & '̊ & & \begin{tabular}{ll|}
$\circlearrowright$ & $\ddots$ \\
$\searrow$ & 0 \\
$>$ & $z$
\end{tabular} & 0 & & 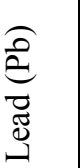 & 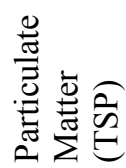 & $\begin{array}{l}\frac{0}{0} \\
\frac{0}{0} \\
\frac{0}{3}\end{array}$ & 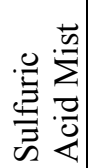 & 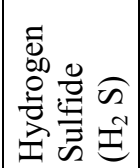 \\
\hline
\end{tabular}




\begin{tabular}{|c|c|c|c|c|c|c|c|c|c|}
\hline \multicolumn{2}{|c|}{ 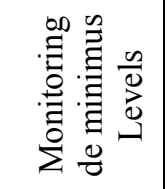 } & $\stackrel{\text { mof }}{\Xi}$ & 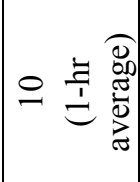 & 을 & 1 & i & i & 1 & i \\
\hline \multicolumn{2}{|c|}{ 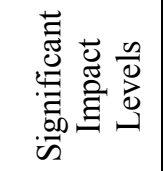 } & ${ }^{m}$ & 1 & 1 & 1 & 1 & i & 1 & I \\
\hline \multicolumn{2}{|c|}{ 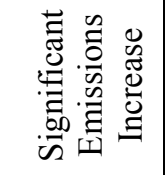 } & 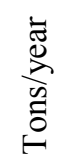 & 으 & 으 & 穻莺 & \& & 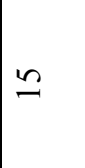 & 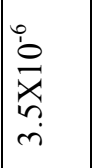 & in \\
\hline \multirow{3}{*}{ 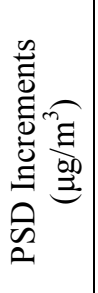 } & \multirow{3}{*}{ 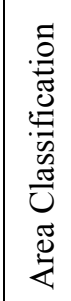 } & $\Xi$ & 1 & $i$ & $i$ & i & $i$ & i & 1 \\
\hline & & $\exists$ & 1 & 1 & 1 & 1 & $i$ & 1 & $i$ \\
\hline & & - & 1 & $i$ & $i$ & 1 & 1 & $i$ & $i$ \\
\hline \multirow{4}{*}{$\begin{array}{l}2 \\
2 \\
z \\
z\end{array}$} & \multirow{2}{*}{ 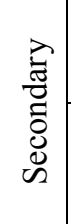 } & בี & 1 & 1 & 1 & 1 & 1 & i & 1 \\
\hline & & $\stackrel{m}{E D}^{m}$ & 1 & i & i & i & i & i & 1 \\
\hline & \multirow{2}{*}{ 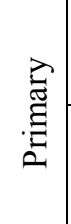 } & 气ิ & 1 & i & i & i & 1 & i & 1 \\
\hline & & $\stackrel{\text { mod }}{E}_{E}^{E}$ & 1 & $i$ & $i$ & i & $i$ & i & $i$ \\
\hline \multicolumn{3}{|c|}{ छ్ } & 1 & 1 & i & 1 & i & I & $i$ \\
\hline \multicolumn{3}{|c|}{ 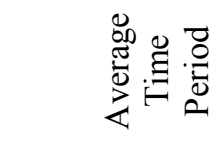 } & 1 & 1 & i & 1 & 1 & $i$ & $i$ \\
\hline \multirow{2}{*}{ 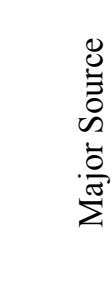 } & 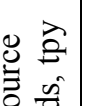 & $\sum_{z}^{+}$ & $i$ & $i$ & 1 & i & i & 1 & 1 \\
\hline & 范 & $\hat{\tilde{n}}$ & $\begin{array}{l}8 \\
\stackrel{8}{2} \\
\vdots \\
i\end{array}$ & $\begin{array}{l}8 \\
\stackrel{8}{2} \\
i \\
i\end{array}$ & $\begin{array}{l}8 \\
\stackrel{8}{2} \\
i \\
i\end{array}$ & $\begin{array}{l}8 \\
\stackrel{8}{2} \\
\stackrel{2}{1}\end{array}$ & $\begin{array}{l}8 \\
\stackrel{1}{2} \\
0 \\
i \\
i\end{array}$ & $\begin{array}{l}8 \\
\stackrel{1}{\infty} \\
\stackrel{1}{N}\end{array}$ & $\begin{array}{l}8 \\
\stackrel{1}{8} \\
\infty \\
i \\
i\end{array}$ \\
\hline \multicolumn{3}{|c|}{ 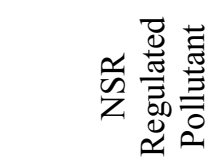 } & 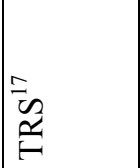 & $\begin{array}{l}\infty \\
\tilde{D} \\
\mathscr{N}\end{array}$ & คิ & 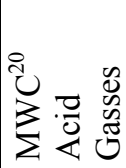 & $\sum \frac{\infty}{\pi}$ & 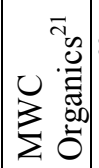 & 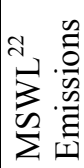 \\
\hline
\end{tabular}




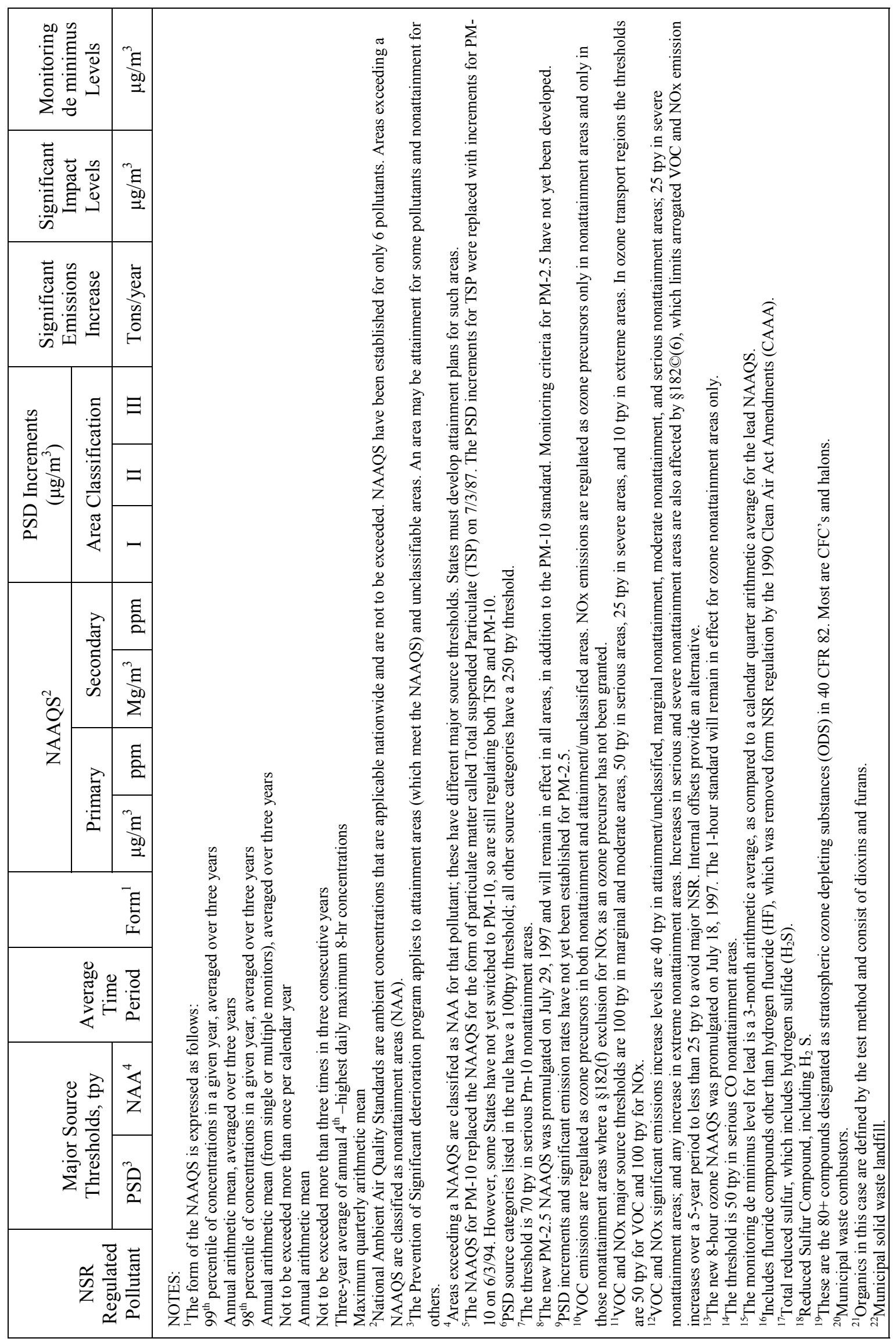




\subsection{SR Schedule and Related}

The overall schedule for the SR SBW treatment alternative cannot achieve the 2012 milestones (late by at least 11 months) primarily due to the time required to permit and construct the SR treatment facility and to treat the SBW in an aggressive, but realistic, time span.

Note that this assessment, similar to the other assessments for all alternatives except CMACT, is based on the construction of a new system in a fixed facility (new but retrofits are possible) on-site at INTEC, and not on a potential modular, mobile facility to be constructed and/or tested off-site and subsequently moved to Idaho later. All processes deal with not only radiologically hot feed but also concentrate the waste in total, or waste components (CsIX), further necessitating heavy shielding and remotely operated systems.

\subsubsection{SR Capital Project Schedule (February 2005 to September 2010)}

\subsubsection{Preliminary Design (February 2005 to October 2005).}

It will require a very aggressive effort to conclude Preliminary Design by the end of October 2005 in only a nine-month period starting in February 2005 and submit environmental permits in December 2005.

The assumed start for the capital project is February 1, 2005, the first day of the new ICP contractor. Preliminary (Title I) Design would commence on this date. However, realistically, even if government funding and approvals (Critical Decision 0, CD-0, Approve Mission Need and CD-1, Approve Alternative Selection and Cost Range) were not to be limiting, Preliminary Design cannot start without a design company being in place under contract and design direction documents such as the Scope of Work (SOW), Technical and Functional Requirements document (TFR), and Project Design Criteria (PDC). These documents have not yet been prepared (the treatment alternatives are many and varied and one has not been chosen yet) but could perhaps be developed in the transition period prior to February 1, 2005 or in the month or two immediately following.

An aggressive Preliminary Design (Title I Design) period of nine months is possible but difficult, during which the process definition must be finalized and P\&IDs developed. Related to this, the following must be done: (1) critical Technical Development test work must be conducted to support process definition - considering the lack of development maturity and process definition for this process, this activity could very well be schedule limiting and extend the time required for Preliminary Design;

(2) remote mock-up testing must be started and iterate with the design to develop and prove the concepts;

(3) safety analysis work must be started and proceed through the fundamental assessment stage to define any safety driven requirements to be inputted to the design; and (4) the draft environmental permit applications must be written. Numbers 1 and 2 would be difficult to achieve in such a short time frame and could be schedule limiting or most likely require design work to proceed at risk based on the best concepts and assumptions available. All this must be coordinated to finalize the P\&IDs such that facility design and mechanical layout work can be performed in sufficient detail to support submittal of the RCRA Part B and Air permit applications. This is considered to be a "Title I Plus" design; that is, a level of detail beyond what is normally developed in a Preliminary / Title I Design effort. The following would be required: 


\section{HWMA/RCRA Permitting}

\section{Process}

- $\quad$ Final process flow diagrams (PFDs), material and energy balances, and process and instrument diagrams (P\&IDs)

- $\quad$ Process descriptions

- $\quad$ Equipment descriptions

- $\quad$ Operating limits

- $\quad$ Operating procedures (at least draft).

\section{Building}

- $\quad$ Site location

- $\quad$ Facility layouts

- $\quad$ Floor plan drawings

- $\quad$ Equipment and piping layouts

- Materials of construction used

- $\quad$ Secondary containment details (at least typical).

\section{Waste}

- $\quad$ Characterization of feed waste (SBW in Tank Farm)

- Waste acceptance requirements for the treatment facility

- $\quad$ Process control requirements

- Description of final waste

- Characterization (typical) of final waste

- $\quad$ Sampling and analytical methods used.

\section{Air Permitting}

\section{MACT}

\section{Air emission modeling}

- Identify sources of emission 
- Identify constituents of concern

- Model emissions.

\section{Trial burn or emission testing plans}

- $\quad$ Sampling planned

- $\quad$ Analysis to be performed

- $\quad$ Monitoring equipment to be used

- $\quad$ Surrogate runs planned

- $\quad$ Spiking to be performed (if any).

\section{NESHAPs}

- $\quad$ Estimated emissions of radionuclides.

\section{PSD}

- $\quad$ Estimated NOx emissions

- $\quad$ Estimated visible emissions.

\section{Title V}

- $\quad$ Estimate emission of hazardous constituents.

At the end of Preliminary Design, the details of the design would be fed into the environmental permit applications and 60 days later, after final reviews, revisions, and approvals, the permit applications would be submitted to the IDEQ for the assumed minimum two year review and approval process (reduced from the 31 months requested by IDEQ by taking time from the Contractor's schedule only) before permission would be given to start of construction.

Additionally, during Preliminary Design, equipment needs will be examined and detailed specifications will be prepared and finalized either at this stage or in the early days of Final Design for equipment that is (1) critical to facility detailed design, (2) needed for the mock-up testing program, or (3) otherwise long-lead and schedule critical. (This equipment is normally referred to as "government furnished equipment", GFE.) Some examples of this are the SR fluidized bed reactor vessel, the thermal oxidizer, the fluidized SR product receiving hoppers and canister loading assembly, the continuous scrub grout mixer and associated assembly, the decon/transfer cart, the canister handling machine, and the tank mixing pumps.

\subsection{Issues related to design and construction of the SR Waste}

Product Packaging Facility-Advantages could be realized if the steam reforming waste product packaging facility (referred to as the Particulate Packaging Facility, PPF, for this discussion) was to be designed for both processing newly formed SBW SR waste product and for receipt and packaging of the existing HLW calcine in the INTEC bin sets. A summary of these benefits to the SBW and HLW Programs are significant cost savings and overall schedule savings for HLW with some net detriment to 
the SBW schedule especially in the design phase. Designing for both SBW SR waste product and HLW calcine would add to the design and construction complexity and schedule inside the project while having a particulate solid receipt, packaging, and load-out facility built early would be advantageous for the HLW program and should enable significantly earlier disposition of the HLW calcine.

The following questions and issues need to be addressed before starting design on a dual service Particulate Packaging Facility, (PPF):

1. The first question is whether or not the INEEL will be successful in obtaining approval for disposal of as-is packaged (no treatment) HLW calcine at the National Geological Repository (Yucca Mountain) If this answer cannot be determined in the short term, should the design on the PPF proceed in any case under this assumption. All of the following questions depend on the answer to this one.

2. If design were to proceed on the dual use PPF, should it be designed for the $15 \mathrm{ft}$ canister or the standard $10 \mathrm{ft}$ design? Hanford has been pursuing approval of the $15 \mathrm{ft}$ canister for HLW disposal for several years now, but it has not yet been approved. It should be noted that WIPP will only accept a $10 \mathrm{ft}$ canister.

3. If the PPF were to be designed for dual use, shielding would have to be provided for the worst case HLW calcine instead of the worst case SBW SR waste product.

4. Information is needed on the intended design of the HLW calcine retrieval system so that the interfaces in the PPF could be properly designed - particulate solid receipt hoppers and filters, transport gas handling and treatment / disposition, etc. as well as the exact location of the PPF on the INTEC plot plan.

5. Both WIPP and Yucca Mountain accept a nominal $2 \mathrm{ft}$ diameter by $10 \mathrm{ft}$ long canister but there are small dimensional differences as well as lid and handling design feature differences. The PPF would have to be designed for both.

6. The SR waste product packaging system inside the SR facility is currently designed with no provision for sampling SBW SR waste product or scrub solution or its grouted final waste form. It is intended that the process and waste form would be pre-qualified by a test program prior to fullscale hot operations. The question as to whether HLW calcine would need to be sampled as it is retrieved and received in the PPF would have to be answered. If so, a sampling system would have to be designed (which in turn could affect the approach taken to canister filling) and the pneumatic transfer system (PTS) extended to get to the remote analytical laboratory (RAL) or a new dedicated lab added on to the PPF must be provided. These particular changes would not be inexpensive.

All this would not only add to the complexity and schedule of the design effort but these questions would have to be answered early in Preliminary Design so that design concepts could be developed for the environmental permits to be submitted.

It should be noted that Preliminary Design, feeding into the environmental permit applications, and the application review process by IDEQ leading to approval to construct is the first of three critical paths on the project schedule. The second, discussed later, is construction, testing, and startup of the SR treatment facility. The third, also discussed later, is treatment (steam reforming) of the SBW, which is a direct function of the throughput of the treatment system. 


\subsubsection{Final Design (November 2005 to July 2007).}

The Final Design schedule does not involve risk nor is it on the critical path. It is dictated by the time required for review and approval of the environmental permits by IDEQ, which will require 24 months after submittal following the completion of Preliminary Design.

Final Design (Title II Design) will start immediately following Preliminary Design in early November 2005. It is assumed that there will be no hold period for CD-2, Approve Performance Baseline (authority to commence Final Design). It is also assumed that an early and partial CD-3 (Approval to Start Construction) consent would be given at CD-2 to procure the GFE equipment cited in the previous section, which would involve a relatively significant expenditure of capital funds.

All technical development test work and remote mock-up testing must be completed by mid-Final Design in order to be factored into the detailed design.

Detailed design would iterate with procurement on GFE items to minimize the overall schedule as well as cost. Design would proceed to the point of preparation of numerous bid packages of equipment specifications and drawings for issuance for competitive bid by either the ICP contractor or their design agency. (The latter is preferred for better communication and control as well as lower cost.) Vendor bids would be received, analyzed, and awarded. Vendor drawings would be produced, reviewed, revised as necessary, and approved, after which the equipment layouts and facility designs would be completed by the design agency to reflect these details in the bid packages for general construction. Vendor material purchases, fabrication, testing, and ultimate delivery to the construction site would be delayed in order to postpone these costs of fabrication without impacting construction as well as to wait until the construction contractor is chosen and on-site to receive delivery of these items. This approach will reduce both costs and schedule by not only initiating early procurement but by providing actual equipment details in the detailed design drawings thus avoiding numerous design related questions and delays during construction.

Final Design, bid and award of the construction contract (normally a 3-4 month process for a project of this size), and notice to proceed and mobilization of the construction contractor on the site to be poised for the start of construction (approximately 1 month) will all fit within the 26 month permit cycle period (minimum 24 months after submittal plus 2 months after Preliminary Design for final submittal preparation) before authorization to proceed with construction is obtained from IDEQ. Final Design then must, and can without difficulty, complete by July 31, 2007 over a 21-month time frame. Final Design could be accomplished sooner, but to no net schedule advantage since construction must wait for the permit review and approval cycle. It would be better for Final Design to be performed over that longer time period so that the design team stays together and a core group can still be kept to support design related questions during construction.

\subsubsection{Construction (January 2008 to September 2009).}

Construction of the SR treatment facility is the second critical path activity on the overall schedule, requiring 21 months if aggressively pursued; 33 months including the testing and readiness review stage leading to hot startup. (NWCF took 71 months, 48 months to construct and 23 months to test and start up.).

Work to obtain Critical Decision-3, Approval to Start Construction will begin at the end of Final Design. It is assumed that CD-3 approval will be obtained by July 2007 authorizing the start of the bid and award process. It is also assumed that CD-3 will release and provide funding support for the construction contractor to start procurement for construction. Fabrication of the GFE procurement items mentioned above in the Final Design section will be released at this time and those contracts will be 
completed by the originating organization (either the design agency or the ICP contractor) and be provided to the construction contractor as GFE for installation. (Schedule analysis will be performed during design and those GFE items that may be schedule limiting, if any, will be released for fabrication earlier during the late stages of Final Design so that no construction delays are encountered due to these items.)

Construction will start in January 2008 (in the middle of winter, not a particularly good time) after approval of the RCRA permit is obtained from IDEQ. Construction will follow a logical installation sequence from site preparation and required demolition, through earthwork, concrete, steel, piping, to completion of instrumentation and electrical installation and construction component checkout (CC Testing).

\subsubsection{Testing and Startup (April 2009 to September 2010).} path.

Testing and startup, overlapping with the final stages of construction, are also on the critical

During the late stages of construction, after construction forces have completed rudimentary component testing (CC Testing), the ICP contractor, with support from the design agency as necessary, will perform system operation (SO) tests and cold tests (CT) on the treatment system and its supporting facility and equipment. After this, an in-house readiness review will be performed leading to a formal operational readiness review (ORR) by DOE and others. Usual participants in an ORR are DOE-ID and DOE-HQ and sometimes the Defense Nuclear Facilities Safety Board (DNFSB). However, in this case the following applies: (1) final waste treatment is to be performed using a high temperature thermal process requiring compliance with the new MACT regulations, (2) RCRA waste is being treated and stored and the system is to be fully compliant and Part B permitted, and (3) the intent is to dispose of the treated waste in a major federal repository (WIPP). As such, the Federal EPA, Idaho DEQ, and WIPP and New Mexico Environmental Department will also be involved, at least informally or an audit mode, in the final ORR and hot startup/ "trial burn" and the waste form qualification and process/program validation leading to program certification for the WIPP repository.

Parallel with the final stages of the ORR, Critical Decision-4, Approval to Start Operations will be conducted and at the conclusion of both, approval will be given for hot startup of the treatment system.

It is planned that pilot scale work, along with process knowledge work such as off-gas modeling, will be performed during the construction phase to qualify the waste form and preliminarily validate the process to the satisfaction of WIPP and the National TRU Waste Management Program. It is through this test work that the waste form will be proven and the "macro-batch" (Tank Farm tank quantities of feed) approach to sampling and characterization, supported by process knowledge, will be validated. (The intent is to physically sample and characterize the feed from the Tank Farm tanks and not the final waste forms or any intermediate treatment streams.) However, the overall process and program validation still must be proven in the full-scale production system using trained operators and procedures.

A "trial burn" using actual hot feed (potentially with the need to add ("spike") certain species to worst case levels) is also required to prove to IDEQ and the Federal EPA that off-gas emissions are acceptably within MACT limits.

Discussions with WIPP in 2002 and 2003 resulted in the baseline premise that WIPP could not and would not certify the SBW treatment process/program and its final waste or authorize shipments until 6 months after start of hot operations. The SBWT project assumes that, primarily for milestone schedule reasons, waste treatment must continue and final treated waste must be formed, packaged, and stored "at 
risk." It is also assumed that a shutdown will be imposed by WIPP, as is historically the case, if anything, to resolve minor procedural, training, or other "paperwork" problems. (Note that it is also assumed that the final SBW SR waste product will not have to be physically reworked in any way, not only due to the assumed success of the prior waste form qualification work, but also because little alteration of it could be performed in any case.) It is also expected that, regardless of what might happen with the WIPP program, a shutdown would most likely be required by the environmental regulators to assess the MACT trial burn results (off-gas sample analytical work, some from special samples to be collected only for the trial burn, and analysis of this data and data from process control instrumentation).

The plan is to operate on hot feed for 4 months and shutdown for 2 months for the WIPP and RCRA/Air Program reviews. It is assumed that at the end of this short shutdown, program certification would be given by WIPP along with approval to make the first shipment from Idaho to New Mexico. It is also assumed that the trial burn review would prove positive and a re-start would be authorized without the need for a second trial burn. Note that historically this is a risky assumption and that at least one repeat of the trial burn may be necessary.

\subsubsection{SR Treatment Operations Schedule (October 2010 to November 2013)}

SBW treatment by steam reforming plus off-gas treatment to meet the new MACT standards and SR product and scrub solution packaging is the third critical path activity on the overall schedule, assumed to require at least 3 years. Improvements to a 3-year operating schedule are possible, but not certain even with added expenditures. And there are risks that even a 3-year schedule can be achieved given the complexity of the process system.

A feasibility study for processing SBW by steam reforming shows a 3-year operating schedule (Williams 2002). Recent mass balances have assumed a 2.5-year treatment schedule (Barnes 2004a) but no major maintenance turnaround is assumed. Considering that this process is very similar to the calcination process, and is, in fact, more complex, at least one major maintenance turnaround of 6 months should be assumed to be required (two such turnarounds are assumed for CMACT).

Shorter treatment schedules are technically feasible, by increasing equipment sizes or using multiple processing lines but this would increase the capital cost of the facility since these costs are a function of throughput. Also, pilot-scale testing clearly indicated the potential for off-normal conditions, such as fouling of feed spray nozzles, bed agglomeration, and failure to achieve a stable size distribution of bed particles. These problems could result in a longer startup or more frequent shutdowns of the process, extending the treatment schedule. While the treatment schedule could possibly be reduced from 3 years, the rate at which WIPP can receive RH-waste is limited and this would only aggravate the interim storage problem, requiring more storage locations, and also adding to the capital cost of the facility.

\subsubsection{SR Waste Shipment Schedule (April 2011 to December 2013)}

\section{Remote handled (RH) waste shipments are receipt rate limited at WIPP and cannot keep pace with treatment nor be completed by the 2012 milestone.}

Idaho's SBW treatment production rate exceeds WIPP's receipt rate. This would result in net accumulation that drives the need for lag storage in Idaho and is a direct function of the treatment rate. Lag storage would be required, as described below.

SBW treatment by steam reforming would produce about $808 \mathrm{RH}$ canisters with dose rates of 45 $\mathrm{R} / \mathrm{hr}$ on contact. The treatment generation rate could vary from as little as 1.6 canisters per operating day for a 500 day operating campaign (assumed to cover 2.5 years) to 4.0 canisters per operating day for a 
200 day campaign ( 1 year) both calculated using a 7 day week at 24 hour per day operation. The WIPP overall RH receipt rate/capacity is 12 canisters per week over a 50 -week year; one canister per cask and one cask per truck shipment. This receipt rate is physically limited by the receipt, off-loading, and handling system on the surface at WIPP and not by transportation or placement in the repository. This compares to the SR production rate of 11.2 to 28.3 canisters per week; 1.6 to 4.0 per day).

WIPP committed to DOE-ID in 2003 to take 6 RH canisters per week (300 per year) in the 2009 to 2012 time frame. RH capacity currently claimed by others in this time period is 3 canisters per week such that $75 \%$ of the total is currently claimed while Idaho claims half of that total. The difference between the generation rate in Idaho by steam reforming and the take-away rate by WIPP is 5.2 canisters per week for a 2.5 year treatment period to 22.3 canisters per week for one year resulting in net accumulation. With the assumption (validated by WIPP) that shipments would not be authorized until 6 months after start of hot operations and the need to continue to treat and generate waste at risk, primarily to minimize schedule, calculations have been done that show that net peak accumulation would range from 129 canisters $(16 \%$ of the 808 total) for a 2.5 year campaign to $508(63 \%)$ for a 1 year campaign given a WIPP RH receipt rate limitation of 6 canisters per week. It would take 2.7 years for WIPP to take all the SR RH waste at a rate of 6 canisters/week, 300/year. For a 2.5 year campaign it would take an additional 1-month, until December 31,2013, to complete shipment of this accumulated inventory to WIPP with a project start date of February 1, 2005 and an end of treatment date of November 30, 2013. For a one-year campaign it would take an additional 21 months to December 31, 2013 after an end of treatment date of March 31, 2012.

In the 2.5-year campaign scenario (38 months total, 2 months for a WIPP imposed shutdown plus 6 months for a major maintenance turnaround) the December 2012 milestone is missed by 11 months for treatment and 12 months for shipment to WIPP. In the 1-year campaign scenario (18 months total, 6 months for a major maintenance turnaround with the 2 month WIPP imposed shutdown inside this) the December 2012 treatment milestone is beat by 9 months but the same milestone for shipment to WIPP is missed by 12 months.

The 1-year scenario looks attractive but is very aggressive. It should be considered that the overall SR schedule is more aggressive and hence less realistic than that for CMACT. The reason for this is that the SR process is more complex than calcination and far less understood and developed. The Preliminary Design schedule is particularly aggressive - significant technical development work would be necessary in order to define the process, develop and fix the P\&IDs, and detail out the equipment and facility designs to the extent necessary to support completion and submittal of the environmental permit applications which are critical path on the front end of the schedule. Also, operationally, striving for an aggressive one year treatment period for steam reforming, being new, complex, and significantly different than calcination, with which INTEC has many years of operating experience, would be quite risky. It looks like there is 9 months of schedule contingency with this scenario but as pointed out earlier in this report, recent pilot-scale testing clearly indicated the potential for off-normal conditions, such as fouling of feed spray nozzles, bed agglomeration, and failure to achieve a stable size distribution of bed particles. These problems could result in a longer startup or more frequent shutdowns of the process, extending the treatment schedule. The 2.5-year treatment schedule is recommended even though it misses the 2012 milestone.

Shorter SBW treatment operating periods (faster throughput), such as the 1-year period cited above, may be possible (but risky) with the SR process, if necessary, in an attempt to minimize schedule and perhaps meet the 2012 treatment milestone. However, besides being quite aggressive itself, this would aggravate the lag storage situation even further and significantly add to the capital project cost to provide for an additional 379 canister storage positions. 


\subsubsection{SR Schedule - Summary}

The 2012 milestone schedule can only be achieved with the steam reforming SBW treatment alternative if a very aggressive and risky treatment schedule is pursued. Schedule risks have been identified and include:

- $\quad$ Beginning Preliminary (Title I) Design activities on February 1, 2005. Any delay releasing this work will impact project completion.

- $\quad$ Completing sufficient technical development test work to support process definition and Preliminary (Title I) Design activities so that environmental permits can be prepared and submitted by January 1, 2006. Any delays in this set of activities, being on the critical path schedule, will impact project completion.

- An environmental permitting timeframe of 24 months, especially in light of opposition to thermal treatment by various Stakeholders.

- $\quad$ DOE funding, reviews, and approvals. The schedule assumes funding will be available in a timely manner and will not impact design, procurement, or construction.

- $\quad$ Technical Development (process testing) as this information iterates with Final (detailed) as well as Preliminary Design.

- $\quad$ Mock-up Testing of SR product packaging system equipment as this information iterates with detailed design.

- $\quad$ GFE procurement as it feeds into Mock-up testing and design.

- $\quad$ Testing, operational readiness reviews (ORRs), startup, WIPP certification, and Trial Burn.

- $\quad$ Treatment over a 3-year period.

In addition to the risks listed above, normal risks associated with a project of this size and complexity can be expected including availability of skilled craftsmen, weather impacts, and timely delivery of equipment and materials. 


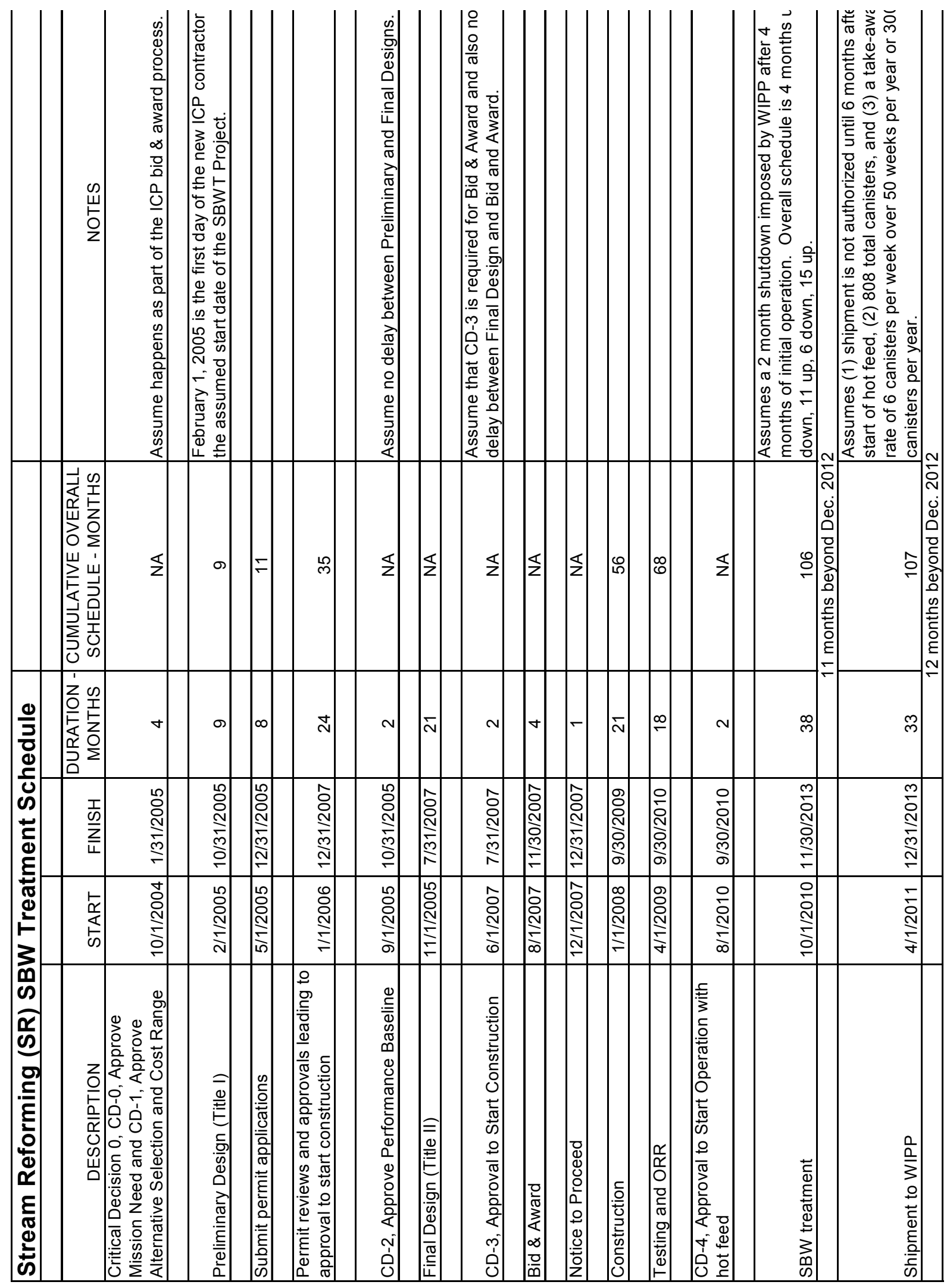




\section{SR product generation and storage}

\begin{tabular}{|l|l|l|l|l|}
\hline & & & & \\
\hline Based on detailed discussions between WIPP, DOE-ID, \& DOE-HQ in 2002/03, assume 300 RH shipments (1 canister/shipment) to WIPP per year ( 6/week).
\end{tabular}

Assume 2.5 years of operation over a 3.2 year (38.0 month) span producing 808 total canisters.

Assumes a 2 month shutdown imposed by WIPP after 4 months of initial operation, adding 2 months to the overall schedule. Overall schedule is 4 months up, 2 down, 11 up, 6 down, 15 up for 38 months total.

\begin{tabular}{|c|c|c|c|c|c|c|c|}
\hline \\
\hline \multicolumn{8}{|c|}{ Overall schedule is 4 months up, 2 down, 11 up, 6 down, 15 up for 38 months total. } \\
\hline & & canisters & $\begin{array}{l}\text { Calendar days } \\
\text { "up" }\end{array}$ & $\begin{array}{l}\text { canisters/ } \\
\text { operating day }\end{array}$ & $\begin{array}{c}\text { canister per } 7 \\
\text { day week }\end{array}$ & $\begin{array}{l}\text { Idaho net } \\
\text { accumulation/day }\end{array}$ & $\begin{array}{l}\text { Idaho net } \\
\text { accumulation/week }\end{array}$ \\
\hline & & 808 & 913 & 0.8855 & \begin{tabular}{|l|l}
6.20 \\
\end{tabular} & 0.03 & 0.20 \\
\hline & & & 2.5 years & & & & \\
\hline 122 & days (4 months) up w/o shipment - produce & 108 & ship & 0 & store & 108 & \\
\hline & & & & & & & \\
\hline 61 & days (2 months) down w/o shipment - produce & 0 & ship & 0 & store & 108 & \\
\hline & & & & & & & \\
\hline 335 & days (11 months) up w/shipment - produce & 296 & ship & 275 & store & 129 & peak storage need \\
\hline 183 & days (6 months) down w/shipment - produce & 0 & ship & 129 & store & 0 & \\
\hline & & & & & & & \\
\hline 456 & days (15 months) up w/shipment - produce & 404 & ship & 375 & store & 29 & \\
\hline & & & & & Ship the 29 car & nisters off to WIPP & ver another \\
\hline 1156 & TOTAL $=38$ months ( 3.2 years) & 808 & & & 2 months $(0.2)$ & years) & \\
\hline & & & & & & & \\
\hline \multirow{2}{*}{\multicolumn{8}{|c|}{ Assume 1.0 year of operation over a 1.5 year (18.0 month) span producing 808 total canisters. }} \\
\hline & & & & & & & \\
\hline \multirow{2}{*}{\multicolumn{8}{|c|}{$\begin{array}{l}\text { Assumes a } 2 \text { month shutdown imposed by WIPP after } 4 \text { months of initial operation, not adding time to the overall schedule (see next assumption) } \\
\text { Assume that during the WIPP induced shutdown a major maintenance turnaround occurs (the only one) of six months total. } \\
\text { Assume that } 2 \text { months into the shutdown WIPP authorizes shipment, which can be done without out reducing rate during the maintenance turnaro }\end{array}$}} \\
\hline & & & & & & & \\
\hline \multicolumn{8}{|c|}{\begin{tabular}{l|l|l} 
Overall schedule is 4 months up, 6 down, 8 up for 18 months total. & \\
\end{tabular}} \\
\hline & & canisters & $\begin{array}{l}\text { Calendar days } \\
\text { "up" }\end{array}$ & $\begin{array}{l}\text { canisters/ } \\
\text { operating day }\end{array}$ & $\begin{array}{c}\text { canister per } 7 \\
\text { day week }\end{array}$ & $\begin{array}{l}\text { Idaho net } \\
\text { accumulation/day }\end{array}$ & $\begin{array}{l}\text { Idaho net } \\
\text { accumulation/week }\end{array}$ \\
\hline & & 808 & 365 & 2.2137 & \begin{tabular}{|l|l|l|l}
15.50 \\
\end{tabular} & 1.36 & 9.50 \\
\hline & & & 1.0 year & & & & \\
\hline 122 & days (4 months) up w/o shipment - produce & 269 & ship & 0 & store & 269 & \\
\hline 61 & days (2 months) down w/o shipment - produce & 0 & ship & 0 & store & 269 & \\
\hline & & & & & & & \\
\hline 122 & days (4 months) down w/shipment - produce & 0 & ship & 100 & store & 169 & \\
\hline & & & & & & & \\
\hline 243 & days (8 months) up w/shipment - produce & 539 & ship & 200 & store & 508 & peak storage need \\
\hline & & & & & Ship the $508 \mathrm{ca}$ & anisters off to WIPP & over another \\
\hline 548 & TOTAL $=18$ months ( 1.5 years) & 808 & & & 21 months $(1.7$ & years) & \\
\hline & & & & & & & \\
\hline \multirow{2}{*}{\multicolumn{8}{|c|}{$\begin{array}{l}\text { Assume treatment rate matched to the shipping rate to WIPP to minimize lag storage. } \\
\text { Calculates out to be } 2.7 \text { years of operation over } 43.3 \text { months (3.6 years) producing } 808 \text { total canisters. }\end{array}$}} \\
\hline & & & & & & & \\
\hline \multicolumn{8}{|c|}{\begin{tabular}{|l|l|l|} 
Assumes a 5 month shutdown imposed by WIPP after 1 month of initial operation, adding 5 months to the overall schedule. \\
\end{tabular}} \\
\hline \multirow{2}{*}{\multicolumn{8}{|c|}{ Overall schedule is 1 month up (for minimal production \& hence storage), 5 down, 17 up, 6 down, 14.3 up for 43.3 months total. }} \\
\hline & & & & & & & \\
\hline & & canisters & $\begin{array}{l}\text { Calendar days } \\
\text { "up" }\end{array}$ & $\begin{array}{l}\text { canisters/ } \\
\text { operating day }\end{array}$ & $\begin{array}{c}\text { canister per } 7 \\
\text { day week }\end{array}$ & $\begin{array}{l}\text { Idaho net } \\
\text { accumulation/day }\end{array}$ & $\begin{array}{c}\text { Idaho net } \\
\text { accumulation/week }\end{array}$ \\
\hline & & 808 & 984 & 0.8219 & \begin{tabular}{|l|l}
5.75 \\
\end{tabular} & 0.00 & 0.00 \\
\hline & & & 2.7 years & & & & \\
\hline 30 & days (1 month) up w/o shipment - produce & 25 & ship & 0 & store & 25 & peak storage need \\
\hline 152 & days (5 months) down w/o shipment - produce & 0 & ship & 0 & store & 25 & peak storage need \\
\hline & & & & & & & \\
\hline 517 & days (17 months) up w/shipment - produce & 425 & ship & 425 & store & 25 & peak storage need \\
\hline 183 & days (6 months) down w/shipment - produce & 0 & ship & 25 & store & 0 & \\
\hline
\end{tabular}




\subsection{SR Major Options}

1. In an attempt to meet the 2012 milestone the SR waste product packaging portion of the SR treatment facility could be eliminated and the SR waste product could be sent to bulk storage in Bins Sets 7 or 6 and 7. Bin Set 7, currently unused and uncontaminated, could hold the entire volume of SBW SR waste product if isolation from the existing HLW calcine was wanted. (Isolation would allow "straddling" the WIR issue; if a favorable decision were to be made at a later date that SBW is not HLW, independent retrieval and packaging of SBW SR material for WIPP and HLW calcine for the NGR would be possible. Conversely, if SBW were to be ruled to be HLW this SR waste form could pose additional problems. It would have both different chemical and physical properties than the existing HLW calcine. For "as-is" disposal at the NGR this material would most likely require additional modeling and other environmental assessments to prove its acceptability. If treatment of Idaho's HLW were to be required, this SR material would be another feed stream to this process and would complicate the design and operation of the treatment system as well as the waste form qualification program.) Bin Set 6 could not hold all of the SR waste product (only 50-80\%) thus necessitating the use of Bin Set 7 in any case not involving packaging or shipment.

This option would result in significant near term cost savings of $\sim \$ 200 \mathrm{M}$ assuming the SR packaging system would be of similar design as the Calcine Packaging Facility (CPF) in the CMACT SBW treatment alternative. There might be some additional technical risk to this option since long-term storage and retrieval properties of the SR waste product are unknown (and would vary with the different SR processes). This could result in schedule savings of $\sim 10-14$ months, which could enable meeting the 2012 milestone even for the 2.5 year treatment base case. This option also would not place the SBW waste into a final packaged, shippable state thus deferring these costs to a future date. Also, contaminating Bin Set 7 would incur additional differed costs of \$20-25 M in 2004 dollars for a retrieval system (differential cost per bin set) and \$10-12 M in 2004 dollars for its ultimate $\mathrm{D} \& \mathrm{D} / \mathrm{Closure}$. If this option were to be chosen, it might be beneficial for the retrieval system for Bin Set 7 to be designed and installed before it is contaminated to minimize future costs and radiation exposure.

2. An option within the baseline concept (i.e., including waste packaging and shipment) would be to separate the SR product capture, packaging, interim storage, and load-out system from the rest of the treatment system, similar to the CPF in the CMACT alternative, and start treatment of the SBW before the product packaging system is complete. Environmental permitting, mostly concerned with the off-gas treatment system design, is the critical path at the front end of the project, while construction of the packaging and related systems would be critical path for the remainder of the schedule. Design, construction, and permitting of the SR packaging facility could be de-coupled from the rest of the project - the fluidized bed system including the feed tanks and Tank Farm mixer installation and the off-gas treatment system. The schedule for this core treatment system could be pushed aggressively (design and permit submittal for this system alone could be done faster than for the full project) in order to get SBW treatment started as soon as possible. The newly formed SBW SR waste product could be sent to Bin Set 6 for up to 2 years while construction and testing of the packaging facility is completed. (A layer of dolomite or other inert material could be put into Bin Set 6 in an attempt to separate SR waste product from HLW calcine for future selective retrieval.) SBW SR waste product would stop being sent to Bin Set 6 once it was full or when the packaging facility is ready for use to package out SBW SR waste product for disposal at WIPP. In this plan, Bin Set 7 would not be used or contaminated so as not to trigger those costs. There would be additional cost impacts to this approach since separate facilities would be required. However, it could be kept to a minimum with proper design and project management to allocate and share resources between the two separate projects. The main advantage is schedule savings of 
$\sim 10$ months, which could enable meeting the 2012 milestone even for the 2.5 year treatment base case. There would also be some additional deferred costs, unquantifiable at this time, for different handling and packaging (WIPP canister vs. Yucca canister) of SR waste product upon retrieval at a later date. This also assumes that both the existing HLW calcine and SBW SR waste product would be retrieved from the bins and that there would be little or no differential cost to retrieve the SR waste product from Bin Set 6. A potential issue is questions about the effectiveness of the SR waste/HLW calcine buffer layer and the ability to selectively retrieve these layers of particulate solids at a later date, which is dependent on the condition of both materials in the bins (agglomerated to any extent or not) and the methods used for retrieval.

3. A second option within the baseline concept would be to slow down treatment to match the RH receipt/disposal rate at WIPP in order to minimize the size of lag storage in Idaho or eliminate it all together. In conjunction with this, a decision could be made not to proceed with treatment while WIPP reviews the overall process/program prior to authorizing initial shipment. This would additionally save the assumed four months of lag storage of waste produced "at risk" in the early stage of treatment. The two steps combined would save approximately $\$ 30 \mathrm{M}$ in capital project costs but add 12 months to the 2.5 year schedule and 32 months to the 1 year schedule, both well beyond 2012.

4. A final major option would be to retrofit the steam reforming system inside the NWCF. This has not been assessed to any extent but it would involve major modifications to the contaminated systems in the hot cells of the NWCF. Extensive changes would be required to the feed preparation system and the fluidized bed (calciner vessel) itself would most likely have to be replaced. The benefits to this approach would be: (1) re-use of the hot cells of the NWCF for possible schedule savings (especially if packaging system design and construction was de-coupled from the process or not required; i.e., bulk storage in the Bin Sets), (2) re-use of some existing utilities, and (3) a good central "fit" for the process - the best possible access to the SBW feed, possible re-use of the first few unit operations involved in off-gas treatment and line tie-ins and a route west out the main INTEC stack, and line tie-ins and a route east to either the Bin Sets or the best possible location for a particulate packaging facility that could serve both SBW SR product and future retrieved HLW calcine. The possible negatives include (1) high radiation exposure required for the in-cell modifications; much higher than that for the CMACT SBW treatment alternative, (2) multiple facilities would be necessary which most likely could result in higher costs even with re-use of the NWCF cells and equipment, and (3) possible throughput limitations (and hence negative schedule impacts) if re-use of the NWCF off-gas treatment equipment or utilities turned out to be limiting. It is not likely that this option would be beneficial, on balance, especially considering the radiation exposure cost.

\subsection{SR References}

Barnes C. M., A. L. Olson, D. D. Taylor, (2004a), Sodium-Bearing Waste Treatment Technology Evaluation Report, INEEL/EXT-04-01692, February 2004.

Barnes C. M., C. B. Millet, (2004b), Feed Composition for the Sodium-Bearing Waste Treatment Process, INEEL/EXT-2000-01378, Revision 4, June 2004.

Barnes C. M., S. K. Janikowski, C. B. Millet, (2003), Feed Composition for the Sodium-Bearing Waste Treatment Process, INEEL/EXT-2000-01378, Revision 3, September, 2003. 
Batcheller, D. D. Taylor, V. J. Johnson, (2003), Characterization of Tank WM-189 Sodium-Bearing Waste at the Idaho Nuclear Technology and Engineering Center, INEEL/EXT-02-01171 Rev. 1, July 2003.

Del Debbio, J. A., T. L. Watson, J. B. Heintzelman, (2003), Long-Term Performance of SulfurImpregnated, Granulated Activated Carbon (GAC) for Mercury Removal From NWCF Off-Gas, INEEL/EXT-03-01102, September, 2003.

DOE, (1999) “Advance Notice of Proposed Rulemaking; Potential Revisions to the Land Disposal Restrictions Mercury Treatment Standards,” United State Government Memorandum, June 7, 1999.

Durante, R., (2003), Preliminary Hazard Evaluation for the Calcination with Maximum Achievable Control Technology Upgrade - SBW Treatment Alternative, INEEL/INT-03-00321, June 2003.

Envirocare, (2001), "Envirocare Successfully Treats NFS Mercury Waste," http://envirocareutah.com/pages/ecnews/ec_successfully_NFS.html.

Herbst, A. K., J. A. Del Debbio, R. J. Kirkham, B. A. Scholes, T. L. Watson, (2002), Idaho Nuclear Engineering Center Sodium-Bearing Waste Treatment Research and Development FY-2002 Status Report, INEEL/EXT-02-00985, September, 2002.

Hulet, G. A., V. C. Maio, M. I. Morris, "Demonstrations to Support Change to the $>260$ ppm Mercury Treatment Regulations,” WM'01 Conference, February 25 - March 1, Arizona.

Marshall, D. W., and N. R. Soelberg, (2003a), TWR Bench-Scale Steam Reforming Demonstration, INEEL/EXT-03-00436, May 2003.

Marshall, D. W., and N. R. Soelberg, (2003b) TWR Bench-scale Steam Reforming DemonstrationProprietary Addendum, INEEL/EXT-03-00436a, May 2003.

Marshall, D. W., N. R. Soelberg, and K. M. Shaber, (2003c), THOR ${ }^{\mathrm{sm}}$ Bench-Scale Steam Reforming Demonstration, INEEL/EXT-03-00437, May 2003.

Merrick \& Company, (2004), Calcination with MACT Upgrade Feasibility Study Report, Project No. 10014501-01, January 23, 2004.

Morrell, D. K., "Mixing Pumps for Homogenizing TFF-SBW Liquids and Solids - Calcination with MACT Upgrade SBW Treatment Alternative,” Engineering Design File EDF-3307, April 24, 2003.

Soelberg, N. R., D. W. Marshall, S. O. Bates, and D. D. Taylor, (2004a), Phase 2 THOR $^{\mathrm{sm}}$ Steam Reforming Tests for Sodium-Bearing Waste Treatment, INEEL/EXT-04-01493, January 30, 2004.

Soelberg, N. R., D. W. Marshall, S. O. Bates, and D. D. Taylor, (2004b), Phase 2 TWR Steam Reforming Tests for Sodium-Bearing Waste Treatment, INEEL/EXT-04-01494, January 2004.

Soelberg, N. R., "MACT Compliance for the 'Calcination with MACT Upgrade' Alternative," Engineering Design File EDF-3311, September 26, 2003. 
Stoller Corporation, S. M., (2003), "Preliminary Hazard Evaluation of All Sodium Bearing Waste Preliminary Process Design and Treatment Options," January 21, 2003.

Williams, C. L., R. A. Wood, B. L. Blakely, and W. H. Landman, Feasibility Study Report for Treatment of Sodium-Bearing Waste by Steam Reforming (Draft), INEEL/EXT-02-1211, Rev. A.

WIPP, (2002a), Safety Analysis Report for the RH-TRU 72-B Waste Shipping Package, November, 2002, http://www.wipp.carlsbad.nm.us/library/RHsar/rhsar/rhsartoc.pdf.

WIPP, (2002b), Remote-Handled TRU Waste Acceptance Criteria for the Waste Isolation Pilot Plant, DOE/WIPP-02-3123, draft, June 2002.

Wood, R. A., (2002), "Heel Solids Processing Evaluation for the SBW Treatment Project - Calcination with MACT Upgrade Alternative,” Engineering Design File EDF-3049, December 4, 2002. 


\section{DIRECT EVAPORATION (DE)}

The baseline process scenario for this SBW treatment alternative involves design and construction of a new evaporation system fed from the existing Tank Farm tanks provided with new mixing pumps to suspend and mix the tank solids with the liquid SBW for co-processing (see Figure 3-1). It involves a new off-gas treatment system close-coupled to the evaporator and construction of an evaporator waste product packaging system for packaging, cooling, and interim storage of the DE waste product, all located in one common new facility.

The direct evaporation process ues an evaporator to remove enough water and nitric acid from SBW that the concentrate will solidify upon cooling. Several variations of the process are possible, differing in how the removed water and nitric acid are processed. These variations are discussed in more detail in the SBW Treatment Technology Evaluation Report (Barnes 2004) and the Direct Evaporation Process Design EDF (Barnes 2003a). Most issues discussed below are common to all variations of the process; those that are unique to one variation will be identified as such.

The three major variations of the process include:

1. Fractionating the evaporator condensate in the existing LET\&D facility, then neutralizing and grouting the concentrated acid.

2. Fractionating the evaporator condensate in the existing LET\&D facility, then neutralizing and recycling the acid to the SBW evaporator

3. Neutralizing the SBW evaporator vapor in an alkaline scrubber and purging the scrub to the SBW evaporator feed.

While a cost and benefit comparison of these three schemes has not been performed, the condensate fractionation, neutralization, and recycle scheme has advantages of lower risk. It uses a proven facility, the LET\&D, to process off-gas condensate rather than an alkaline scrubber, which has not been tested for this specific use. And in contrast to the acid grouting scheme, it requires no grouting operations, both simplifying the overall process and eliminating a major waste stream.

\subsection{DE Physical Systems - Process/Technical and Related}

\subsubsection{DE Technical Risks Related to Off-Gas and Emissions}

Emissions from the direct evaporation process are low, and all major issues can be addressed by design features.

Three off-gas streams are generated by the direct evaporation process - a vent gas, a process gas, and the LET\&D vapor. ${ }^{\mathrm{b}}$ The LET\&D vapor is by far the largest of these three streams. Modeling predicts that the LET\&D vapor will be $99.99 \%$ steam, with the balance being nitric acid and $\mathrm{HCl}$. Emission rates are estimated to be about $0.2 \mathrm{lb} / \mathrm{hr}$ nitric acid and $0.1 \mathrm{lb} / \mathrm{hr} \mathrm{HCl}$ (see Appendix C of Barnes 2004). The other two off-gas streams consist mostly of air from in-leakage, sparging tanks, instrument purges, and vacuum pump control. The off-gas streams will be HEPA filtered to ensure no release of entrained hazardous or radioactive contaminants.

b. For the alkaline scrub option, only two off-gas streams are generated (vent gas and process gas), which includes the equivalent of the LET\&D vapor. 

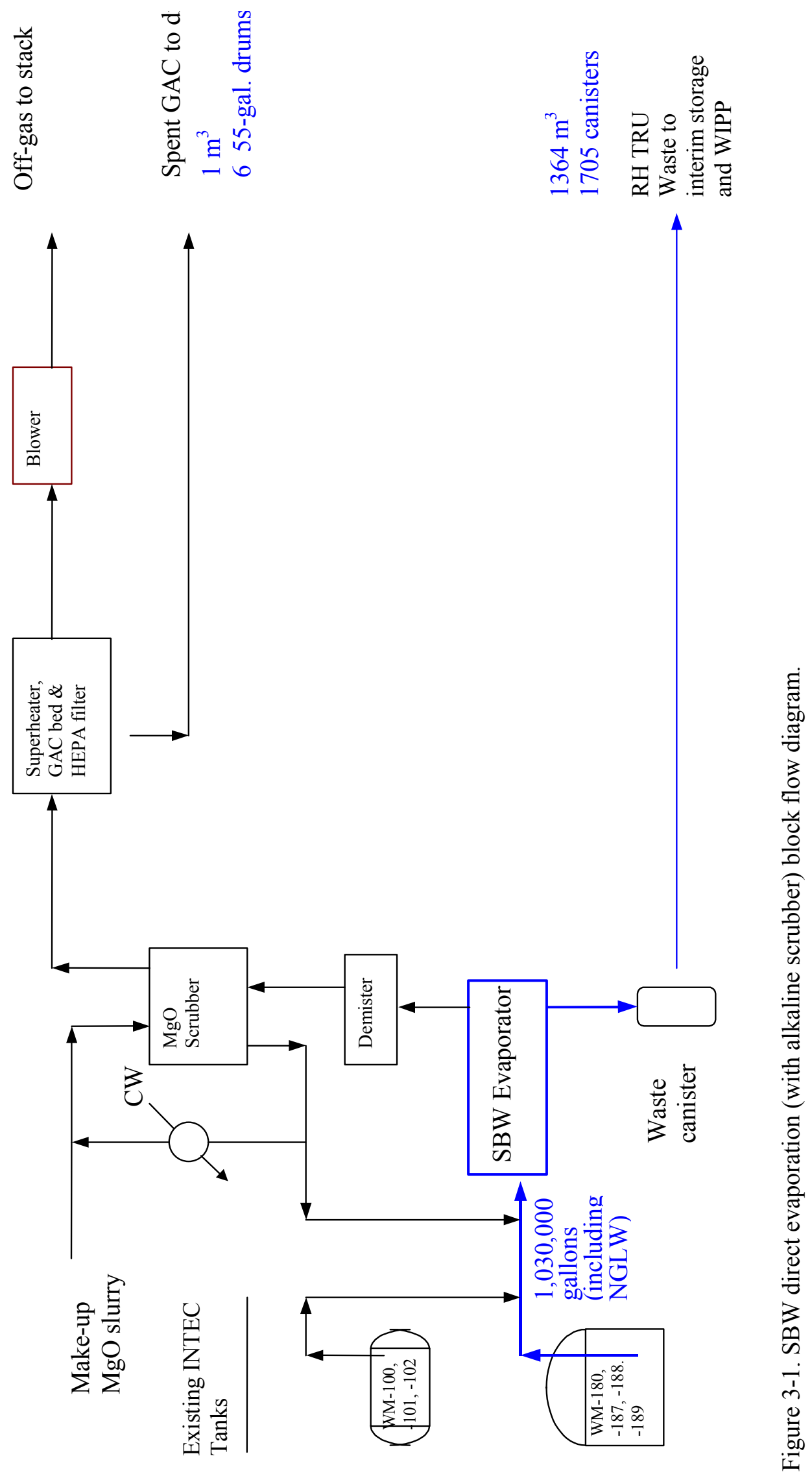
Three series of pilot tests have shown that the evaporator vapor can be totally condensed at a temperature of $85^{\circ} \mathrm{C}$ or less (Griffith 2003a; Griffith 2003b; and Griffith 2004). Analysis of noncondensible off-gas was also attempted for model-scale (in-can) and flask-scale direct evaporation tests (Kirkham 2004). These analysis showed concentrations of as much as 6 vol $\% \mathrm{~N}_{2} \mathrm{O}$, small concentrations of $\mathrm{NO}$, and no $\mathrm{NO}_{2}$ in the noncondensible gas (Kirkham 2004). While uncertainty remains about the exact composition of this noncondensible gas, its rate has been shown to be so small that the risk of exceeding any emissions limit is very low.

Pilot tests have shown $\mathrm{NO}_{\mathrm{x}}$ concentrations in the headspace of waste product containers initially start from 200-2000 ppm and fall to zero as the product cools. In a full-scale facility, the canister would be connected to a vent system during cooling, and any vapors combined with other off-gas streams. Although uncertainty remains in the amount of $\mathrm{NO}_{\mathrm{x}}$ released during cooling, the inclusion of this $\mathrm{NO}_{\mathrm{x}^{-}}$ containing canister vent gas with other off-gases is expected to have a negligible effect on its total composition.

SBW contains small concentrations ( 0.2-1 g/liter) of organics (Barnes 2003b). Because the present waste has been previously concentrated by evaporation, any remaining organics in SBW have low volatility. The behavior of these organics during direct evaporation is not known. Should any hazardous organics volatilize or semivolatile organic compounds decompose to more volatile forms, an additional off-gas treatment step, such as a carbon bed, may be required to prevent release of hazardous organics.

The alkaline scrubber scheme does not totally condense the SBW evaporator vapor, and hence mercury is expected to be present in the off-gas at measurable concentrations. A granulated activated carbon (GAC) bed is included in this scheme to remove mercury from the off-gas.

\subsubsection{DE Technical Risks Related to Waste Product Qualification and Characteristics}

\section{Most uncertainties related to waste product qualification are very low risk; others will require additional interaction with WIPP and demonstration tests to resolve.}

Radiolytic hydrogen generation in the SBW evaporator waste product canisters is uncertain. The WIPP RH-TRU 72-B Cask Safety Analysis Report requires that hydrogen concentrations in all void spaces within a 72-B shipping cask be less than 5 vol\% (WIPP 2002a). Compliance can be demonstrated by measuring either a hydrogen generation rate or decay heat value or by calculating either of these using conservative assumptions. Calculations for both of these methods depend on the waste code of the particular waste stream. The waste code for direct evaporation waste has not been established. However, preliminary calculations have been done to estimate how much water is allowable in SBW solids wastes. Given the radionuclide content of the waste, the rate of hydrogen generation in the waste product canister depends primarily on its water content. Mass balances show a water content of 22-33 wt\% (Barnes 2004), and pilot-scale test data show 27-33 wt\% (Griffith 2004), based on taking the difference between feed and condensate. Wendt (2003) modeled hydrogen generation from SBW solids dried to different levels and recommended removal of water to less than $20 \mathrm{wt} \%$. However, Wendt also reported that nitrates present in the waste could inhibit hydrogen generation and allow water in excess of $35 \mathrm{wt} \%$ to be present. The issue of hydrogen generation in the direct evaporation waste product is hence not resolved and requires tests with actual SBW.

Related to the issue of hydrogen generation is pressure buildup. The total gas pressure in the 72-B cask must be less than 50 psig (WIPP 2002). Waste canisters will be vented during cooling and the storage facility could be designed for venting during storage or prior to loading into a cask if needed. Based on experience opening sealed waste containers from evaporator tests, a pressure buildup is not expected. However, data to substantiate this claim has not been obtained. 
The SBW evaporator waste is deliquescent and will form liquid under humid conditions. When product samples from various direct evaporation tests were subjected to 50-70\% relative humidity, weight gains of up to $80 \%$ were seen (Kirkham 2004). However, when the humidity was then reduced to $25 \%$, the samples quickly lost most or all of the mass gained. No further mass gain was seen as the relative humidity was then increased in steps to $40 \%$ over 500 hours. These tests demonstrated that liquid would form in the waste containers if they experience very humid conditions. However, if the relative humidity is kept below about $30 \%$, deliquescence by the waste will not occur.

The effect of headspace gas on cask seals is not known. Sampling of the head space of cooled waste drums has shown that the head space gas contains levels of $\mathrm{NO}_{\mathrm{x}}$ of up to $100 \mathrm{ppm}$, and if the drum is purged with air and resealed, the $\mathrm{NO}_{\mathrm{x}}$ will return to approximately the same level within days (Griffith 2004). A specific limit for $\mathrm{NO}_{\mathrm{x}}$ in the headspace has not been determined but the issue has been raised because of the possible effect it could have on the o-rings used in the 72-B shipping cask. Should the head space gas prove corrosive to cask seals, engineering solutions could be evaluated, such as venting or purging the canisters until head space gas becomes noncorrosive or adding a "getter" on top of the waste to absorb corrosive species.

Whether requirements for waste carrying the U134 hazardous waste number will be met without process modifications are not clear. The SBW carries the U134 hazardous waste number (hydrofluoric acid), although the waste also contains more than an adequate amount of aluminum to complex all fluoride ions. The evaporator product waste will thus also carry this hazardous waste number. In response to an INEEL question about disposal of this type of waste at WIPP, Celeste Marsh of WIPP said that "Acidic waste carrying the U134 hazardous waste number must be neutralized and contain no residual liquid prior to disposal at WIPP (Hotline response ID \#251).” Further discussion with WIPP personnel clarified that neutralization to a $\mathrm{pH}$ greater than 2 would be acceptable, and information demonstrating neutralization would be required. Whether WIPP will accept arguments that complexing HF in SBW with aluminum is equivalent to neutralization, or that neutralization and recycle of LET\&D bottoms acid is equivalent to neutralization of the SBW, is uncertain. The other alternative to meet this requirement, partial neutralization of the evaporator feed, is likely feasible, although its affects on evaporator performance and evaporator waste product characteristics have not been determined. Additional discussion of this issue is found in Appendix A of the WIPP Waste Certification Strategy for the SodiumBearing Waste Treatment Project (Bosley 2003).

The effect of actual undissolved solids in the waste on the product properties is uncertain. In 2003, pilot tests were performed using different solids added to an SBW simulant (Griffith 2003b). The solids included $2 \mu \mathrm{m}$ silica added in an amount equivalent to $5 \mathrm{wt} \%$ of the feed, $5 \mathrm{wt} \%$ kaolin clay, $5 \mathrm{wt} \%$ zirconium phosphate, $5 \mathrm{wt} \%$ of a composite of the previous three solids, and $3 \mathrm{wt} \%$ of the composite. These solids were intended to be similar to waste solids either physically (particle size) or chemically, but inadequate tank solids characterization and solids simulant development work had been performed at the time to define solids that more closely matched actual tank solids. However, water-free evaporator products were generated with all of the types of solids used (Griffith 2003b). Because of these results, and because the properties of the solids used should overlap those of actual tank solids, the risk of actual solids affecting product properties, to the extent it would affect waste disposal, is negligibly small. The primary effect the solids could have on the product is its water content, which can be controlled by changing the extent of evaporation.

The effect of trace chemical species in the waste on the product properties is uncertain. The three series of evaporator pilot tests (Griffith 2003a, Griffith 2003b, and Griffith, 2004) all used SBW simulants that contained 12-16 chemical species. The actual waste contains many more species, and the effect that these other species will have on the product properties is not known. However, because these other species are all present at very low concentrations, their effect on the product should be small. Also, 
nearly all waste acceptance criteria relate to radiological properties of the product, which are not affected by the untested trace chemical species. And the primary property that could be affected, the presence of liquids can be corrected, if needed, by changing evaporator operating parameters.

The WIPP Waste Acceptance Criteria for RH has not been issued. The Waste Isolation Pilot Plant (WIPP) has prepared a draft Waste Acceptance Criteria (WAC) document for remote-handled (RH) waste (WIPP 2002b), but the document is not final. Additional requirements for RH TRU waste are contained in the RH-TRU 72-B Cask Safety Analysis Report (SAR) (WIPP 2002a). Until the RH-WIPP WAC is issued, there will be uncertainty regarding the disposal requirements for evaporator waste. Working closely with WIPP during all phases of the project should mitigate this risk.

\subsubsection{DE Risks Related to Feed Uncertainties and Feed Transfer}

\section{While uncertainties exist in the composition of the waste that will be fed to the direct evaporation process, the success of tests performed, along with certain design features, provides confidence that all the SBW and NGLW can be successfully treated by the direct evaporation process.}

Present Tank Farm management plans call for consolidation of all SBW into three tanks (WM-187, WM-188, and WM-189) by the end of CY 2004. Additional waste generated in 2005 would continue to be added to WM-187 and WM-188, and then from 2006 on, segregated in separate, smaller tanks (WM100, WM-101 and WM-102). Waste in one Tank Farm tank, WM-189, was sampled and analyzed in 2002 (Batcheller 2003), and its composition is not expected to change prior to treatment. While changes are expected in the contents and composition of waste in WM-187 and WM-188, waste to be sent to these tanks has been sufficiently well characterized to have high confidence in the predicted compositions for the liquid in these tanks (as documented in Barnes 2004b).

Most of the solids ( $>85 \%)$ contained in the Tank Farm will be in consolidated in Tank WM-187. The solids in this tank were sampled and analyzed in February 2004. Since solids in Tank WM-187 have not been well mixed, the recent analysis may not be representative of all the solids in the tank. Analyses of solids samples from other tanks that were flushed to WM-187 provide a basis to estimate the range of solids composition in the tank. The uncertainty in the solids composition is not as important to the design as several other issues related to the solids.

The solids must be homogeneously mixed in one or more tanks. Mixing pumps will need to be installed in WM-187, and possibly other tanks, in order to characterize the feed for process control and waste qualification purposes and provide a homogeneous feed to treatment using the existing steam jets. The mixing pumps will need to be installed through the existing 12-inch diameter tank risers. Studies of mixing pumps (Wood 2002 and Morrell 2003) recommend mock-up testing of the tank mixing pumps to demonstrate performance. Proceeding into construction without demonstration tests of these pumps would risk schedule delays and additional costs should the pumps need to be redesigned and/or additional equipment installed to achieve a homogeneous liquid/solids feed to the treatment facility feed tanks.

A solids-blending scheme needs to be defined. A scheme for blending tank solids was defined based on four SBW feed tanks (Wood 2002; and Barnes 2003b), but with the recent decision to consolidate SBW into three tanks, a new scheme is needed. Current estimates indicate that if distributed evenly, Tank WM-187 will have between 65 and 120 grams undissolved solids per liter (Barnes 2004b). The higher end of this concentration range risks settling of solids in the transfer lines from the Tank Farm to the treatment facility. But to minimize the load of solids on the evaporator and produce a product more consistent in properties, a lower concentration of solids, constant throughout processing all of the waste, is desirable. Barnes (2004b) suggests two schemes, each involving the installation of mixing pumps in 
two tanks and lowering the undissolved solids content of the feed to $20-40 \mathrm{~g} /$ liter. Whatever solids blending scheme is proposed, it should ensure that the waste is transferred to the NWCF without solids settling in the transfer lines, provide a somewhat uniform solids concentration in all or most of the SBW, and minimize the effect of the uncertainty in the total amount of solids contained in the Tank Farm tanks.

Incorporation of NGLW into the tank-blending scenario would also eliminate risks due to uncertainties in NGLW volume and composition. The expected total volume of NGLW is small relative to SBW $(\sim 8 \%)$, but planning for separate NGLW evaporation would risk not being able to qualify the product waste as well as potentially needing to develop a different set of operating parameters due to differences in the NGLW composition compared to SBW. The radionuclide content of future NGLW is highly uncertain, yet if blended with the entire inventory of SBW, the effect of this uncertainty is minimal.

\subsubsection{DE Risks Related to the SBW Evaporator Performance}

All concerns regarding the evaporator performance, except for corrosion, have been in large part resolved by test results. The issue of corrosion can be addressed by testing or conservative design selections.

Prior to testing, concerns related to evaporator performance included (a) potential fouling of heat transfer surfaces, (b) potential plugging of the evaporator discharge, (c) control of the bottoms composition, and (d) potential corrosion of the evaporator discharge materials. Testing provided data that alleviates the concerns regarding the first three of these issues, but did not address the corrosion issue.

No evidence of fouling of heat transfer surfaces was seen in any of the pilot tests (Griffith, 2003a, Griffith 2003b, and Griffith 2004). However, the tests were of short duration (typically 0.5-3 hours) and the simulant did not include all species present in SBW. Longer tests with a more complete stimulant would be needed to completely resolve this uncertainty. However, based on the test results, the risk of heat surface fouling is low.

During the three pilot test series, two instances of plugging of the evaporator were seen (Griffith 2003a; Griffith 2003b; and Griffith 2004). One of these cases was attributed to waste that had solidified in the evaporator during a prior run. Given that one of the goals of the tests was to define the limit for the extent of evaporation, the fact that not more cases of plugging were seen indicates that this will not be a significant issue in a full-scale plant. A larger scale evaporator, operating within limits determined by the pilot tests, should have a very low risk of plugging. In addition, an operating procedure was worked out during the pilot tests of rinsing the evaporator discharge that will also minimize the risk of plugging.

Control of the bottoms composition ensuring that the product will contain no liquid upon coolingis critical in producing an acceptable waste product. In most of the pilot tests, the bottoms composition was controlled by establishing a constant feed rate and adjusting the steam pressure/temperature to achieve the desired condensate production rate. Data from the tests showed a linear correlation between the bottoms temperature and fraction evaporated. Once this correlation is determined for a specific feed composition, temperature can be used to control the bottoms composition.

The concentrated waste exiting the evaporator will be corrosive due to high concentration of acid and chlorides. Materials testing has been recommended to identify a material of construction for the evaporator and connecting line to the waste canister that will have an acceptable corrosion rate during the lifetime of the processing facility. In lieu of these tests, the short duration of treatment, the inclusion of a spare evaporator, and conservative selection of materials and corrosion allowance would mitigate the risk of this uncertainty. 


\subsubsection{DE Risks Related to Evaporator Product Packaging}

A detailed design has not been developed for the canister handling, filling, and cooling systems, leaving open issues that may need to be resolved by performing mock-up tests.

Initial concepts for canister handling and filling have been defined (Barnes 2004a, and Kimmitt 2003), but the details of these systems have yet to be determined. The design will need to:

- $\quad$ Ensure that product falls from the high-vacuum evaporator outlet into the canister.

- $\quad$ Ensure that the product does not prematurely solidify and cause flow restrictions or plugs.

- $\quad$ Ensure canisters do not overfill with waste.

- Control contamination present in liquid, gaseous, and solid waste during filling, during the time canisters are moved into the fill position, during the time canisters are moved out of the fill position, during the cooling operation, and during capping.

- $\quad$ Provide for waste off-gassing during filling and cooling.

- $\quad$ Provide for canister capping, contamination assay, and decontamination.

Once a design has been proposed, mock-up testing may be needed to confirm the performance of the design and provide a basis for final design.

Product cooling-rate data was collected during the last series of pilot tests (Griffith 2004), but uncertainty remains in the time requirement to cool waste in canisters. Modeling of product cooling using the test data may help determine this time requirement that would then be used to design the cooling area in the treatment facility. If a mock up of the canister fill system is built and tested, verification of cooling rates of waste in canisters could also be obtained.

\subsubsection{DE Risks Related to Off-gas Treatment}

As mentioned at the beginning of this section, three different methods could be used to treat the off-gas from the SBW evaporator: (1) a condensation, acid fractionation, and grouting scheme; (2) a condensation, acid fractionation, neutralization, and recycle scheme; and (3) an alkaline scrubber, GAC bed scheme. No risks related to off-gas treatment have been identified for the first two schemes. While alkaline scrubbers are commonly used in the chemical process industry, test data would be needed for this specific application to ensure performance. The testing would develop a basis for the design, including answering the following:

- What removal efficiencies can be achieved for $\mathrm{HNO}_{3}, \mathrm{HCl}, \mathrm{HF}$, and $\mathrm{Hg}$ ?

- What form of $\mathrm{MgO}$ should be used?

- Do undissolved solids build up in the scrub liquid, and, if so, to what concentration? What are the optimum operating parameters $-\mathrm{L} / \mathrm{V}$ ratio, purge rate? 


\subsubsection{DE Risks Related to Use of and Upgrade of the LET\&D System}

There are uncertainties in modifications needed to be made to the LET\&D system in order to process the evaporator condensate. An initial review suggests that the only change needed is to change the feed tray. But a more thorough evaluation of processing the evaporator condensate, which has a much higher acid concentration than previous feedstock to the LET\&D facility, (the process effluent waste evaporator PEWE overhead) is needed to determine if other modifications in equipment or operating procedures would be required. This evaluation would include a review of the LET\&D metallurgy against the expected SBW evaporator condensate composition. Besides being more concentrated in acid the SBW evaporator condensate will be more concentrated in chlorides than the PEWE condensate, the normal feed to the LET\&D system.

\subsubsection{DE balance of plant requirements, facility siting, and interfaces}

A new boiler would be required to generate 150-psig steam for the SBW evaporator. Based on a 2.5 -year operating schedule, the boiler would need to generate approximately $600 \mathrm{lb} / \mathrm{hr}$ of steam.

Other existing utilities systems at INTEC are adequate to support the direct evaporation process (Kimmitt 2003).

Sampling requirements for the direct evaporation process have not been defined. However, because it was determined that existing INTEC analytical capabilities (RAL) were sufficient for the CMACT process, and because the direct evaporation process is a simpler process with fewer process streams, it's very likely the analytical capabilities of RAL would be sufficient for the direct evaporation alternative.

Adequate space is available for the new direct evaporation treatment facility on the north side of the existing Tank Farm facility (Kimmitt 2003). A new transfer line would be installed to connect the direct evaporation facility with the Tank Farm. For the schemes that use the LET\&D facility, new transfer lines would also be needed from the direct evaporation facility to and from the LET\&D facility.

\subsubsection{DE Safety Concerns}

No hazards analysis or safety analysis has been performed specifically for the direct evaporation process, although a preliminary hazard analysis (PHA) of various SBW treatment options was completed, including direct evaporation (Stoller 2003). In the PHA, 17 potential hazardous events were identified for the direct evaporation process, and for each event, design and administrative preventive and mitigative features were also identified.

With the exception of waste packaging operations, the steps in the direct evaporation are the same or similar to steps that have been safely performed at the INEEL for many years. Hazards are expected to be minimal compared to other SBW treatment alternatives. The maximum temperature in the process is $125^{\circ} \mathrm{C}$, which is within historical operating experience at INTEC and below the level of concern for "red oil" (trace nitrated organics) explosion initiation. No fuels are required except for the steam boiler. The only chemical additive used is magnesium oxide as either a neutralization agent or scrubbing agent. ${ }^{\mathrm{c}}$

A PHA was performed for the LET\&D facility (Lee 2003). The only nonroutine hazards identified in this analysis were as follows (from Lee, 2003, Table 2-7 of Lee 2003):

c. The variation of the direct evaporation process in which the LET\&D bottoms is grouted uses calcium hydroxide, blast furnace slag, and Portland cement as additives in the grouting process. 


\section{Hazard}

Hazardous materials

Radioactive materials

External events

Natural phenomena

\section{Concern}

Acid spill or acid vapor release

Process solution spill

Stack collapse or damage to the pipe bridge could release process solution

An earthquake could damage process vessels releasing process solution

The LET\&D hazards analysis determined that all possible hazardous events would have negligible consequences to the public and workers, and either negligible or low consequences to the environment (see Table 2-10 of Lee 2003).

\subsubsection{DE future Use Considerations}

NGLW will continue to be generated after 2012, although at a decreasing rate and possibly with decreasing radioactivity. Current projections indicate an annual generation rate decreasing from 4,400 to 3,100 gallons from 2012 to 2035 . The annual NGLW production could be processed in the direct evaporation treatment facility in about 2 days. Processing small batches is technically feasible, but maintaining the facility for only a few days operation per year may not be economical. However, present estimates of NGLW production do not include the decontamination of many INTEC facilities. The direct evaporation process would likely be able to process the liquid waste from closure of these INTEC facilities.

\subsubsection{DE Process/Technical Summary}

The following table presents a summary of the technical risks and issues for the direct evaporation process. The probability and impact values shown are on a scale of 1 to $10(1=$ low probability or impact $)$ and based on the author's judgment rather than any formal process or group evaluation. A probability of 5 is equivalent to a $50 \%$ chance that the identified risk would occur or uncertainty cause detrimental effects. The Resolution column presents a recommendation on how the issue should be resolved, usually either by evaluations during design or testing.

Table 3-1. Summary of technical issues and risks - direct evaporation (DE).

\begin{tabular}{|c|c|c|c|c|}
\hline & Risk or Issue & Probability & Impact & Resolution \\
\hline 1 & $\begin{array}{l}\text { The composition of noncondensible } \\
\text { gas from the evaporator is uncertain, } \\
\text { resulting in uncertain treatment } \\
\text { requirements and off-gas emissions }\end{array}$ & 3 & 2 & $\begin{array}{l}\text { During preparation of permit } \\
\text { application }\end{array}$ \\
\hline 2 & $\begin{array}{l}\text { Release of } \mathrm{NO}_{\mathrm{x}} \text { from waste in } \\
\text { canisters could add treatment } \\
\text { requirements }\end{array}$ & 3 & 6 & $\begin{array}{l}\text { During preparation of permit } \\
\text { application }\end{array}$ \\
\hline 3 & $\begin{array}{l}\text { Organics in SBW could volatilize in } \\
\text { the evaporator }\end{array}$ & 2 & 4 & Design evaluation \\
\hline
\end{tabular}




\begin{tabular}{|c|c|c|c|c|}
\hline & Risk or Issue & Probability & Impact & Resolution \\
\hline 4 & $\begin{array}{l}\text { The radiolytic hydrogen generation in } \\
\text { the product waste canisters is } \\
\text { uncertain and potentially could } \\
\text { exceed WAC }\end{array}$ & 5 & 10 & $\begin{array}{l}\text { Assign waste code and perform } \\
\text { calculations during design, } \\
\text { possibly followed by testing }\end{array}$ \\
\hline 5 & $\begin{array}{l}\text { Gas generation in the waste canisters } \\
\text { could possibly build up pressure in } \\
\text { the cask to a level exceeding that } \\
\text { allowable }\end{array}$ & 2 & 10 & Testing \\
\hline 6 & $\begin{array}{l}\text { Gas in the headspace of canisters } \\
\text { could possibly degrade cask seals }\end{array}$ & 3 & 6 & $\begin{array}{l}\text { Testing to determine effect on } \\
\text { seals of headspace gas }\end{array}$ \\
\hline 7 & $\begin{array}{l}\text { Treatment requirements relative to } \\
\text { the U134 hazardous waste number } \\
\text { carried by SBW are uncertain, and if } \\
\text { not resolved could lead to waste not } \\
\text { being accepted at WIPP }\end{array}$ & 3 & 10 & $\begin{array}{l}\text { Discussions with WIPP } \\
\text { personnel during design }\end{array}$ \\
\hline 8 & $\begin{array}{l}\text { The effect of tank solids on the } \\
\text { properties of the product waste is } \\
\text { uncertain, potentially requiring } \\
\text { adjustment of evaporator operating } \\
\text { parameters }\end{array}$ & 1 & 4 & $\begin{array}{l}\text { Testing with solids simulants } \\
\text { developed in } 2004 \text { could } \\
\text { resolve this; however risk is } \\
\text { very small }\end{array}$ \\
\hline 9 & $\begin{array}{l}\text { The effect of trace chemical species } \\
\text { in the SBW feed on the properties of } \\
\text { the product waste is uncertain, } \\
\text { potentially requiring adjustment of } \\
\text { evaporator operating parameters }\end{array}$ & 2 & 4 & $\begin{array}{l}\text { Testing with more complete } \\
\text { simulants developed in } 2004 \\
\text { could resolve this; however risk } \\
\text { is very small }\end{array}$ \\
\hline 10 & $\begin{array}{l}\text { Changes could be made in final WIPP } \\
\text { RH WAC }\end{array}$ & 5 & 5 & $\begin{array}{l}\text { Design and negotiation with } \\
\text { WIPP }\end{array}$ \\
\hline 11 & $\begin{array}{l}\text { Performance of mix pumps for TFF } \\
\text { tanks uncertain, with risk of varying } \\
\text { solids content in feed }\end{array}$ & 5 & 8 & Mock up testing of mix pumps \\
\hline 12 & $\begin{array}{l}\text { Tank blending scheme has not been } \\
\text { finalized }\end{array}$ & 5 & 5 & Design \\
\hline 13 & $\begin{array}{l}\text { NGLW generation rates and } \\
\text { composition uncertain and could } \\
\text { affect process }\end{array}$ & 3 & 2 & Design \\
\hline 14 & $\begin{array}{l}\text { The evaporator concentrate could } \\
\text { cause corrosion in the outlet and } \\
\text { transfer piping resulting in } \\
\text { component failure or downtime for } \\
\text { replacement }\end{array}$ & 6 & 6 & Materials testing \\
\hline 15 & $\begin{array}{l}\text { Basis for design and performance of } \\
\text { evaporator product packaging } \\
\text { equipment uncertain }\end{array}$ & 8 & 7 & Mock up testing of equipment \\
\hline
\end{tabular}




\begin{tabular}{|c|c|c|c|c|}
\hline & Risk or Issue & Probability & Impact & Resolution \\
\hline 16 & $\begin{array}{l}\text { Product cooling rate uncertain, } \\
\text { making design requirements for } \\
\text { product cooling uncertain }\end{array}$ & 5 & 4 & $\begin{array}{l}\text { Calculations during design, } \\
\text { with possible testing }\end{array}$ \\
\hline 17 & $\begin{array}{l}\text { The extent of modifications needed to } \\
\text { the LET\&D fractionator is uncertain }\end{array}$ & 4 & 4 & Evaluation during design \\
\hline
\end{tabular}

\subsection{DE Environmental/Regulatory and Related}

\subsubsection{DE Permitting}

\section{A 24-month permitting schedule, critical path early in the project schedule, appears to be the best that can be achieved.}

The baseline for the SBWT project identifies a 24-month permitting schedule, including the Hazardous Waste Management Act (HWMA) and Clean Air Act (CAA) permits. This may be optimistic, since discussions with the State of Idaho, Department of Environmental Quality (DEQ) in the spring of 2003 estimated 32-months to permit the SBWT project after receiving the HWMA and CAA permit modifications or applications. The project will need to work with the DEQ to streamline the permitting schedule. (The 32-month schedule was worked down to 24 months by taking time out of the operating contractor's activities only.)

The Direct Evaporation Facility will require CAA permits and HWMA permits. The direct evaporation unit will require a CAA Title V and PSD permits. The direct evaporation unit and product packaging and storage facility will need HWMA permits for hazardous waste activities. The direct evaporation unit may also need a site-specific risk assessment to address hazardous air pollutants (HAPs) and non-HAPs risk to human health and the environment not covered by PSD or Title V emission limits.

The following sections describe the permitting activities necessary for the direct evaporation treatment alternative.

The direct evaporation SBW treatment alternative consists of four parts to be permitted and constructed to treat the waste by the end of 2012: (1) Construction of the direct evaporation treatment unit and off-gas emissions treatment unit. The off-gas emission treatment unit would lower the amount and concentration of constituents emitted up the stack to meet Subpart AA, PSD and Title V Standards. (2) Construction of a new boiler to supply heat to the direct evaporation process. The boiler would be subject to permitting under the Clean Air Act PSD and Title V. (3) Construction of the direct evaporation product packaging and storage facility to collect and place the direct evaporation waste streams in containers for shipment to WIPP or a low-level disposal site. (4) Installation of mixing pumps in 2 or 3 Tank Farm tanks to produce homogeneous feed to the treatment process and enable solids-liquid co-processing.

3.2.1.1 Direct Evaporation Permitting. The direct evaporation treatment unit will generate emissions. These emissions will be similar to the PEWE, Volume 14 of the INEEL HWMA Permit, and will need to meet the requirements in 40 CFR 264 Subpart AA for organic emissions from evaporation units. The direct evaporation treatment unit and associated tanks and storage areas will be permitted under the HWMA regulations and the direct evaporator and boiler emissions will be permitted under the Clean Air Act, NESHAPS, PSD, and Title V. The direct evaporation product storage tanks, product packaging, and container storage will be permitted under the HWMA. Tanks and equipment in the NWCF, PEWE, 
LET\&D, which will provide support to the direct evaporation process, are permitted in Volume 14 or Volume 18 to the INEEL HWMA Permit.

3.2.1.1 Clean Air Act - New Emission Sources-The direct evaporation alternative identifies installation of a new boiler to provide heat for the evaporator. Boilers are considered to be new sources and require a new source review.

The New Source Review (NSR) Program is the primary mechanism for preventing facilities from causing or contributing to violations of National Ambient Air Quality Standards (NAAQS). NSR applies to what are known as "major" stationary sources, which are defined differently for attainment versus nonattainment areas. The INEEL is in an attainment area adjacent to a wilderness area (Craters of the Moon) and would be a Class 1 attainment area. The NSR program uses the preconstruction permitting process to control the construction of new major sources (and modifications to existing sources). In attainment areas, these preconstruction permits are referred to as prevention of significant deterioration (PSD) permits.

The project needs to determine if the emissions from the direct evaporation unit and boiler are minor new sources or major in a Class 1 attainment area.

The direct evaporation unit or boiler will be classified as a new major source unless emissions of pollutants are below the potential to emit 100 tpy of any PSD pollutant or any other source with potential to emit (PTE) of 250 tpy of any PSD pollutant. (See Table 3-2 at the end of this section.)

For a new major source, NSR applicability is relatively straightforward. Since the facility is not in operation, the baseline emissions are zero, and the emissions impact of the new facility is based on the PTE of all the new emission sources combined. If the new sources meet the applicability thresholds for PSD, the facility must complete the appropriate permit application, review, and approval process. In attainment areas, the applicability threshold is a PTE of 250 tpy, or 100 tpy for certain source types.

The PSD application process requires air monitoring and emission models, stringent pollution controls, estimates of regional emissions for each hazardous air pollutant, public involvement, and Federal Land Manager involvement near Class 1 attainment areas.

3.2.1.1. Title V Permit-The Title V Air Permit for the INEEL has been submitted to the State of Idaho DEQ for approval. The IDEQ is still reviewing the application and should issue a final permit by May 2005.

The Title V permitting sets forth the comprehensive State air quality operating permits program and emission limits. Sources subject to the operating permit requirements shall have a permit to operate that assures compliance by the source with all requirements. Of primary interest are emissions of radionuclides, organics, and nitrogen oxides. Table 3-2 at the end of the section identifies the list of constituents that need to be addressed in the permit modification.

The Title V permit identifies the NESHAPs emission limits, process controls, and emission control equipment for each source. New emission sources are added to the Title V permit through the permit to construct and the permit to operate. The permit to construct identifies the potential emissions and controls based on the facility design. The permit to operate is based on emission testing when the source is operating. Emission limits and controls are established for each source based on the emission testing. The emission limits and controls are then added to the Title $\mathrm{V}$ permit by modifying the permit to include the new source. 
The risk is that emissions from the direct evaporation unit and boiler or a combination of the INEEL sources will exceed the PSD or NESHAPs limits, requiring additional off-gas treatment to meet the emission limits. The risk is that NOx emission cannot be reduced below the visible range and the Federal Land Manager delays or opposes the air permits. The project needs to start early in the design to gather the information necessary to submit applications for the Title V permit, permit to construct, and new source review for PSD.

\subsubsection{HWMA Permitting.}

3.2.1.2.1 Direct Evaporation-Direct evaporation is a hazardous waste treatment unit subject to permitting under 40 CFR 264 Subpart X miscellaneous unit and Subpart AA emission standards. The direct evaporation facility could be added to the INEEL HWMA permit either as a class 2 modification to Volume 14 or as a separate application.

The direct evaporation processes the same waste in an evaporator similar to the PEWE and ETS systems permitted in Volume 14, and should present little risk related to permitting.

LET\&D is permitted in Volume 14 of the INEEL HWMA permit. Changes to the LET\&D needed to support this option should be added to the Volume 14 through a Class 1 permit modification.

If the final design results in significant changes to the direct evaporation facility or PPF, a permit modification would be required (e.g., tank size, number of tanks, tank location, cell dimension, etc.). The risk is that changes to the design during final design or construction could result in a permit modification approval before waste could be managed in the direct evaporation facility or PPF and delay the shipment of SBW. It is recommended that the project negotiate with the State of Idaho early in design to determine how changes will be handled during the application, final design, and construction stages of the project.

\subsection{Subpart AA Standards:}

The direct evaporation SBW treatment alternative would construct a new facility to house the direct evaporation treatment unit and off-gas system. The emission control equipment would treat the offgas to the Subpart AA requirements for the emission of volatile organic compound limits in 40 CFR 264 Subpart AA standards.

The emission limits for Subpart AA are for total organic emissions are $3 \mathrm{lb} / \mathrm{hr}$ and 3.1 tons/year, or by use of a control devise, total organic emissions from all affected process vents at the facility must be reduced by $95 \mathrm{wt} \%$.

Based on the operational history of the PEWE and the concentration of organic compounds in SBW additional control devises should not be required to meet this emission standard.

\subsection{Site-Specific Risk Assessment}

DEQ permit writers may require a site-specific risk assessment (SSRA) if they believe that operation in accordance with the HAPs standards alone may not be protective of human health and the environment. The SSRA will focus on the emission rate of HAPs and non-HAPs, stack gas characteristics, meteorological conditions, and exposed populations. There is a high probability that DEQ will requires a risk assessment, since they required one for the evaporators permitted in Volume 14. The SBWT project has developed a template for a site-specific risk assessment for SBW in 2004. 
A SSRA will evaluate the potential impacts to human health, the environment, and ecology from the emission from the Direct Evaporation Facility.

The risk is that the SSRA may result in additional HWMA permit conditions that affect the feed rate, emission controls and emission monitoring.

\section{Direct Evaporation Product Packaging and Storage:}

The direct evaporation product would be packaged in canisters directly underneath the evaporator. The waste packaging process places the product in canisters where is cools and solidifies. The canisters of waste are stored pending shipment to WIPP. The direct evaporation product storage and packaging units would be subject to the 40 CFR 264 and 270 requirements for new tank systems and container storage. The waste packaging process would be located adjacent to the Direct Evaporation Facilities. These units could be added to the INEEL HWMA permit as a modification to either Volumes 14 or 18, or as a separate volume.

The addition of the waste packaging process will result in less than $25 \%$ increase in the tank capacity and container storage capacity at the INEEL. Therefore, the changes should be a Class 2 modification. It should be possible to submit individual permit modifications for the building, tank systems, and container storage, which should allow the start of construction of the building, floor, walls, roof, and secondary containment, while designs are finalized for tank systems and container storage. The PPF are replacement storage for the waste in the tank farm. The net result would be a reduction in storage volume at the INEEL Storage areas that store containers holding wastes that do not contain free liquids need not have a containment system (40 CFR §264.175(c)).

It is recommended that PPF container storage be submitted to the State of Idaho as a Class 2 modification to either INEEL HWMA permit Volume 14 or 18. The PPF canister storage areas are for dry waste with no free liquids, which should simplify the permitting and construction. The tank and container storage areas replace noncompliant storage in the tank farm and will not increase waste storage capacity.

If the final design results in significant changes to the PPF, a permit modification would be required (e.g., tank size, number of tanks, tank location, cell dimension, etc.). The risk is that changes to the design during final design or construction could result in a permit modification approval before waste could be managed in the PPF and delay the shipment of SBW. It is recommended that the project negotiate with the State of Idaho early in design to determine how design and construction changes will be handled during the application, final design, and construction stages of the project.

3.2.1.3 Mixing Pumps. The mixing pumps would be ancillary equipment to the tank systems in the Tank Farm. The tanks in the Tank Farm have interim status, but cannot be permitted since it is not practical to upgrade the secondary containment. Changes to interim status units require the approval of the director as outlined in 40 CFR \$270.72, Changes During Interim Status and 40 CFR §270.42, "Permit Modification at the Request of the Permitte".

The addition of the mixers to the Tank Farm should be a Class 1 modification under interim status and requires notification of the administrator prior to implementing the change. Adding the pumps would not change to the tank's storage capabilities so the administrator should have little concern with this action.

3.2.1.4 Organic Sample Bias. The DEQ proposes, in Volume 14 to the INEEL HWMA permit, to approve the use of a double-needle sampler as an alternative sampling procedure when collecting mixed (hazardous and radioactive) volatile organic and total organic samples from the INTEC Liquid 
Waste Management System. However, the resulting sample analysis results must not be used in Land Disposal Restriction (LDR) Certifications. The appropriateness of the sampling procedure shall be confirmed at least three times within the life of the permit by correlation of the analytical results with the permit required off-gas data.

The project should request the use of double needle sampling in the CAA permits and HWMA permit applications. The project should compare sample data from the double needle and simple samplers to show that the organic constituents in the Tank Farm waste are at or near the method detection limits and the sampling method does not affect the results for organics, due to the low concentration in the feed. The project should propose a reduced number of organic analyzes based on the low concentration in the feed. The project should pursue DEQ approval for use of double-needle samplers for all remote-handled samples, including emission testing, LDR, delisting, and waste characterization samples as required to dispose of waste.

3.2.1.5 PE Certifications. CAA permits will not require PE certifications for the design and construction of the evaporator and emission control units.

HWMA requires PE certification of the design submitted with the permit modification or application and before waste is placed in the tank systems 40 CFR $\$ 264.192$ and 40 CFR $\$ 270.11(d)$. PE certification would be required for DE product storage and container storage facilities. The project should contract with an independent, registered, PE early in the design stage for PE support to facilitate certification of the design for the permit application or permit modification.

3.2.1.6 In-cell Leaks. In-cell leaks from air emission treatment equipment are not specifically addressed in an air permit. They are addressed in the estimated range of emissions from the cell or building. Waste leaked into sumps will need to be removed within 24-hours or secondary containment will be considered primary containment and would be regulated under the HWMA requirements.

HWMA requires that operation of a leaky tank system be stopped immediately after the leak is detected, waste be removed from tank systems within 24-hours, and waste be removed from secondary containment within 24-hours (40 CFR \$264.193). The system will have to be repaired before it is used. Depending on the extent of the repairs, a PE certification may be required before resuming operations.

Historically, the piping from the feed tanks to calciner has leakage problems during operation. The direct evaporation pumps and piping may have similar problems and could be a schedule risk if operations are stopped to repair leaks as they occur. The project should negotiate with the State of Idaho to operate with leaking pumps, pipes, and valves until they can be replaced at scheduled maintenance shutdowns.

3.2.1.7 As-built Drawings. CAA permits do not require as-built drawings of the facility. The air permits need the emissions from each system, the ranges of the emissions, and a list of equipment.

HWMA permitting requires as-built drawings of the facility, equipment, and piping. A permit application could include between 50 and 100 drawings (40 CFR \$270). The project should negotiate with the State of Idaho to add the as-built drawings certified by a PE to the INEEL HWMA permit as a Class 1 modification prior to start of operations.

\subsubsection{DE NEPA}

NEPA exposure is low risk and little or no activity should be required here. 
The risk of additional NEPA action for the SBWT project is low. The HLW\&FD EIS covered over 120 different alternatives to treat the SBW from no action to vitrification. It does not appear at this time that additional NEPA action would be required for the treatment and storage of SBW.

If required, an environmental assessment (EA) should cover any additional action or process not specifically mentioned in the EIS.

\subsubsection{DE Waste Disposal - TRU Waste}

\section{Waste disposal is fairly high risk and is further aggravated by schedule delays.}

The direct evaporation SBW Treatment alternative would generate canisters of product and debris (spent GAC and HEPA filters). The majority of the waste would be remote-handled TRU waste. The WIPP facility is limited to $7080 \mathrm{~m}^{3}$ of RH-TRU waste by the Land Withdrawal Act (LWA). Hanford, SRS, and the INEEL have proposed sending RH-TRU waste not identified in previous estimates. The volume of RH-TRU waste in the DOE complex may exceed the LWA capacity. Disposal is based on first come, first disposed.

The risk to the project is that delays in the schedule caused by permitting, design, construction, and startup could reduce the number of shipments of RH-TRU SBW that WIPP can receive before the capacity authorized in the LWA is exceeded. If low-level waste is generated with a dose greater than Class A radioactivity limits then it is a waste without a path for disposal.

\subsubsection{DE Waste Qualification/Certification}

\section{Waste qualification/certification is a very high risk area for the Project.}

The issues related to waste qualification/certification are: (a) the waste classification through the Waste Incidental to Reprocessing (WIR) determination process, (b) waste acceptance criteria at WIPP, (c) waste acceptance criteria at the National Geologic Repository (NGR), (d) RH-TRU permit approval, (e) New Mexico Environmental Department (NMED) acceptance of SBW (f) WIPP Waste Certification Authorization, and $(\mathrm{g})$ acceptance of greater than Class A low-level waste.

a. The Federal District Court in Boise ruled that DOE does not have the authority to classify waste using the WIR determination process in DOE Order 435.1. DOE has appealed the ruling to the U.S. Appeals Court and has asked Congress to clarify DOE's authority under the Nuclear Waste Policy Act.

The risk to the project is that the appeals process drags on for several years and delays treatment of the waste beyond 2012. The project should consider placing the waste in thin metal containers (liners) that could be placed in either the RH-TRU canister or the HLW canister. The treatment alternative would then be neutral to the disposal location. This would unfortunately decrease the net volume per canister and result in increasing the canister count and associated costs for storage, transport, handling, and disposal. In addition, if the WIR determination for SBW is disallowed, then classification of the spent GAC and debris would be in question.

b. The State of New Mexico issued a Hazardous Waste Facility Permit (HWFP) to WIPP that covers CH-TRU waste streams. The U.S. Congress, in Section 311(b) to the Energy and Water Appropriations Act, required WIPP to submit a modification to WIPP's HWFP to limit confirmatory testing of TRU waste containers to radiography or visual inspection. 
These changes, when implemented, will significantly reduce the type and number of waste characterization samples required to confirm the acceptable knowledge. The modification was submitted to the State of New Mexico on December 31, 2003. The State of New Mexico is still reviewing the Section 311(b) modification.

The waste acceptance criteria for RH-TRU waste at WIPP are in the process of being established. WIPP and the EPA have established requirements for radionuclides, since the EPA approved the RH-TRU Waste Characterization Program Implementation Plan (PIP) for characterization of radionuclides on March 26, 2004. DOE must submit site-specific implementing plans for EPA approval before sites may be authorized to characterize RHTRU waste for certification and shipment to WIPP. Sites will not be authorized to certify and ship RH-TRU waste to WIPP until EPA conducts an onsite inspection and issues its final authorization. The RH-TRU Waste Characterization PIP requires each site to prepare sampling and analytical plans for characterization of each waste stream and have them approved by the EPA.

The WIPP RH-TRU Program has not received approval of the RH-TRU waste modification to the WIPP HWFP. The criteria for hazardous constituents in RH-TRU waste have not been added to the WIPP HWFP. WIPP submitted a Class 3 permit modification for RH-TRU waste to the State of New Mexico in May 2003. The State of New Mexico is still reviewing the modification. WIPP is not ready to receive RH-TRU waste and will require facility modifications and testing prior to receipt of waste.

The risk to the project is starting the design without having all of the waste characterization and certification requirements finalized for either $\mathrm{CH}$ - or RH-TRU wastes resulting in design changes, permit modification during construction, and delays in the shipment of waste.

It is recommended that the SBWT project work closely with WIPP and EPA to develop sampling and analysis plans for characterization of the feed. The plans will describe the use of acceptable knowledge for radioisotopes, prohibited items, and dose-to-curie measurements and calculations.

The project should also work with WIPP to include project specific waste characterization procedures for RH-TRU waste in the WIPP HWFP, if required.

c. If the DOE WIR Determination process is found to be outside their authority, then SBW containing reprocessing waste and debris contaminated with SBW, could be classified as HLW, based on the Nuclear Waste Policy Act. SBW and SBW contaminated debris would then have to be packaged for disposal at the NGR. The waste acceptance criteria at the NGR are based on an assessment of the performance of the waste in the package and performance of the waste package in the repository.

The only waste form that has been evaluated and approved for HLW disposal is borosilicate glass. Other waste forms such as evaporates or grout will have to be evaluated for acceptability on a case-by-case basis. Failure of the WIR does not mean that the SBW would automatically go to the NGR, but it could result in the project generating waste without a disposal path. DOE has a limited capacity available for the disposal of HLW at the NGR. If all reprocessing wastes are classified as HLW, then the volume of HLW will exceed DOE's allocated capacity requiring long-term storage at the INEEL. 
The INEEL needs to develop the following technical information to support the acceptance of a waste form for disposal at the NGR. The information needed for the Memorandum of Agreement with the Civilian Radioactive Waste Management System includes the Environmental Management Waste Acceptance Product Specifications (EM-WAPS), Waste Form Compliance Plan (WFCP), Waste Form Qualification Report, and supporting documentation that comply with QARD RW-0333P requirements.

1. The Chemical Composition and Waste Form Projections for the HLW. Information on the chemical composition shall include identification of the speciation of elements and compounds present in concentration greater than $0.5 \mathrm{wt} \%$ in the waste form, and an estimate of the uncertainty of these concentrations for the HLW.

2. Information required for determining that the HLW does not exhibit the characteristics of hazardous waste.

3. Estimates of the total facility inventory and individual canister inventory of radionuclides (in curies) that have half-lives longer than 10 years and are or will be present in concentration greater than $0.05 \%$ of the total radioactive inventory. The estimates shall be indexed to the years 2010 and 3110 . The producer shall also report the estimate of the uncertainty in the radionuclide inventories.

4. The time-temperature-transformation diagrams for the HLW and identification of temperature limits (if any) necessary to preserve the properties of the HLW.

5. Identification of the method to be used to ensure consistency of production batches, and any other information necessary to establish post-closure performance of the waste forms such as identification of organic compounds that may be present and estimated quantities. Product consistency test and comparison to the performance of EA benchmark glass.

6. Canister material.

7. Canister dimensions (at the time of acceptance).

8. Canister lifting and handling arrangements.

9. Canister labeling conventions.

10. Information required to assess the canister drop performance including information regarding particulates, pyearophorics, combustibles, explosives, etc. that all may come into play in a Design Basis Earthquake II event. This is likely to be a detailed list, much of which has not yet been determined. the need for this information will be developed more fully in a future revision of the WASRD.

11. Information required to assess canister criticality, both pre-and post-closure. This is likely to be a detailed list, much of which has not yet been determined. The need for this information will be developed more fully in a future revision of the WASRD.

12. Estimated maximum gamma and neutron dose rates at the canister surface.

13. Projected distribution of canister thermal outputs, including the maximum. 
14. Method used to assign individual canister Metric Ton Heavy Metal (MTHM) content for accounting against the repository 70,000 MTHM capacity limit as specified in Section 114d of the nuclear Waste Policy Act of 1982, as amended.

The SBW waste has been assigned four listed waste codes. The NRG is not permitted as a Subtitle $\mathrm{C}$ hazardous waste landfill therefore the project will need to delist the waste streams before they can be shipped to the NGR. The waste streams cannot exhibit a characteristic of a hazardous waste. In addition to delisting, the SBW must be treated to meet the land disposal restriction standards for hazardous metals before shipment to the NGR. Waste form and waste packaging performance assessments and approvals could delay treating the SBW. The NGR will need to request a license change from NRC and EPA to receive waste forms other than borosilicate glass. (See discussion of petition to exclude/delisting petition in Section 3.2.4.7.)

d. The WIPP RH-TRU Program is not ready to receive RH-TRU waste and will require facility modifications and testing prior to receipt of waste.

The WIPP RH-TRU Program could present a schedule risk to the project if they do not nave a permit and the WIPP receiving facility is not modified in time to support the SBW shipment schedule. In addition, the project could also have a risk and have to modify its design during construction or start up to comply with the requirements in the approved modification for RH-TRU waste to the WIPP HWFP.

e. SBW is not identified in the 1995 TRU Waste Baseline Inventory Report (TBWIR) as a waste destined for disposal at WIPP. SBW is listed as a potential waste stream in the 2004 TWBIR, but the SBW source term was not included in 2004 performance assessment for the Compliance Recertification Application to EPA. The State of New Mexico has proposed (1) to amend the permit for the WIPP to prohibit the shipment of reclassified high-level waste to the site, (2) to amend WIPP's permit to limit waste for disposal to those wastes identified in the 1995 TBWIR, and (3) legislation to exclude all TRU waste not identified in the 1995 TWBIR. DOE is currently working the issue with the State of New Mexico to resolve these issues.

These proposed restrictions could delay the approval of the RH-TRU Waste Permit Modification and finalization of the RH-TRU waste acceptance requirements in the HWFP. Worst case is that the restrictions prohibit the disposal of SBW at WIPP.

f. The WIPP waste certification authorization process consists of a series of document reviews, assessments, and confirmation audits. The DOE-Carlsbad Field Office (CBFO), EPA, and NMED participate, in the process. Waste certification authority is based on the project demonstrating verbatim implementation of the characterization, operating, confirmation, and validation procedures and plans used for characterization and certification of waste shipments.

DOE-CBFO will approve the plans and procedures prior to start of operations and assess implementation during system operation testing. DOE-CBFO and NMED will audit the project during the first 6 weeks of operations to verify that the operators are trained and hazardous waste management plans and procedures have been implemented as approved. EPA will audit the project to verify that the radioactive waste management plans and procedures are being implemented as approved. Audit findings have to be resolved before waste certification authority is granted. 
NOTE: Changes to approved radioactive and hazardous waste management plans and procedures, equipment, and equipment calibrations that affect waste certification have to be approved by CBFO prior to implementation of the change. The DOE-CBFO, EPA, and NMED expect verbatim compliance with the approved plans and procedures and conduct quarterly assessments and yearly compliance audits to ensure that the plans and procedures are being followed.

The risk to the project is that changes to approved plans and procedures before, during, and after hot startup delay waste shipments. The risk is that waste certification authority approval could be delayed by the time and manpower it takes to correct the audit findings or to recertify waste containers because plans, procedures, and equipment calibrations were changed or not followed as approved.

g. Low-level waste generated by the SBWT project is listed hazardous waste and assigned RCRA hazardous waste numbers F001, F002, F005, and U134. At the present time the only disposal site permitted and licensed for radioactive and hazardous waste with these hazardous waste numbers is Envirocare. Envirocare is licensed for low-level Class A radioactive waste. For low-level waste streams, with INTEC hazardous waste numbers that exceed the radioisotope limits for Class A low-level waste, there are no disposal sites available. If the project generates low-level (non-TRU) waste with activity greater than Class A low-level limits, it will be a waste without a path for disposal and require on-site storage. The Nevada Test Site disposes of radioactive- only waste from offsite generators. The Hanford site is not permitted to receive radioactive and hazardous mixed waste from offsite generators or wastes with the U134 hazardous waste number. At the INEEL, the Radioactive Waste Management Complex (RWMC) receives radioactive waste and the Idaho CERCLA Disposal Facility (ICDF) receives CERCLA waste. In order, for the project to dispose of waste at either the RWMC, Nevada Test Site, or Hanford Site the project will need to treat the waste for characteristically hazardous constituents and prepare a delisting petition to remove the hazardous waste number above. In order for the waste to be disposed of at the ICDF the project and waste generated would have to be added to the INEEL CERCLA Program under the Federal Facilities Agreements/Consent Order (FFA/CO). The proposed treatment option would generate low-level waste in the form of grouted scrub, GAC, PPE, and debris.

To avoid these risks, it is recommended that the SBWT project work with the State of Idaho, Region 20 EPA, and the disposal site state to delist low-level waste generated from this process, since it does not contain the hazard constituents for which it was listed. The delisting petition, or a petition to exclude waste from hazardous waste regulation, requires approval in the generating state, the states through which the waste is transported, and the state where in the waste will be disposed of. There is still the risk that the disposal site state may not accept the delisting for SBW even if approved by the State of Idaho and Region 10. The proposed treatment option would generate low-level waste in the form of spent GAC and HEPA filters, PPE, and debris.

\subsubsection{DE Regulatory Risks - Summary}

\section{WIPP}

- $\quad$ The State of New Mexico delays the approval of the RH-TRU permit modification.

- The State of New Mexico delays the approval of the 311(b) permit modification. 
- $\quad$ The State of New Mexico amends the WIPP HWFP to exclude waste classified as TRU using the WIR process.

- $\quad$ The State of New Mexico amends the WIPP HWFP to exclude waste not listed in the 1995 Transuranic Waste Baseline Inventory Report.

- $\quad$ The EPA or State of New Mexico requires additional sampling and analysis for acceptable knowledge characterization for RH-TRU waste.

- $\quad$ WIPP/EPA/NM do not grant waste certification authority to the project until 180 days after hot start. (30 days of production, audit, 4-6 months wait until approval is granted).

- $\quad$ WIPP does not have the manpower or onsite capabilities to support the shipping schedule.

- $\quad$ WIPP does not have 72-B transporters available for the project to support the shipping schedule.

- WIPP does not have the LWA capacity to receive the RH-TRU SBW.

- $\quad$ NMED continues to require headspace gas analysis for every container in storage.

- $\quad$ NMED continues to require verification sampling and analysis of the waste in containers in addition to acceptable knowledge.

- WIPP approval of changes to equipment and procedures identified during SO testing, readiness review, and hot startup delays waste certification authority or implementation of new procedures.

- $\quad$ Court challenges by the State of New Mexico or stakeholders prevent or delay the project shipping of waste to WIPP.

- $\quad$ The State of New Mexico passes legislation that prevents or delays the shipping of SBW to WIPP.

\section{Permitting}

- $\quad$ State of Idaho DEQ cannot support the aggressive permitting modification schedule for start of construction.

- $\quad$ State of Idaho DEQ does not approve a general permit modification to support the start of building construction.

- $\quad$ State of Idaho DEQ does not issue a permit to construct (air) to support the schedule for start of building construction.

- State of Idaho DEQ does not approve the modifications to the HWMA permit in time to support the start of operations.

- State of Idaho DEQ does not issue a permit to operate (air) in time to support the start of operations.

- $\quad$ State of Idaho DEQ and Federal Land Manager, PSD new source review requires additional off-gas cleanup and delays permit approval. 
- $\quad$ The emission testing delays the start of production operations.

- $\quad$ Court challenges by INEEL stakeholders delay or prevent permit modifications needed for the SBW project.

- State of Idaho does not approve the SBW petition to exclude the waste from hazardous waste regulation.

- $\quad$ The disposal site state does not approve the SBW petition to exclude the waste from hazardous waste regulation.

\section{DOE O 435.1}

- $\quad$ Federal courts vacate DOE's authority to make WIR determinations.

- $\quad$ Federal courts delay DOE's authority to make WIR determinations.

- $\quad$ Congress does not clarify DOE's authority to make WIR determinations.

- The project generates waste without a path to disposal requiring permitting and construction of additional storage capacity.

\section{Safety}

- $\quad$ PDSA is not approved in time to support the schedule for ordering long lead equipment and start of construction.

- $\quad$ FDSA is not approved in time to support the readiness review schedule.

- $\quad$ Systems operations testing identifies problems that delay the hot startup schedule.

- $\quad$ Readiness review process takes additional time to correct findings and delays the hot startup schedule.

- $\quad$ Radioactive Waste Management Authority is not approved in time to support the hot startup schedule causing a delay in WIPP Waste Certification Authority. 


\begin{tabular}{|c|c|c|c|c|c|c|c|c|c|c|c|c|c|c|c|c|c|}
\hline 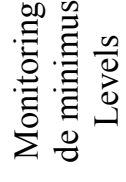 & 政 & & $i$ & $\sigma \cdot \sigma$. & . 1 & $\leadsto$ & $: \quad \Xi$ & $i$ & 1 & 1 & $\stackrel{n}{n} \stackrel{n}{n}_{0}^{n}$ & 1 & 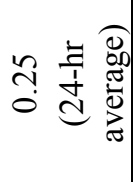 & i & 농 & 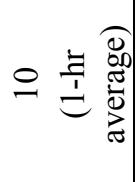 & \\
\hline 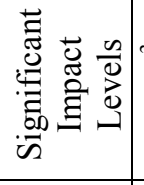 & 告 & $n$ & - & $\sigma \cdot \sigma$. & $\approx$ & $n-$ & $-z$ & $\mathrm{i}$ & 1 & ঠి & \begin{tabular}{ll}
8 & 1 \\
\hdashline & 1
\end{tabular} & 1 & $i$ & 1 & 1 & $i$ & i \\
\hline 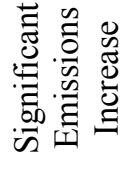 & 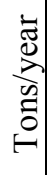 & \multicolumn{2}{|l|}{ 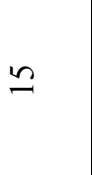 } & a. & \multicolumn{2}{|l|}{ \& } & \multicolumn{3}{|c|}{ 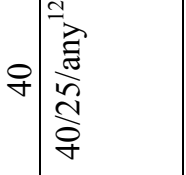 } & 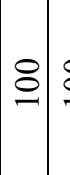 & \begin{tabular}{lll}
8 & 0 \\
\hdashline & 0
\end{tabular} & $\approx$ & $n$ & $r$ & 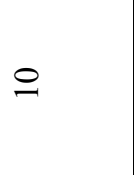 & $\stackrel{ }{ }$ & \\
\hline \multirow{3}{*}{ 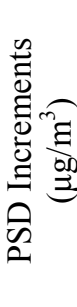 } & $\Xi$ & 8 & $m$ & $\therefore$. & . & 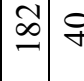 & for & $\mathrm{i}$ & 1 & $\mathrm{i}$ & 1 & 1 & 1 & 1 & 1 & 1 & i \\
\hline & $=$ & 요 & ㄱo & a. $\quad$ a. & $\left|\frac{n}{n}\right|$ & ন & $\stackrel{\imath}{\sim}$ & $\mathrm{i}$ & i & $\mathrm{i}$ & 1 & i & $i$ & $i$ & $i$ & 1 & i \\
\hline & - & $\infty$ & +8 & c. $\sigma$. & $\approx$ & in & $\left.\begin{array}{cc}n \\
\sim\end{array}\right]$ & 1 & 1 & 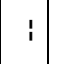 & $\mathrm{i}$ & i & 1 & $i$ & 1 & 1 & i \\
\hline \multirow{4}{*}{$\underset{z}{2}$} & ฉี & $:$ & 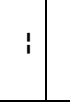 & $\mathrm{i}$ & $\begin{array}{ll}n \\
1 \\
0\end{array}$ & $i$ & $1\left|\begin{array}{l}n \\
\hat{0} \\
0 \\
0\end{array}\right|$ & $\stackrel{9}{9}$ & $\stackrel{\infty}{\stackrel{\infty}{0}}$ & $\mathrm{i}$ & 1 & 1 & 1 & 1 & 1 & 1 & ! \\
\hline & $\frac{\Xi}{\sum_{0}^{0}}$ & $\stackrel{\circ}{-1}$ & 요 & $6)$ & 0 \begin{tabular}{l}
8 \\
\hdashline \\
-1
\end{tabular} & $i$ & 1 & $\tilde{\approx}$ & $\hat{n}$ & $\mathrm{i}$ & $1:$ & i & 1 & 1 & 1 & 1 & ! \\
\hline & 咅 & $:$ & i & $i$ & $:$ & $\begin{array}{l} \pm \\
\dot{0}\end{array}$ & \begin{tabular}{l|l}
$\tilde{0}$ & $\tilde{2}$ \\
$\dot{0}$ & 0 \\
0
\end{tabular} & $\stackrel{7}{0}$ & $\stackrel{\infty}{\circ}$ & $\approx$ & $a$ & i & 1 & i & 1 & i & ! \\
\hline & $\frac{{ }^{m}}{B_{0}^{\infty}}$ & $\stackrel{n}{n}$ & in & 6 & 01 & $\left|\begin{array}{l}n \\
0 \\
n\end{array}\right| \propto$ & $\infty$ & $\approx$ & $\hat{n}$ & 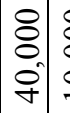 & \begin{tabular}{l|l}
8 & $n$ \\
0 & $?$ \\
0 & $=$
\end{tabular} & 1 & 1 & 1 & 1 & 1 & i \\
\hline & $\begin{array}{c}\Xi \\
0 \\
0 \\
1\end{array}$ & $\varangle$ & 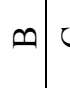 & 0 & \begin{tabular}{l|l|l|l|}
\end{tabular} & 디 & $I|I|$ & 0 & $I$ & 디 & 디 & 1 & i & 1 & 1 & 1 & i \\
\hline \multicolumn{2}{|c|}{ 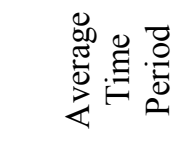 } & $\begin{array}{l}\dot{z} \\
\bar{\Xi} \\
\dot{\tau}\end{array}$ & 妾 & 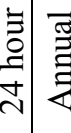 & 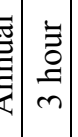 & 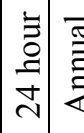 & 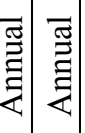 & $\mid \begin{array}{l}\vdots \\
\vdots \\
\beth \\
-\end{array}$ & $\begin{array}{l}m \\
\\
\\
\end{array}$ & 离 & 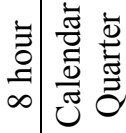 & $i$ & i & 1 & 1 & 1 & \\
\hline \multirow{2}{*}{ 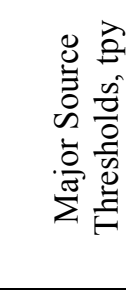 } & $\mathbb{Z}_{z}^{+}$ & $\frac{\circ}{\circ}$ & & \& & \multicolumn{2}{|l|}{ 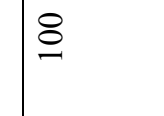 } & 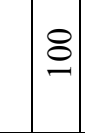 & \multicolumn{2}{|c|}{ 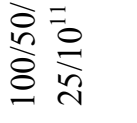 } & 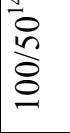 & 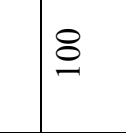 & 1 & 1 & 1 & 1 & 1 & i \\
\hline & ڤิ) & $\begin{array}{l}0 \\
8 \\
\frac{8}{2} \\
i n \\
i\end{array}$ & & $\begin{array}{l}8 \\
\frac{8}{2} \\
\frac{1}{1} \\
\text { an }\end{array}$ & \multicolumn{2}{|l|}{$\begin{array}{l}8 \\
\frac{8}{0} \\
2 \\
\end{array}$} & $\begin{array}{l}8 \\
\vdots \\
\vdots \\
\vdots \\
\\
\end{array}$ & \multicolumn{2}{|l|}{$\begin{array}{l}8 \\
\stackrel{8}{2} \\
\\
\end{array}$} & $\begin{array}{l}8 \\
\stackrel{1}{2} \\
\infty \\
i \\
i\end{array}$ & $\begin{array}{l}8 \\
\stackrel{1}{2} \\
0 \\
\vdots \\
i\end{array}$ & $\begin{array}{l}8 \\
\stackrel{1}{\circ} \\
\vdots \\
i\end{array}$ & $\begin{array}{l}8 \\
\stackrel{1}{\infty} \\
\vdots \\
i\end{array}$ & $\begin{array}{l}8 \\
\stackrel{8}{\circ} \\
\stackrel{2}{n}\end{array}$ & $\begin{array}{l}8 \\
\stackrel{1}{8} \\
\vdots \\
\end{array}$ & $\begin{array}{l}8 \\
\stackrel{1}{2} \\
\stackrel{2}{1}\end{array}$ & \\
\hline \multicolumn{2}{|c|}{ 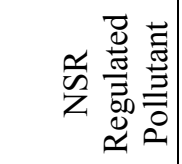 } & $\frac{3}{\sum_{1}^{1}}$ & & $\sum_{i}^{i}$ & $\delta_{\mathscr{N}}^{N}$ & & $\begin{array}{l} \\
\vdots \\
Z\end{array}$ & & 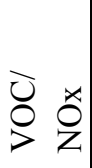 & 0 & 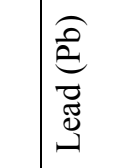 & 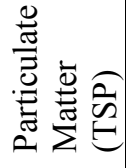 & 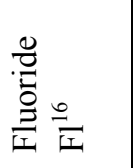 & 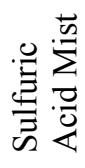 & 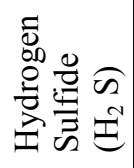 & $\overrightarrow{\tilde{w}}$ & \\
\hline
\end{tabular}




\begin{tabular}{|c|c|c|c|c|c|c|c|}
\hline 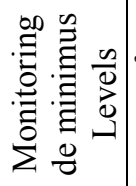 & ${ }_{3}^{m} \Xi$ & 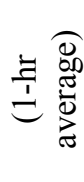 & 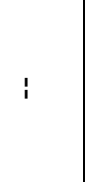 & $i$ & i & i & i \\
\hline 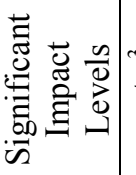 & 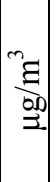 & & i & 1 & i & i & $i$ \\
\hline 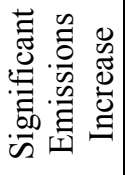 & 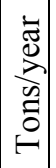 & & 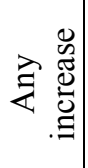 & 우 & 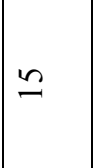 & $\begin{array}{l}i \\
i \\
x \\
n \\
n\end{array}$ & in \\
\hline \multirow{3}{*}{ 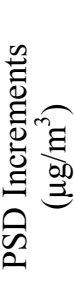 } & $\exists$ & & 1 & 1 & 1 & 1 & 1 \\
\hline & $=$ & & i & i & i & 1 & $i$ \\
\hline & - & & i & $i$ & i & $i$ & $i$ \\
\hline \multirow{4}{*}{$\underset{\frac{1}{2}}{2}$} & हี & & $i$ & 1 & $i$ & 1 & 1 \\
\hline & $\mid \begin{array}{c}n \\
z \\
\sum_{0}^{\infty} \\
\Sigma\end{array}$ & & $i$ & 1 & 1 & 1 & $i$ \\
\hline & : & & i & 1 & 1 & 1 & 1 \\
\hline & $\mid \begin{array}{c}n \\
z \\
\sum^{n} \\
\Sigma\end{array}$ & & i & $i$ & 1 & $i$ & i \\
\hline \multicolumn{2}{|c|}{ בี } & & i & i & $i$ & i & $i$ \\
\hline \multicolumn{2}{|c|}{ 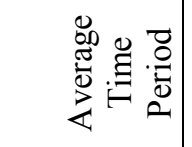 } & & $i$ & $i$ & i & $i$ & $i$ \\
\hline \multirow{2}{*}{ 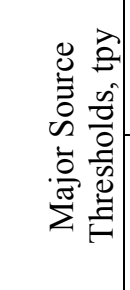 } & $\mid \underset{\mathbb{Z}}{\mathbb{*}}$ & & 1 & 1 & 1 & 1 & 1 \\
\hline & $\begin{array}{l}3 \\
\hat{2} \\
2 \\
2\end{array}$ & & $\begin{array}{l}8 \\
\stackrel{1}{2} \\
0 \\
i \\
i\end{array}$ & 辛 & $\begin{array}{l}8 \\
\stackrel{8}{2} \\
\stackrel{2}{1} \\
1\end{array}$ & $\begin{array}{l}8 \\
\stackrel{8}{8} \\
\end{array}$ & 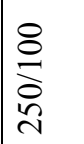 \\
\hline \multicolumn{2}{|c|}{ 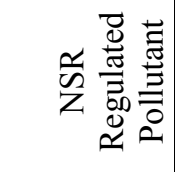 } & & के & 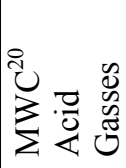 & $\sum_{i}^{0} \frac{\infty}{\frac{\pi}{0}}$ & 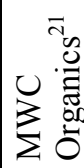 & 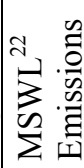 \\
\hline
\end{tabular}




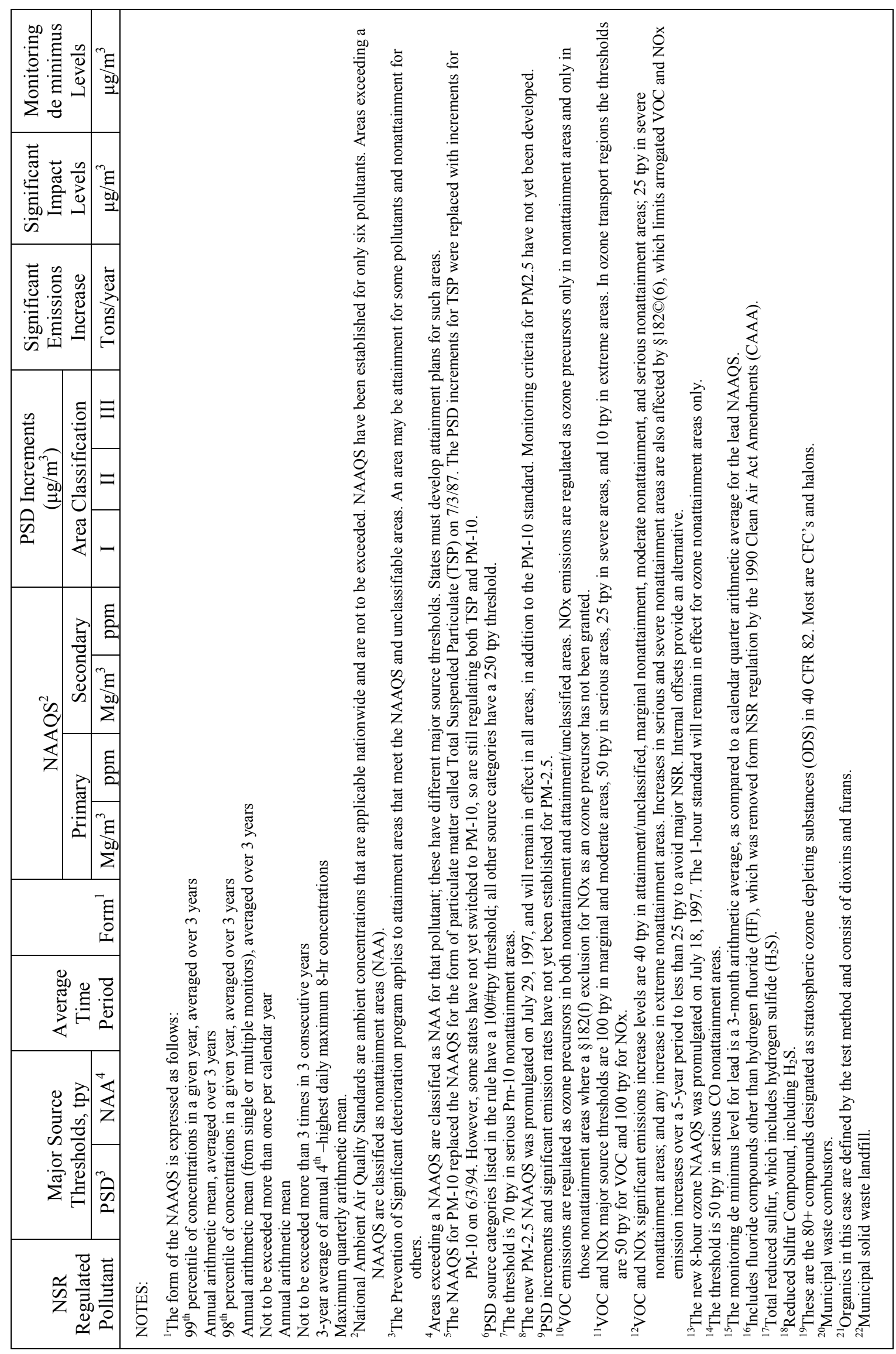




\subsection{DE Schedule and Related}

The overall schedule for the DE SBW treatment alternative cannot achieve the 2012 milestones (late by at least 11 months) primarily due to the time required to permit and construct the DE treatment facility and to treat the SBW in an aggressive, but realistic, time span.

\subsubsection{DE Capital Project Schedule (February 2005 to September 2010)}

\subsubsection{Preliminary Design (February 2005 to October 2005).}

It will require a very aggressive effort to conclude the preliminary design by the end of October 2005 in only a 9-month period starting in February 2005 and submit environmental permits in December 2005.

The assumed start for the capital project is February 1, 2005, the first day of the new ICP contractor. Preliminary (Title I) design would commence on this date. However, realistically, even if government funding and approvals (Critical Decision 0, CD-0, Approve Mission Need and CD-1, Approve Alternative Selection and Cost Range) were not to be limiting, preliminary design cannot start without a design company being in place under contract and design direction documents such as the Scope of Work (SOW), Technical and Functional Requirements document (TFR), and Project Design Criteria (PDC). These documents have not yet been prepared (the treatment alternatives are many and varied and one has not been chosen yet) but could perhaps be developed in the transition period prior to February 1, 2005, or in the month or two immediately following.

An aggressive preliminary design (Title I Design) period of 9 months is possible but difficult during which the process definition must be finalized and process and instrument diagrams (P\&IDs) developed. Related to this, the following must be done: (1) critical Technical Development test work must be conducted to support process definition; (2) remote mock-up testing must be started and iterate which design to develop and prove the concepts; (3) safety analysis work must be started and proceed through the fundamental assessment stage to define any safety driven requirements to be inputted to the design; and (4) the draft environmental permit applications must be written. Numbers 1 and 2 would be difficult to achieve in such a short time frame and could be schedule limiting or most likely require design work to proceed at risk based on the best concepts and assumptions available. All this must be coordinated to finalize the P\&IDs such that facility design and mechanical layout work can be performed in sufficient detail to support submittal of the RCRA Part B and Air permit applications. This is considered to be a Title I Plus design; (a level of detail beyond what is normally developed in a Preliminary/Title I Design effort). As such the following would be required.

\section{HWMA/RCRA Permitting}

\section{Process}

- $\quad$ Final process flow diagrams (PFDs), material and energy balances, and P\&IDs

- $\quad$ Process descriptions

- $\quad$ Equipment descriptions

- $\quad$ Operating limits

- $\quad$ Operating procedures (at least draft). 


\section{Building}

- $\quad$ Site location

- $\quad$ Facility layouts

- $\quad$ Floor plan drawings

- $\quad$ Equipment and piping layouts

- Materials of construction used

- Secondary containment details (at least typical).

\section{Waste}

- $\quad$ Characterization of feed waste (SBW in Tank Farm)

- Waste acceptance requirements for the treatment facility

- $\quad$ Process control requirements

- Description of final waste

- Characterization (typical) of final waste

- $\quad$ Sampling and analytical methods used.

\section{Air Permitting}

\section{Air emission modeling}

- Identify sources of emission

- Identify constituents of concern

- $\quad$ Model emissions.

\section{NESHAPs}

- $\quad$ Estimated emissions of radionuclides.

\section{PSD}

- $\quad$ Estimated NOx emissions

- $\quad$ Estimated visible emissions.

\section{Title V}

- $\quad$ Estimate emission of hazardous constituents.

At the end of preliminary design, the details of the design would be fed into the environmental permit applications and 60 days later, after final reviews, revisions, and approvals, the permit applications would be submitted to the Idaho Department of Environmental Quality (IDEQ) for the assumed minimum two year review and approval process (reduced from the 31 months requested by Idaho DEQ by taking time from the Contractor's schedule only) before permission would be given to start of construction. 
Additionally, during preliminary design equipment needs will be examined and detailed specifications will be prepared and finalized either at this stage or in the early days of final design for equipment that is (1) critical to facility detailed design, (2) needed for the mock-up testing program, or (3) otherwise long-lead and schedule critical. This equipment is normally referred to as GFE. Some examples of this are the DE evaporator, the DE canister loading assembly, the decon/transfer cart, the canister handling machine, and the tank mixing pumps.

It should be noted that preliminary design, feeding into the environmental permit applications, and the application review process by Idaho DEQ leading to approval to construct is the first of three critical paths on the project schedule. The second one, discussed later, is construction, testing, and startup of the DE treatment facility. The third, also discussed later, is treatment (direct evaporation) of the SBW, which is a direct function of the throughput of the treatment system.

\subsubsection{Final Design (November 2005 to July 2007).}

The final design schedule does not involve risk nor is it on the critical path. It is dictated by the time required for review and approval of the environmental permits by Idaho DEQ, which will require 24 months after submittal following the completion of preliminary design.

Final design (Title II Design) will start immediately following preliminary design in early November 2005. It is assumed that there will be no hold period for CD-2, Approve Performance Baseline (authority to commence final design). It is also assumed that an early and partial CD-3 (Approval to start construction) consent would be given at CD-2 to procure the GFE equipment cited above in the preliminary design write-up, which would involve a relatively significant expenditure of capital funds.

All technical development test work and remote mock-up testing must be completed by mid-final design in order to be factored into the detailed design.

Detailed design would iterate with procurement on GFE items to minimize the overall schedule as well as cost. Design would proceed to the point of preparation of numerous bid packages of equipment specifications and drawings for issuance for competitive bid by either the ICP contractor or his design agency. (The latter is preferred for better communication and control as well as lower cost.) Vendor bids would be received, analyzed, and awarded. Vendor drawings would be produced, reviewed, revised as necessary, and approved after which the equipment layouts and facility designs would be completed by the design agency to reflect these details in the bid packages for general construction. Vendor material

purchases, fabrication, testing, and ultimate delivery to the construction site would be delayed in order to postpone these costs of fabrication without impacting construction as well as to wait until the construction contractor is chosen and on site to receive delivery of these items. This approach will reduce both costs and schedule by not only initiating early procurement, but by providing actual equipment details in the detailed design drawings thus avoiding numerous design related questions and delays during construction.

Final design, bid and award of the construction contract (normally a 3-4 month process for a project of this size), and notice to proceed and mobilize the construction contractor on the site to be poised for the start of construction (approximately 1 month) will all fit within the 26 month permit cycle period (minimum 24 months after submittal plus 2 months after preliminary design for final submittal preparation) before authorization to proceed with construction is obtained from DEQ. Final design then must, and can without difficulty, complete by July 31, 2007, over a 21-month timeframe. Final design could be accomplished sooner, but to no net schedule advantage since construction start must wait for the permit review and approval cycle. It would be better for final design to be performed over that longer time period so the design team stays together and a core group can still be kept to support design related questions during construction. 


\subsubsection{Construction (January 2008 to September 2009).}

Construction of the DE Treatment Facility is the second critical path activity on the overall schedule, requiring 21 months if aggressively pursued; 33 months including the testing and readiness review stage leading to hot startup. (NWCF took 71 months, 48 months to construct and 23 months to test and start up.).

Work to obtain Critical Decision-3, "Approval to Start Construction", will begin at the end of final design. It is assumed that CD-3 approval will be obtained by July 2007 authorizing the start of the bid and award process. It is also assumed that CD-3 will release and provide funding support for the construction contractor to start procurement for construction. Fabrication of the GFE procurement items mentioned above in the final design section will be released at this time and those contracts completed by the originating organization (either the design agency or the ICP contractor) and be provided to the construction contractor as GFE for installation. (Schedule analysis will be performed during final design, and those GFE items that may be schedule limiting, any, will be released for fabrication earlier during the late stages of final design so that no construction delays are encountered due to these items.)

Construction will start in January 2008 (in the middle of winter, not a particularly good time) after approval of the RCRA permit is obtained from DEQ. Construction will follow a logical installation sequence from site preparation and required demolition, through earthwork, concrete, steel, piping, to completion of instrumentation, electrical installation, and construction component checkout (CC Testing).

\subsubsection{Testing and Startup (April 2009 to September 2010)} path.

Testing and startup, overlapping with the final stages of construction, are also on the critical

During the late stages of construction, after construction forces have completed rudimentary component testing (CC Testing), the ICP contractor, with support from the design agency as necessary, will perform system operation (SO) tests and cold tests (CT) on the treatment system and its supporting facility and equipment. After this, an in-house readiness review will be performed leading to a formal operational readiness review (ORR) by DOE and others. Usual participants in an ORR are DOE-ID and DOE-HQ, and sometimes the Defense Nuclear Facilities Safety Board (DNFSB). However, in this case, the following apply: (1) final waste treatment is to be performed using a thermal process requiring compliance with the air regulations, (2) RCRA waste is being treated and stored, and the system is to be fully compliant and Part B permitted, and (3) the intent is to dispose of the treated waste in a major federal repository (WIPP). As such, the Federal EPA, Idaho DEQ, and WIPP and New Mexico Environmental Department will also be involved, at least informally or in an audit mode, in the final ORR and hot startup and the waste form qualification and process/program validation leading to program certification for the WIPP repository.

Parallel with the final stages of the ORR, Critical Decision-4, "Approval to Start Operations", will be conducted and at the conclusion of both, approval will be given for hot startup of the treatment system.

It is planned that pilot scale work, along with process knowledge work such as off-gas modeling, will be performed during the construction phase to qualify the waste form and preliminarily validate the process to the satisfaction of WIPP and the National TRU Waste Management Program. It is through this test work that the waste form will be proven and the "macro-batch" - Tank Farm tank quantities of feed approach to sampling and characterization, supported by process knowledge - will be validated. The intent is to physically sample and characterize the feed from the Tank Farm tanks and not the final waste 
forms or any intermediate treatment streams.) However, the overall process and program validation still must be proven in the full-scale production system using trained operators and procedures.

Discussions with WIPP in 2002 and 2003 resulted in the baseline premise that WIPP could not and would not certify the SBW treatment process/program and its final waste or authorize shipments until 6 months after start of hot operations. The SBWT project assumes, primarily for milestone schedule reasons, that waste treatment must continue and final treated waste must be formed, packaged, and stored at risk. It is also assumed that a shutdown will be imposed by WIPP, as is historically the case, if anything, to resolve minor procedural, training, or other paperwork problems. (Note that it is also assumed that the final SBW DE waste product will not have to be physically reworked in any way, not only due to the assumed success of the prior waste form qualification work, but also because little alteration of it could be performed in any case.)

The plan is to operate on hot feed for 4 months and shutdown for 2 months for the WIPP review and possibly RCRA/Air Program reviews. It is assumed that at the end of this short shutdown, program certification would be given by WIPP along with approval to make the first shipment from Idaho to New Mexico.

\subsubsection{DE Treatment Operations Schedule (October 2010 to November 2013)}

SBW treatment by direct evaporation plus off-gas treatment to meet the air emission standards and DE product packaging is the third critical path activity on the overall schedule, assumed to require at least 3 years. Improvements to a 3-year operating schedule are possible, but not certain even with added expenditures.

Past studies (Barnes 2004a, Barnes 2003a) have assumed a 2.5-year treatment schedule for the direct evaporation process, but no major maintenance turnaround is assumed. At least one major maintenance turnaround of 6 months should be assumed to be required (two such turnarounds are assumed for CMACT). Shorter treatment schedules are technically feasible, by increasing equipment sizes or using multiple processing lines. While the treatment schedule can be reduced from 2.5 years, the shipping schedule cannot be reduced from about 6 years.

Shorter treatment schedules are technically feasible by increasing equipment sizes or using multiple processing lines, but this would increase the capital cost of the facility since these costs are a function of throughput. The DE process, being the simplest of the SBW treatment alternatives, is most adaptable to an aggressive treatment schedule. However, this is complicated by the relatively large volume of RH waste canisters 1,705 generated by the process, the most of all SBW treatment alternatives and more than twice that of the other two low volume RH treatment alternatives (SR and DV). The large number of RH canisters produced could mean that more frequent handling/mechanical problems arise while operating at a high rate. This could in turn result in more frequent shutdowns of the process, extending the treatment schedule. While the treatment schedule could possibly be reduced from 3 years, the rate at which WIPP can receive $\mathrm{RH}$-waste is limited and this would only aggravate the interim storage problem, requiring more storage locations, and also adding to the capital cost of the facility.

\subsubsection{DE Waste Shipment Schedule (April 2011 to December 2016)}

Remote handled (RH) waste shipments are receipt rate limited at WIPP and cannot keep pace with treatment nor be completed by the 2012 milestone. 
Idaho's SBW treatment production rate exceeds WIPP's receipt rate. This would result in net accumulation that drives the need for lag storage in Idaho and is a direct function of the treatment rate. Lag storage would be required, as described in the following paragraphs.

SBW treatment by direct evaporation would produce about $1705 \mathrm{RH}$ canisters with dose rates of 28 $\mathrm{R} / \mathrm{hr}$ on contact. The treatment generation rate could vary from as little as 3.4 canisters per operating day for a 500 day operating campaign (assumed to cover 2.5 years) to 8.5 canisters per operating day for a 200 day campaign ( 1 year) both calculated using a 7 day week at 24 hour per day operation. The WIPP overall RH receipt rate/capacity is 12 canisters per week over a 50-week year; one canister per cask and one cask per truck shipment. This receipt rate is physically limited by the receipt, off-loading, and handling system on the surface at WIPP and not by transportation or placement in the repository. This compares to the DE production rate of 23.9 to 59.7 canisters per week, 3.4 to 8.5 per day).

WIPP committed to DOE-ID in 2003 to take 6 RH canisters per week (300 per year) in the 2009 to 2012 time frame. RH capacity currently claimed by others in this time period is 3 canisters per week such that $75 \%$ of the total is currently claimed while Idaho claims half of that total. The difference between the generation rate in Idaho by direct evaporation and the take-away rate by WIPP is 17.9 canisters per week for a 2.5 year treatment period to 53.7 canisters per week for one year resulting in net accumulation. With the assumption (validated by WIPP) that shipments would not be authorized until 6 months after start of hot operations and the need to continue to treat and generate waste at risk, primarily to minimize schedule, calculations have been done that show that net peak accumulation would range from 905 canisters $(53 \%$ of the 1705 total) for a 2.5 year campaign to $1,405(82 \%)$ for a 1 year campaign given a WIPP RH receipt rate limitation of 6 canisters per week. It would take 5.7 years for WIPP to take all the DE RH waste at a rate of 6 canisters/week, 300/year. For a 2.5-year campaign it would take an additional 37 months, until December 31, 2016, to complete shipment of this accumulated inventory to WIPP with a project start date of February 1, 2005 and an end-of-treatment date of November 30, 2013. For a 1-year campaign it would take an additional 57 months to December 31, 2016 after an end-of-treatment date of March 31, 2012.

In the 2.5-year campaign scenario (38 months total, 2 months for a WIPP imposed shutdown plus 6 months for a major maintenance turnaround) the December 2012 milestone is missed by 11 months for treatment and 48 months for shipment to WIPP. In the 1-year campaign scenario (18 months total, 6 months for a major maintenance turnaround with the 2 month WIPP imposed shutdown inside this) the December 2012 treatment milestone is beat by 9 months but the same milestone for shipment to WIPP is missed by 48 months.

The 1-year scenario looks attractive but is very aggressive. Operationally, striving for an aggressive one-year treatment period for direct evaporation would be quite risky. It looks like there is a 9 month schedule contingency with this scenario, but as pointed out earlier in this report, the large number of RH canisters produced could mean that more frequent handling / mechanical problems would be encountered while operating at a high rate. This could in turn result in more frequent shutdowns of the process, extending the treatment schedule. The 2.5-year treatment schedule is recommended even though it misses the 2012 milestone.

Shorter SBW treatment operating periods (faster throughput), such as the 1-year period cited above, may be possible (but risky) with the DE process, if necessary, in an attempt to minimize schedule and perhaps meet the 2012 treatment milestone. However, besides being quite aggressive itself, this would aggravate the lag storage situation even further and significantly add to the capital project cost to provide for an additional 500 canister storage positions. 


\subsubsection{DE Schedule - Summary}

The 2012 milestone schedule can only be achieved with the direct evaporation SBW treatment alternative, if a very aggressive and risky treatment schedule is pursued. Schedule risks have been identified and include:

- $\quad$ Beginning Preliminary (Title I) Design activities on February 1, 2005. Any delay releasing this work will impact project completion.

- Completing sufficient technical development test work to support process definition and preliminary (Title I) design activities so that environmental permits can be prepared and submitted by January 1, 2006. Any delays in this set of activities, being on the critical path schedule, will impact project completion.

- An environmental permitting timeframe of 24 months, especially in light of opposition to thermal treatment by various Stakeholders.

- $\quad$ DOE funding, reviews, and approvals. The schedule assumes funding will be available in a timely manner and will not impact design, procurement, or construction.

- $\quad$ Technical Development (process testing) as this information iterates with final (detailed) as well as preliminary design.

- $\quad$ Mock-up testing of DE product packaging system equipment as this information iterates with detailed design.

- $\quad$ GFE procurement as it feeds into Mock-up testing and design.

- $\quad$ Testing, operational readiness reviews (ORRs), startup, and WIPP certification.

- $\quad$ Treatment over a 3-year period.

In addition to the risks listed above, normal risks associated with a project of this size and complexity can be expected including availability of skilled craftsmen, weather impacts, and timely delivery of equipment and materials. 


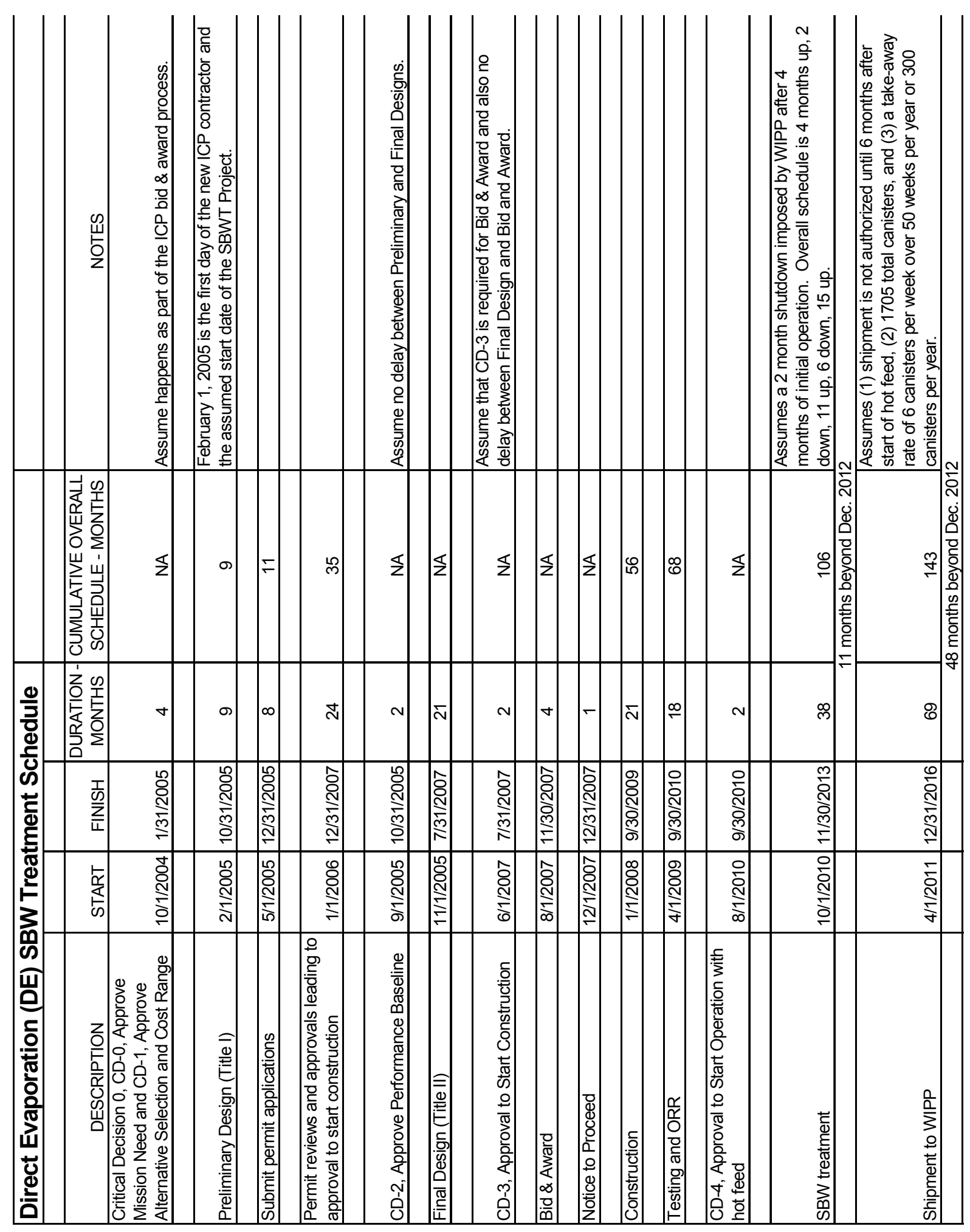




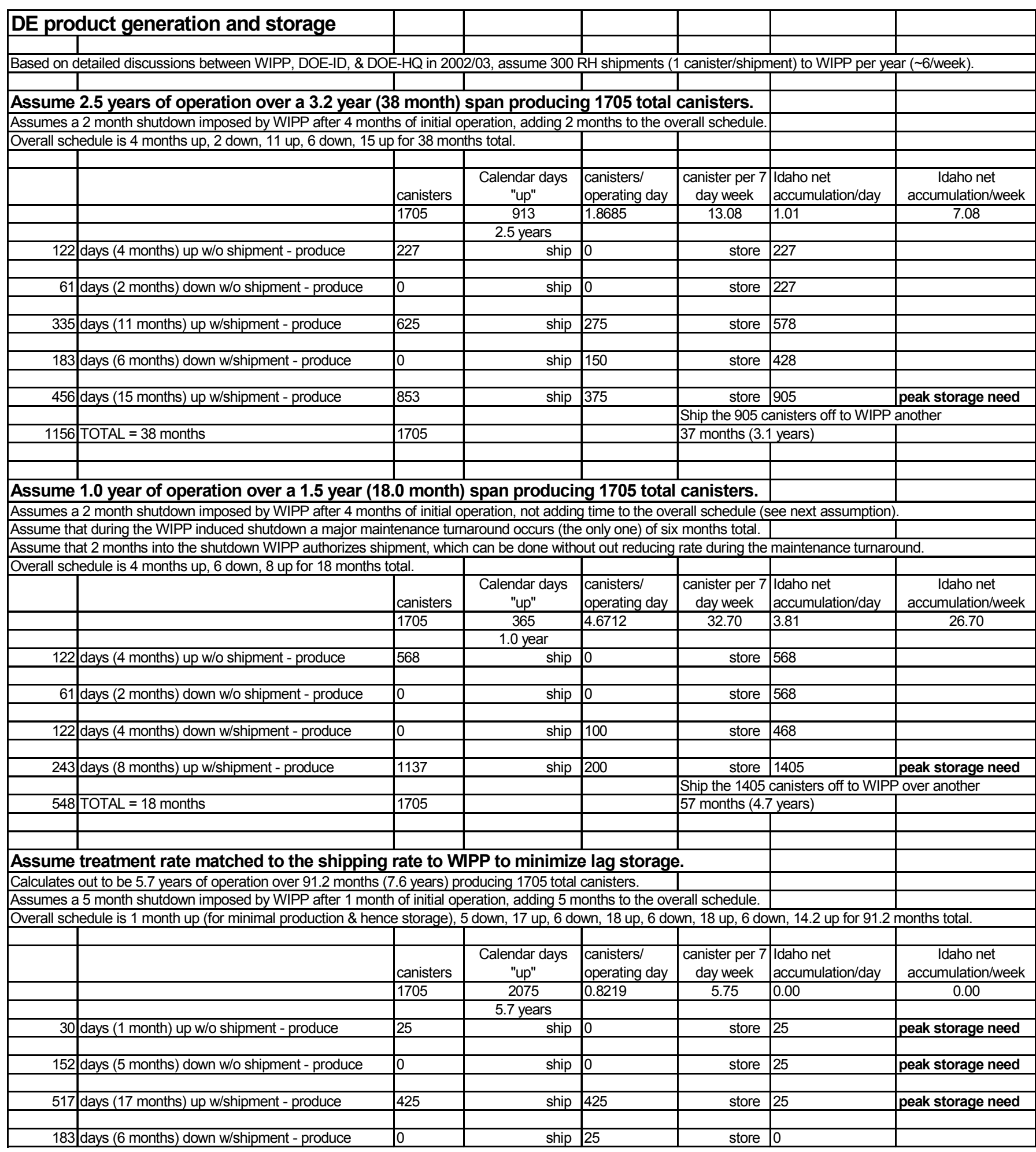




\subsection{DE Major Options}

1. An option within the baseline concept would be to slow down treatment to match the RH receipt/disposal rate at WIPP in order to minimize the size of lag storage in Idaho or eliminate it all together. In conjunction with this, a decision could be made not to proceed with treatment while WIPP reviews the overall process/program prior to authorizing initial shipment. This would additionally save the assumed 4 months of lag storage of waste produced at risk in the early stage of treatment. The two steps combined would save approximately $\$ 30 \mathrm{M}$ in capital project costs, but would add 54 months to the 2.5 year schedule and 74 months to the 1 year schedule, both well beyond 2012. However, in this particular SBW treatment alternative, which produces the greatest number of canisters, the costs of the significant extension to the treatment phase would almost certainly exceed any savings from smaller lag storage.

2. Another major option would be to retrofit the direct evaporation system inside the NWCF. This has not been assessed to any extent, but it would involve significant modifications to the contaminated systems in the hot cells of the NWCF. Changes would be required to the feed preparation system and either the fluidized bed (calciner vessel) would have to be removed to make space for the DE evaporator or other hot cells would have to be modified (with corresponding D\&D) in order to place the DE system. It should be noted that although a canister fill system might be possibly located inside the NWCF hot cells - in fact it must be - the maintenance area inside the NWCF, located above and providing access to the hot cells, does not have sufficient elevation nor crane capacity to load and handle RH casks. Besides this, an area must be provided for the DE canisters to cool/cure and significant lag storage must be provided for the peak need of 905 canisters, $53 \%$ of the total. The benefits to this approach would be: (1) re-use of the hot cells of the NWCF for possible cost and schedule savings, (2) re-use of some existing utilities, and (3) a good central fit for the process - the best possible access to the SBW feed, possible re-use of the first few unit operations involved in off-gas treatment, and line tie-ins and a route west out the main INTEC stack. The possible negatives include (1) high radiation exposure required for the in-cell modifications - much higher than that for the CMACT SBW treatment alternative; (2) multiple facilities would be necessary for canister storage and cask loading, which most likely could result in higher costs even with re-use of the NWCF cells and equipment; and (3) possible throughput limitations, and hence negative schedule impacts, if re-use of the NWCF off-gas treatment equipment or utilities turned out to be limiting. It is not likely that this option would be beneficial, on balance, if the radiation exposure cost turned out to be significant.

\subsection{DE References}

Barnes C. M., A. L. Olson D., D. Taylor (2004a), Sodium-Bearing Waste Treatment Technology Evaluation Report, INEEL/EXT-04-01692, February 2004.

Barnes C. M., C. B. Millet (2004b), Feed Composition for the Sodium-Bearing Waste Treatment Process, INEEL/EXT-2000-01378, Revision 4, June 2004.

Barnes C. M., R. A. Wood E. B. Packer (2003a), "Direct Evaporation Process Design,” Engineering Design File EDF-3679, September 10, 2003.

Barnes C. M., S. K. Janikowski, and C. B. Millet (2003b), Feed Composition for the Sodium-Bearing Waste Treatment Process," INEEL/EXT-2000-01378, Rev. 3, September 2003. 
Batcheller D., D. Taylor, V., and J. Johnson (2003), Characterization of Tank WM-189 Sodium-Bearing Waste at the Idaho Nuclear Technology and Engineering Center, INEEL/EXT-02-01171 Rev. 1, July 2003.

Bosley J. B., WIPP Waste Certification Strategy for the Sodium-Bearing Waste Treatment Project, DOE/ID-11057, August 2003.

Griffith D. L., S. J. Losinski, B. E. Olaveson, and L. G. Olson (2003a), Testing an Agitated Thin Film Evaporator for Solidifying Simulated Sodium-Bearing Waste (Test Series 1), INEEL/EXT-0300680, June 2003.

Griffith D. L. (2003b), Testing an Agitated Thin Film Evaporator for Solidifying a Mixture of Simulated Sodium-Bearing Waste and Undissolved Solids (Test Series 2), INEEL/EXT-03-01189, November 2003.

Griffith D. L., R. J. Kirkham, L. G. Olson, W. D. St. Michel , and S. J. Losinski (2004), Converting Simulated Sodium-Bearing Waste into a Single Solid Waste Form By Evaporation: Laboratoryand Pilot-Scale Test Results on Recycling Evaporator Overheads, INEEL/EXT-04-00172, January, 2004.

Kimmitt R. R. (2003), “Feasibility Study for Direct Evaporation of Sodium Bearing Waste,” Engineering Design File EDF-2524, Rev. 0, May 20, 2003.

Kirkham R. J. (2004), “Laboratory-Scale Direct Evaporation Development Report FY-03; Bottoms Product Concentration and it's Relation to Off Gas Emissions and Volume," Engineering Design File EDF-4538, February 2, 2004.

Lee L. G. "Liquid Effluent Treatment \& Disposal Facility Hazards Analysis," Engineering Design File EDF-3329, June 19, 2003.

Morrell D. K. "Mixing Pumps for Homogenizing TFF-SBW Liquids and Solids - Calcination with MACT Upgrade SBW Treatment Alternative,” Engineering Design File EDF-3307, April 24, 2003.

Stoller Corporation S. M. (2003), "Preliminary Hazard Evaluation of All Sodium Bearing Waste Preliminary Process Design and Treatment Options," January 21, 2003.

Wendt D. S. (2003) "Radiolytic Hydrogen Gas Generation in Dried SBW UDS and Tank Solids," Engineering Design File EDF-3392, January 27, 2003.

WIPP (2002a), Safety Analysis Report for the RH-TRU 72-B Waste Shipping Package, November, 2002, http://www.wipp.carlsbad.nm.us/library/RHsar/rhsar/rhsartoc.pdf.

WIPP (2002b), Remote-Handled TRU Waste Acceptance Criteria for the Waste Isolation Pilot Plant, DOE/WIPP-02-3123, draft, June 2002.

Wood R. A. (2002), "Heel Solids Processing Evaluation for the SBW Treatment Project - Calcination with MACT Upgrade Alternative,” Engineering Design File EDF-3049, December 4, 2002. 


\section{CESIUM ION EXCHANGE AND STABILIZATION (CsIX)}

The baseline process scenario for this SBW treatment alternative involves independent processing of liquid SBW and tank solids. The steps include neutralization of the liquid SBW feed, filtration to remove tank solids, ion exchange to remove cesium (and with it most of the contribution to the radiation field), and then grouting to form a contact-handled ( $\mathrm{CH})$ waste for disposal at WIPP. The cesium-loaded ion exchange sorbent is a high activity remote-handled (RH) TRU waste to be disposed of as-is (washed and dried and disposed with the column) at WIPP. The tank solids will be captured on a cloth/candle type filter, washed and dried in-place on the filter, and back-pulsed off the filter into canisters for disposal as RH waste at WIPP. See Figure 4-1. All operations would be located in one common new facility.

\subsection{CsIX Physical Systems - Process/Technical and Related}

\subsubsection{CsIX Technical Risks Related to Waste Product Qualification, Characteristics, and Storage}

Uncertainties about the radiological properties of the RH wastes produced by the CsIX process (ion exchange sorbent and tank solids) require additional analysis and possibly testing with actual waste to resolve.

The TRU content of the spent ion exchange media is uncertain and may be less than the minimum required for WIPP disposal. Calculations based on assuming no absorption of transuranic radionuclides by the ion exchange sorbent and flushing of spent sorbent with water using four times the amount of interstitial liquid in the sorbent predict a TRU content of $104-135 \mathrm{nCi} / \mathrm{g}$ for the spent sorbent. For disposal at WIPP, the waste must have a TRU content greater than $100 \mathrm{nCi} / \mathrm{g}$ (WIPP 2004). Test data with a simulant spiked with ${ }^{239} \mathrm{Pu}$ suggests a higher TRU content of the spent sorbent, approximately 300 $\mathrm{nCi} / \mathrm{g}$ (Tranter 2003a). ${ }^{\mathrm{d}}$ Additional testing could provide a higher confidence that the spent sorbent will meet the TRU content acceptance criteria at WIPP. Design changes could also be made to eliminate the risk of not meeting this disposal criterion. For example, flushing the spent sorbent with waste from the tank solids receiving tank would increase the TRU content of the spent sorbent.

Radiolytic hydrogen generation in the spent sorbent and tank solids waste product canisters are uncertain. The WIPP RH-TRU 72-B Cask Safety Analysis Report requires that hydrogen concentrations in all void spaces within a 72-B shipping cask be less than 5 vol\% (WIPP 2002a). Compliance can be demonstrated by measuring either a hydrogen generation rate or decay heat value, or by calculating either of these using conservative assumptions. Calculations for both of these methods depend on the waste code of the particular waste stream. The waste code for the tank solids and the spent sorbent wastes have not been established. However, preliminary calculations have been done to estimate how much water is allowable in SBW solids wastes (Wendt 2003). Given the radionuclide content of the waste, the rate of hydrogen generation in the waste product canister depends primarily on its water content. Wendt modeled hydrogen generation from SBW solids dried to different levels and recommended removal of water to less than $20 \mathrm{wt} \%$ (Wendt 2003). Both the tank solids and spent IX sorbent wastes are dried before they are packaged, and hence the moisture content can very likely be controlled. However, the moisture content achievable by drying and the extent of drying required are both uncertain. Nitrites present in the tank solids could alter the hydrogen generation rate, allowing a higher fraction of water. And the amount of hydrated water contained in dried tank solids is uncertain. Analysis of a sample of undissolved solids

d. The value of $368 \mathrm{nCi} / \mathrm{g}$ shown in Table 2 of Tranter is based on a higher feed TRU content than expected in two of the SBW waste tanks. 


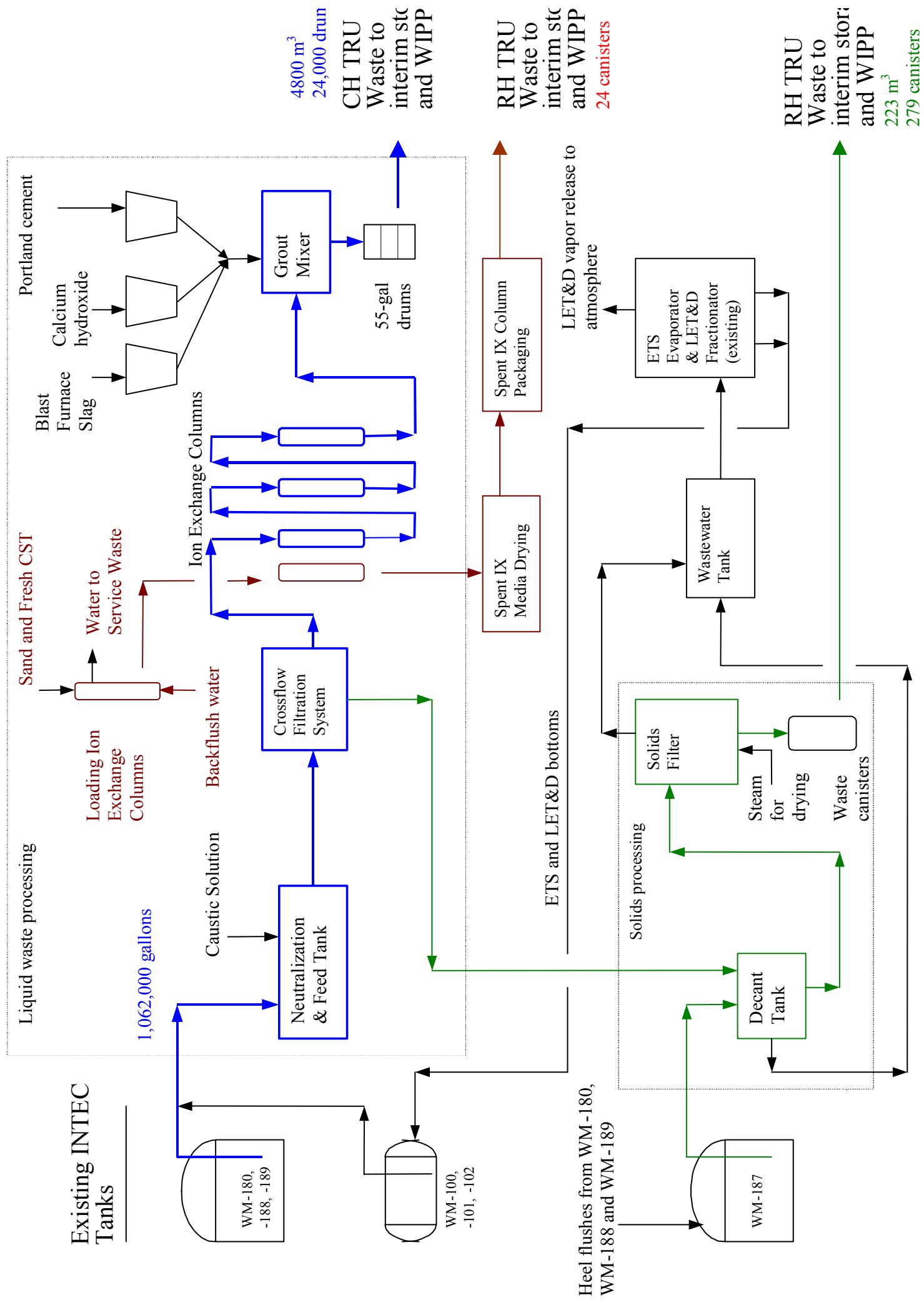

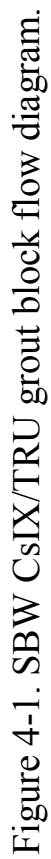


from Tank WM-1 80 shows a water of hydration content of $25 \mathrm{wt} \%$ (Christian 2002), and the water of hydration of solids in other tanks could be higher (Barnes 2003).

The ion exchange media is not expected to form hydrates, and thus there is high confidence that the sorbent can be dried to low moisture content. However, the heat generation rate of the spent sorbent waste will be much higher than the tank solids waste. Hence, the issue of hydrogen generation for both spent sorbent and tank solid waste products is not resolved. Proposed methods of drying each of the waste types have not been tested. Additional test data and calculations would provide a better basis for detailed design and help resolve this risk.

The WIPP WAC for RH has not been issued. WIPP has prepared a draft WAC document for RH waste (WIPP 2002b), but the document is not final. Additional requirements for RH TRU waste are contained in the RH-TRU 72-B "Cask Safety Analysis Report" (SAR) (WIPP 2002a). Until the RH-WIPP WAC is issued, there will be uncertainty regarding the disposal requirements for tank solids and spent sorbent wastes. Working closely with WIPP during all phases of the project should mitigate this risk.

The concentration of VOCs in the headspace of CH-grout is uncertain. SBW contains small concentrations ( $\sim 0.2-1 \mathrm{~g} /$ liter) of organics (Barnes 2003). Because the present waste has been previously concentrated by evaporation, any remaining organics in SBW have low volatility. Thus the risk that these organics would volatilize after the waste has been solidified and packaged is very low. However, no tests have been performed to determine the concentration of VOCs in the headspace of waste containers. If the concentration exceeds $500 \mathrm{ppm}$, the waste would not be acceptable for disposal at WIPP.

\subsubsection{CsIX Risks Related to Feed Uncertainties and Feed Transfer}

\section{Consequences to the process performance of feed uncertainties are small or negligible if appropriate design steps are taken.}

Present Tank Farm management plans call for consolidation of all SBW into tanks WM-187, WM188, and WM-189 by the end of CY 2004. Additional waste generated in 2005 would continue to be added to WM-187 and WM-188, and then from 2006 on, segregated in separate, smaller tanks (WM-100, WM-101, and WM-102). Waste in one Tank Farm tank, WM-189, was sampled and analyzed in 2002 (Batcheller, 2003), and its composition is not expected to change prior to treatment. While changes are expected in the contents and composition of waste in WM-187 and WM-188, waste to be sent to these tanks has been sufficiently well characterized to have high confidence in the predicted compositions for the liquid in these tanks (as documented in Barnes 2004b).

The composition of tank solids is uncertaint. Most of the solids ( $>85 \%)$ contained in the Tank Farm have been consolidated in Tank WM-187 by tank closure work. The solids in this tank were sampled and analyzed in February 2004. Since solids in Tank WM-187 have not been well mixed, the recent analysis may not be representative of all the solids in the tank. Analyses of solids samples from other tanks that were flushed to WM-187 provide a basis to estimate the range of solids composition in the tank. Knowing an approximate composition range, the uncertainty in the solids composition should not affect the performance of the solids treatment operations that depend more on the solids physical properties. Also, samples will be taken of fully mixed solids slurry in the treatment facility to provide data for waste qualification.

The most recent process design for the CsIX treatment alternative (Barnes 2004) has not been updated to incorporate effects of the consolidation of WM-180 waste into Tank WM-187. This change has both positive and negative effects on the process. Concentration of Tank WM-180 waste will result in a lower volume of $\mathrm{CH}$ grout waste generated by the CsIX process. However, with the bulk of the tank 
solids now contained in a concentrated rather than a dilute liquid, the solids processing strategy will require more or larger equipment, or more processing time. The present process configuration has separate processing equipment for SBW liquid and solids, and these two feed streams are processed simultaneously. Since the solids will now be contained in SBW liquid, the liquid in Tank WM-187, if simply drawn out of the tank using the existing steam jets, will need to be processed before the solids can be accessed and retrieved with assistance from the tank closure wash ball, creating a significant delay in solids processing. Alternatively, mixing pumps could be installed in Tank WM-187 to enable treatment of solids in a process modified for integrated solids/liquid processing. In any case, with or without tank mixing pumps, after bulk waste retrieval and processing, the three SBW feed tanks (WM-187, 188, and 189) will need to be washed for closure generating a dilute liquid/undissolved solids feed that will also need to be processed through the CsIX plant after re-concentration in the INTEC evaporators. Thus, with the possible exception of the cross-flow filter, the integrated CsIX process would not eliminate any equipment from the present design. Additional evaluations are needed to modify the CsIX process design for the recent Tank Farm management changes.

If mixing pumps are not installed in WM-187, which is the present plan, transferring the solidsliquid mixture to the treatment facility using the tank cleaning wash ball and existing steam jets could be problematic. The estimated undissolved solids content of a well-mixed Tank WM-187 is 63-130 g/liter; settled on the bottom of the tank it is much higher. Flocking up solids into the jet suction leg using the wash ball, without control to any extent, could result in higher concentrations being sucked into the transfer line while the distance to the new CsIX plant would, by necessity, be longer than tank-to-tank transfers within the Tank Farm. Mixtures with up to about $100 \mathrm{~g} /$ liter have been transferred in the past; with higher solids concentrations, some solids may settle in transfer lines. A better estimate of the amount of solids in Tank WM-187 may be available in mid-2004 when liquid in the tank has been withdrawn to the minimum heel level.

Solids settling behavior with a flocculent has not been demonstrated. Although the particle size distribution of solids from different tanks is approximately the same, the settling rate behavior of different samples has been found to be very different (see Figure 3 of the Feed Composition for Sodium-Bearing Waste Treatment Process, Rev. 3, Barnes 2003). To reduce the settling time for the worst case solids, the present design assumes that a flocculent is used. No tests have been performed using the recommended flocculent; thus, there is uncertainty about its behavior. The flocculent selected is caustic. By reducing the acidity of the tank solids liquids, additional solids should precipitate, agglomerate, and increase the settling rate.

The amount and composition of NGLW are uncertain. NGLW that will be fed to the SBW treatment facility will be a collection of dozens of different wastes streams. Some of these waste streams have been generated in the past, sampled, and analyzed. For many, analysis was performed for only a few species, and for others, the waste has yet to be generated and so no analysis is available. The greatest uncertainties in the NGLW composition are for radionuclides. To minimize the effect of these uncertainties on characterization and qualification of waste from the treatment facility, the NGLW will be blended with SBW prior to treatment. The expected total volume of NGLW is small relative to SBW $(\sim 8 \%)$; hence, blending it with SBW will significantly reduce the uncertainty in the treatment facility feed composition.

\subsubsection{CsIX Risks Related to Use of Existing Evaporators and the LET\&D Facility}

No significant risks have been identified for use of existing facilities in the CsIX alternative.

Dilute waste streams generated by the CsIX process include decant water from solids transfer, filtrate from solids separation, condensate from drying spent sorbent and solids, and rinse water from 
rinsing spent ion exchange sorbent. These wastes will be combined and periodically processed by existing INTEC facilities, namely the Process Equipment Waste Evaporator (PEWE), Evaporator Tank System (ETS), and Liquid Effluent Treatment and Disposal (LET\&D) Facility. The dilute wastes generated are expected to be very similar in composition to wastes previously treated by these facilities and require no modifications other than an appropriate tie in to the PEWE feed system. There is a small risk that one or more of these facilities would be closed prior to SBW treatment. However, should CsIX be selected for SBW treatment, the need for use of these facilities would likely preclude any effort to close them.

\subsubsection{CsIX Risks Related to Ion Exchange}

\section{Testing has repeatedly demonstrated that the selected cesium ion exchange sorbent ("CST") can adequately remove cesium from partially neutralized SBW. Uncertainties remain but have minimal consequences.}

The recommended sorbent for removal of cesium from SBW is IONSIV IE-911, also known as crystalline silicotitanate or "CST" (Kimmitt, 2003; Todd, 2003, Tranter, 2003a). Testing of this sorbent using simulated and actual SBW has been performed since 1997 (Mann, 1999; Mann, 2000; Todd, 2001; Tranter, 2003a; Tranter, 2003b, Tranter, 2003c, Tranter, 2004a, and Tranter, 2004b).

There have been concerns about the stability of the selected sorbent in the acidic SBW, but these concerns have been allayed with recent test data. Initial batch contact tests with CST exposed to SBW and NGLW showed inconsistent results in terms of degradation of the sorbent (Tranter 2003b). These batch tests were followed by column tests at small scale $\left(2-4 \mathrm{~cm}^{3}\right.$ bed), which showed $16-18 \%$ degradation based on dissolved zirconium in the total column effluent (Tranter 2003a). Larger-scale tests $\left(500-\mathrm{cm}^{3}\right)$ indicated less than 3\% degradation (Tranter 2004a). To resolve the apparent inconsistencies seen in the sorbent stability in these tests, a final set was performed in which degradation was measured versus the amount of feed processed. The results of these tests are presented and discussed in EDF-4612 (Tranter 2004). In brief, the results show that the sorbent degradation falls off very rapidly with time and does not significantly affect either the ability of the sorbent to remove and retain cesium and or its cesium capacity.

There is a risk of variation in performance of different batches of cesium sorbent received from the supplier. Breakthrough curves for dynamic column tests using two different batches of CST sorbent show significant differences (see Figure 4 of Tranter 2004a). While the shape of the breakthrough curves for the two sorbent batches are different, the cesium removal at low bed volumes, which will determine the waste effluent cesium concentration (and hence the grout dose rate), and the cesium loading of the two batches, appear to be very similar. Thus the effect of the differences appears to be negligible. Discussions with the supplier and a possible audit of the supplier's quality control procedures for manufacture of the sorbent may reduce this risk.

There is uncertainty in the behavior and effect of fine particles that pass through the cross-flow filter or are formed in the bed on ion exchange column performance. A small fraction of undissolved particles present in the SBW feed will pass through the filter and enter the ion exchange column. A small amount of ion exchange media fines may also be generated through degradation of the bed. The ion exchange column contains a layer of sand in the bottom to act as a filter for both ion exchange bed media fines and these waste solids fines. No testing of the filtration of this sand bed has been done. Particles that pass through the ion exchange bed potentially could cause the grouted waste to exceed the limiting dose rate for contact-handled waste. The probability of this occurring is very small because particles would need to pass through three beds in series and the ion exchange effluent will be monitored, and if ${ }^{137} \mathrm{Cs}$ is detected above a set level, the effluent recycled to the feed. Also the potential for these solids causing detrimental effects on the sorbent performance is very small because of the small quantity of solids and the change-out frequency of ion exchange columns. If this was expected to be a problem, or if 
conservatism warranted it, a polishing filter, such as a dead-head cartridge type, could be installed on the IX effluent line.

\subsubsection{CsIX Risks Related to Grouting}

Testing has provided a basis for the design of equipment to grout the cesium-free SBW. Uncertainty remains regarding the optimum formulation for each of the tank wastes and the effect of trace species in the waste on grout properties.

The possibility of off-spec grouted product should be addressed during design. Off-spec product could result from a variety of equipment malfunctions. Free liquid present in drums could result from inadequate mixing or failure of valves or instrumentation. The design should evaluate where redundancy or additional equipment is needed to prevent or reduce failures or to handle off-spec product and recover from failure events.

The effect of some trace species present in the SBW on the grout is uncertain, and testing has not been performed for the full range of the SBW tank wastes. Grout formulation tests for the CsIX process have been performed over the past 6 years (McCray 1999; Herbst 1999; Herbst 2000; Herbst 2002, Raman 2003). These tests have used simulants representing a composite of average SBW composition, Tank WM-180 waste and Tank WM-189 waste. Many low concentration species present in the waste were not included in the simulants. A recent change in Tank Farm Management plans will result in Tank WM-180 waste being more concentrated than that which was tested. Also, Tank WM-188 waste, while similar in composition to waste in WM-189, will have higher concentrations of chloride and fluoride than WM-189. The effects of most species present in SBW but not included in simulants should be negligible. However, a few species, such as the organics, could affect grout properties. These uncertainties should be addressed by additional testing or by flexibility and conservatism in the design.

The tendency of the grouted waste to loose or bleed water inside the drum will need to be addressed in the design. Concerns have been raised about the potential for water formation over time in grouted waste containers due to either thermal cycling or evaporation/condensation while in storage. Tests performed in 2000 (Herbst 2000) showed no evidence of water formation during thermal cycling but did show significant mass loss $(\sim 15-30 \%)$ when exposed to dry air over a period of days. The design should address this tendency of the waste to loose water such that waste as shipped will contain no free liquid. NOTE: The WIPP hazardous waste facility permit for waste with a U134 hazardous waste number requires that the waste container contain no liquid, including condensation inside the container.

\subsubsection{CsIX Risks Related to Solids Processing}

Certain solid/liquid separation design parameters have not been determined experimentally with either actual waste or a suitably representative stimulant. While some of these parameters can be determined during start up, testing of some systems may be needed to confirm a trouble-free design.

The present design (Barnes 2004a, and Appendix B) includes a cross-flow filter for removing undissolved solids from ion exchange column feed and a cartridge-type (Fundabac) filter for removal and drying of solids from tank heel slurries. The selection of multiple filter types or arrangement of the filters could be affected by the recent decision to add concentrated WM-180 waste to the heel solids collected in Tank WM-187. However, regardless of whether one or both of these filters is selected for an SBW treatment facility design, certain design parameters have yet to be established experimentally. 
There is uncertainty in the behavior of very small solids ( $<0.5$ micron) in the cross flow filter. These solids could pass through the filter, or could accumulate in the membrane pores and reduce the permeate rate. Related to this uncertainty is the cross-flow filter recirculation rate. Including a variable speed pump in the design so that the recirculation rate can be adjusted will mitigate this uncertainty. In addition to the recirculation rate, the operating parameters of pressure, permeate flux, and solids blowdown frequency will need to be optimized during startup.

For the Fundabac filter, current designs dry the filter cake in-place prior to discharge. This is a common practice in industrial use of these filters, but operating parameters (temperature, rate, drying time, and type of drying gas) have not been determined experimentally for the tank solids filter cake. Drying the solids on the filter was selected over other methods of drying because of its simplicity compared to alternatives, but without demonstration tests, drying could be a high-maintenance operation.

Tests using a small-scale filter have shown that dried filter cake easily separates from the filter cloth (Pao 2003). These tests alleviate to some degree the concern about discharge of the dried solids from the Fundabac filter into the canister. After design concepts for the canister filling/handling system have been defined, mock-up tests are recommended to (1) demonstrate that solids do not clog the passageway into the canister during filling, (2) demonstrate contamination control, (3) determine the solids bulk density in the canister, (4) demonstrate a method for determining when the canister is full, and (5) determine cycle times and maintenance requirements for the filling/packaging system.

\subsubsection{CsIX Balance of Plant Requirements, Facility Siting, and Interfaces}

Steam is required for the CsIX process to support existing operations (jets to transfer waste from the Tank Farm, PEWE reboiler, ETS reboiler, and LET\&D reboiler), and may also be used to dry the tank solids, transfer waste water from the treatment facility to the PEWE, and possibly to heat air that dries spent ion exchange sorbent. The expected usages are within INTEC steam generation capabilities. Existing INTEC systems are expected to be adequate for other utilities - air, electricity, cooling water, and process water - although this should be confirmed during design.

Sampling requirements for the CsIX process have not been defined. However, because it was determined that existing INTEC analytical capabilities (RAL) were sufficient for the CMACT process, and because the CsIX process is a simpler process with fewer process streams, it's very likely the analytical capabilities of RAL would be sufficient for this treatment alternative.

In their feasibility study of the CsIX treatment process, Raytheon sited the facility to the north of the Tank Farm Facility (Raytheon 2003), based on its proximity to the Tank Farm, the availability of utilities, economy of construction, availability of land, vehicle access, and not being in a flood plain. While the process has been updated from the Raytheon design, the rationale for the location has not changed. A new transfer line would connect the CsIX facility with the Tank Farm, and connect the wastewater tank in the CsIX facility with the PEWE feed collection system.

\subsubsection{CsIX Safety Concerns}

A preliminary hazards analysis (PHA) was performed as part of the Raytheon Feasibility Study (see Section 9.5 of Raytheon 2000) that identified 8 potential hazards and 11 safety features incorporated into the design to prevent or mitigate these hazards.

More recent PHAs have been performed by Stoller (2003) and Anderson (2003). In the PHA documented by Anderson, 55 potential hazardous events were identified. Design features to prevent and mitigate these hazardous events were not identified, but the likelihood category and relative risks were 
quantified. Events with the highest risks included a system leak, an ion exchange column being dropped, breathing toxic fumes, and direct exposure to an ion exchange column.

In the Stoller PHA, 33 hazardous events were identified and preventive or mitigative features identified for some of these events.

\subsubsection{CsIX Future Use Considerations}

NGLW will continue to be generated after 2012, although at a decreasing rate and possibly with decreasing radioactivity. Current projections indicate an annual generation rate decreasing from 4,400 to 3,100 gallons from 2012 to 2035 . The annual NGLW production could be processed in the CsIX treatment facility in about 2 days. Processing small batches is technically feasible, but maintaining the facility for only a few days operation per year may not be economical. However, present estimates of NGLW production do not include the decontamination of many INTEC facilities. The CsIX evaporation process would likely be able to process the liquid waste from closure of these INTEC facilities. Also, because the CsIX process will have systems capable of processing both liquid wastes and slurries, it may be able to process a greater fraction of facility decontamination wastes than other treatment alternatives.

\subsubsection{CsIX Process/Technical Summary}

Table 4-1 presents a summary of the technical risks and issues for the CsIX/TRU Grout process. The probability and impact values shown are on a scale of 1 to $10(1=$ low probability or impact $)$ and based on the author's judgment rather than any formal process or group evaluation. A probability of 5 is equivalent to a $50 \%$ chance that the identified risk would occur or cause detrimental effects. The "Resolution" column presents a recommendation on how the issue should be resolved, usually either by evaluations during design or testing.

Table 4-1. Summary of technical issues and risks - cesium ion exchange/TRU grout (CsIX).

\begin{tabular}{|c|c|c|c|c|}
\hline & Risk or Issue & Probability & Impact & Resolution \\
\hline 1 & $\begin{array}{l}\text { The TRU content of the spent ion } \\
\text { exchange media may be less than } \\
\text { the minimum required for WIPP } \\
\text { disposal. }\end{array}$ & 4 & 8 & $\begin{array}{l}\text { Design studies to develop } \\
\text { a method for ensuring } \\
\text { TRU content is above } \\
\text { minimum or testing with } \\
\text { actual waste. }\end{array}$ \\
\hline 2 & $\begin{array}{l}\text { The radiolytic hydrogen generation } \\
\text { in the tank solids waste and spent } \\
\text { sorbent waste canisters is uncertain } \\
\text { and potentially could exceed WAC }\end{array}$ & 4 & 5 & $\begin{array}{l}\text { Assign waste code and } \\
\text { perform calculations } \\
\text { during design, possibly } \\
\text { followed by testing to } \\
\text { confirm adequate drying } \\
\text { can be achieved }\end{array}$ \\
\hline 3 & $\begin{array}{l}\text { Changes could be made in final } \\
\text { WIPP RH WAC }\end{array}$ & 5 & 5 & $\begin{array}{l}\text { Design and negotiation } \\
\text { with WIPP }\end{array}$ \\
\hline 4 & $\begin{array}{l}\text { The concentration of VOCs in the } \\
\text { headspace of the contact handled } \\
\text { grout waste product is uncertain } \\
\text { and could possibly exceed WAC }\end{array}$ & 2 & 7 & Testing \\
\hline 5 & $\begin{array}{l}\text { The CsIX process design has not } \\
\text { been updated for consolidation of } \\
\text { SBW into three TFF tanks }\end{array}$ & 4 & 4 & Design \\
\hline 6 & $\begin{array}{l}\text { Steam jet transfer of high-solids } \\
\text { WM- } 187 \text { waste could result in } \\
\text { settling of solids in transfer line }\end{array}$ & 5 & 7 & Design evaluation \\
\hline
\end{tabular}




\begin{tabular}{|c|c|c|c|c|}
\hline & Risk or Issue & Probability & Impact & Resolution \\
\hline 7 & $\begin{array}{l}\text { Solids settling behavior is uncertain } \\
\text { risking oversized tanks or longer } \\
\text { solids processing times }\end{array}$ & 4 & 3 & $\begin{array}{l}\text { Testing using recently } \\
\text { developed stimulant } \\
\text { could reduce this risk; } \\
\text { design evaluations could } \\
\text { better determine and } \\
\text { reduce the impact of this } \\
\text { uncertainty }\end{array}$ \\
\hline 8 & $\begin{array}{l}\text { NGLW generation rates and } \\
\text { composition uncertain and could } \\
\text { affect process }\end{array}$ & 3 & 2 & Design \\
\hline 9 & $\begin{array}{l}\text { Inconsistent CST performance } \\
\text { could possibly be seen if purchased } \\
\text { from different batches }\end{array}$ & 5 & 6 & $\begin{array}{l}\text { Review of supplier's } \\
\text { quality control method } \\
\text { followed by discussions } \\
\text { of possible changes }\end{array}$ \\
\hline 10 & $\begin{array}{l}\text { The behavior of fines in the ion } \\
\text { exchange column is uncertain, } \\
\text { resulting in the potential for CH- } \\
\text { waste contamination by high- } \\
\text { activity fines }\end{array}$ & 2 & 7 & Design \\
\hline 11 & $\begin{array}{l}\text { Equipment malfunctions could } \\
\text { result in off-spec grouted waste }\end{array}$ & 5 & 9 & $\begin{array}{l}\text { Design RAM studies and } \\
\text { evaluations of methods of } \\
\text { recovery if failures occur }\end{array}$ \\
\hline 12 & $\begin{array}{l}\text { The effect of trace species in SBW } \\
\text { on grout properties is uncertain, } \\
\text { also the full range of expected } \\
\text { SBW composition has not been } \\
\text { tested }\end{array}$ & 2 & 6 & $\begin{array}{l}\text { Flexibility in the design } \\
\text { to adjust grout } \\
\text { formulation and possible } \\
\text { testing of actual tank } \\
\text { waste or more complete } \\
\text { simulants }\end{array}$ \\
\hline 13 & $\begin{array}{l}\text { Water could form in grouted waste } \\
\text { due to evaporation/condensation or } \\
\text { thermal cycling }\end{array}$ & 3 & 6 & Design evaluations \\
\hline 14 & $\begin{array}{l}\text { The behavior of very small } \\
\text { particles in the cross flow filter is } \\
\text { uncertain; these particles could } \\
\text { potentially clog the filter }\end{array}$ & 3 & 5 & $\begin{array}{l}\text { A design evaluation to } \\
\text { select the filter type(s), } \\
\text { followed by possible } \\
\text { filter testing }\end{array}$ \\
\hline 15 & $\begin{array}{l}\text { Operating parameters of the cross- } \\
\text { flow filter are somewhat uncertain }\end{array}$ & 3 & 4 & $\begin{array}{l}\text { Optimization of these } \\
\text { operating parameters } \\
\text { during startup }\end{array}$ \\
\hline 16 & $\begin{array}{l}\text { Operating parameters for drying of } \\
\text { the filter cake on the Fundabac } \\
\text { filter are uncertain }\end{array}$ & 5 & 6 & $\begin{array}{l}\text { Tests of drying simulated } \\
\text { solids on a Fundabac } \\
\text { filter }\end{array}$ \\
\hline 17 & $\begin{array}{l}\text { The basis for the design and } \\
\text { performance of the tank solids } \\
\text { packaging system is uncertain }\end{array}$ & 8 & 9 & $\begin{array}{l}\text { Mock up testing of } \\
\text { packaging system }\end{array}$ \\
\hline 18 & $\begin{array}{l}\text { The density of the dried tank solids } \\
\text { is uncertain, resulting in possibly } \\
\text { more (or less) solids waste than } \\
\text { expected }\end{array}$ & 5 & 4 & $\begin{array}{l}\text { Design evaluation to } \\
\text { better determine impact } \\
\text { of low density solids and } \\
\text { evaluate densification } \\
\text { techniques }\end{array}$ \\
\hline
\end{tabular}




\subsection{CsIX - Environmental / Regulatory and Related}

\subsubsection{CsIX Permitting}

\section{A 24-month permitting schedule, critical path early in the project schedule, appears to be the best that can be achieved.}

The baseline for the SBWT project identifies a 24-month permitting schedule, including the Hazardous Waste Management Act (HWMA) and Clean Air Act (CAA) permits. This may be optimistic, since discussions with the State of Idaho, Department of Environmental Quality (IDEQ) in the spring of 2003 indicated that IDEQ estimated 32-months to permit the SBWT project after receiving the HWMA or CAA permit modifications or applications. The project will need to work with the DEQ to streamline the permitting schedule. (The 32-month schedule was worked down to 24 months by taking time out of the operating contractor's activities only.) The following discussion identifies the permitting and regulatory needs for the three parts of the CsIX SBW treatment alternative.

The CsIX facility will require CAA and HWMA permits. The emission from waste transfers, neutralization, and solids dry will need to be evaluated for inclusion in the Title V permit. The CsIX facility and storage area will need to be permitted as hazardous waste management units. The CsIX storage tanks, grout treatment, product packaging, and container storage will be permitted under the Hazardous Waste Management Act. Tanks and equipment in the PEWE that will provide support to the CsIX process are permitted in Volume 14 or Volume 18 to the INEEL HWMA Permit.

The CsIX SBW treatment alternative consists of three parts to be permitted and constructed to treat the waste by the end of 2012: (1) Construction of the filtering and ion exchange treatment units to remove solids and lower the radioactivity of the liquid waste. (2) Construction of the grouting and packaging facilities to place the contact-handled grout in drums and to place the remote-handled solids in canisters. (3) Construction of container storage and load-out facilities for RH and CH-TRU wastes pending shipment to WIPP. (The process off-gas emission would be subject to Title V Standards).

4.2.1.1 CsIX Air Permitting. The CsIX treatment unit will generate emissions from filters, solids drying, and tanks similar to the PEWE System, Volume 14 of the INEEL HWMA permit, and will need to meet the requirements in the CAA. The CsIX treatment units and associated tanks and storage areas will be permitted under HWMA regulations and the emissions will be permitted under the CAA, NESHAPS, and Title V.

4.2.1.1.1 CAA - New Emission Sources-The CsIX treatment alternative will generate a small quantity of emission from waste transfers and solids drying. Therefore, it is anticipated that the CsIX treatment alternative will not need a new source review or PSD permit.

4.2.1.1. Title V Permit-The Title V Permit application for the INEEL has been submitted to IDEQ for approval. IDEQ is still reviewing the application and should issue a final permit by May 2005.

The Title V permitting sets forth the comprehensive state air quality operating permits program and emission limits. Sources subject to the operating permit requirements shall have a permit to operate that assures compliance by the source with all requirements. Of primary interest for SBW are emissions of radionuclides, organics, and nitrogen oxides. Table 4-2 at the end of the section identifies the list of constituents that need to be addressed when evaluating if the CsIX treatment alternative requires a permit modification. 
The Title V Air Permit identifies the NESHAPs emission limits, process controls, and emission control equipment for each source. New emissions are added to the Title V permit through the permit to construct and the permit to operate. The permit to construct identifies the potential emissions and controls based on the facility design. The permit to operate is based on emissions testing when the source is operating. Emission limits and controls are established for each source based on emission testing, if required. The emission limits and controls are then added to the Title $\mathrm{V}$ permit by modifying the permit to include the new source.

The risk is low that emissions from the CsIX treatment or storage units or a combination of the INEEL sources will exceed the NESHAPs limits requiring additional off-gas treatment to meet the emission limits. The project needs to start early in the design to gather the information necessary to submit applications for the Title $\mathrm{V}$ and permit to construct.

4.2.1.2 CsIX HWMA Permit. The CsIX facilities would treat, package, transfer, and store the waste in containers. The waste treatment of the remote-handled solids would be filtering solids, removal cesium by ion exchange, drying of solids and spent ion exchange media, packaging the waste in canisters, and storing the canisters pending shipment to WIPP. Waste treatment of the contact-handled waste is accomplished through neutralization, grouting of the liquid SBW, placing it is 55-gallon drums, and storing the drums pending shipment to WIPP. The CsIX treatment and storage units would be subject to the 40 CFR 264 and 270 requirements for new tank systems, miscellaneous units, and container storage. These units could be added to the INEEL HWMA permit as a modification to either Volumes 14 or 18, or as a separate volume.

The addition of the waste packaging process will result in less than $25 \%$ increase in the tank capacity and container storage capacity at the INEEL. Therefore, the changes should be a Class 2 modification. It should be possible to submit individual modifications for the building, tank systems, and container storage, which should allow the start of construction of the building, floor, walls, roof, and secondary containment, while designs are finalized for tank systems and container storage. CsIX waste packaging and storage facilities are replacement storage for the waste in the tank farm. The net result would be a reduction in storage volume at the INEEL. Tank systems used to store or treat hazardous wastes that contain no free liquids and are situated inside a building with an impermeable floor are exempt from the secondary containment requirements, (40 CFR \$264.190(a)). Storage areas that store containers holding wastes that do not contain free liquids need not have a containment system (40 CFR $\S 264.175(\mathrm{c}))$.

It is recommended that filtering, ion exchange, grout treatment, and container storage be submitted to the State of Idaho as a Class 2 modification to either INEEL HWMA permit Volume 14 or 18 . The CsIX drum storage and canister storage areas are for dry waste with no free liquids, which should simplify permitting and construction. The tank and container storage areas replace noncompliant storage in the Tank Farm. It is recommended that container storage be added as a Class 2 modification to Volume 18.

If the final design results in significant changes to the CsIX system then a permit modification would be required (e.g., tank size, number of tanks, tank location, cell dimension, etc.). The risk is that changes to the design during final design or construction could result in a permit modification approval before waste could be managed in the new CsIX facilities and delay the shipment of waste. It is recommended that the project negotiate with the State of Idaho early in design to determine how design and construction changes will be handled during the application, final design, and construction stages of the project. 
A site-specific risk assessment should not be required for the CsIX treatment alternative. Since the CsIX treatment alternative is a low temperature operation and will generate minimal emissions from solid drying and waste transfers.

4.2.1.3 Mixing pumps. At the present time the CsIX treatment option is not designed to use mixing pumps in the Tank Farm. If the design is changed and pumps are used they will be added as a Class 1 modification to the interim status permit.

4.2.1.4 Organic Sample Bias. IDEQ proposes in Volume 14 to the INEEL HWMA permit to approve the use of a double-needle sampler as an alternative sampling procedure when collecting mixed (hazardous and radioactive) volatile organic and total organic samples from the INTEC Liquid Waste Management System. However, the resulting sample analysis results must not be used in Land Disposal Restriction (LDR) certifications. The appropriateness of the sampling procedure shall be confirmed, at least three times within the life of the permit by correlating of the analytical results with the permit required off-gas data.

The project should request the use of double-needle sampling in the HWMA permit applications or modifications. The project should compare sample data from the double-needle and simple samplers to show that the organic constituents in the Tank Farm waste are at or near the method detection limits and the sampling method does not affect the results for organics, due to the low concentration in the feed. The project should propose a reduced number of organic analyzes based on the low concentration in the feed. The project should pursue IDEQ approval for use of double-needle samplers for all RH samples, including LDR, delisting, and waste characterization samples as required to dispose of waste.

\subsubsection{PE Certifications}

HWMA requires PE certification of the design submitted with the permit modification or application and before waste is placed in the tank systems 40 CFR $\$ 264.192$ and 40 CFR $\$ 270.11(d)$. PE Certification would be required for feed storage, filters, ion exchange, grout treatment, and container storage facilities. The project should contract with an independent, registered, PE early in design for PE support to facilitate certification of the design for the permit application or permit modification.

4.2.1.6 In-cell Leaks. HWMA requires that operation of a leaky tank system be stopped immediately after the leak is detected, waste be removed from tank systems within 24-hours, and waste be removed from secondary containment within 24-hours (40 CFR \$264.193). The system will have to be repaired before it is used. Depending on the extent of the repairs, a PE certification may be required before resuming operations.

Historically, the piping from the feed tanks to the calciner has leakage problems during operation. The CsIX pumps and piping may have similar problems and could be a schedule risk if operations are stopped to repair leaks as they occur. The project should negotiate with the State of Idaho to operate with leaking pipes and valves until they can be replaced at scheduled maintenance shutdowns.

4.2.1.7 As-built Drawings. Air permitting does not require as-built drawings of the facility. The air permit requires the air emissions from each system, the ranges of the emissions, and a list of equipment.

HWMA permitting requires as-built drawings of the facility, equipment, and piping. A permit application could include between 50 and 100 drawings (40 CFR §270). The project should negotiate with the State of Idaho to add the as-built drawings certified by a PE to the INEEL HWMA permit as a Class 1 modification prior to start of operations. 


\subsubsection{CsIX NEPA.}

NEPA exposure is low risk and little or no activity should be required here.

The risk of additional NEPA action for the SBWT project is low. The HLW\&FD EIS covered over 120 different alternatives to treat the SBW from no action to vitrification. It does not appear at this time that additional NEPA action would be required for the treatment and storage of SBW.

If required, an environmental assessment (EA) should cover any additional action or process not specifically mentioned in the EIS.

\subsubsection{CsIX Waste Disposal - TRU Waste}

Waste disposal is fairly high risk and is further aggravated by schedule delays.

The CsIX SBW treatment alternative would generate remote-handled canisters of dried solids and ion exchange media, 55-gallon drums of contact-handled grouted waste, and debris (spent HEPA filters). The majority of the waste would be CH-TRU waste. The WIPP facility is limited to 7,080 $\mathrm{m}^{3}$ of RH-TRU waste, of which $354 \mathrm{~m}^{3}$ can be $>100 \mathrm{R} / \mathrm{hr}$ on contact, by the Land Withdrawal Act (LWA). Hanford, SRS, and the INEEL have proposed sending remote-handled TRU waste to WIPP that were not identified in previous estimates. WIPP has a limited approved capacity for remote-handled waste with a dose over $100 \mathrm{R} / \mathrm{hr}$. The spent ion exchange media would consume approximately $6 \%$ of the available capacity for waste with a dose $>100 \mathrm{R} / \mathrm{hr}$. The volume of RH-TRU waste in the DOE complex may exceed the LWA capacity. Disposal is based on first come, first disposed.

The risk to the project is that delays in the schedule caused by permitting, design, construction, and startup could reduce the number of shipments of RH-TRU SBW $>100 \mathrm{R} / \mathrm{hr}$ that WIPP can receive before the capacity authorized in the LWA is exceeded. If low-level waste streams are generated with a dose greater than Class A radioactivity limits, it is a waste without a path for disposal. (See discussion on lowlevel waste Section 4.2.4.7.)

\subsubsection{CsIX Waste Qualification / Certification}

\section{Waste qualification/certification is a very high risk area for the project.}

The issues related to waste qualification/certification are: (a) the waste classification through the WIR determination process, (b) waste acceptance criteria at WIPP, (c) waste acceptance criteria at the National Geologic Repository (NGR), (d) RH-TRU permit approval, (e) New Mexico Environmental Department (NMED) acceptance of SBW, (f) WIPP Waste Certification Authorization, and (g) acceptance of greater than Class A low-level waste.

a. The Federal District Court in Boise ruled that DOE does not have the authority to classify waste using the waste incidental to reprocessing (WIR) determination process in DOE Order 435.1. DOE has appealed the ruling to the U.S. Appeals Court and has asked Congress to clarify DOE's authority under the Nuclear Waste Policy Act.

The risk to the project is that the appeals process drags on for several years and delays treatment of the waste beyond 2012. The project should consider placing the RH-waste in thin metal containers (liners) that could be placed in either the RH-TRU canister or the HLW canister. The $\mathrm{CH}$-grouted waste in drums could be placed in HLW canisters and qualify the grouted waste package, as necessary. The treatment alternative would then be neutral to the 
disposal location. This would unfortunately decrease the net volume per canister and result in increasing the canister count and associated costs for storage, transport, handling, and disposal. In addition, if the WIR determination for SBW is disallowed, then classification of all three CsIX primary waste forms ( $\mathrm{CH}$ grout, $\mathrm{RH}$ tank solids, RH spent IX sorbent) would be in question.

b. The State of New Mexico has issued a HWFP to WIPP that covers CH-TRU waste streams. Congress, in Section 311(b) to the Energy and Water Appropriations Act, required WIPP to submit a modification to WIPP's HWFP to limit confirmatory testing of TRU waste containers to radiography or visual inspection. These changes, when implemented, will significantly reduce the type and number of waste characterization samples required to confirm the acceptable knowledge. The modification was submitted to the State of New Mexico on December 31, 2003. The State of New Mexico is still reviewing the Section 311(b) modification.

The WAC for RH-TRU waste at WIPP are being established. WIPP and EPA have established requirements for radionuclides with EPA's approval of the RH-TRU Waste Characterization Program Implementation Plan for characterization of radionuclides on March 26, 2004. DOE must submit site-specific implementing plans for EPA approval before sites may be authorized to characterize RH-TRU waste for certification and shipment to WIPP. Sites will not be authorized to certify and ship RH-TRU waste to WIPP until EPA conducts an onsite inspection and issues its final authorization. The RH-TRU Waste Characterization PIP requires each site to prepare sampling and analytical plans for characterization of each waste stream and have them approved by the EPA.

The WIPP PH-TRU Program has not received approval of the RH-TRU waste modification to the WIPP HWFP. The criteria for hazardous constituents in RH-TRU waste have not been added to the WIPP HWFP. WIPP submitted a Class 3 permit modification for RH-TRU waste to the State of New Mexico in May 2003. The State of New Mexico is still reviewing the modification. WIPP is not ready to receive RH-TRU waste, and will require facility modifications and testing prior to receipt of waste.

The risk to the project is starting the design without having all of the waste characterization and certification requirements finalized for either $\mathrm{CH}-$ or RH-TRU wastes resulting in design changes, permit modifications during construction, and in delays the shipment of waste.

It is recommended that the SBWT project work closely with WIPP and EPA to develop sampling and analysis plans for characterization of the feed. The plans will describe the use of acceptable knowledge for radioisotopes, prohibited items, and dose-to-curie measurements and calculations.

The project should also work with WIPP to include project specific waste characterization procedures for RH-TRU waste in the WIPP HWFP, if required.

c. The waste acceptance criteria at the NGR are based on an assessment of the performance of the waste in the package and performance of the waste package in the repository. The only waste form that has been evaluated and approved for HLW disposal is borosilicate glass.

Other waste forms such as grout, dried SBW tank solids, cesium-loaded ion exchange resin, or debris will have to be evaluated for acceptability on a case-by-case basis. Failure of the WIR does not mean that the SBW nor any of the specific CsIX process waste streams would 
automatically go to the NGR, but could result in the project generating waste without a disposal path. DOE has a limited capacity available for the disposal of HLW at the NGR, if all reprocessing wastes are classified as HLW, then the volume of HLW will exceed DOE's allocated capacity requiring long-term storage at the INEEL.

The INEEL needs to develop the following technical information to support the acceptance of a waste form for disposal at the NGR. The information needed for the Memorandum of Agreement with the Civilian Radioactive Waste Management System includes the Environmental Management Waste Acceptance Product Specifications (EM-WAPS), Waste Form Compliance Plan (WFCP), Waste Form Qualification Report, and supporting documentation that comply with QARD RW-0333P requirements.

1. The chemical composition and waste form projections for the HLW. Information on the chemical composition shall include identification of the speciation of elements and compounds present in concentration greater than 0.5 percent by weight in the waste form and an estimate of the uncertainty of these concentrations for the HLW.

2. Information required for determining that the HLW does not exhibit the characteristics of hazardous waste.

3. Estimates of the total facility inventory and individual canister inventory of radionuclides (in curies) that have half-lives longer than 10 years and are or will be present in concentration greater than $0.05 \%$ the total radioactive inventory. The estimates shall be indexed to the years 2010 and 3110 . The producer shall also report the estimate of the uncertainty in the radionuclide inventories.

4. The time-temperature-transformation diagrams for the HLW and identification of temperature limits (if any) necessary to preserve the properties of the HLW.

5. Identification of the method to be used to ensure consistency of production batches, and any other information necessary to establish post-closure performance of the waste forms (such as, identification of organic compounds that may be present and estimated quantities). Product consistency test and comparison to the performance of EA benchmark glass.

6. Canister material.

7. Canister dimensions (at the time of acceptance).

8. Canister lifting and handling arrangements.

9. Canister labeling conventions.

10. Information required to assess the canister drop performance including information regarding particulates, pyearophorics, combustibles, explosives, etc. that all may come into play in a Design Basis Earthquake II event. This is likely to be a detailed list, much of which has not yet been determined. The need for this information will be developed more fully in a future revision of the WASRD. 
11. Information required to assess canister criticality, both pre and post closure. This is likely to be a detailed list, much of which has not yet been determined. The need for this information will be developed more fully in a future revision of the WASRD.

12. Estimated maximum gamma and neutron dose rates at the canister surface.

13. Projected distribution of canister thermal outputs, including the maximum.

14. Method used to assign individual canister Metric Ton Heavy Metal (MTHM) content for accounting against the repository 70,000 MTHM capacity limit as specified in Section 114d of the nuclear Waste Policy Act of 1982, as amended.

The SBW waste has been assigned four listed waste codes. The NRG is not permitted as a Subtitle $\mathrm{C}$ hazardous waste landfill therefore the project will need to delist the waste streams before they can be shipped to the NGR. The waste streams cannot exhibit a characteristic of a hazardous waste. Waste form and waste packaging performance assessment and approval could delay treating the SBW. In addition to delisting, the SBW must be treated to meet the land disposal restriction standards for hazardous metals, before it could be sent to the NGR. Waste form and waste packaging performance assessments and approvals could delay treating the SBW. The NGR will need to request a license change from NRC and EPA to receive waste forms other than borosilicate glass. (See discussion of petition to exclude/delisting petition in Section 4.2.6.7)

d. The WIPP RH-TRU Program is not ready to receive RH-TRU waste and will require facility modifications and testing prior to receipt waste.

The WIPP RH-TRU Program could present a schedule risk to the project if they do not have a permit and the WIPP receiving facility is not modified in time to support the SBW shipping schedule. An additional risk is that the SBWT project could have to modify its design during construction or startup to comply with the requirements in the approved modification for RH-TRU waste to the WIPP HWFP.

The WIPP RH-TRU Program is not ready to receive RH-TRU waste and will require facility modifications and testing prior to receipt waste.

These proposed restrictions could delay the approval of the RH-TRU Waste Permit modification and finalization of the RH-TRU waste acceptance requirements in the HWFP. Worst case is that the restrictions would prohibit the disposal of SBW at WIPP.

e. The WIPP waste certification authorization process consists of a series of document reviews, assessments, and confirmation audits. DOE-Carlsbad Field Office (CBFO), EPA, and the State of New Mexico Environmental Department (NMED) participate in the process. Waste certification authority is based on the project demonstrating verbatim implementation of the characterization, operating, confirmation, and validation procedures and plans used for characterization and certification of waste shipments.

DOE-CBFO will approve the plans and procedures prior to start of operations and assess implementation during system operation testing. DOE-CBFO and NMED will audit the project during the first 6 weeks of operations to verify that operators are trained and hazardous waste management plans and procedures have been implemented as approved. EPA will audit the project to verify that the radioactive waste management plans and 
procedures are being implemented as approved. Audit findings have to be resolved before waste certification authority is granted.

NOTE: Changes to approved radioactive and hazardous waste management plans and procedures, equipment, and equipment calibrations that affect waste certification have to be approved by CBFO prior to implementation of the change. The DOE-CBFO, EPA, and NMED expect verbatim compliance with the approved plans, and procedures and conduct quarterly assessments and yearly compliance audits to ensure that plans and procedures are being followed.

The risk to the project is that changes to approved plans and procedures before, during, and after hot startup delay waste shipments. The risk is that waste certification authority approval could be delayed by the time and manpower it takes to correct the audit findings of the audit or to recertify waste containers because plans, procedures, and equipment calibrations were changed or not followed as approved.

f. Low-level waste generated by the project is listed hazardous waste and assigned RCRA hazardous waste numbers F001, F002, F005, and U134. At the present time the only disposal site permitted and licensed for radioactive and hazardous waste with these hazardous waste numbers is Envirocare. Envirocare is licensed for low-level Class A radioactive waste. For low-level waste streams with INTEC hazardous waste numbers that exceed the radioisotope limits for Class A low-level waste, there are no disposal sites available. If the project generates low-level (non-TRU) waste with activity greater than Class A limits, then it will be a waste without a path for disposal and would require on-site storage. The Nevada Test Site disposes of radioactive only waste from off-site generators. The Hanford site is not permitted to receive radioactive and hazardous mixed waste from off-site generators or wastes with the U134 hazardous waste number. The Radioactive Waste Management Complex (RWMC) at the INEEL receives radioactive waste and the Idaho CERCLA Disposal Facility (ICDF) receives CERCLA waste. In order for the project to dispose of waste at either the RWMC, Nevada Test Site, or Hanford Site, the project will need to treat the waste for characteristically hazardous constituents and prepare a delisting petition to remove the hazardous waste number above. In order for the waste to be disposed of at the ICDF, the project and waste generated would have to be added to the INEEL CERCLA Program under the Federal Facilities Agreements/Consent Order. The proposed treatment alternative would generate low-level waste in the form of PPE and debris.

To avoid these risks, it is recommended that the SBWT project work with the State of Idaho, Region 20 EPA, and the disposal site state to delist low-level waste generated from this process, since it does not contain the hazard constituents for, which it was listed. A delisting petition, or a petition to exclude a waste from hazardous waste regulation, requires approval in the generating state, states through which the waste is transported, and the state in which the waste will be disposed of. There is still the risk that the disposal site state may not accept the delisting for SBW.

\subsubsection{CsIX Regulatory Risks - Summary}

\section{WIPP}

- $\quad$ The State of New Mexico delays the approval of the RH-TRU permit modification

- The State of New Mexico delays the approval of the 311(b) permit modification 
- $\quad$ The State of New Mexico amends the WIPP HWFP to exclude waste classified as TRU using the WIR process.

- $\quad$ The State of New Mexico amends the WIPP HWFP to exclude waste not listed in the 1995 Transuranic Waste Baseline Inventory Report.

- $\quad$ The EPA or State of New Mexico requires additional sampling and analysis for acceptable knowledge characterization for RH-TRU waste.

- $\quad$ WIPP/EPA/NM do not grant waste certification authority to the project until 180 days after hot start (30 days of production, audit, 4-6 months wait until approval is granted).

- $\quad$ WIPP does not have the manpower or onsite capabilities to support the shipping schedule.

- $\quad$ WIPP does not have 72-B transporters available for the project to support the shipping schedule.

- $\quad$ WIPP does not have TRUPAC II transporters available for the project to support the shipping schedule.

- WIPP does not have the LWA capacity to receive the RH-TRU SBW.

- $\quad$ NMED continues to require headspace gas analysis for every container in storage.

- $\quad$ NMED continues to require verification sampling and analysis of the waste in containers in addition to acceptable knowledge.

- WIPP approval of changes to equipment and procedures identified during SO testing, readiness review, and hot start up delays waste certification authority or implementation of new procedures.

- Court challenges by the State of New Mexico or stakeholders prevent or delay the project from shipping waste to WIPP.

- $\quad$ The State of New Mexico passes legislation that prevents or delays the shipping of SBW to WIPP.

\section{Permitting}

- $\quad$ State of Idaho DEQ cannot support the aggressive permitting modification schedule for start of construction.

- State of Idaho DEQ does not approve a general permit modification to support the start of building construction.

- $\quad$ State of Idaho DEQ does not issue a permit to construct (air) to support the schedule for start of building construction.

- State of Idaho DEQ does not approve the modifications to the HWMA permit in time to support the start of operations.

- State of Idaho DEQ does not issue a permit to operate (air) in time to support the start of operations. 
- $\quad$ Court challenges by INEEL stakeholders delay or prevent permit modifications needed for the SBW project.

- State of Idaho does not approve the SBW petition to exclude the waste from hazardous waste regulation.

- $\quad$ The disposal site state does not approve the SBW petition to exclude the waste from hazardous waste regulation.

\section{DOE O 435.1}

- $\quad$ Federal courts vacate DOE's authority to make WIR determinations.

- $\quad$ Federal courts delay DOE's authority to make WIR determinations.

- $\quad$ Congress does not clarify DOE's authority to make WIR determinations.

- $\quad$ The project generates waste streams without a path to disposal requiring permitting and construction of additional storage capacity.

\section{Safety}

- $\quad$ PDSA is not approved in time to support the schedule for ordering long lead equipment and start of construction.

- $\quad$ FDSA is not approved in time to support the readiness review schedule.

- $\quad$ Systems operations testing identify problems that delay the hot start up schedule.

- $\quad$ Readiness review process takes additional time to correct findings and delays the hot startup schedule.

- $\quad$ Radioactive Waste Management Authority is not approved in time to support the hot startup schedule causing a delay in WIPP Waste Certification Authority. 


\begin{tabular}{|c|c|c|c|c|c|c|c|c|c|c|c|c|c|c|c|c|c|c|c|}
\hline \multicolumn{2}{|c|}{ 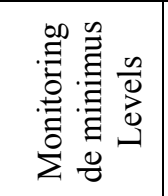 } & $\frac{\text { है }}{200}$ & $ㅇ$ & i & ๙. & a. & i & $\stackrel{m}{2}$ & i & $\Xi$ & i & i & & i & $\frac{n}{n}$ & $\stackrel{n}{=}$ & i & & $\stackrel{\text { ț }}{\stackrel{1}{d}}$ \\
\hline \multicolumn{2}{|c|}{ 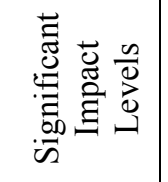 } & $\frac{\text { है }}{00}$ & in & - & a. & a. & $\approx$ & in & - & $=$ & i & i & & ஓి & $\stackrel{8}{\circ}$ & 1 & i & i & \\
\hline \multicolumn{2}{|c|}{ 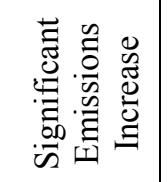 } & $\frac{\vec{D}}{2}$ & \multicolumn{2}{|l|}{$\because$} & \multicolumn{2}{|l|}{ a. } & \multicolumn{3}{|l|}{ 우 } & $\stackrel{f}{q}$ & \multicolumn{3}{|l|}{ 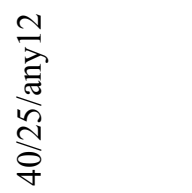 } & 8 & $\stackrel{8}{ }$ & $\stackrel{0}{0}$ & $\approx$ & $m$ & \\
\hline \multirow{3}{*}{ 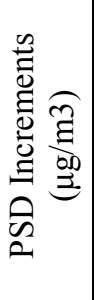 } & \multirow{3}{*}{ 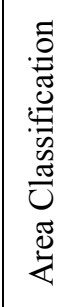 } & $\Xi$ & 8 & iे & $\sigma$. & $\sigma$. & ஜ & $\underset{\varnothing}{\sim}$ & \& & in & 1 & 1 & & 1 & 1 & $i$ & 1 & i & \\
\hline & & $=$ & \& & $=$ & $\sigma$. & $\sigma$. & $\frac{N}{n}$ & $\bar{a}$ & ㄱ & $\approx$ & 1 & 1 & & i & i & 1 & 1 & $i$ & \\
\hline & & $\neg$ & $\infty$ & $\nabla$ & פ. & ๙. & $\approx$ & $n$ & $\sim$ & $\tilde{\sim}$ & 1 & i & & i & 1 & 1 & 1 & i & \\
\hline \multirow{4}{*}{$\begin{array}{l}\pi \\
0 \\
\frac{1}{z} \\
z\end{array}$} & \multirow{2}{*}{ 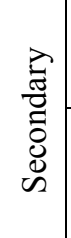 } & : & i & $i$ & $i$ & $i$ & $\tilde{0}$ & $i$ & $i$ & $\begin{array}{l}\tilde{n} \\
\tilde{0} \\
0\end{array}$ & $\frac{1}{\circ}$ & $\stackrel{\infty}{\circ} \stackrel{0}{0}$ & & i & i & 1 & 1 & i & \\
\hline & & $\overbrace{\sum}^{\tilde{B}}$ & 으 & in & $\tilde{\sigma}$ & $n$ & 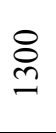 & $i$ & 1 & 8 & $\ddot{\sim}$ & $\hat{n}$ & & i & i & $\stackrel{n}{-}$ & i & i & \\
\hline & \multirow{2}{*}{ 胥 } & 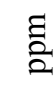 & i & i & $i$ & i & $i$ & $\frac{ \pm}{\dot{0}}$ & $\stackrel{0}{0}$ & $\begin{array}{l}\tilde{n} \\
\hat{\theta} \\
0\end{array}$ & $\frac{\sim}{0}$ & $\stackrel{\infty}{\circ}$ & & $\tilde{m}$ & $a$ & 1 & i & 1 & \\
\hline & & 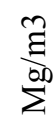 & $\stackrel{\circ}{n}$ & in & $\tilde{\sigma}$ & $n$ & i & $\underset{n}{n}$ & $\infty$ & 8 & $\tilde{\approx}$ & $\hat{n}$ & & $\begin{array}{l}8 \\
8 \\
8\end{array}$ & $\begin{array}{l}8 \\
8 \\
0\end{array}$ & $\stackrel{n}{-}$ & i & i & \\
\hline & & E & $\varangle$ & 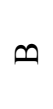 & U & D & 피 & 피 & L & 工 & 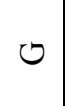 & $\Psi$ & & 피 & $\amalg$ & - & i & i & \\
\hline \multicolumn{3}{|c|}{ 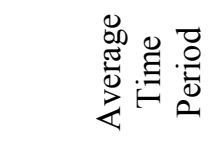 } & $\begin{array}{l}\vec{\Xi} \\
\stackrel{\Xi}{ \pm} \\
\stackrel{d}{d}\end{array}$ & 袢 & $\begin{array}{l}\vec{\Xi} \\
\stackrel{\Xi}{\Xi} \\
\stackrel{\sim}{J}\end{array}$ & 丞 & $\frac{\grave{\Xi}}{m}$ & $\begin{array}{l}\vec{\Xi} \\
\stackrel{\Xi}{\beth} \\
\stackrel{J}{d}\end{array}$ & $\begin{array}{l}\text { 完 } \\
\text { 宗 }\end{array}$ & $\begin{array}{l}\bar{\Xi} \\
\text { 害 }\end{array}$ & $\Xi$ & $\underset{\infty}{m}$ & & $\stackrel{\bar{\Xi}}{\Xi}$ & $\frac{\Xi}{\infty}$ & 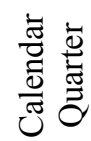 & 1 & i & \\
\hline \multirow{2}{*}{\multicolumn{2}{|c|}{ 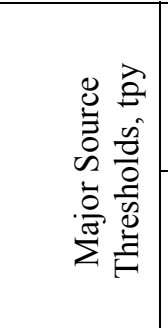 }} & $\sum_{Z}^{J}$ & $\frac{\hat{8}}{8}$ & & 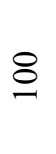 & & ○ & & & 8 & $\begin{array}{l}\stackrel{\circ}{n} \\
\stackrel{\circ}{8}\end{array}$ & $\frac{\vec{a}}{\stackrel{a}{a}}$ & & 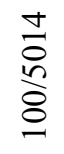 & & 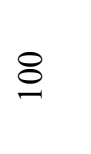 & $i$ & i & \\
\hline & & $\hat{\tilde{n}}$ & $\begin{array}{l}8 \\
8 \\
\frac{1}{1} \\
8 \\
i n\end{array}$ & & 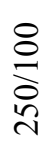 & & $\begin{array}{l}8 \\
\stackrel{1}{2} \\
\stackrel{1}{1}\end{array}$ & & & $\begin{array}{l}8 \\
\stackrel{1}{2} \\
\stackrel{2}{i}\end{array}$ & $\begin{array}{l}8 \\
\stackrel{8}{8} \\
\text { in }\end{array}$ & & & 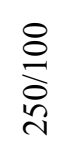 & & $\begin{array}{l}8 \\
\stackrel{8}{2} \\
\stackrel{2}{N}\end{array}$ & $\stackrel{8}{\stackrel{8}{2}}$ & $\begin{array}{l}8 \\
\stackrel{8}{8} \\
\stackrel{2}{N}\end{array}$ & \\
\hline \multicolumn{3}{|c|}{ 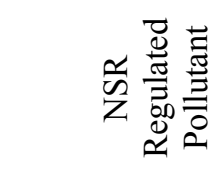 } & $\frac{n}{2}$ & & $\sum_{\substack{n \\
n \\
n}}^{1}$ & & రิ & & & Õ & 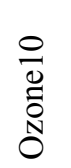 & $\begin{array}{l}\bar{y} \\
\text { ঠ }\end{array}$ & $\begin{array}{l}\not{0} \\
z\end{array}$ & O & & 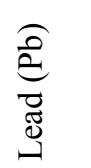 & 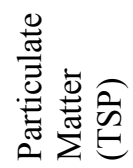 & $\begin{array}{l}\frac{0}{0} \\
\frac{0}{0} \\
\frac{0}{I}\end{array}$ & $\underset{\underline{I}}{=}$ \\
\hline
\end{tabular}




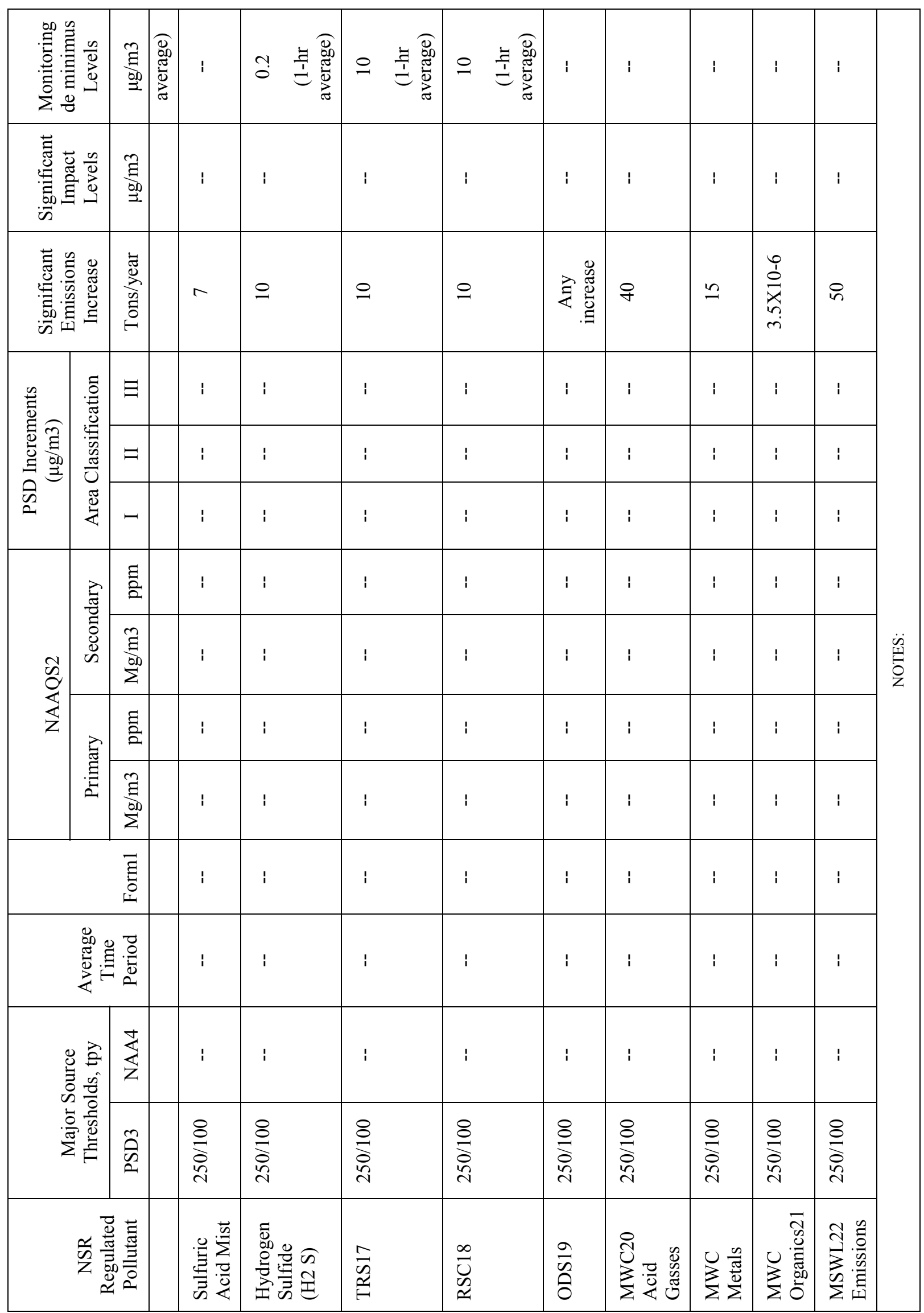




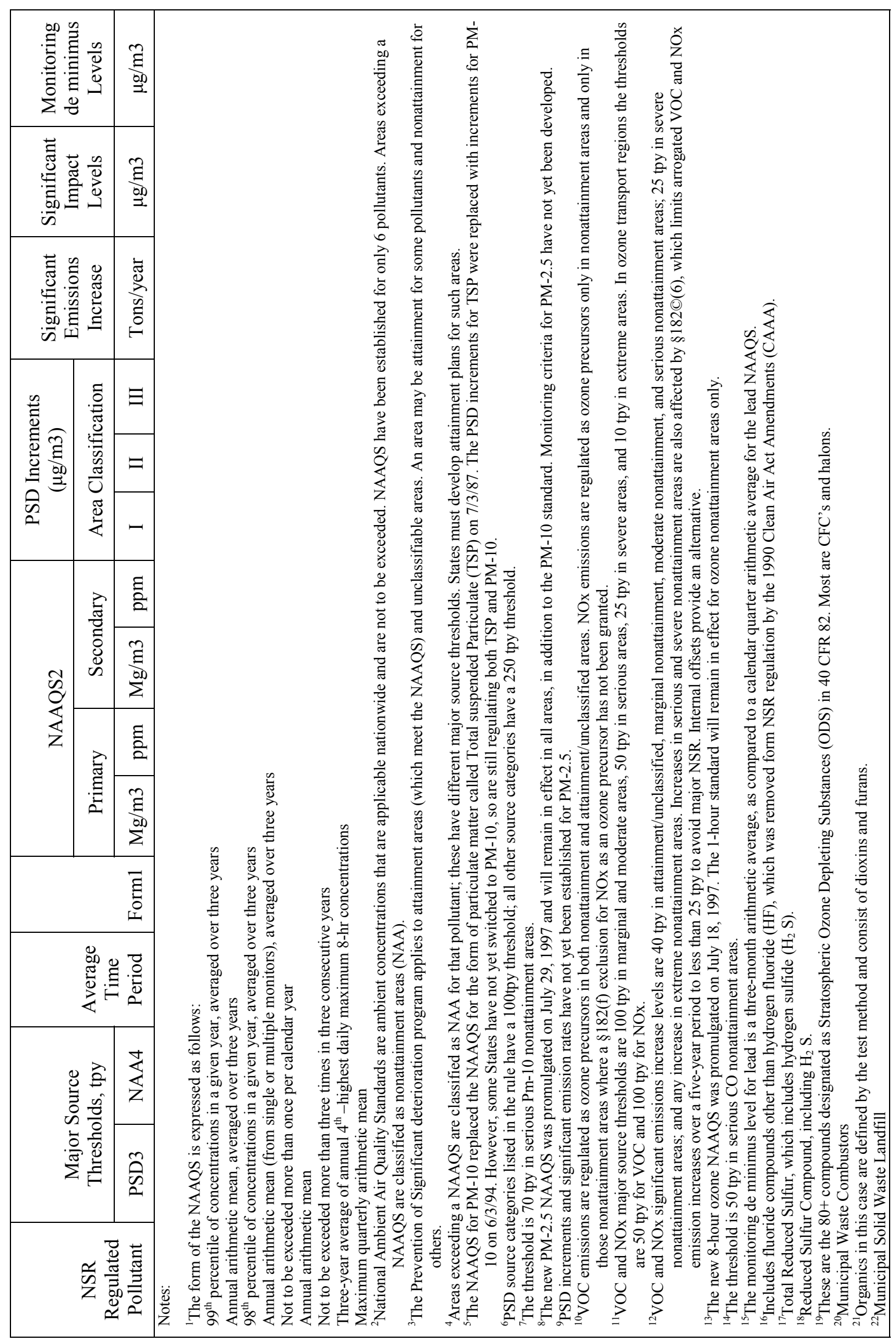




\subsection{CsIX Schedule and Related}

The overall schedule for the CsIX SBW treatment alternative cannot achieve the 2012 milestones (late by at least 11 months) primarily due to the time required to permit and construct the CsIX treatment facility and to treat the SBW in an aggressive, but realistic, time span.

\subsubsection{CsIX Capital Project Schedule (February 2005 to September 2010)}

\subsubsection{Preliminary Design (February 2005 to October 2005)}

It will require a very aggressive effort to conclude preliminary design by the end of October 2005 in only a 9-month period starting in February 2005 and submit environmental permits in December 2005.

The assumed start for the capital project is February 1, 2005, the first day of the new ICP contractor. Preliminary (Title I) design would commence on this date. However, realistically, even if government funding and approvals (Critical Decision 0, CD-0, Approve Mission Need and CD-1, Approve Alternative Selection and Cost Range) were not to be limiting, preliminary design cannot start without a design company being in place under contract and design direction documents such as the Scope of Work (SOW), Technical and Functional Requirements document (TFR), and Project Design Criteria (PDC). These documents have not yet been prepared (the treatment alternatives are many and varied and one has not been chosen yet) but could perhaps be developed in the transition period prior to February 1, 2005, or in the month or two immediately following.

An aggressive preliminary design (Title I Design) period of 9 months is possible but difficult during which the process definition must be finalized and Process and Instrument Design (P\&Ids) developed. Related to this, the following must be done: (1) critical Technical Development test work must be conducted to support process definition, (2) remote mock-up testing must be started and iterate with design to develop and prove the concepts, (3) safety analysis work must be started and proceed through the fundamental assessment stage to define any safety driven requirements to be inputted to the design, and (4) the draft environmental permit applications must be written. Numbers 1 and 2 would be difficult to achieve in such a short time frame and could be schedule limiting or most likely require design work to proceed at-risk based on the best concepts and assumptions available. All this must be coordinated to finalize the P\&IDs such that facility design and mechanical layout work can be performed in sufficient detail to support submittal of the RCRA Part B and Air permit applications. This is considered to be a Title I Plus design; that is, a level of detail beyond what is normally developed in a preliminary/Title I design effort. The following would be required:

\section{HWMA/RCRA Permitting}

\section{Process}

- $\quad$ Final process flow diagrams (PFDs), material and energy balances, and P\&IDs

- $\quad$ Process descriptions

- $\quad$ Equipment descriptions

- $\quad$ Operating limits

- $\quad$ Operating procedures (at least draft). 


\section{Building}

- $\quad$ Site location

- $\quad$ Facility layouts

- $\quad$ Floor plan drawings

- $\quad$ Equipment and piping layouts

- Materials of construction used

- $\quad$ Secondary containment details (at least typical).

\section{Waste}

- Characterization of feed waste (SBW in Tank Farm)

- Waste acceptance requirements for the treatment facility

- $\quad$ Process control requirements

- Description of final waste

- Characterization (typical) of final waste

- $\quad$ Sampling and analytical methods used.

\section{Air Permitting}

\section{Air emission modeling}

- Identify sources of emission

- Identify constituents of concern

- $\quad$ Model emissions.

\section{NESHAPs}

- $\quad$ Estimated emissions of radionuclides.

\section{Title V}

- $\quad$ Estimate emission of hazardous constituents.

At the end of preliminary design, the details of the design would be fed into the environmental permit applications and 60 days later, after final reviews, revisions, and approvals, the permit applications would be submitted to the IDEQ for the assumed minimum 2 year review and approval process (reduced from the 31 months requested by IDEQ by taking time from the Contractor's schedule only) before permission would be given to start of construction.

Additionally, during preliminary design, equipment needs will be examined and detailed specifications will be prepared and finalized, either at this stage or in the early days of final design for equipment that is critical to facility detailed design, needed for the mock-up testing program, or otherwise long-lead and schedule critical. This equipment is normally referred to as GFE. Some examples of this are the ion exchange column and canister loading assembly, the crossflow filter, the Fundabac filter and the 
tank solids canister loading assembly, the continuous grout mixer, the decon/transfer cart, and the canister handling machine.

Note that Preliminary Design, feeding into the environmental permit applications, and the application review process by DEQ leading to approval to construct is the first of three critical paths on the project schedule. The second one, discussed later, is construction, testing, and startup of the CsIX treatment facility. The third one, also discussed later, is treatment of the SBW, which is a direct function of the throughput of the treatment system.

\subsubsection{Final Design (November 2005 to July 2007).}

The final design schedule does not involve risk nor is it on the critical path. It is dictated by the time required for review and approval of the environmental permits by IDEQ, which will require 24 months after submittal following the completion of preliminary design.

Final design (Title II Design) will start immediately following preliminary design in early November 2005. It is assumed that there will be a no hold period for CD-2, approve performance baseline (authority to commence final design). It is also assumed that an early and partial CD-3 (approval to start construction) consent would be given at CD-2 to procure the GFE equipment cited above in the preliminary design write-up, which would involve a relatively significant expenditure of capital funds.

All Technical Development test work and remote mock-up testing must be completed by mid-Final Design in order to be factored into the detailed design.

Detailed design would iterate with procurement on GFE items to minimize the overall schedule as well as cost. Design would proceed to the point of preparation of numerous bid packages of equipment specifications and drawings for issuance for competitive bid by either the ICP contractor or his design agency. (The latter is preferred for better communication and control as well as lower cost.) Vendor bids would be received, analyzed, and awarded. Vendor drawings would be produced, reviewed, revised as necessary, and approved after which the equipment layouts and facility designs would be completed by the design agency to reflect these details in the bid packages for general construction. Vendor material purchases, fabrication, testing, and ultimate delivery to the construction site would be delayed in order to postpone these costs of fabrication without impacting construction as well as to wait until the construction contractor is chosen and onsite to receive delivery of these items. This approach will reduce both costs and schedule by not only initiating early procurement, but by providing actual equipment details in the detailed design drawings; thus, avoiding numerous design related questions and delays during construction.

Final design, bid, and award of the construction contract (normally a 3-4 month process for a project of this size), and notice to proceed and mobilize the construction contractor on the site to be poised for the start of construction (approximately 1 month) will all fit within the 26 month permit cycle period (minimum 24 months after submittal plus 2 months after preliminary design for final submittal preparation) before authorization to proceed with construction is obtained from IDEQ. Final Design then must, and can without difficulty, complete by July 31, 2007, over a 21-month time frame. Final design could be accomplished sooner, but to no net schedule advantage, since construction start must wait for the permit review and approval cycle. It would be better for final design to be performed over that longer time period so that the design team stays together and a core group can still be kept to support design related questions during construction. 


\subsubsection{Construction (January 2008 to September 2009).}

Construction of the CsIX treatment facility is the second critical path activity on the overall schedule, requiring 21 months if aggressively pursued; 33 months including the testing and readiness review stage leading to hot startup. (NWCF took 71 months, 48 months to construct and 23 months to test and start up.).

Work to obtain Critical Decision-3, Approval to Start Construction will begin at the end of final design. It is assumed that CD-3 approval will be obtained by July 2007 authorizing the start of the bid and award process. It is also assumed that CD-3 will release and provide funding support for the construction contractor to start procurement for construction. Fabrication of the GFE procurement items mentioned above in the final design section will be released at this time and those contracts will be completed by the originating organization (either the design agency or the ICP contractor) and be provided to the construction contractor as GFE for installation.

Schedule analysis will be performed during design, and those GFE items that may be schedule limiting, if any, will be released for fabrication earlier during the late stages of final design so that no construction delays are encountered due to these items.

Construction will start in January 2008 (in the middle of winter, not a particularly good time) after approval of the RCRA permit is obtained from IDEQ. Construction will follow a logical installation sequence from site preparation and required demolition, through earthwork, concrete, steel, piping, to completion of instrumentation and electrical installation and construction component checkout CC testing.

\subsubsection{Testing and Startup (April 2009 to September 2010)} path.

Testing and startup, overlapping with the final stages of construction, are also on the critical

During the late stages of construction, after construction forces have completed rudimentary CC Testing, the ICP contractor, with support from the design agency as necessary, will perform system operation (SO) tests and cold tests (CT) on the treatment system and its supporting facility and equipment. After this, an in-house readiness review will be performed leading to a formal operational readiness review (ORR) by DOE and others. Usual participants in an ORR are DOE-ID and DOE-HQ and sometimes the Defense Nuclear Facilities Safety Board (DNFSB). However, in this case the following applies: (1) RCRA waste is being treated and stored and the system is to be fully compliant and Part B permitted, and (2) the intent is to dispose of the treated waste in a major federal repository (WIPP). As such, the Federal EPA, Idaho DEQ, and WIPP, (New Mexico Environmental Department will also be involved, at least informally or in an audit mode), in the final ORR and hot startup and the waste form qualification and process/program validation leading to program certification for the WIPP repository.

Critical Decision-4, Approval to Start Operations will be conducted Parallel with the final stages, of the ORR. At the conclusion of both, approval will be given for hot startup of the treatment system.

It is planned that pilot scale work, along with process knowledge work such as off-gas modeling (very small emissions in this case), will be performed during the construction phase to qualify the three waste forms and preliminarily validate the process to the satisfaction of WIPP and the National TRU Waste Management Program. It is through this test work that the waste forms will be proven and the macro-batch (Tank Farm tank quantities of feed) approach to sampling and characterization, supported by process knowledge, will be validated. The intent is to physically sample and characterize the feed from 
the Tank Farm tanks and not the final waste forms or any intermediate treatment streams. However, the overall process and program validation still must be proven in the full-scale production system using trained operators and procedures.

Discussions with WIPP in 2002 and 2003 resulted in the baseline premise that WIPP could not and would not certify the SBW treatment process/program and its final waste or authorize shipments until 6 months after start of hot operations. The SBWT project assumes that, primarily for milestone schedule reasons, waste treatment must continue and final treated waste must be formed, packaged, and stored at risk. It is also assumed that a shutdown will be imposed by WIPP, as is historically the case, if anything, to resolve minor procedural, training, or other paperwork problems. (Note that it is also assumed that the final SBW CsIX waste product (grout) will not have to be physically reworked in any way, not only due to the assumed success of the prior waste form qualification work, but also because little alteration of it could be performed in any case.)

The plan is to operate on hot feed for 4 months and shutdown for 2 months for the WIPP review and possibly RCRA Program review. It is assumed that at the end of this short shutdown, program certification would be given by WIPP along with approval to make the first shipment from Idaho to New Mexico.

\subsubsection{CsIX Treatment Operations Schedule (October 2010 to November 2013)}

SBW treatment by cesium ion exchange and grouting and CsIX product packaging is the third critical path activity on the overall schedule, assumed to require at least 3 years. Improvements to a 3-year operating schedule are possible, but not certain even with added expenditures.

Recent process studies have assumed a 2.5-year processing schedule for the CsIX process but no major maintenance turnaround is assumed. At least one major maintenance turnaround of 6 months should be assumed to be required (two such turnarounds are assumed for CMACT). This 2-5-year schedule requires a throughput of only $1.4 \mathrm{gpm}$ through the liquid processing operations and $1.1 \mathrm{gpm}$ of slurry to the solids treatment equipment. Equipment could be sized for larger throughputs to achieve a shorter treatment schedule. The minimum treatment schedule time has not been determined, but it must be understood that although the liquid phase flow rates are relatively small, the true challenge comes in the grouting operation - formulating 24,000 drums. This involves addition of multiple grout forming additives, lidding, decon, labeling, and curing of each drum. In the nominal 2.5-year treatment schedule, drums are produced at the rate of 48 per day or one every 30 minutes continuously. This will require multiple grouting lines if batch in-drum mixing (lost paddle) were to be used - three in the Raytheon 2000 design, but perhaps only one or two if an external continuous mixer were to be used. In a nominal 1 - year treatment schedule, drums are produced at the rate of 120 per day or one every 12 minutes continuously which would require even more grouting lines perhaps as many as six or more. Certainly at some point this becomes very problematic since the additional equipment would result in more mechanical problems and breakdowns as well as very high operations costs (e.g., process operator staffing) with the result being diminishing returns.

Shorter treatment schedules are technically feasible by increasing equipment sizes or using multiple processing lines, but this would increase the capital cost of the facility since these costs are a function of throughput. The CsIX process, being the second simplest SBW treatment alternatives, is more adaptable to an aggressive treatment schedule. However, this is complicated by the relatively large volume of $\mathrm{CH}$ waste canisters generated by the process $(24,000)$, the most of all SBW treatment alternatives and more than 30 times, on a waste package count basis, that of the two low volume RH treatment alternatives, SR and DV. On a shipment basis CsIX would require 1,446 shipments, 1,143 $\mathrm{CH}$ 
plus $303 \mathrm{RH}$, vs. as little as 778 for DV and 808 for SR. The large number of $\mathrm{CH}$ drums produced could mean that more frequent handling/mechanical problems arise while operating at a high rate. This could in turn result in more frequent shutdowns of the process, extending the treatment schedule.

\subsubsection{CsIX Waste Shipment Schedule (April 2011 to November 2013)}

\section{Neither remote-handled $(\mathrm{RH})$ nor contact-handled $(\mathrm{CH})$ waste shipments are receipt rate limited by WIPP. Shipments can keep pace real-time with treatment and no shipping limited lag storage in Idaho is required.}

Idaho's SBW treatment production rate by the CsIX process does not exceed WIPP's receipt rate. Thus no shipment induced net accumulation would result to drive the need for lag storage in Idaho even at an aggressive 1-year (nominal) treatment rate. The details are described as follows.

SBW treatment by cesium ion exchange and grouting would produce $24,000 \mathrm{CH}$ drums (55-gallon) with dose rates of 11 to $84 \mathrm{mR} / \mathrm{hr}$ on contact, $24 \mathrm{RH}$ canisters of spent ion exchange sorbent (disposed inside the IX columns) with dose rates of $758 \mathrm{R} / \mathrm{hr}$ on contact, and $229 \mathrm{RH}$ canisters of dried tank solids with dose rates of $86 \mathrm{R} / \mathrm{hr}$ on contact. Remote-handled waste, relatively small in volume for this SBW treatment alternative, is not shipping rate limited by WIPP. The RH rate has been previously described so the following discussion will focus on the contact-handled waste. The treatment generation rate for $\mathrm{CH}$ waste could vary from as little as 48 drums per operating day for a 500 day operating campaign (assumed to cover 2.5 years) to 120 drums per operating day for a 200 day campaign ( 1 year) both calculated using a 7 day week at 24 hour per day operation. The WIPP overall CH receipt rate/capacity is at least 50 trucks per week ramping up to 100 in the time frame of SBW treatment. Each truck received at WIPP can contain as many as 42 drums in three TRUPACTs with 14 drums each. This amounts to 2,100 to 4,200 drums per week as WIPP's CH waste shipping and receipt capacity. CsIX would generate only 336 to 840 drums per week, a rate that would not challenge WIPP's capabilities. Thus, neither $\mathrm{CH}$ nor RH waste produced from the CsIX process is shipping-rate limited.

The need for lag storage in Idaho (CH waste only; $\mathrm{RH}$ waste processing can be managed to match real-time shipment to WIPP) is a function of the length of the treat-but-do-not-ship initial phase of hot operations (done for schedule minimization purposes) and the rate of treatment. With the assumption (validated by WIPP) that shipments would not be authorized until 6 months after start of hot operations and the need to continue to treat and generate waste at risk, primarily to minimize schedule, calculations have been done that show that net peak accumulation would range from 3,200 drums $(13 \%$ of the 24,000 total) for a 2.5 year campaign to $8,000(33 \%)$ for a 1 year campaign given a 4 month treat-but-do-not-ship initial phase of hot operations. After this initial phase and the start of shipment (and re-start of operations) after WIPP approvals are obtained, this net accumulation of treated waste can be shipped off to WIPP along with the new production packages. After this, both $\mathrm{CH}$ and $\mathrm{RH}$ shipments could keep pace with operations for real-time take-away such that shipment would conclude at the same time as treatment (or very shortly thereafter). This would be November 30, 2013, for a 2.5-year campaign or March 30, 2012, for a 1-year campaign, both with an assumed project start date of February 1, 2005.

In the 2.5-year campaign scenario (38 months total, 2 months for a WIPP imposed shutdown plus 6 months for a major maintenance turnaround) the December 2012 milestone is missed by 11 months for treatment as well as shipment to WIPP. In the 1-year campaign scenario (18 months total, 6 months for a major maintenance turnaround with the 2 month WIPP imposed shutdown inside this) the December 2012 treatment and shipment milestones are both beat by 9 months.

The 1-year scenario looks attractive but is extremely aggressive. Operationally, striving for an aggressive 1-year treatment period for cesium ion exchange and grouting would be risky. It looks like 
there is 9 months of schedule contingency with this scenario but as pointed out earlier in this report, the large number of $\mathrm{CH}$ drums produced could mean that more frequent handling/mechanical problems would be encountered while operating at a high rate. This could in turn result in more frequent shutdowns of the process, extending the treatment schedule. The 2.5-year treatment schedule is recommended even though it misses the 2012 milestone.

Shorter SBW treatment operating periods (faster throughput), such as the 1-year period cited above, may be possible (but risky) with the CsIX process, if necessary, in an attempt to minimize schedule and perhaps meet the 2012 treatment milestone. However, besides being quite aggressive itself, this would aggravate the lag storage situation even further and significantly add to the capital project cost to provide for an additional 4,800 drum storage positions.

\subsubsection{CsIX Schedule - Summary}

The 2012 milestone schedule can only be achieved with the cesium ion exchange and grouting SBW treatment alternative if a very aggressive and risky treatment schedule is pursued. Schedule risks have been identified and include:

- $\quad$ Beginning preliminary (Title I) design activities on February 1, 2005. Any delay releasing this work will impact project completion.

- $\quad$ Completing sufficient technical development test work to support process definition and preliminary (Title I) design activities so that environmental permits can be prepared and submitted by January 1, 2006. Any delays in this set of activities, being on the critical path schedule, will impact project completion.

- $\quad$ An environmental permitting timeframe of 24 months.

- DOE funding, reviews, and approvals. The schedule assumes funding will be available in a timely manner and will not impact design, procurement, or construction.

- $\quad$ Technical development (process testing) as this information iterates with final (detailed) as well as preliminary design.

- $\quad$ Mock-up testing of CsIX product packaging system equipment as this information iterates with detailed design.

- $\quad$ GFE procurement as it feeds into mock-up testing and design.

- $\quad$ Testing, operational readiness reviews (ORRs), startup, and WIPP certification.

- $\quad$ Treatment over a 3-year period.

In addition to the risks listed above, normal risks associated with a project of this size and complexity can be expected including availability of skilled craftsmen, weather impacts, and timely delivery of equipment and materials. 


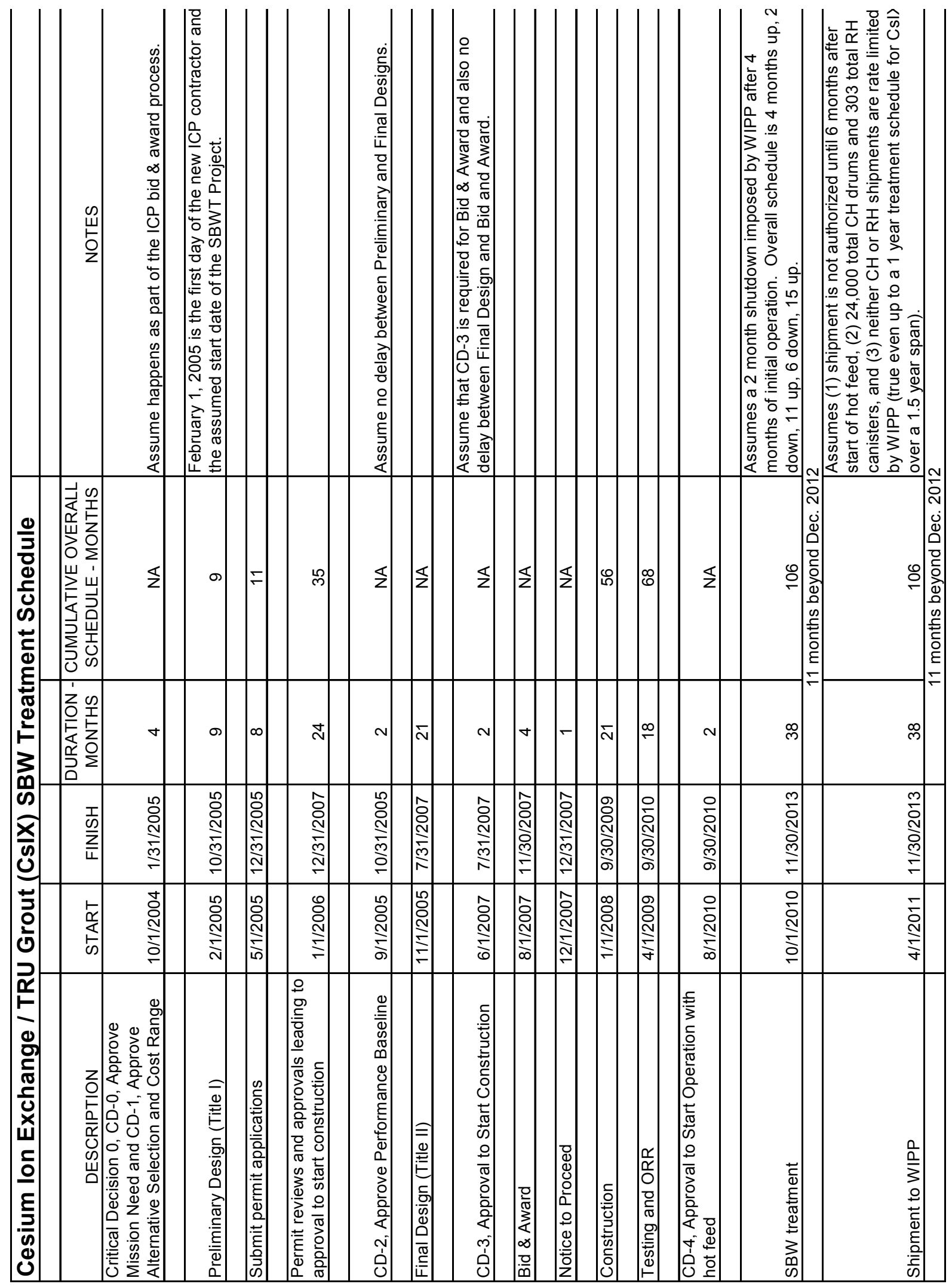




\begin{tabular}{|c|c|c|c|c|c|c|c|}
\hline \multicolumn{6}{|c|}{\begin{tabular}{|l|l|l|l|l|l|} 
CsIX product generation and storage & & & & \\
\end{tabular}} & & \\
\hline \multicolumn{8}{|c|}{ Due to weight restrictions CsIX will ship the CH grout in HALFPACTs holding 7 drums each, 3 HALFPACTs per truck for 21 drums total per shipment. } \\
\hline \multicolumn{8}{|c|}{ WIPP's CH receipt capacity is 100 trucks per week with 3 full TRUPACTs with 14 drums each or 42 drums per truck. CsIX does not approach this. } \\
\hline \multirow{2}{*}{\multicolumn{8}{|c|}{\begin{tabular}{|l|l|l|l} 
Therefore, WIPP can handle the CsIX CH waste at the rate it is generated without the need for WIPP im posed interim storage in Idaho. & \\
\end{tabular}}} \\
\hline \multirow{2}{*}{\multicolumn{7}{|c|}{ CsIX RH waste, being relatively small in volume, can be worked off to WIPP with real-time shipment requiring no lag storage. }} & \\
\hline \multirow{2}{*}{\multicolumn{8}{|c|}{ Assume 2.5 years of operation over a 3.2 year $(38 \mathrm{month}$ ) span producing 24,000 drums (55-gallon) of $\mathrm{CH}$ waste. }} \\
\hline & & & & & & & \\
\hline \multirow{2}{*}{\multicolumn{8}{|c|}{\begin{tabular}{|l|} 
Assumes a 2 month shutdown im posed by WIPP after 4 months of initial operation, adding 2 months to the overall schedule. \\
Overall schedule is 4 months up, 2 down, 11 up, 6 down, 15 up for 38 months total.
\end{tabular}}} \\
\hline & & & & & & & \\
\hline & & drums & \begin{tabular}{|l} 
Calendar days \\
"up"
\end{tabular} & $\begin{array}{l}\text { drums/ } \\
\text { operating day }\end{array}$ & $\begin{array}{c}\text { drums per } 7 \\
\text { day week }\end{array}$ & $\begin{array}{l}\text { Interim storage } \\
\text { needed in Idaho }\end{array}$ & shipments to WIPP/week \\
\hline & & 24000 & 913 & 26.3014 & 184.11 & & \\
\hline & & & 2.5 years & & & & \\
\hline 122 & days (4 months) up w/o shipment - produce & 3200 & ship & 0 & store & 3200 & peak storage need \\
\hline 61 & days (2 months) down w/o shipment - produce & 0 & ship & 0 & store & 3200 & peak storage need \\
\hline & & & & & & & \\
\hline 335 & days (11 months) up w/shipment - produce & 8800 & ship & 12000 & store & 0 & 12.0 \\
\hline & & & & & & & \\
\hline 183 & days (6 months) down w/shipment - produce & 0 & ship & 0 & store & 0 & \\
\hline 456 & do & 10000 . & shin & 12000 & store & I & 88 \\
\hline & & & & & & & \\
\hline 1156 & TOTAL $=38.0$ months $(3.2$ years $)$ & 24000 & & & & & \\
\hline & & & & & & & \\
\hline \multirow{2}{*}{\multicolumn{8}{|c|}{\begin{tabular}{|l|l|l|} 
Assume 1.0 year of operation over a 1.5 year (18.0 month) span producing $\mathbf{2 4 , 0 0 0}$ drums $(\mathbf{5 5}$-gallon) of CH waste. & \\
Assumes a 2 month shutdown imposed by WIPP after 4 months of initial operation, not adding time to the overall schedule (see next assumption)
\end{tabular}}} \\
\hline \multirow{2}{*}{\multicolumn{8}{|c|}{\begin{tabular}{|l} 
Assumes a 2 month shutdown imposed by WIPP after 4 months of initial operation, not adding time to the overall schedule (see next assumption). \\
Assume that during the WIPP induced shutdown a major maintenance turnaround occurs (the only one) of six months total.
\end{tabular}}} \\
\hline & & & & & & & \\
\hline Assum & e that 2 months into the shutdown WIPP author & s shipme & & e without out rec & ducing rate dur & ring the maintenanc & turnaround. \\
\hline Overall & schedule is 4 months up, 6 down, 8 up for $18 \mathrm{~m}$ & ths total. & & & & & \\
\hline & & drums & $\begin{array}{l}\text { Calendar days } \\
\text { "up" }\end{array}$ & $\begin{array}{l}\text { drums/ } \\
\text { operating day }\end{array}$ & $\begin{array}{c}\text { drums per } 7 \\
\text { day week }\end{array}$ & $\begin{array}{l}\text { Interim storage } \\
\text { needed in Idaho }\end{array}$ & shipments to WIPP/week \\
\hline & & 24000 & 365 & 65.7534 & 460.27 & & \\
\hline & & & 1.0 year & & & & \\
\hline 122 & days (4 months) up w/o shipment - produce & 8000 & ship & 0 & store & 8000 & peak storage need \\
\hline & & & & & & & \\
\hline 61 & days (2 months) down w/o shipment - produce & 0 & ship & 0 & store & 8000 & peak storage need \\
\hline & & & & & & & \\
\hline 122 & days (4 months) down w/shipment - produce & 0 & ship & 8000 & store & 0 & 22.0 \\
\hline & & & & & & & \\
\hline 243 & days (8 months) up w/shipment - produce & 16000 & ship & 16000 & store & 0 & 22.0 \\
\hline & & & & & & & \\
\hline 548 & TOTAL $=18.0$ months $(1.5$ years $)$ & 24000 & & & & & \\
\hline Acsum & 25 vear treatment rate but only 1 month o & oductiol & orior to WIPP's a & aproval to shin & in order to $\mathrm{mi}$ & & \\
\hline Assumila & at out to be 2.5 years of operation over $41.0 \mathrm{~m}$ & ths $(3.4$ y & rs) producing 24 & Do0 drums. & & & \\
\hline Assum & es a 5 month shutdown imposed by WIPP after & nonth of & ial operation, add & ing 5 months to $t$ & the overall sche & edule. & \\
\hline Overall & schedule is 1 month up (for minimal production & hence st & ge), 5 down, 14 & $\mathrm{p}, 6$ down, 15 up & for $41.0 \mathrm{mont}$ & ths total. & \\
\hline & & drums & $\begin{array}{l}\text { Calendar days } \\
\text { "up" }\end{array}$ & $\begin{array}{l}\text { drums/ } \\
\text { operating day }\end{array}$ & $\begin{array}{c}\text { drums per } 7 \\
\text { day week }\end{array}$ & $\begin{array}{l}\text { Interim storage } \\
\text { needed in Idaho }\end{array}$ & shipments to WIPP/week \\
\hline & & 24000 & 913 & 26.3014 & 184.11 & & \\
\hline & & & 2.5 years & & & & \\
\hline 30 & days (1 month) up w/o shipment - produce & 800 & ship & 0 & store & 800 & peak storage need \\
\hline & & & & & & & \\
\hline 152 & days (5 months) down w/o shipment - produce & 0 & ship & 0 & store & 800 & peak storage need \\
\hline & & & & & & & \\
\hline 426 & days (14 months) up w/shipment - produce & 11200 & ship & 12000 & store & 0 & 9.4 \\
\hline & & & & & & & \\
\hline 183 & days (6 months) down w/shipment - produce & 0 & ship & $\overline{0}$ & store & 0 & \\
\hline & & & & & & & \\
\hline 456 & days (15 months) up w/shipment - produce & 12000 & ship & 12000 & store & 0 & 8.8 \\
\hline 1247 & TOTAL $=41.0$ months $(3.4$ years $)$ & 24000 & & & & & \\
\hline & & & & & & & \\
\hline Assum & 1 year treatment rate but only 1 month of $p$ & duction & or to WIPP's app & roval to ship & order to mini & imize lag s & \\
\hline Calcula & tes out to be 1.0 year of operation over $17.0 \mathrm{mo}$ & $\mathrm{is}(1.4 \mathrm{ye}$ & s) producing 24,0 & 00 drums. & & & \\
\hline Assum & es a 5 month shutdown imposed by WIPP after & nonth of & fial operation, add & ing 5 months to & e overall sc & edule. & \\
\hline Overall & schedule is 1 month up (for minimal production & hence st & ge), 5 down, $11 \mathrm{u}$ & p 17.0 months tc & otal. & & \\
\hline & & drums & $\begin{array}{c}\text { Calendar days } \\
\text { "up" }\end{array}$ & $\begin{array}{l}\text { drums/ } \\
\text { operating day }\end{array}$ & \begin{tabular}{|c|} 
drums per 7 \\
day week
\end{tabular} & $\begin{array}{l}\text { Interim storage } \\
\text { needed in Idaho }\end{array}$ & shipments to WIPP/week \\
\hline & & 24000 & 365 & 65.7534 & 460.27 & & \\
\hline & & & 1.0 year & & & & \\
\hline 30 & days (1 month) up w/o shipment - produce & 2000 & ship & 0 & store & 2000 & peak storage need \\
\hline & & & & & & & \\
\hline 152 & days (5 months) down w/o shipment - produce & 0 & ship & 0 & store & 2000 & peak storage need \\
\hline & & & & & & & \\
\hline 335 & days (11 months) up w/shipment - produce & 22000 & ship & 24000 & store & 0 & 24.0 \\
\hline & & & & & & & \\
\hline 517 & TOTAL $=17$ months $(1.4$ years $)$ & 24000 & & & & & \\
\hline
\end{tabular}




\subsection{CsIX Major Options}

1. As an option within the baseline concept, a decision could be made not to proceed with treatment while WIPP reviews the overall process / program prior to authorizing initial shipment. This would save the assumed 4 months of lag storage of waste produced at risk in the early stage of treatment. At the 2.5-year treatment schedule rate this would generate only 800 drums instead of 3,200 saving 2,400 drum lag storage positions. At the 1-year treatment schedule rate this would generate 2,000 drums instead of 8,000 saving 6,000 drum lag storage positions. Only 3 months would be added to the nominal 2.5-year treatment schedule. One month would be subtracted from the 1 year schedule with the assumption that 1 month of operation would shake out all problems to be fixed during the WIPP-imposed hold period (5 months in this case) such that all treatment would occur in one 11 month uninterrupted campaign upon restart. (This is a risky assumption; another shutdown would most likely be needed adding to the schedule.)

2. Outside of the baseline concept, volume reduction of the $\mathrm{CH}$ grout should be possible with added process equipment. There is unclaimed dose rate relative to the $\mathrm{CH}$ grout that may be usable. The projected final $\mathrm{CH}$ grout dose rates range from only 11 to $84 \mathrm{mR} / \mathrm{hr}$ (much less than thought years ago prior to the recent feed sampling and characterization work) while the WIPP CH limit is 200 $\mathrm{mR} / \mathrm{hr}$. An IX effluent evaporator could be installed in the system, a mechanical assist one if necessary, to concentrate the SBW even more and reduce the $\mathrm{CH}$ volume/drum count much further. Especially with blending of the high activity feeds with the lesser ones, the total volume of $\mathrm{CH}$ waste could be significantly reduced. More grout formulation studies (as well as evaporator work) would be required to determine proper grout formulations. However, it is possible that a point could be reached where reasonable grout formulations could not be obtained with maximum concentration of the waste (to approach the $\mathrm{CH}$ dose limit) due to the need to have sufficient liquid in the waste (or add-back of water - not preferred) in order to properly form grout. In this case, not all the underutilized $\mathrm{CH}$ dose rate could be used, but significant volume reduction should be obtainable nonetheless. All this would require careful reassessment of the radiation field calculations and some process design and cost estimating work to determine if it is worth the additional cost and complexity.

3. Add another major step in the process to make less waste. A more complex variation on this would be to run the DE process on IX effluent (radiologically relatively cold in this case), making a lower activity evaporator product that, since it would go over the $\mathrm{CH}$ dose rate limit while being concentrated in the evaporator, could be dosed down by blending inert solids into the thermally hot evaporator discharge so that upon cooling a solid monolith would form at or just below the $\mathrm{CH}$ rate

limit. This would be a more complex process since it would require good mechanical mixing, but it could fully optimize/minimize the $\mathrm{CH}$ waste volume.

4. If the SBW were to be ruled to be HLW as-is (as feed to any treatment system) or if this was left as an open question, CsIX is the only SBW treatment alternative that could undergo a successful formal WIR ruling since all others involve further concentration of the SBW to RH waste forms. Such a WIR assessment (perhaps by the NRC, who has already informally signed off on the CsIX process) would entail ruling that the liquid SBW, minus the tank solids and the cesium (the last "key radionuclide" that can be feasibly and economically removed), is non-HLW, transuranic waste that can be disposed of at WIPP. The tank solids and/or cesium-loaded IX sorbent, perhaps being HLW, although not necessarily requiring that label, especially the cesium if held at low levels of TRU contamination by process design and control, could be safely stored to be dealt with later when the HLW calcine was dispositioned. 
5. Regardless of the HLW question, major near-term savings could be realized if the cesium-loaded sorbent and/or tank solids were not processed/packaged out. They could simply be dried and stored for future disposition like the option to store SBW calcine in the existing bins for that SBW treatment alternative. The cesium-loaded sorbent and tank solids could be stored together, although that is not recommended since the solids are well above the WIPP minimum TRU content, while the cesium-loaded sorbent might not be, or could be made to not be through proper process design and control. Other options would be to store the solids and/or sorbent wet (or at least not dry to WIPP standards) in bulk storage vessels or to dry them and pneumatically transport them into the bins. This latter option would be cheap, but it is not recommended for various reasons including the high radiation dose rate and retrievability considerations.

\subsection{CsIX References}

Anderson B. S., (2003), Preliminary Hazard Evaluation Report for the Cesium Ion Exchange (CsIX) Sodium-Bearing Waste Treatment Alternative, INEEL/INT-03-00878, August 2003.

Barnes C. M., A. L. Olson, D. D. Taylor (2004a), Sodium-Bearing Waste Treatment Technology Evaluation Report, INEEL/EXT-04-01692, February 2004.

Barnes C. M., C. B. Millet, (2004b), Feed Composition for the Sodium-Bearing Waste Treatment Process, INEEL/EXT-2000-01378, Revision 4, June 2004.

Barnes C. M., S. K. Janikowski, C. B. Millet, (2003), Feed Composition for the Sodium-Bearing Waste Treatment Process,” INEEL/EXT-2000-01378, Rev. 3, September 2003.

Batcheller D. D. Taylor, V. J. Johnson, (2003), Characterization of Tank WM-189 Sodium-Bearing Waste at the Idaho Nuclear Technology and Engineering Center, INEEL/EXT-02-01171 Rev. 1, July 2003.

Christian J. D., Composition and Simulation of Tank WM-180 Sodium-Bearing Waste at the Idaho Nuclear Technology and Engineering Center, INEEL/EXT-2001-00600, May 2001.

Herbst A. K., J. A. Del Debbio, R. J. Kirkham, B. A. Scholes, and T. L. Watson, (2002), Idaho Nuclear Technology and Engineering Center Low-Activity Waste Process Technology Program FY-2002 Status Report, INEEL/EXT-02-00985, September, 2002.

Herbst A. K., J. A. McCray, R. J. Kirkham, J. Pao, M. D. Argyle, L. Lauerhass, C. L. Bendixsen, and S. H. Hinckley, (2000), Idaho Nuclear Technology and Engineering Center Low-Activity Waste Process Technology Program FY-2000 Status Report, INEEL/EXT-2000-01167, October, 2000.

Herbst A. K., J. A. McCray, R. J. Kirkham, J. Pao, and S. H. Hinckley, (1999), Idaho Nuclear Technology and Engineering Center Low-Activity Waste Process Technology Program FY-99 Status Report, INEEL/EXT-99-00973, September 1999.

Kimmitt R. R., (2003) "Review of Cesium-Selective Ion Exchange Materials for Use in the Sodium Bearing Waste Treatment Facility,” Engineering Design File EDF-3601, September 15, 2003.

Mann N. R., T. A. Todd, K. N. Brewer, D. J. Wood, T. J. Tranter, and P. A. Tullock, (1999), Evaluation and Testing of IONSIV IE-911 for the Removal of Cesium-137 from INEEL Tank Waste and Dissolved Calcine, INEEL/EXT-99-00332, April 1999. 
Mann N. R., and T. A. Todd, (2000), Removal of Cesium-137 from INEEL Tank Waste Using IONSIV IE-911 Sorbent, INEEL/EXT-2000-01570 (draft), September 2000.

McCray J. A., to A. K. Herbst, (1999), Status Report for CsIX and NGLW Demonstration Grout Testing, Lockheed Martin Idaho Technologies Company Interdepartmental Communication JAM-03-99, September 30, 1999.

Jenn-Hai Pao R. Lewis, (2003) Experimental Study of Filtration and Solids' Post Treatment from Simulated Sodium-Bearing Waste Derived Slurry, INEEL/EXT-03-01106, September 2003.

Raman S. V., A. K. Herbst, B. A. Scholes, S. H. Hinckley, and R. D. Colby, (2003), Solidification of Simulated Liquid Effluents Originating form Sodium-Bearing Waste at the Idaho Nuclear Technology and Engineering Center, FY-03 Report, INEEL/EXT-03-01096, September 2003.

Raytheon Engineers and Constructors, (2000), Idaho National Technology \& Engineering Center Sodium Bearing Waste (SBW) Treatment Facility project CsIX/TRU Grout Process Feasibility Study Report, Volumes 1-4, September 2000.

Stoller Corporation, S. M., (2003), "Preliminary Hazard Evaluation of All Sodium Bearing Waste Preliminary Process Design and Treatment Options," January 21, 2003.

Todd T. A., (2003), "A Review of Cesium Ion Exchange Technologies Applicable to the Treatment of INEEL Tank Waste,” Engineering Design File EDF-2558, April 10, 2003.

Todd T. A., K. N. Brewer, D. J. Wood, P. A. Tullock, N. R. Mann, and L. G. Olson, (2001), "Evaluation and Testing of Inorganic Ion Exchange Sorbents for the Removal of Cesium-137 from Actual Idaho Nuclear Technology and Engineering Center Acidic Tank Waste, Separation Science and Technology 36, pp. 999-1016.

Tranter T. J., (2004a), "Dynamic Stability Testing of IONSIV® IE911 for Cesium Removal from INEEL Acidic Tank Waste,” Engineering Design File EDF-4612, February 24, 2004.

Tranter T. J., R.D. Tillotson, M.D. Argyle, and T.A. Batcheller, (2004b), "Evaluation of IONSIV ${ }^{\mathrm{TM}}$ IE911 as a Cesium Removal Option for INEEL Acidic Tank Waste: Phase II Semi-Scale Column Tests," Engineering Design File EDF-4536, January 30, 2004.

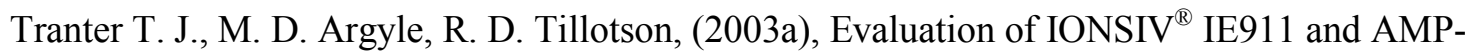
Cenosphere Composites as Cesium Removal Options for INEEL Acidic Tank Waste - Phase 1, INEEL/EXT-03-00757, July 2003.

Tranter T. J., (2003b), “AMP-CST Static Stability Testing,” Engineering Design File EDF-3655, August $13,2003$.

Tranter T. J., (2003c), "Evaluation of IONSIV IE911 and AMP-Cenosphere Composites as Cesium Removal Options for INEEL Acidic Tank Waste,” Engineering Design File EDF-3602, May 23, 2003.

Wendt D. S., (2003), "Radiolytic Hydrogen Gas Generation in Dried SBW UDS and Tank Solids," Engineering Design File EDF-3392, January 27, 2003. 
WIPP (2004), Contact-Handled TRU Waste Acceptance Criteria for the Waste Isolation Pilot Plant, DOE/WIPP-02-3122, Revision 1, March 1, 2004.

WIPP (2002a), Safety Analysis Report for the RH-TRU 72-B Waste Shipping Package, November 2002, http://www.wipp.carlsbad.nm.us/library/RHsar/rhsar/rhsartoc.pdf.

WIPP (2002b), Remote-Handled TRU Waste Acceptance Criteria for the Waste Isolation Pilot Plant, DOE/WIPP-02-3123, draft, June 2002. 


\section{DIRECT VITRIFICATION (DV)}

The baseline process scenario for this SBW treatment alternative involves design and construction of a new vitrification treatment system fed from the existing Tank Farm tanks and provided with new mixing pumps to suspend and mix the tank solids with the liquid SBW for co-processing. It involves a new off-gas treatment system close-coupled to the melter; and construction of a new glass packaging system for packaging, cooling, and interim storage of the SBW glass and neutralization, cesium ion change, and grouting, packaging, and interim storage of melter off-gas treatment scrub solution, all located in one common new facility (see Figure 5-1).

Vitrification was evaluated and tested for treating SBW during the period 1999-2001. The intent of the development program was primarily to define melter operating parameters and glass formulations to meet acceptance criteria for a high-level waste repository, conservatively bounding the case of disposal at WIPP as non-HLW TRU waste. The test program and all engineering evaluations assumed a joule-heated melter producing borosilicate glass. While these activities included the definition of a process (Quigley 2000; Taylor 2001; Bates 2001), not all aspects of the baseline flowsheet have been tested and numerous variations are possible. An initial evaluation of 33 variations or alternatives (Barnes 2001), was made and some schemes offer large potential savings over the baseline scheme. Verification of these savings would require additional studies and testing. The information in this section is based on the SBW vitrification engineering studies and development tests completed during 1999-2001, and does not address vitrification options that use other melter types or produce other glass waste forms.

The risks involved in SBW processing by vitrification have not undergone as formal an identification process as those for the other processes discussed in this report. The risks identified below draw heavily on comments from Defense Waste Processing Facility (DWPF) personnel during a December 2001 review meeting of the SBW treatment vitrification development program, a report summarizing development work performed in 2001 (Taylor 2002), and issues identified during the SBW vitrification feasibility study (Quigley 2000)

\subsection{Physical Systems - Process / Technical and Related}

\subsubsection{Technical Risks Related to Waste Product Qualification, Characteristics, and Storage}

A strategy for qualification of wastes from the direct vitrification process for disposal at WIPP has not been developed. Testing and collaboration with regulatory agencies and disposal sites will be required to resolve uncertainties regarding the grouted scrub, spent ion exchange sorbent, and spent GAC waste produced by the process.

SBW glass disposal at WIPP would require a waste stream profile and characterization plan for hazardous constituents and radionuclides. WIPP requirements are that the waste does not contain prohibited items, such as corrosives, reactives, or explosives, and does not contain free liquids. For waste streams assigned the U-134 hazardous waste number, the waste must not contain any liquids. WIPP is exempt from the RCRA land disposal restrictions; therefore, there are not waste form criteria for disposal at WIPP. 


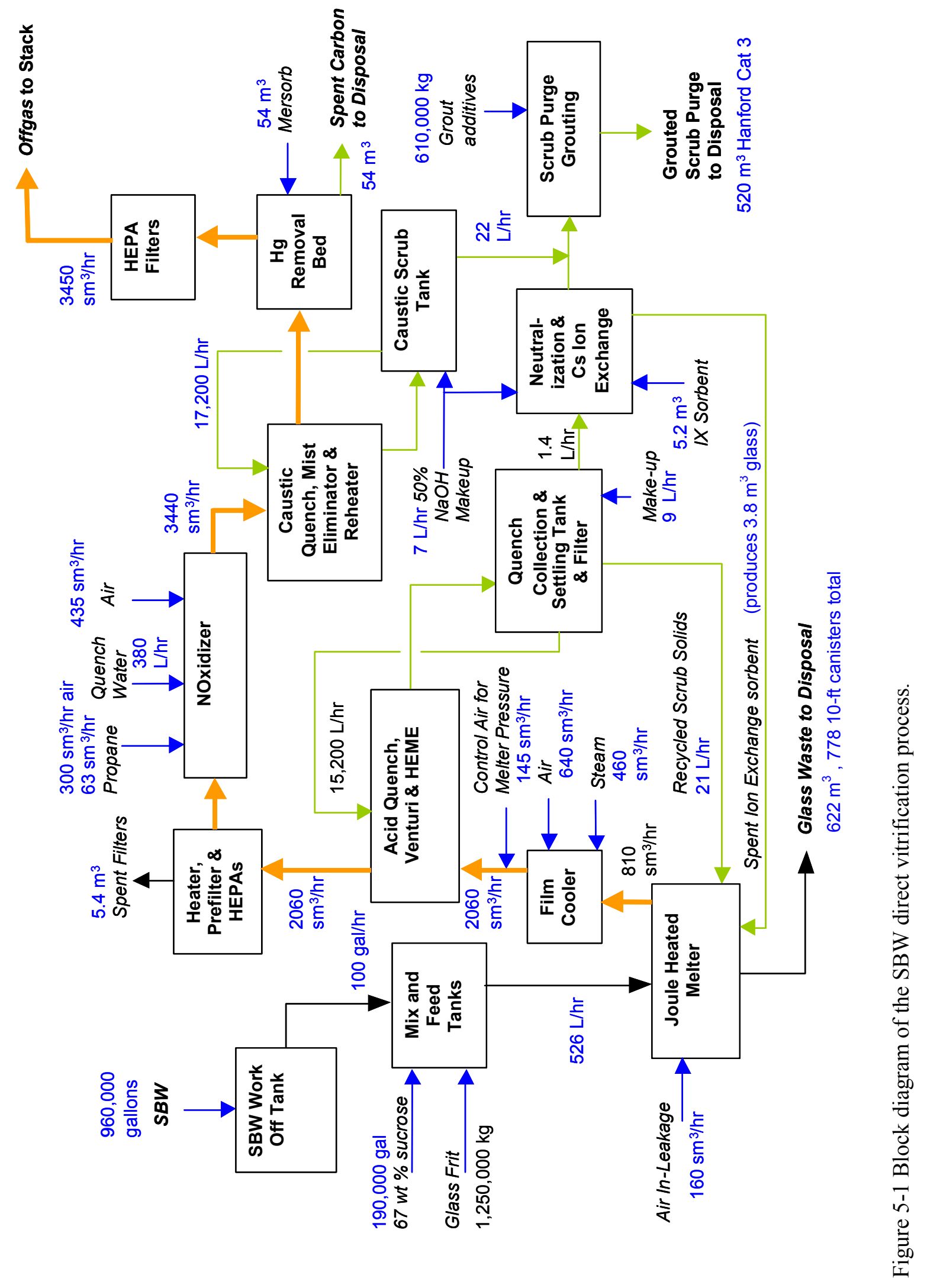


SBW glass disposal at the NGR would require development of a Waste Form Qualification Plan (WFQP) and acceptance of INEEL's vitrified waste at the NGR would be based on demonstrable conformity to that WFQP. The WFQP would document the development of a glass recipe (consisting of prescribed envelopes of feed composition and melter operating conditions) that ensures that the resulting glass meets the NGR acceptance criteria. The development of this recipe is heavily dependent on the choice of additives that are blended with the waste. The nature of these additives (both the composition and the physical form--as frit or as glass forming chemicals, or GFCs) influences the quality of the glass and the processing behavior. Choice of frit or GFCs will, therefore, dictate the course of development of the glass recipe and of the WFQP. At the end of development work for SBW vitrification, DWPF personnel flagged this choice as a high-priority uncertainty requiring attention. The WFQP for DWPF for glass disposal at Yucca Mountain is a multi-volume document reflecting a sizable investment of time and money. Development of a WFQP for SBW was barely started when development work for SBW vitrification was terminated at the end of FY 2001. The WFQP is a long-lead item that influences the system design, and it would require prompt attention to implement SBW vitrification in a timely fashion. It should be noted, however, that the effort required to achieve waste certification for WIPP disposal is not anticipated to be nearly as grent as for Yucca Mountain.

Disposal of glass waste at WIPP would require final resolution of the issue of the U134 hazardous waste number. Because SBW carries the U134 hazardous waste number (hydrofluoric acid), the waste glass generated by the process would also carry this number. Based on discussions with WIPP personnel regarding the direct evaporation waste, the treatment process would need to neutralize the SBW. Additional discussions would be needed to determine whether vitrification itself, or the addition of alkaline glass forming chemicals followed by vitrification would satisfy WIPP's requirements relative to removal of the hazardous waste number to permit disposal.

The volumes and compositions of off-gas treatment wastes are highly uncertain. The feasibility study mass balance (Quigley 2000) shows three wastes generated from off-gas treatment - a grouted blowdown from the scrub system, a spent cesium/strontium ion exchange sorbent, and spent activated carbon. The grout and spent GAC are expected to be low-level wastes (LLW) that may be able to be disposal at Hanford and/or Envirocare. However, the concentrations of contaminants, both radiological and chemical, are highly uncertain, and, hence, meeting acceptance criteria of any disposal site is uncertain. Once the composition of the scrub purge is better defined through test results, testing would be needed to develop a grout formulation such that the waste will meet the disposal site acceptance criteria.

Disposal of the spent GAC is further complicated by conflicting data from recent GAC tests. Leach tests of GAC from testing performed in 2002 showed leached mercury concentrations below the RCRA Land Disposal Restriction (LDR) limit of $0.025 \mathrm{mg} /$ liter (Herbst 2002), but similar tests from the longterm mercury removal tests in 2003 showed leach concentrations far in excess of the LDR limit (Del Debbio 2003). In either case, present regulations would require that the spent GAC, classified as a "high mercury" waste, be retorted. The Environmental Protection Agency is considering changes to this requirement (DOE 1999; Hulet 2001). If required, several methods could be used to stabilize the spent $\mathrm{GAC}$ waste for disposal. If the spent GAC waste is shown to meet TCLP limits, it could be argued that amalgamation of mercury with the sulfur present in the GAC is adequate immobilization. One stabilization method, Nuclear Fuel Services’ DeHg® process, has been used by Envirocare to enable disposal of mercury-containing waste (Envirocare 2001). Thus, it may be possible to ship the spent GAC directly to Envirocare for treatment and disposal. However, no contact has yet been made with any disposal site regarding this waste.

The spent ion exchange media would be a remote handled waste that could likely be vitrified, but no development of a glass formulation or melter conditions has been performed for this waste. 


\title{
5.1.2 DV Risks Related to Feed Uncertainties and Feed Transfer
}

\author{
Several uncertainties regarding SBW feed composition, feed blending, and frit or glass \\ forming chemical additional will require additional sample analysis, evaluations, and testing to \\ resolve.
}

Tests of SBW vitrification used a simulant for Tank WM-180 waste or a simulant for WM-189 waste defined prior to sampling in 2002. The feasibility study (Quigley 2000) did not include processing tank solids, although a later mass balance was prepared that considered both separate processing of solids and processing the solids with a fourth of the liquid SBW (Quigley 2001). Thus, there are discrepancies between the expected future feed composition and feed compositions use in documented tests and SBW vitrification evaluations.

Present Tank Farm management plans call for consolidation of all SBW into three tanks-WM187, WM-188, and WM-189- by the end of CY 2004. Additional waste generated in 2005 would continue to be added to WM-187 and WM-188, then from 2006 on, segregated in separate, smaller tanks (WM-100, WM-101, and WM-102). Waste in one Tank Farm tank, WM-189, was sampled and analyzed in 2002 (Batcheller 2003), and its composition is not expected to change prior to treatment. While changes are expected in the contents and composition of waste in WM-187 and WM-188, waste to be sent to these tanks has been sufficiently well characterized to have high confidence in the predicted compositions for the liquid in these tanks (as documented in Barnes 2004b).

Most of the solids ( $>85 \%$ ) contained in the Tank Farm have been consolidated in Tank WM-187 by tank closure work. The solids in this tank were sampled and analyzed in February 2004. Since solids in Tank WM-187 have not been well mixed, the recent analysis may not be representative of all the solids in the tank. Analysis of solids samples from other tanks that were flushed to WM-187 provide a basis to estimate the range of solids composition in the tank. Accurate analysis of the solids is very important to glass formulation, as major species in the solids will affect the glass formulation.

A tank blending scheme needs to be defined for the vitrification process that minimizes the effect of uncertainties in tank solids composition and volume. Given the consolidation of SBW into three tanks, blending wastes from the different tanks prior to feeding to a melter offers many advantages. Once blended, the waste can be sampled, analyzed, and processed as a single batch. If all the waste was blended to make a single feed composition, only a single glass frit or GFC composition would be needed. The feed rate of the reductant and the melter operating parameters could also be constant. And the ratio of undissolved solids in the feed would be reduced, avoiding solids settling in lines during transfer. Barnes (2004b) has suggested two blend schemes, each involving the installation of mixing pumps in two tanks and lowering the undissolved solids content of the feed to $20-40 \mathrm{~g} /$ liter. One of the schemes brings equal amounts of SBW from the three tanks, plus NGLW, into WM-190 where the wastes are mixed, creating a nearly uniform composition for the entire waste inventory. This scheme may be preferable for the direct vitrification process. Whatever solids blending scheme is proposed, it should ensure that the waste is transferred to the vitrification plant without solids settling in the transfer lines, minimize the effects tank solids would have on glass formulation and melter operation, and minimize the effect of the uncertainty in the composition and amount of solids contained in the Tank Farm tanks.

No evaluation of frit versus glass forming chemicals has been performed. The nature of feed additives (both the composition and the physical form - as frit or as glass forming chemicals) influences the feed system requirement, melter operating conditions, and glass properties. The choice between frit and glass forming chemicals will, therefore, dictate the course of development of the glass recipe and of the waste form qualification plan, as well as set numerous requirements for the design. 
In the RSM-2 test (Goles 2002), the use of alkaline glass forming chemicals resulted in neutralization of SBW, precipitation of solid and gelatinous species, and the release of heat. To resolubilize the SBW, acid was added. Also, rheology studies of this feed show it to be very abrasive and chemically aggressive. These results need to be considered in setting material requirements for the feed transfer, mix, and storage systems.

There is uncertainty about the concentrations of noble metals in SBW. Analysis for noble metals, including $\mathrm{Ru}, \mathrm{Rh}, \mathrm{Pd}$, and $\mathrm{Ag}$, has not been performed for most Tank Farm samples. Noble metals can form a separate metallic phase in a melter and short out electrodes. Thus, analysis of SBW for noble metals is needed, along with glass formulation tests based on the analysis results.

\subsubsection{Risks Related to Melter Chemistry and Corrosion}

\section{Updated SBW compositions will require development through testing of glass formulations. Additional testing is needed to resolve issues of corrosion, reductant additives, and melter scale-up.}

An acceptable feed composition envelope and glass recipe for SBW has not been firmly established. Sulfur has a finite solubility limit in any glass recipe. Once the limit is reached in a melter, excess sulfur will form a separate molten salt phase. Such phases were observed in some subscale and pilot tests during FY-01 (Perry 2001; Peeler 2001; Olson 2001; Darab 2001). The salt phase is undesirable for several reasons. First, it introduces the possibility of a steam explosion if mixed with a small amount of water. Second, a salt phase can accelerate corrosion of melter materials. Third, it may be more difficult to qualify the waste product. It may be possible to detect and remove any molten sulfate salt layer that may develop during processing, but such a system would require development. Lowering waste loadings to $<20 \%$ is another way to control salt layer formation (Goles, 2002), but with associated higher costs for increased waste production.

Another uncertainty in the glass formulation for SBW relates to its noble metal content. Noble metals are problematic in joule-heated melters due to their propensity to separate and form a separate molten metal phase that can cause electrical shorting between the melter electrodes (Grunewald, 1996).

Noble metals present in SBW include $\mathrm{Ru}, \mathrm{Rh}, \mathrm{Pd}$, and $\mathrm{Ag}$. The amount of molten metal present at steady state under varying conditions with SBW feed has not been quantified, nor has a threshold amount above which problems occur.

Additional development of glass formulations for SBW would be needed for several reasons. SBW compositions will not match the simulants used in the tests. The glass formulation work that was performed in the 1999-2001 time period was done using mostly Tank WM-180 simulants because this waste had the highest sulfur content. Since these tests, the decision was made to concentrate Tank WM180 waste and transfer it to Tank WM-187. Some tests were performed with a WM-189 simulant. But later analysis of Tank WM-189 waste (Batcheller, 2003) has shown that this waste has a much higher sulfur content than previously thought (198\% of the concentration of Tank WM-180 waste). Finally, no testing has been performed with simulants that included SBW undissolved solids. The tank solids are known to have high concentrations of phosphate which, based on earlier glass development of high phosphate feeds (Vienna 1999), strongly affects the glass waste loading.

Should vitrification be proposed for processing SBW, the present Tank Farm waste compositions, including solids, would need to be used to define an updated melter feed composition range, and then glass formulations would need to be developed and demonstrated.

There is a risk of high corrosion rates in the melter. SBW is a highly acidic waste. The concentration of sulfate, chloride, and phosphate in SBW provides the potential to form corrosive acids 
and/or molten salts in a high temperature environment. Unacceptable electrode loss was observed in some tests that may have been due to a low redox ratio or the choice of material for the electrodes. Inadequate understanding of corrosion behavior of melter components could result in a melter design and/or operating parameters that lead to premature system failure and negative cost and schedule impacts.

The selection of the reductant is not final. Sugar is the preferred candidate reductant due to its history of use for various nuclear waste treatment applications and its success in SBW vitrification tests. However, other organic reductants (e.g., activated carbon, glycolic acid, corn starch) have been considered for various reasons. Choice and concentration of a reductant was singled out by DWPF personnel as a high-risk uncertainty that impacts several parameters, among them nitrate destruction rates and glass redox ratio, which in turn impacts glass foaming and possibly glass durability.

The effects of melter scale on operating parameters has not been determined. Testing of SBW vitrification has been performed in the Envitco EV-16 melter at the Clemson Environmental Technologies Laboratory (CETL), which has a nominal glass capacity of about $3 \mathrm{ft}^{3}$, and also at other much small laboratory melters. A full scale melter would need a capacity of about 30 times the EV-16 melter. ${ }^{\mathrm{e}}$ Based on DWPF experience, data from larger-scale melters will be required to design the full-scale melter.

\subsubsection{Risks Related to Canister Loading and Handling}

The design of the SBW melter/canister interface, canister loading, and canister handling system will benefit from the proven designs and operating experience of West Valley and DWPF. However the SBW Vitrification Feasibility Study (Quigley 2000) still recommended full-scale mock-up testing of mechanical equipment, remote handling equipment, viewing, and cell sizes and arrangements to check accessibility, interferences, visibility, maintainability, operability, transfer routes, and lifting mechanisms and devices.

\subsubsection{Risks Related to Off-Gas Treatment and Emissions}

Vitrification is a high-temperature process that will require extensive off-gas treatment. Offgas treatment requirements, are at this time, not well defined. Updated melter tests followed by offgas treatment evaluations and demonstration testing will be needed to minimize performance failures of off-gas treatment unit operations.

Concentrations of hazardous and radioactive species in the off-gas are uncertain. Vitrification is a high temperature process that will volatilize both hazardous and radioactive species that must be removed from the off-gas. Stack concentrations of $\mathrm{HCl}, \mathrm{Cl}_{2}, \mathrm{Hg},{ }^{129} \mathrm{I}$, and other species must be controlled for compliance with MACT and NESHAP standards. In addition, experience with calcination in the NWCF indicates the potential for buildup of mercury in scrub solutions. The fate of $\mathrm{SO}_{2} / \mathrm{SO}_{3} / \mathrm{H}_{2} \mathrm{SO}_{4}$ is uncertain, and needed in the prediction of sulfate concentrations in recycle streams to the melter to control formation of molten sulfate salts. The fate of carbon dioxide is needed to design the caustic quench column. The vapor/liquid partitioning of these species in acid and caustic scrubbing is needed in system models used to design and optimize unit operations to ensure compliance with stack emission limits. Testing in 2001 provided some initial estimates of off-gas composition (Perry 2001; Goles 2002), but large uncertainties remain, due to changes in feed composition and operating conditions from those used in the tests, as well as the analytical uncertainty present in test data.

e. The 30-times EV capacity factor is based on the SBW Vitrification Feasibility Study (Quigley, 2000) which shows a melter capacity of about 2,500 liters. The later discovery of needing to lower waste loading to avoid a molten salt phase would require a larger melter or a longer processing schedule. 
This uncertainty incorporates several components. Uncertainties in partitioning of species to the melter off-gas are due to the limited testing performed using SBW simulants, the changes to the SBW composition since the tests were performed, and potential changes in feed additives and melter operating conditions from those used in the tests. Uncertainties in downstream off-gas compositions relates to the lack of testing of certain features or operations of the flowsheet (such as recycle of scrub solution to the melter), the potential for changes in the configuration of the off-gas treatment system, the inadequacy of process models to accurately predict behavior of certain species in certain unit operations, differences between the equipment and conditions used in tests and full-scale process equipment and operating conditions, and the lack of mass balances seen for many species in the test data. One way of minimizing the affect of these uncertainties is to use very conservative assumptions in the design, but this adds both cost and complexity to the treatment process. To reduce these costs, testing is needed to supply the basis for the off-gas system design after a better melter off-gas composition is determined.

There is uncertainty in off-gas flow control. The baseline process control in the vitrification off-gas system is patterned after a system of throttling valves, air bleeds, and compressors similar to that used in the calcination system in the NWCF. However, it has been pointed out by DWPF personnel that the melter system is far less tolerant of pressure instability and fluctuations than is the NWCF due to the use of hydrostatic pressure to control the flow of molten glass through the pour spout into the canisters. No detailed design or testing has been performed to compare system dynamic behavior with that of DWPF, where a considerable effort was expended before a workable system was developed and demonstrated.

There is uncertainty in the design and performance of the film cooler. The function of the film cooler is to prevent deposition of solids (molten glass) in off-gas piping. Air and/or steam is added in the film cooler to cool the off-gas and entrained solids to a temperature below that at which solids would stick to the walls of piping and equipment. Testing would be needed to demonstrate a design that adequately prevents solids deposition.

Data from SBW vitrification tests has raised several unanswered questions about off-gas treatment. These are summarized by Taylor (2002), and listed below:

- Data from Clemson-1 tests showed that $>50 \%$ of the solids collected in the scrub are $<1 \mu \mathrm{m}$ in diameter. Can they be prevented from being formed, or if not, how can these small particles be filtered?

- $\quad$ Analysis of RSM-2 samples showed no Hg in the HEME effluent gas. Is all the mercury captured in the scrub solution or does it partition to other places? Will mercury need to be removed from the scrub and if so how?

- $\quad$ Neutralization of simulated scrub solution resulted in precipitation, suggesting that filtration upstream of the ion exchange columns will be needed. How should these solids be processed?

- What sorbent should be used to remove cesium from the scrub solution? Is removal of strontium also required?

- How will the organics captured in the scrub solution affect the performance of the ion exchange operations, the grouting operation, and grout properties?

Process variations have been suggested to answer some of the above questions (see Taylor 2002; Barnes 2001), but test data will also be required to confirm the performance of any recommended system.

Selection of the $\mathrm{NO}_{\mathrm{x}}$ abatement system warrants reevaluation. Vendor recommendations, as well as recent testing of a staged combustor (Boardman 2004), indicate that the air requirement for the staged combustor is much larger than assumed in the mass balance (Quigley 2000), such that the effluent flow 
will increase by about a factor of 4 over what is shown in the feasibility study mass balance. This increase will require larger equipment for downstream treatment, increasing the facility size and cost.

Recent tests of a staged-combustor treating off-gas from calcination (Boardman 2004) have demonstrated that the staged combustor can adequately destroy total hydrocarbons and $\mathrm{CO}$ to below MACT limits and achieve acceptable levels of $\mathrm{NO}_{\mathrm{x}}$ destruction. No tests have been performed to demonstrate whether the staged combustor will meet the required $99.99 \%$ destruction of principal organic hazardous constituents.

The need for acid gas removal downstream of the $\mathrm{NO}_{\mathrm{x}}$ abatement system is uncertain. Insufficient off-gas data is available to establish whether removal of acid gas-including $\mathrm{HCl}, \mathrm{HF}, \mathrm{HI}$, and/or $\mathrm{SO}_{2}$ - is required downstream of the $\mathrm{NO}_{\mathrm{x}}$ abatement system.

There is a risk that emissions standards may change. Between now and when the facility comes on line ( 2009), regulations may change that would affect how the plant is designed and operated.

\subsubsection{Balance of Plant Requirements, Facility Siting, and Interfaces}

A new steam facility would be required to meet the steam demand for the SBW Vitrification Facility (see Quigley 2000, Section 8.9). At the time the SBW Vitrification Feasibility Study was performed, spare electrical capacity of INTEC could not be determined because of uncertainties in other projects (Quigley 2000). In light of that uncertainty, it was assumed the SBW Vitrification Facility would provide a new 2,000-kVA diesel generator and associated equipment in a generator plant. To support $\mathrm{NO}_{\mathrm{x}}$ abatement of melter off-gas, new or supplemental utilities systems such as a propane fuel system and added demineralized water capacity would also likely be required.

The SBW Vitrification Feasibility Study (Quigley 2000) tentatively sited the facility in the northeast corner of INTEC, but recommended a siting study.

A sampling strategy has been defined in the SBW Vitrification Feasibility Study (Quigley 2001). Samples of 37 process streams or tank contents would be taken using 16 sampling stations for all purposes. While a detailed evaluation of the ability of existing analytical facilities to meet the requirements of the SBW vitrification process has not been performed, a related study indicate that the present capabilities are adequate. Based on sampling frequencies stated in the SBW Vitrification Feasibility Study, the number of samples generated by the SBW treatment facility would be about $150 /$ month. This rate is about $40 \%$ of that estimated for the Early Vitrification Option (processing highlevel waste), for which it was determined that existing analytical capabilities were adequate (Childs 2000).

\subsubsection{Safety Concerns}

No hazards identification study has been performed for an SBW vitrification process. However, relative to other SBW treatment options, the process operates at higher temperatures, has more unit operations and equipment, generates more waste streams, and possibly uses a greater number of hazardous feed materials.

Analysis and modeling of melter off-gas must be done to ensure off-gas compositions are outside the flammability region. The total flammability of a gas mixture is the sum of the percent flammabilities of the separate flammable gases and should be less than $50 \%$ to ensure system safety. The true flammability of the melter off-gas is affected by the melter outlet gas temperature and the presence of other gas species (e.g., water) that can dilute any oxygen that is present. The flammabilities of melter off- 
gas upstream of the film cooler must be defined (and probably demonstrated) under all expected conditions to preclude any possibility of explosion in the melter or off-gas system. This uncertainty was flagged by DWPF personnel as high priority (Barnes 2004a). SRS has developed and qualified a flammability model for this purpose.

Safety concerns regarding the addition of sugar to SBW feed will need to be resolved. In the present process flow diagrams, sugar is added to SBW to reduce the oxidation potential of the melt and control foaming of the molten glass. Numerous safety concerns were identified in the past for the addition of sugar to SBW in the calcination process (for example, see Groshner 1996), and these safety concerns heavily influenced the decision not to pursue SBW calcination using sugar. One of the major issues is the potential for the formation of nitrated organics. A similar review of the potential for fires or explosions due to sugar in the vitrification process would be needed.

\subsubsection{Future Use Considerations}

An SBW vitrification facility could be designed to process high-level waste (HLW) calcine at a later date. Additional shielding would be required because the HLW glass generates a higher radiation field than glass from SBW. The waste container for HLW glass may or may not be different from that for SBW glass, depending on where the SBW glass is disposed. Design for HLW calcine processing could affect the siting of the treatment facility, to optimally tie in to each of the calcine storage facilities as well as receive SBW from the Tank Farm. The effects on the design of other requirements for HLW calcine disposition, such as processing rate, transport gas handling, and provisions for sampling would have to be considered in the design.

NGLW will continue to be generated after 2012, although at a decreasing rate and, possibly, with decreasing radioactivity. Current projections indicate an annual generation rate decreasing from 4400 to 3100 gallons between 2012 and 2035. Processing small batches of feed through the melter is very inefficient, due to the time, energy, and other utilities used to start up the equipment, and the waste generated upon decontamination. To process NGLW by vitrification, new glass formulations may need to be developed, as present projections of NGLW composition for the years 2004-2012 show significant differences from SBW. The annual NGLW production, if compatible with vitrification, could be processed in a few days.

\subsubsection{Process/Technical Summary}

The following table presents a summary of the technical risks and issues for the direct vitrification process. The probability and impact values shown are on a scale of 1 to $10(1=$ low probability or impact $)$ and based on the author's judgment rather than any formal process or group evaluation. A probability of 5 is equivalent to a $50 \%$ chance that the identified risk would occur or uncertainty cause detrimental effects. The "Resolution" column presents a recommendation on how the issue should be resolved, usually either by evaluations during design or testing.

Table 5-1. Summary of technical issues and risks - Direct Vitrification (DV).

\begin{tabular}{|l|l|c|c|l|}
\hline & \multicolumn{1}{|c|}{ Risk or Issue } & Probability & Impact & \multicolumn{1}{c|}{ Resolution } \\
\hline 1 & $\begin{array}{l}\text { Preparation of a waste form } \\
\text { qualification plan has not been } \\
\text { started, risking schedule to } \\
\text { complete tests prior to or } \\
\text { during design }\end{array}$ & 5 & 10 & $\begin{array}{l}\text { Negotiations with WIPP } \\
\text { regarding what } \\
\text { documentation will be } \\
\text { needed to qualify the waste }\end{array}$ \\
\hline
\end{tabular}




\begin{tabular}{|c|c|c|c|c|}
\hline & Risk or Issue & Probability & Impact & Resolution \\
\hline 2 & $\begin{array}{l}\text { Treatment requirements } \\
\text { relative to the U134 hazardous } \\
\text { waste number carried by SBW } \\
\text { are uncertain, and if not } \\
\text { resolved could lead to waste } \\
\text { not being accepted at WIPP }\end{array}$ & 3 & 10 & $\begin{array}{l}\text { Discussions with WIPP } \\
\text { personnel during design }\end{array}$ \\
\hline 3 & $\begin{array}{l}\text { The volumes and } \\
\text { compositions of off-gas } \\
\text { treatment wastes are highly } \\
\text { uncertain; without additional } \\
\text { test data, off-gas wastes may } \\
\text { not meet selected disposal site } \\
\text { WAC }\end{array}$ & 5 & 9 & $\begin{array}{l}\text { Integrated melter/off-gas } \\
\text { treatment system testing is } \\
\text { needed to determine the } \\
\text { melter off-gas, liquid scrub } \\
\text { compositions, and } \\
\text { performance of off-gas } \\
\text { treatment unit operations }\end{array}$ \\
\hline 4 & $\begin{array}{l}\text { Stabilization of spent GAC } \\
\text { prior to disposal may be } \\
\text { required }\end{array}$ & 5 & 4 & $\begin{array}{l}\text { Negotiation with disposal } \\
\text { sites and regulators; } \\
\text { possible testing }\end{array}$ \\
\hline 5 & $\begin{array}{l}\text { Processing requirements of } \\
\text { spent ion exchange sorbent are } \\
\text { uncertain }\end{array}$ & 5 & 7 & $\begin{array}{l}\text { Following long-term tests } \\
\text { that determine off-gas } \\
\text { scrub composition, design } \\
\text { evaluations would be } \\
\text { performed to define scrub } \\
\text { treatment steps and, if } \\
\text { warranted, further testing } \\
\text { of these steps would then } \\
\text { be done, (e.g., developing } \\
\text { a glass formulation for } \\
\text { spent ion exchange media) }\end{array}$ \\
\hline 6 & $\begin{array}{l}\text { Uncertainties in tank waste } \\
\text { solids composition could } \\
\text { affect glass formulations }\end{array}$ & 5 & 8 & $\begin{array}{l}\text { Additional sampling and } \\
\text { analysis of Tank WM-187 } \\
\text { solids }\end{array}$ \\
\hline 7 & $\begin{array}{l}\text { Performance of mix pumps for } \\
\text { TFF tanks uncertain, with risk } \\
\text { of varying solids content in } \\
\text { feed }\end{array}$ & 5 & 8 & $\begin{array}{l}\text { Mock up testing of mix } \\
\text { pumps }\end{array}$ \\
\hline 8 & $\begin{array}{l}\text { Tank blending scheme has not } \\
\text { been finalized }\end{array}$ & 5 & 5 & Design \\
\hline 9 & $\begin{array}{l}\text { The selection between glass } \\
\text { frit and glass forming } \\
\text { chemicals (GFC) has not been } \\
\text { made, creating uncertainty in } \\
\text { the design basis }\end{array}$ & 8 & 6 & $\begin{array}{l}\text { Design evaluation, } \\
\text { possibly preceded or } \\
\text { followed by testing }\end{array}$ \\
\hline 10 & $\begin{array}{l}\text { Material requirements for the } \\
\text { feed system are uncertain }\end{array}$ & 8 & 6 & $\begin{array}{l}\text { Following the selection of } \\
\text { frit or GFC, feed rheology } \\
\text { tests should be done to } \\
\text { resolve this issue }\end{array}$ \\
\hline 11 & $\begin{array}{l}\text { There is a high uncertainty in } \\
\text { the quantity of noble metal in } \\
\text { the feed SBW, both liquids } \\
\text { and solids, which could result } \\
\text { in melter operational problems }\end{array}$ & 5 & 9 & $\begin{array}{l}\text { Additional analyses of tank } \\
\text { samples for noble metals, } \\
\text { followed by glass } \\
\text { formulation tests }\end{array}$ \\
\hline
\end{tabular}




\begin{tabular}{|c|c|c|c|c|}
\hline & Risk or Issue & Probability & Impact & Resolution \\
\hline 12 & $\begin{array}{l}\text { There is uncertainty in the } \\
\text { glass recipe for SBW, with } \\
\text { potential risks of second phase } \\
\text { formation, corrosion in the } \\
\text { melter, and problems } \\
\text { qualifying the glass waste }\end{array}$ & 8 & 10 & $\begin{array}{l}\text { Following the developing } \\
\text { of a tank mix scenario and } \\
\text { calculating melter feed } \\
\text { compositions, glass } \\
\text { formulation tests are } \\
\text { needed to resolve this risk }\end{array}$ \\
\hline 13 & $\begin{array}{l}\text { There is a risk of high } \\
\text { corrosion rates in the melter, } \\
\text { risking possible failure }\end{array}$ & 7 & 7 & Materials testing \\
\hline 14 & $\begin{array}{l}\text { There is uncertainty in the } \\
\text { selection of the reductant, } \\
\text { affecting melter operability } \\
\text { and possibly waste } \\
\text { qualification }\end{array}$ & 6 & 6 & $\begin{array}{l}\text { Design evaluation, } \\
\text { possibly preceded or } \\
\text { followed by testing }\end{array}$ \\
\hline 15 & $\begin{array}{l}\text { Scale up of melter design is } \\
\text { uncertain }\end{array}$ & 7 & 7 & Large-scale melter testing \\
\hline 16 & $\begin{array}{l}\text { The basis for design and } \\
\text { performance of glass } \\
\text { discharge and packaging } \\
\text { equipment is uncertain }\end{array}$ & 8 & 10 & $\begin{array}{l}\text { Mock up testing of } \\
\text { equipment }\end{array}$ \\
\hline 17 & $\begin{array}{l}\text { There is uncertainty in off-gas } \\
\text { flow control }\end{array}$ & 7 & 7 & $\begin{array}{l}\text { Design concepts followed } \\
\text { by testing }\end{array}$ \\
\hline 18 & $\begin{array}{l}\text { There is uncertainty in the } \\
\text { design and performance of the } \\
\text { film cooling }\end{array}$ & 6 & 6 & $\begin{array}{l}\text { Testing of film cooler } \\
\text { designs }\end{array}$ \\
\hline 19 & $\begin{array}{l}\text { The selection of the NOx } \\
\text { abatement system is uncertain, } \\
\text { and could be larger and more } \\
\text { costly than required }\end{array}$ & 6 & 6 & $\begin{array}{l}\text { Reevaluation of } \mathrm{NOx} \\
\text { abatement system selection } \\
\text { during design }\end{array}$ \\
\hline 20 & $\begin{array}{l}\text { The required destruction } \\
\text { efficiency of principle organic } \\
\text { hazardous constituents in the } \\
\text { NOx abatement system has not } \\
\text { been demonstrated }\end{array}$ & 5 & 7 & $\begin{array}{l}\text { NOx abatement system } \\
\text { tests }\end{array}$ \\
\hline 21 & $\begin{array}{l}\text { The need for acid gas removal } \\
\text { downstream of the NOx } \\
\text { abatement system is uncertain }\end{array}$ & 5 & 5 & $\begin{array}{l}\text { NOx abatement system } \\
\text { tests if system feed } \\
\text { composition has been well- } \\
\text { defined; integrated system } \\
\text { tests otherwise }\end{array}$ \\
\hline 22 & $\begin{array}{l}\text { Changes could be made in } \\
\text { final WIPP RH WAC }\end{array}$ & 5 & 5 & $\begin{array}{l}\text { Design and negotiation } \\
\text { with WIPP }\end{array}$ \\
\hline
\end{tabular}

\subsection{Environmental/Regulatory and Related}

\subsubsection{Permitting}

A 24-month permitting schedule, a critical path early in the project schedule, appears to be the best that can be achieved.

The baseline for the SBWT project identifies a 24-month permitting schedule, including the Hazardous Waste Management Act (HWMA) and Clean Air Act (CAA) permits. This may be optimistic, 
since discussions with the State of Idaho, Department of Environmental Quality (IDEQ) in the spring of 2003 indicated that the IDEQ estimated 32-months to permit the SBWT project after receiving the HWMA and CAA permit modifications or applications. The project will need to work with the IDEQ to streamline the permitting schedule. (The 32-month schedule was worked down to 24 months by taking time out of the operating contractor's activities only.)

The Direct Vitrification Facility will require CAA permits and HWMA permits. The direct vitrification unit will require a CAA Title V and PSD permits and a demonstration that emissions meet the MACT standards for hazardous waste incinerators. The direct vitrification unit and product packaging facility (PPF) will need HWMA permits for hazardous waste management activities. The direct vitrification unit will need a site-specific risk assessment to address hazardous air pollutants (HAPs), and non-HAPs risk to human health and the environment not covered by the MACT, PSD, and Title V emission limits.

EPA recommends hazardous waste combustors provide copies of the facility's notice of intent to comply (NIC), compliance performance test plan, and draft Title V permit modification to the public at the same time the facility holds the public information meeting prior to submitting the HWMA permit application. In addition, EPA suggests placing copies of the MACT and air permit documents with the HWMA permit application in the facility reading rooms. This will allow the public adequate comment on the facility for both the HWMA and CAA requirements

The following sections describe the permitting activities necessary for the direct vitrification treatment alternative.

The direct vitrification SBW treatment alternative consists of three parts to be permitted and constructed to treat the waste by the end of 2012: (1) Construction of the direct vitrification treatment unit and MACT-compliant off-gas treatment system. (The off-gas treatment system would lower the amount and concentration of constituents emitted up the stack to meet MACT, PSD, and Title V Standards). (2) Construction of the direct vitrification product packaging, scrub grouting, feed and mix tanks, and container storage facility to store canisters pending shipment to WIPP. (3) Installation of mixing pumps in 2 or 3 Tank Farm tanks to produce homogeneous feed to the treatment process and enable solids-liquid co-processing.

5.2.1.1 DV Treatment System Permitting. The direct vitrification treatment unit and MACTcompliant off-gas treatment system will generate emissions similar to a hazardous waste combustion unit, and it must meet the same emission limits and comply to the same permitting process. The direct vitrification treatment unit and off-gas equipment emissions and operations will be permitted under the Clean Air Act, NESHAPS, PSD, and Title V. The direct vitrification treatment unit will require a HWMA permit for hazardous waste management activities, such as waste characterization, tank management, public participation, closure, and other operations related to hazardous waste management. The direct vitrification product packaging, container storage, and scrub grout treatment will be permitted under the HWMA. Tanks and equipment in the PEWE that will provide support to the direct vitrification process are permitted in Volume 14 or Volume 18 to the INEEL HWMA Permit.

\subsection{Air Permitting-}

\subsection{MACT Standards}

The direct vitrification SBW treatment alternative would construct a new facility to house the vitrification treatment unit and off-gas treatment system. The emission control equipment in the MCF 
would treat the off-gas to the Maximum Achievable Control Technology (MACT) standards for hazardous waste incinerators.

The State of Idaho and EPA Region 10 have both stated that, in their opinion, the direct vitrification emissions are similar to those from a hazardous waste incinerator, and the emissions and operations should be permitted under 40 CFR §63, Subpart EEE National Emission Standards for Hazardous Air Pollutants From Hazardous Waste Combustors. Subpart EEE contains the MACT emission limits and process control requirements for hazardous waste incinerators. (See Table 5-2 at the end of the section for limits for Interim Rule for existing and new source incinerators and proposed Final Rule MACT limits for new source incinerators.)

The project will need to submit several documents to the State of Idaho to comply with the MACT rule. First, the project needs to submit a Notice of Intent to Comply (NIC) to explain how the design for the direct vitrification unit and off-gas treatment will control emissions, monitor emissions, comply with the emission standards, and minimize waste generation. Second, the project will submit a compliance performance test plan to explain how the direct vitrification unit will be tested, what emissions will be monitored, what analytical methods will be used, and how the unit will be operated during the test (time frames, feed rates, spiking, emission control equipment, and emission monitoring equipment). Third, the project will submit a notice of compliance to document that the direct vitrification unit operated below the MACT emission limits. Fourth, the project will submit a Title V permit modification to add the emission limits and operating controls necessary to maintain compliance.

Hazardous waste incinerators permitted under the 40 CFR $\S 63$ standards are required to submit a compliance test plan (similar to a RCRA trial burn) with the permit application and complete compliance performance testing to demonstrate that the emission control technologies and emissions from direct vitrification will meet the MACT standards. The project can achieve compliance by feed control or emission control technologies, or a combination of both. The compliance performance test demonstration will test the process at normal and maximum feed rates and hazardous waste concentrations to develop the operating limits for the treatment process. Compliance performance testing may require spiking the waste with know-concentrations of chemicals. In the past, EPA has considered the use of reagent chemical for spiking to be the incineration of un-used commercial chemical products and have added the $\mathrm{P}$ and $\mathrm{U}$ listed hazardous waste numbers to the glass and scrub solution generated during the test. The project needs to work with the State of Idaho to select chemicals or surrogates that will not add new hazardous waste numbers to the waste.

The risk is that all of the waste treated after the compliance performance test will be assigned the new hazardous waste numbers due to mixing of the bed material and spent scrub solutions with the SBW in the tank farm. This could exclude the waste from disposal at WIPP. This could also exclude waste streams from disposal at the National Geologic Repository (NGR), Envirocare, Nevada Test Site (NTS), or Hanford Site without additional work to delist the waste. (See discussion in Sections 5.2.4.c and 5.2.4.f.)

Hazardous waste incinerators permitted under the 40 CFR $\S 63$ standards are exempt from the incinerator permitting requirements for emissions and operations at 40 CFR §264 Subpart O, and $\$ 270.62$, (Hazardous Incinerators Waste Incinerator Permits), except for provision the Director determines are necessary to ensure compliance with subpart $\$ 264.345$ (a) and (c) Releases During Startup or Shutdow.

It is recommended that the direct vitrification facility be permitted under 40 CFR $\S 63$, Subpart EEE to eliminate dual regulation of operations and emissions. The project needs to evaluate the proposed final 
rule limits to determine if the limits for mercury and chlorides can be achieved, considering the concentration of constituents in SBW and the emission control technology available.

If the chlorine limit cannot be achieved, then the project could establish a site-specific risk-based limit for total chlorides based on the national exposure standard. The project needs to demonstrate that emission of total chlorides from on-site hazardous waste combustion units results in an exposure to the most exposed individual of a Hazards Index less than or equal to 1.

If the mercury limit cannot be achieved, then DOE should consider asking for a separate category and emission limits for the direct vitrification unit. The information submitted for DOE thermal treatment units to EPA did not indicate that they could not meet the MACT standard for new hazardous waste incinerators. The project would need to document why it is not practical to remove mercury below the level in the current direct vitrification design; either the technology is not available or the cost to remove additional mercury is not beneficial. DOE could use the same approach EPA used in setting the current proposed standards for new hazardous waste incinerators and evaluating whether it is practical to achieve lower levels of mercury removal from emissions. EPA used \$18 million/ton of mercury removed when they evaluated the practicality of removing mercury from emissions below the limit proposed for new sources.

The risk is that design changes, emission control and monitoring equipment modifications, or feed rate reductions will be required to meet the MACT standard. The project should contract with a compliance performance testing contractor early in design to develop the NIC, sampling location, testing protocol, and the compliance performance plan.

5.2.1.1.2 Clean Air Act - New Emission Sources-The direct vitrification treatment unit would be considered a new source and would require a new source review.

The New Source Review (NSR) program is the primary mechanism for preventing facilities from causing or contributing to violations of national ambient air quality standards (NAAQS). NSR applies to what are known as "major" stationary sources, which are defined differently for attainment versus nonattainment areas. The INEEL is in an attainment area adjacent to a wilderness area (Craters of the Moon) and would be a Class 1 attainment area. The NSR program uses the preconstruction permitting process to control the construction of new major sources (and modifications to existing sources). In attainment areas, these preconstruction permits are referred to as prevention of significant deterioration (PSD) permits.

The project needs to determine if the emissions from the direct vitrification unit are minor new sources or major new sources in a Class 1 attainment area.

The direct vitrification unit will be classified as a new major source unless emissions of pollutants are below the potential to emit 100 tpy of any PSD pollutant or any other source with potential to emit (PTE) of 250 tpy of any PSD pollutant. (See Table 5-3 at the end of this section.)

For a new major source, NSR applicability is relatively straightforward. Since the facility is not in operation, the baseline emissions are zero, and the emissions impact of the new facility is based on the PTE of all the new emission sources combined. If the new sources meet the applicability thresholds for PSD, the facility must complete the appropriate permit application, review, and approval process. In attainment areas, the applicability threshold is a PTE of 250 tpy, or 100 tpy for certain source types. 
The PSD application process requires air monitoring and emission models, stringent pollution controls, estimates of the regional emissions for each hazardous air pollutant, public involvement, and Federal Land Manager involvement near Class 1 attainment areas.

5.2.1.2 Title V Permit-The Title V Air Permit application for the INEEL has been submitted to the State of Idaho Department of Environmental Quality (IDEQ) for approval. The IDEQ is still reviewing the application and should issue a final permit by May 2005.

The Title V permitting sets forth the comprehensive state air quality operating permits program and emission limits. Sources subject to the operating permit requirements shall have a permit to operate that assures compliance by the source with all requirements. Of primary interest for SBW are emissions of radionuclides, organics, nitrogen oxides, and the MACT standards. Tables 5-2 and 5-3 at the end of the section identify the list of constituents to be addressed in the permit modification.

The Title V Air Permit will identifies the NESHAPs emission limits, process controls, and emission control equipment for each source. New emission sources are added to the Title $\mathrm{V}$ permit through a permit to construct and a permit to operate. The permit to construct identifies the potential emissions and controls based on the facility design. The permit to operate is based on emissions testing when the source is operating. Emission limits and controls are established for each source based on the emission testing. The emission limits and controls are then added to the Title V Air Permit by modifying the permit to include the new sources.

The risk is that emissions from the direct vitrification unit or a combination of the INEEL sources will exceed the NESHAPs limits, which will require additional off-gas treatment or operating at reduced feed to meet the emission limits. The risk is that NOx emission cannot be reduced below the visible range and the Federal Land Manager delays or opposes the air permits. The project needs to start early in the design to gather the information necessary to submit applications for the permit to construct, MACT compliance plan, and new source review for PSD.

\subsubsection{HWMA Permits.}

5.2.1.2.1 Direct Vitrification Unit and MACT Compliance Facility-The direct vitrification unit and related equipment in the MCF are subject to HWMA permitting. A permit application will cover all permit sections except for MACT air emissions and related operating requirements. The permit application for the direct vitrification unit will cover tank storage, waste characterization, general facility standards, material handling, risk-based emission limits for HAPs and non-HAPs, and operating requirements. A permit is required before construction can begin on hazardous waste units.

It is recommended that the direct vitrification unit be added to Volume 14 of the INEEL permit with the other liquid waste treatment equipment.

5.2.1.2.2 Site-Specific Risk Assessment-A site-specific risk assessment (SSRA) may be required by the IDEQ permit writers, if they believe that operation in accordance with the MACT standards alone may not be protective of human health and the environment. The SSRA will focus on the emission rate of HAPs and non-HAPs, stack gas characteristics, meteorological conditions, and exposed populations. There is a high probability that IDEQ will require a risk assessment, since they required one for the evaporators permitted in Volume 14. The SBWT project developed a template for a site-specific assessment for SBW in 2004. 
The risk is that the SSRA may result in additional HWMA permit conditions that affect the feed rate, emission controls, and monitoring of emissions.

5.2.1.2.3 Direct Vitrification Product Packaging Facility-The direct vitrification product produced will be drained from the melter into canisters. The off-gas scrub solutions will be collected and stored the in tanks prior to grouting. The Product Packaging Facility (PPF) will store canisters of remote-handled glass pending shipment to WIPP. The PPF, including the melter feed tank, spent scrub solution tanks, canister storage, packaging, and grouting units will be subject to the 40 CFR 264 and 270 requirements for miscellaneous units, new tank systems, and container storage units. The PPF processes would be located adjacent to the direct vitrification facilities and could be added to the INEEL HWMA permit in one of two ways: (1) as a modification to either volumes 14 or 18, or (2) as a separate volume.

The addition of the PPF will result in less than 25\% increase in the tank capacity and container storage capacity at the facility (INEEL). Therefore, the changes should be a Class 2 modification. It should be possible to submit individual permit modifications for the building, tank systems, and container storage, which should allow the start of construction of the building, floor, walls, roof, and secondary containment, while designs are finalized for tank systems and container storage.

The direct vitrification waste packaging and storage facilities are replacement storage for the waste storage capacity in the tank farm. The net result would be a reduction in storage volume at the INEEL. Tank systems that are used to store or treat hazardous waste that contains no free liquids and is situated inside a building with an impermeable floor are exempt from the secondary containment requirements, 40 CFR §264.190(a). Storage areas that store containers holding wastes that do not contain free liquids need not have a containment system (40 CFR $§ 264.175(c))$.

It is recommended that PPF, which includes grout treatment tank storage and container storage, be submitted to the State of Idaho as a Class 2 modification to either INEEL HWMA Permit, Volume 14 or 18. The PPF canister storage area is for dry waste with no free liquids, which should simplify the permitting and construction. The tanks and container storage areas replace non-compliant storage in the tank farm and will not increase waste storage capacity. It is recommended that container storage be submitted to the State of Idaho as a Class 2 modification to Volume 18.

If the final design results in significant changes to the PPF, then a permit modification would be required (e.g., tank size, number of tanks, tank location, cell dimension, etc.). The risk is that changes to the design during final design or construction could result in a permit modification approval before waste could be managed in the PPF, which would delay the shipment of SBW. It is recommended that the project negotiate with the State of Idaho early in design to determine how design and construction changes will be handled during the application, final design, and construction stages of the project.

5.2.1.3 Mixing Pumps. The mixing pumps would be ancillary equipment to the tank systems in the tank farm. The tanks in the tank farm have interim status, but cannot be permitted since it is not practical to upgrade the secondary containment. Changes to interim status units require the approval of the director, as outlined in 40 CFR \$270.72, Changes During Interim Status and 40 CFR $\$ 270.42$, Permit Modification at the Request of the Permittee.

The addition of the mixers to the tank farm should be a Class 1 modification under interim status, and requires notification of the administrator prior to implementing the change. Adding the pumps would not change to the tank's storage capabilities, so the administrator should have little concern with this action. 
5.2.1.4 Organic Sample Bias. The IDEQ proposes in Volume 14 to the INEEL HWMA permit to approve the use of a double-needle sampler as an alternative sampling procedure when collecting mixed (hazardous and radioactive) volatile organic and total organic samples from the INTEC Liquid Waste Management System. However, the resulting sample analysis results must not be used in Land Disposal Restriction (LDR) certifications. The appropriateness of the sampling procedure shall be confirmed, at least three times within the life of the permit, by correlation of the analytical results with the permit-required off-gas data.

The project should request the use of double needle sampling in the CAA permits and HWMA permit applications. The project should compare sample data from the double needle and simple samplers to show that the organic constituents in the tank farm waste are at or near the method detection limits and the sampling method does not affect the results for organics, due to the low concentration in the feed. The project should propose a reduced number of organic analyzes based on the low concentration in the feed. The project should pursue IDEQ approval for use of double-needle samplers for all remote-handled samples, including compliance performance test, LDR, delisting, and waste characterization samples, as required to dispose of waste.

5.2.1.5 PE Certifications. CAA permits will not require PE certifications for the design and construction of the direct vitrification unit and off-gas treatment equipment in the direct vitrification unit and MCF.

HWMA requires PE certification of the design submitted with the permit modification or application, before waste is placed in the tank systems per 40 CFR $\$ 264.192$ and 40 CFR $\$ 270.11(d)$. PE certification would be required for grout treatment, direct vitrification product storage, and container storage facilities. The project should contract with an independent, registered PE early in design for PE support to facilitate certification of the design for the permit application or permit modification.

Due to the dual regulation of hazardous waste combustion units, P.E. certification of the direct vitrification unit and MCF may be required as part of the general HWMA permit requirements. The project will need to clarify this issue with the State of Idaho to define specifically what information is required for the direct vitrification unit and MCF in the HWMA, and the MACT compliance documents.

5.2.1.6 In-cell Leaks. In-cell leaks from air emission treatment equipment are not specifically addressed in an air permit. They are addressed in the estimated range of emissions from the cell or building. Waste leaked into sumps will need to be removed within 24-hours or secondary containment will be considered primary containment and regulated under the HWMA requirements.

HWMA requires that operation of a leaky tank system be stopped immediately after the leak is detected, waste be removed from tank systems within 24-hours, and waste be removed from secondary containment within 24-hours (40 CFR \$264.193). The system will have to be repaired before it is used. Depending on the extent of the repairs, a PE certification may be required before resuming operations.

Historically, the piping from the feed tanks to calciner has leakage problems during operation. The direct vitrification piping may have similar problems that could be a schedule risk if operations are stopped to repair leaks as they occur. The project should negotiate with the State of Idaho to operate with leaking pumps, pipes, and valves until they can be replaced at scheduled maintenance shutdowns.

5.2.1.7 As-built Drawings. Air permitting does not require as-built drawings of the facility. The air permits require the air emissions from each system, the ranges of the emissions, and a list of equipment. 
HWMA permitting requires as-built drawings of the facility, equipment, and piping. A permit application could include between 50 and 100 drawings (40 CFR §270). The risk to the project is that approval to operate is delayed until permit modifications are approved for design changes made during final design and construction. The project should negotiate with the State of Idaho to add the as-built drawings certified by a PE to the INEEL HWMA permit as a Class 1 modification prior to start of operations.

Due to the dual regulation of hazardous waste combustion units, as-built drawings of the direct vitrification unit and MCF may be required as part of the general HWMA permit requirements. The project will need to clarify this issue with the State of Idaho to define specifically what information needs are required for the direct vitrification unit and MCF in the HWMA permit and the MACT compliance documents.

\subsubsection{NEPA}

NEPA exposure is low risk, and little or no activity should be required here.

The risk of additional NEPA action for the SBWT project is low. The HLW\&FD EIS covered over 120 different alternatives to treat the SBW from no action to vitrification. It does not appear at this time that additional NEPA action would be required for the treatment and storage of SBW.

If required, an environmental assessment (EA) should cover any additional action or process not specifically mention in the EIS.

\subsubsection{Waste Disposal - TRU Waste}

\section{Waste disposal is fairly high risk and is further aggravated by schedule delays.}

The direct vitrification treatment alternative would generate a large number of canisters of glass product, as well as canisters of solidified scrub waste and debris (spent GAC and HEPA filters). The majority of the waste would be remote-handled TRU waste. The WIPP facility is limited to $7080 \mathrm{~m}^{3}$ of RH-TRU waste by the Land Withdrawal Act (LWA). Hanford, SRS, and INEEL have proposed sending RH-TRU waste not identified in previous estimates. The volume of RH-TRU waste in the DOE complex may exceed the LWA capacity. Disposal is based on first come, first disposed.

The risk to the project is that delays in the schedule caused by permitting, design, construction, and startup could reduce the number of shipments of RH-TRU SBW that WIPP can receive before the capacity authorized in the LWA is exceeded.

\subsubsection{Waste Qualification/Certification}

\section{Waste qualification/certification is a very high risk area for the project.}

Issues related to waste qualification/certification are: (a) the waste classification through the WIR determination process, (b) waste acceptance criteria at WIPP, (c) waste acceptance criteria at the National Geologic Repository (NGR), (d) RH-TRU permits approval, (e) New Mexico Environmental Department (NMED) acceptance of SBW and (f) WIPP Waste Certification Authority,and (g) acceptance of greater than Class A low-level waste.

a. The Federal District Court in Boise ruled that DOE does not have the authority to classify waste using the waste incidental to reprocessing (WIR) determination process in DOE Order 
435.1. DOE has appealed the ruling to the U.S. Appeals Court and has asked Congress to clarify DOE's authority under the Nuclear Waste Policy Act.

The risk to the project is that the appeals process drags on for several years and delays treatment of the waste beyond 2012. The project should consider placing the waste in thin metal containers (liners) that could be placed in either the RH-TRU canister or the HLW canister. The treatment alternative would then be neutral to the disposal location. This would, unfortunately, decrease the net volume per canister and result in increasing the canister count and associated costs for storage, transport, handling, and disposal. In addition, if the WIR determination for SBW is disallowed, then classification of the grouted scrub, $\mathrm{GAC}$, and debris would be in question.

b. The Federal District Court in Boise ruled that DOE does not have the authority to classify waste using the waste incidental to reprocessing (WIR) determination process in DOE Order 435.1. DOE has appealed the ruling to the U.S. Appeals Court and has asked Congress to The risk to the project is that the appeals process drags on for several years and delays treatment of the waste beyond 2012. The project should consider placing the waste in thin metal containers (liners) that could be placed in either the RH-TRU canister or the HLW canister. The treatment alternative would then be neutral to the disposal location. This would unfortunately decrease the net volume per canister and result in increasing the canister count and associated costs for storage, transport, handling, and disposal. In addition, if the WIR determination for SBW is disallowed, then classification of the grouted scrub, GAC and debris would be in question.

The WIPP RH-TRU Program has not received approval of the RH-TRU waste modification to the WIPP HWFP. The criteria for hazardous constituents in RH-TRU waste have not been added to the WIPP HWFP. WIPP submitted a Class 3 permit modification for RH-TRU waste to the State of New Mexico in May 2003. The State of New Mexico is still reviewing the modification. WIPP is not ready to receive RH-TRU waste and will require facility modifications and testing prior to receipt of waste.

The risk to the project is starting the design without having all of the waste characterization and certification requirements finalized for either $\mathrm{CH}$ - or RH-TRU wastes, resulting in design changes, permit modifications during construction, and delays for shipment of waste.

It is recommended that the SBWT project work closely with WIPP and EPA to develop sampling and analysis plans for characterization of the feed. The plans will describe the use of acceptable knowledge for radioisotopes, prohibited items, and dose-to-curie measurements and calculations.

The project should also work with WIPP to include project-specific waste characterization procedures for RH-TRU waste in the WIPP HWFP, if required.

c. If the DOE WIR determination process is found to be outside their authority, then SBW, containing reprocessing waste and debris contaminated with SBW could be classified as HLW, based on the Nuclear Waste Policy Act. Then SBW and SBW-contaminated debris would have to be packaged for disposal at the National Geologic Repository (NGR). The waste acceptance criteria at the NGR are based on an assessment of the performance of the waste in the package and performance of the waste package in the repository. The only waste form that has been evaluated and approved for HLW disposal is borosilicate glass. 
Other waste forms, such as phosphate-rich glass, if pursued for SBW treatment, scrub system grout, or debris will have to be evaluated case-by-case for acceptability. Failure of the WIR does not mean that the SBW would automatically go to the NGR and could result in the project generating waste without a disposal path. DOE has a limited capacity available for the disposal of HLW at the NGR. If all reprocessing wastes are classified as HLW, then the volume of HLW will exceed DOE's allocated capacity, requiring long term storage at the INEEL.

The INEEL needs to develop the following technical information to support the acceptance of a waste form for disposal at the NGR. The information needed for the Memorandum of Agreement with the Civilian Radioactive Waste Management System includes the Environmental Management Waste Acceptance Product Specifications (EM-WAPS), Waste Form Compliance Plan (WFCP), Waste Form Qualification Report, and supporting documentation to comply with the QARD RW-0333P requirements.

1. Information on the chemical composition shall include identification of the speciation of elements and compounds present in concentration greater than 0.5 percent by weight in the waste form and an estimate of the uncertainty of these concentrations for the HLW.

2. Information required to assess that the HLW does not exhibit the characteristics of hazardous waste.

3. Estimates of the total facility inventory and individual canister inventory of radionuclides (in curies) that have half-lives longer than 10 years and are, or will be, present in concentration greater than 0.05 percent of the total radioactive inventory. The estimates shall be indexed to the years 2010 and 3110 . The producer shall also report the estimate of the uncertainty in the radionuclide inventories.

4. The Time-Temperature-Transformation diagrams for the HLW and identification of temperature limits (if any) necessary to preserve the properties of the HLW.

5. Identification of the method to be used to ensure consistency of production batches, and any other information necessary to establish post-closure performance of the waste forms (e.g., identification of organic compounds that may be present and estimated quantities). Product consistency test and comparison to the performance of EA benchmark glass.

6. Canister material

7. Canister dimensions (at the time of acceptance)

8. Canister lifting and handling arrangements

9. Canister labeling conventions

10. Information required to assess the canister drop performance, including information regarding particulates, pyearophorics, combustibles, explosives, etc. that all may come into play in a Design Basis Earthquake II event. This is likely to be a detailed list, much of which has not yet been determined. This information need will be developed more fully in a future revision of the WASRD. 
11. Information required to assess canister criticality, both pre-and post-closure. This is likely to be a detailed list, much of which has not yet been determined. This information need will be developed more fully in a future revision of the WASRD.

12. Estimated maximum gamma and neutron dose rates at the canister surface.

13. Projected distribution of canister thermal outputs, including the maximum.

14. Method used to assign individual canister Metric Ton Heavy Metal (MTHM) content for accounting against the repository 70,000 MTHM capacity limit as specified in Section 114d of the Nuclear Waste Policy Act of 1982, as amended.

The SBW waste has been assigned four listed waste codes. The NRG is not permitted as a Subtitle $\mathrm{C}$ hazardous waste landfill, therefore, the project will need to delist the waste streams before they can be shipped to the NGR. The waste streams cannot exhibit a characteristic of a hazardous waste. In addition to delisting, the SBW must be treated to meet the land disposal restriction standards for hazardous metals before it can be sent to the NGR. The risk is that waste form and waste packaging performance assessments and approvals could delay treating the SBW. The NGR will need to request a license change from NRC and EPA to receive waste forms other than borosilicate glass. (See discussion of petition to exclude/delist in section ii4f)

d. The WIPP RH-TRU Program is not ready to receive RH-TRU waste and will require facility modifications and testing prior to receipt of waste.

The WIPP RH-TRU Program could present a schedule risk to the project if they do not have a permit and the WIPP receiving facility is not modified in time to support the SBW shipment schedule. An additional risk is that the SBWT project could have to modify its' design during construction or startup to comply with the requirements in the approved modification for RH-TRU waste to the WIPP HWFP.

e. SBW is not identified in the 1995 TRU Waste Baseline Inventory Report (TWBIR) as a waste destined for disposal at WIPP. SBW is listed as a potential waste stream in the 2004 TWBIR, but the SBW source term has not been included in the 2004 performance assessment for the compliance re-certification application to EPA. The State of New Mexico has proposed: 1) to amend the permit for the Waste Isolation Pilot Plant to prohibit the shipment of reclassified high-level waste to the site, 2) to amend WIPP's permit to limit waste for disposal to those wastes identified in the 1995 TRU Waste Baseline Inventory Report, and 3) legislation to exclude all TRU waste not identified in the 1995 TBWIR. DOE is currently working with the State of New Mexico to resolve these issues.

These proposed restrictions could delay approval of the RH-TRU waste permit modification and finalization of the RH-TRU waste acceptance requirements in the HWFP. Worst case is that the restrictions prohibit the disposal of SBW at WIPP.

The WIPP waste certification authorization process consists of a series of document reviews, assessments, and confirmation audits. DOE-Carlsbad Field Office (CBFO), EPA, and the State of New Mexico Environmental Department (NMED) participate in the process. Waste certification authority is based on the project demonstrating verbatim implementation of the characterization, operating, confirmation and validation procedures and plans used for characterization and certification of waste shipments. 
DOE-CBFO will approve the plans and procedures prior to start of operations and assess implementation during system operation testing. DOE-CBFO and NMED will audit the project during the first 6 weeks of operations to verify that the operators are trained and hazardous waste management plans and procedures have been implemented as approved. EPA will audit the project to verify that the radioactive waste management plans and procedures are being implemented as approved. Audit findings have to be resolved before waste certification authority is granted.

NOTE: Changes to approved radioactive and hazardous waste management plans and procedures, equipment, and equipment calibrations that affect waste certification have to be approved by CBFO prior to implementation of the change. The DOE-CBFO, EPA, and NMED expect verbatim compliance with the approved plans and procedures, and conduct quarterly assessments and yearly compliance audits to ensure that plans and procedures are being followed.

The risk to the project is that changes to approved plans and procedures before, during, and after hot startup delay waste shipments. The risk is that waste certification authority approval could be delayed by the time and manpower it takes to correct the audit findings or to recertify waste containers because plans, procedures, and equipment calibrations were changed or not followed as approved.

Low-level waste generated by the SBWT project is listed hazardous waste and assigned RCRA hazardous waste numbers F001, F002, F005 and U134. At present, the only disposal site permitted and licensed for radioactive and hazardous waste with these hazardous waste numbers is Envirocare. Envirocare is licensed for low-level, Class A, radioactive low-level waste. For low-level waste streams with the INTEC hazardous waste numbers that exceed the radioisotope limits for Class A low-level waste, there are no disposal sites available. If the project generates low-level (non-TRU) waste with activity greater than Class A limits, then it will be a waste without a path for disposal and would require on-site storage. The Nevada Test Site disposes of radioactive only waste from off-site generators. The Hanford site is not permitted to receive radioactive and hazardous mixed waste from off-site generators or wastes with the U134 hazardous waste number. At the INEEL, the Radioactive Waste Management Complex (RWMC) receives radioactive waste and the Idaho CERCLA Disposal Facility (ICDF) receives CERCLA waste. In order for the project to dispose of waste at either the RWMC, Nevada Test Site, or Hanford Site, the project will need to treat the waste for characteristically hazardous constituents and prepare a delisting petition to remove the hazardous waste number above. In order for the waste to be disposed of at the ICDF, the project and waste generated would have to be added to the INEEL CERCLA program under the Federal Facilities Agreement/Consent Order. The proposed treatment option would generate low-level waste in the form of grouted scrub, GAC, PPE, and debris.

To avoid these risks, it is recommended that the SBWT project work with the State of Idaho, Region 10 EPA, and the disposal site state to delist low-level waste generated from this process, since it does not contain the hazard constituents for which it was listed. Delisting petition or a petition to exclude waste from hazardous waste regulation requires approval in the generating state, states through which the waste is transported, and the state in which the waste will be disposed of. There is still the risk that the disposal site state may not accept the delisting for SBW, even if it is approved in Idaho and Region 10. 


\subsubsection{Regulatory Risks - Summary}

\section{WIPP}

- $\quad$ The State of New Mexico delays the approval of the RH-TRU permit modification

- The State of New Mexico delays the approval of the 311(b) permit modification

- $\quad$ The State of New Mexico amends the WIPP HWFP to exclude waste classified as TRU using the WIR process

- $\quad$ The State of New Mexico amends the WIPP HWFP to exclude waste not listed in the 1995 Transuranic Waste Baseline Inventory Report

- $\quad$ The EPA or State of New Mexico requires additional sampling and analysis for acceptable knowledge characterization for RH-TRU waste.

- $\quad$ WIPP/EPA/NM do not grant waste certification authority to the project until 180 days after hot start (30 days of production, audit, 4-6 months wait until approval is granted).

- $\quad$ WIPP does not have the manpower or on-site capabilities to support the shipping schedule.

- $\quad$ WIPP does not have 72-B transporters available for the SBWT project to support the shipping schedule.

- WIPP does not have the LWA capacity to receive the RH-TRU SBW.

- $\quad$ NMED continues to require headspace gas analysis for every container in storage.

- $\quad$ NMED continues to require verification sampling and analysis of the waste in containers, in addition to acceptable knowledge.

- WIPP approval of changes to equipment and procedures identified during SO testing, readiness review, and hot start up delays waste certification authority or implementation of new procedures.

- $\quad$ Court challenges by the State of New Mexico or stakeholders prevent or delay the SBWT project shipping waste to WIPP.

- $\quad$ The State of New Mexico passes legislation that prevents or delays shipping SBW to WIPP.

\section{Permitting}

- $\quad$ State of Idaho DEQ cannot support the aggressive permitting modification schedule for start of construction.

- $\quad$ State of Idaho DEQ does not approve a general permit modification to support the start of building construction.

- $\quad$ State of Idaho DEQ does not issue a permit to construct (air) to support the schedule for start of building construction.

- State of Idaho DEQ does not approve the modifications to the HWMA permit in time to support the start of operations.

- $\quad$ State of Idaho DEQ does not issue a permit to operate (air) in time to support the start of operations.

- $\quad$ State of Idaho DEQ and Federal Land Manager, PSD new source review requires additional off gas clean up and delays permit approval. 
- State of Idaho DEQ does not cooperate with permitting the high temperature thermal treatment alternatives.

- The compliance performance testing (trail burn) delays the start of production operations

- $\quad$ States with disposal site delay or do not approve of the delisting petition for disposal of the waste in their state.

- Court challenges by INEEL stakeholders delay or prevent permit modifications needed for the SBW project

- $\quad$ State of Idaho does not approve the SBW petition to exclude the waste from hazardous waste regulation.

- $\quad$ The disposal site state does not approve the SBW to exclude the waste from hazardous waste regulation.

- $\quad$ Compliance testing to demonstrate compliance with MACT requires the use of chemical spiking that adds new P-and U-listed waste hazardous waste number to the SBW that affect disposal at WIPP, NGR, or low-level waste sites.

\section{DOE O 435.1}

- $\quad$ Federal courts vacate DOE's authority to make WIR determinations.

- $\quad$ Federal courts delay DOE's authority to make WIR determinations.

- $\quad$ Congress does not clarify DOE's authority to make WIR determinations.

- The project generates waste streams without a path for disposal requiring permitting and construction of additional storage capacity.

\section{Safety}

- $\quad$ PDSA is not approved in time to support the schedule for ordering long lead equipment and starting construction.

- $\quad$ FDSA is not approved in time to support the readiness review schedule.

- $\quad$ Systems operations testing identifies problems that delay the hot start up schedule.

- $\quad$ Readiness review process takes additional time to correct findings and delays the hot start schedule causing a delay in WIPP Waste Certification Authority.

- $\quad$ Radioactive Waste Management Authority is not approved in time to support the hot start schedule. 
Table 5-2. MACT Standards for Hazardous Waste Incinerators 40 CFR $\S 63 \S \S E E E$.

\begin{tabular}{|l|l|l|l|}
\hline Constituent & $\begin{array}{l}\text { Existing Sourcea } \\
\text { Interim Rule }\end{array}$ & $\begin{array}{l}\text { New Sourceb } \\
\text { Interim Rule }\end{array}$ & $\begin{array}{l}\text { New Sourcec Final } \\
\text { Proposed Rule 4-20-04 }\end{array}$ \\
\hline Dioxins/furans & $<0.20 \mathrm{ng}$ TEQ/dscm & $<0.20 \mathrm{ng}$ TEQ/dscm & $\begin{array}{l}0.11 \text { for dry APCD or } \\
\text { WHBs1; 0.2 for others }\end{array}$ \\
\hline & $<0.40 \mathrm{ng} \mathrm{TEQ} / \mathrm{dscm} \leq 400^{\circ} \mathrm{F}$ & & \\
\hline Mercury & $<130 \mu \mathrm{g} / \mathrm{dscm}$ & $<45 \mu \mathrm{g} / \mathrm{dscm}$ & $8 \mu \mathrm{g} / \mathrm{dscm}$ \\
\hline Lead and cadmium & $<240 \mu \mathrm{g} / \mathrm{dscm}$ & $<120 \mu \mathrm{g} / \mathrm{dscm}$ & $6.5 \mu \mathrm{g} / \mathrm{dscm}$ \\
\hline $\begin{array}{l}\text { Arsenic, beryllium, and } \\
\text { chromium }\end{array}$ & $<97 \mu \mathrm{g} / \mathrm{dscm}$ & $<97 \mu \mathrm{g} / \mathrm{dscm}$ & $8.9 \mu \mathrm{g} / \mathrm{dscm}$ \\
\hline Carbon Monoxide & $<100 \mathrm{ppm}$ & $<100 \mathrm{ppm}$ & $\begin{array}{l}100 \mathrm{ppmv}(\mathrm{CO}) \text { or } 10 \\
\mathrm{ppmv} \mathrm{HWC}\end{array}$ \\
\hline $\begin{array}{l}\text { Hydrochloric acid and } \\
\text { chlorine gas }\end{array}$ & $<77 \mathrm{ppm}$ & $<77 \mathrm{ppm}$ & $0.18 \mathrm{ppmv} 2$ \\
\hline Particulate Matter & $>34 \mathrm{mg} / \mathrm{dscm}$ & $>34 \mathrm{mg} / \mathrm{dscm}$ & $0.0070 \mathrm{gr} / \mathrm{dscf} 3$ \\
\hline Notes: & &
\end{tabular}

(a) Emission limits for existing sources. You must not discharge or cause combustion gases to be emitted into the atmosphere that contain: (1) For dioxins and furans:

(i) Emissions in excess of $0.20 \mathrm{ng} \mathrm{TEQ} / \mathrm{dscm}$ corrected to 7 percent oxygen

(ii) Emissions in excess of $0.40 \mathrm{ng} \mathrm{TEQ} / \mathrm{dscm}$ corrected to 7 percent oxygen provided that the combustion gas temperature at the inlet to the initial particulate matter control device is $400^{\circ} \mathrm{F}$ or lower based on the average of the test run average temperatures. (For purposes of compliance, operation of a wet particulate control device is presumed to meet the $400{ }^{\circ} \mathrm{F}$ or lower requirement)

(2) Mercury in excess of $130 \mu \mathrm{g} / \mathrm{dscm}$ corrected to 7 percent oxygen

(3) Lead and cadmium in excess of $240 \mu \mathrm{g} / \mathrm{dscm}$, combined emissions, corrected to 7 percent oxygen

(4) Arsenic, beryllium, and chromium in excess of $97 \mu \mathrm{g} / \mathrm{dscm}$, combined emissions, corrected to 7 percent oxygen

(5) For carbon monoxide and hydrocarbons, either:

(i) Carbon monoxide in excess of 100 parts per million by volume, over an hourly rolling average (National continuously with a continuous emissions monitoring system), dry basis and corrected to 7 percent oxygen. If you elect to comply with this carbon monoxide standard rather than the hydrocarbon standard under paragraph (a)(5)(ii) of this section, you must also document that, during the destruction and removal efficiency (DRE) test runs or their equivalent as provided by $\S 63.1206(\mathrm{~b})(7)$, hydrocarbons do not exceed 10 parts per million by volume during those runs, over an hourly rolling average (National continuously with a continuous emissions monitoring system), dry basis, corrected to 7 percent oxygen, and reported as propane

(ii) Hydrocarbons in excess of 10 parts per million by volume, over an hourly rolling average (National continuously with a continuous emissions monitoring system), dry basis, corrected to 7 percent oxygen, and reported as propane.

(6) Hydrochloric acid and chlorine gas in excess of 77 parts per million by volume, combined emissions, expressed as hydrochloric acid equivalents, dry basis and corrected to 7 percent oxygen

(7) Particulate matter in excess of $34 \mathrm{mg} / \mathrm{dscm}$ corrected to 7 percent oxygen.

(b) Emission limits for new sources. You must not discharge or cause combustion gases to be emitted into the atmosphere that contain:

(1) Dioxins and furans in excess of $0.20 \mathrm{ng} \mathrm{TEQ} / \mathrm{dscm}$, corrected to 7 percent oxygen

(2) Mercury in excess of $45 \mu \mathrm{g} / \mathrm{dscm}$ corrected to 7 percent oxygen

(3) Lead and cadmium in excess of $120 \mu \mathrm{g} / \mathrm{dscm}$, combined emissions, corrected to 7 percent oxygen

(4) Arsenic, beryllium, and chromium in excess of $97 \mu \mathrm{g} / \mathrm{dscm}$, combined emissions, corrected to 7 percent oxygen.

(5) For carbon monoxide and hydrocarbons, either:

(i) Carbon monoxide in excess of 100 parts per million by volume, over an hourly rolling average (National continuously with a continuous emissions monitoring system), dry basis and corrected to 7 percent oxygen. If you elect to comply with this carbon monoxide standard rather than the hydrocarbon standard under paragraph (b)(5)(ii) of this section, you must also document that, during the destruction and removal efficiency (DRE) test runs or their equivalent as provided by $\S 63.1206(\mathrm{~b})(7)$, hydrocarbons do not exceed 10 parts per million by volume during those runs, over an hourly rolling average (National continuously with a continuous emissions monitoring system), dry basis, corrected to 7 percent oxygen, and reported as propane

(ii) Hydrocarbons in excess of 10 parts per million by volume, over an hourly rolling average (National continuously with a continuous emissions monitoring system), dry basis, corrected to 7 percent oxygen, and reported as propane.

(6) Hydrochloric acid and chlorine gas in excess of 21 parts per million by volume, combined emissions, expressed as hydrochloric acid equivalents, dry basis and corrected to 7 percent oxygen

(7) Particulate matter in excess of $34 \mathrm{mg} / \mathrm{dscm}$ corrected to 7 percent oxygen. 


\begin{tabular}{|c|c|c|c|c|c|c|c|c|c|c|c|c|c|c|c|c|c|c|c|}
\hline \multicolumn{2}{|c|}{ 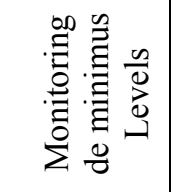 } & $\begin{array}{l}\tilde{\Xi} \\
= \\
=\end{array}$ & 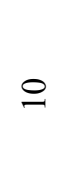 & $i$ & $\sigma$. & ๙. & i & $\cong$ & $i$ & \pm & i & i & & i & $\frac{n}{n}$ & $\stackrel{n}{=}$ & i & & $\stackrel{\frac{z}{1}}{\stackrel{1}{d}}$ \\
\hline \multicolumn{2}{|c|}{ 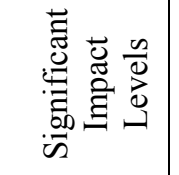 } & $\frac{\text { है }}{200}$ & in & - & $\sigma$. & a. & $\stackrel{\sim}{\sim}$ & $n$ & - & $=$ & 1 & 1 & & ¿্ঠ & \& & i & i & i & \\
\hline \multicolumn{2}{|c|}{ 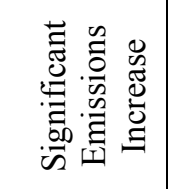 } & 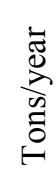 & \multicolumn{2}{|l|}{ 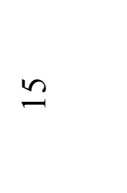 } & \multicolumn{2}{|l|}{ ๙. } & \multicolumn{3}{|l|}{ f } & $\stackrel{P}{+}$ & \multicolumn{3}{|l|}{ 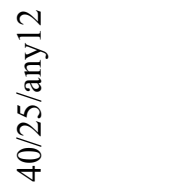 } & 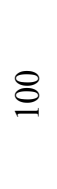 & 8 & $\stackrel{0}{0}$ & $\stackrel{\sim}{\sim}$ & $m$ & \\
\hline \multirow{3}{*}{ 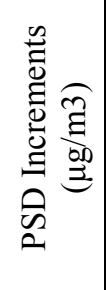 } & \multirow{3}{*}{ 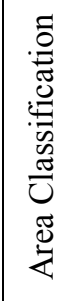 } & $\Xi$ & 8 & mे & $\sigma$. & r. & \& & $\stackrel{\widetilde{\infty}}{-}$ & \& & in & 1 & i & & i & i & i & i & i & \\
\hline & & $=$ & ) & $I$ & $\sigma$. & $\sigma$. & $\frac{\sim}{n}$ & $\bar{a}$ & $\stackrel{\sim}{\text { i }}$ & $\ddot{\sim}$ & i & i & & 1 & 1 & i & 1 & i & \\
\hline & & - & $\infty$ & $\nabla$ & 2. & a. & $\stackrel{\sim}{\sim}$ & $n$ & $N$ & $\tilde{\sim}$ & i & i & & i & i & i & i & $\mathrm{i}$ & \\
\hline \multirow{4}{*}{ 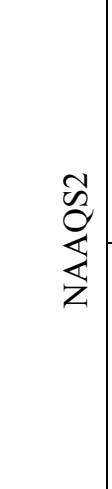 } & \multirow{2}{*}{ 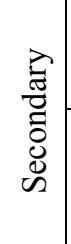 } & 气ี & I & 1 & 1 & 1 & $\stackrel{n}{0}$ & 1 & 1 & $\stackrel{n}{\tilde{o}}$ & $\frac{1}{0}$ & $\stackrel{\infty}{\circ}$ & & i & 1 & 1 & I & i & \\
\hline & & $\frac{\mathfrak{Z}}{\sum^{\infty}}$ & 은 & in & $\approx$ & $\cong$ & 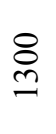 & 1 & i & 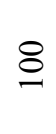 & $\tilde{\vartheta}$ & $\hat{n}$ & & i & i & $\because$ & i & $i$ & \\
\hline & \multirow{2}{*}{ 离 } & 气ี & i & 1 & 1 & $i$ & $i$ & $\stackrel{ \pm}{\overrightarrow{0}}$ & $\tilde{0}$ & $\begin{array}{l}n \\
\hat{c} \\
0\end{array}$ & $\frac{N}{0}$ & $\stackrel{\infty}{\stackrel{\infty}{0}}$ & & $\tilde{m}$ & $a$ & $i$ & i & i & \\
\hline & & $\frac{\tilde{g}}{00}$ & 은 & in & 6 & $\cong$ & i & $\tilde{n}$ & $\triangleright$ & 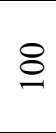 & $\ddot{n}$ & $\hat{n}$ & & $\begin{array}{l}8 \\
8 \\
8\end{array}$ & $\begin{array}{l}8 \\
8 \\
0\end{array}$ & $\stackrel{n}{-}$ & 1 & 1 & \\
\hline \multicolumn{3}{|c|}{$\begin{array}{r}\bar{\Xi} \\
\text { I } \\
\text { I }\end{array}$} & $\varangle$ & 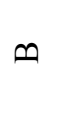 & $U$ & a & II & 피 & 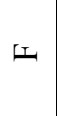 & 工 & ט & $I$ & & 피 & 山 & - & i & i & \\
\hline \multicolumn{3}{|c|}{ 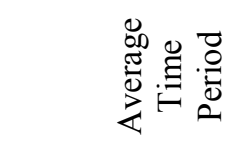 } & 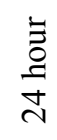 & 䄈 & $\begin{array}{l}\stackrel{\Xi}{\Xi} \\
\stackrel{\Xi}{ \pm}\end{array}$ & 䄈 & $\frac{\Xi}{\grave{g}}$ & $\begin{array}{l}\stackrel{\Xi}{\Xi} \\
\stackrel{d}{ \pm}\end{array}$ & 丞 & 袢 & $\Xi$ & $\begin{array}{l}m \\
\Xi \\
\vdots \\
\infty\end{array}$ & & $\stackrel{\Xi}{\Xi}$ & $\underset{\infty}{\Xi}$ & 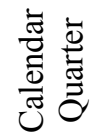 & I & i & \\
\hline \multirow{2}{*}{\multicolumn{2}{|c|}{ 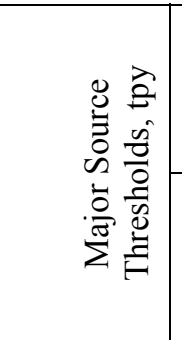 }} & $\sum_{Z}^{ \pm}$ & $\frac{\hat{8}}{8}$ & & 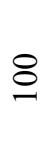 & & 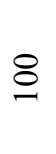 & & & 8 & 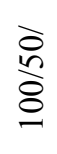 & $\frac{\bar{\sigma}}{\stackrel{2}{a}}$ & & 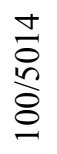 & & ¿ & i & i & \\
\hline & & $\hat{\tilde{n}}$ & $\begin{array}{l}8 \\
8 \\
0 \\
\vdots \\
2 \\
\end{array}$ & & 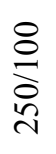 & & 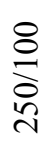 & & & $\begin{array}{l}8 \\
\stackrel{8}{8} \\
\text { in }\end{array}$ & $\begin{array}{l}8 \\
\stackrel{0}{5} \\
\stackrel{n}{1}\end{array}$ & & & $\begin{array}{l}8 \\
\stackrel{8}{1} \\
\\
\end{array}$ & & $\begin{array}{l}8 \\
\stackrel{8}{5} \\
\text { in }\end{array}$ & 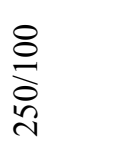 & $\begin{array}{l}8 \\
\stackrel{8}{8} \\
\text { in }\end{array}$ & \\
\hline \multicolumn{3}{|c|}{ 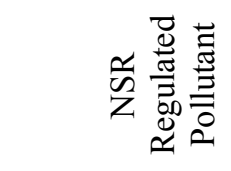 } & $\frac{n}{1}$ & & $\sum_{\substack{n \\
n}}^{\infty}$ & & ชิ & & & $\begin{array}{l}\text { ô } \\
z\end{array}$ & 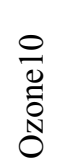 & $\begin{array}{l}\bar{y} \\
\text { O }\end{array}$ & $\stackrel{\check{z}}{\mathrm{z}}$ & O & & 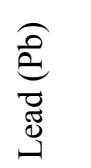 & 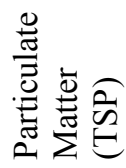 & $\begin{array}{l}\frac{0}{0} \\
\frac{0}{0} \\
\frac{3}{I}\end{array}$ & $\stackrel{0}{\stackrel{\vec{I}}{I}}$ \\
\hline
\end{tabular}




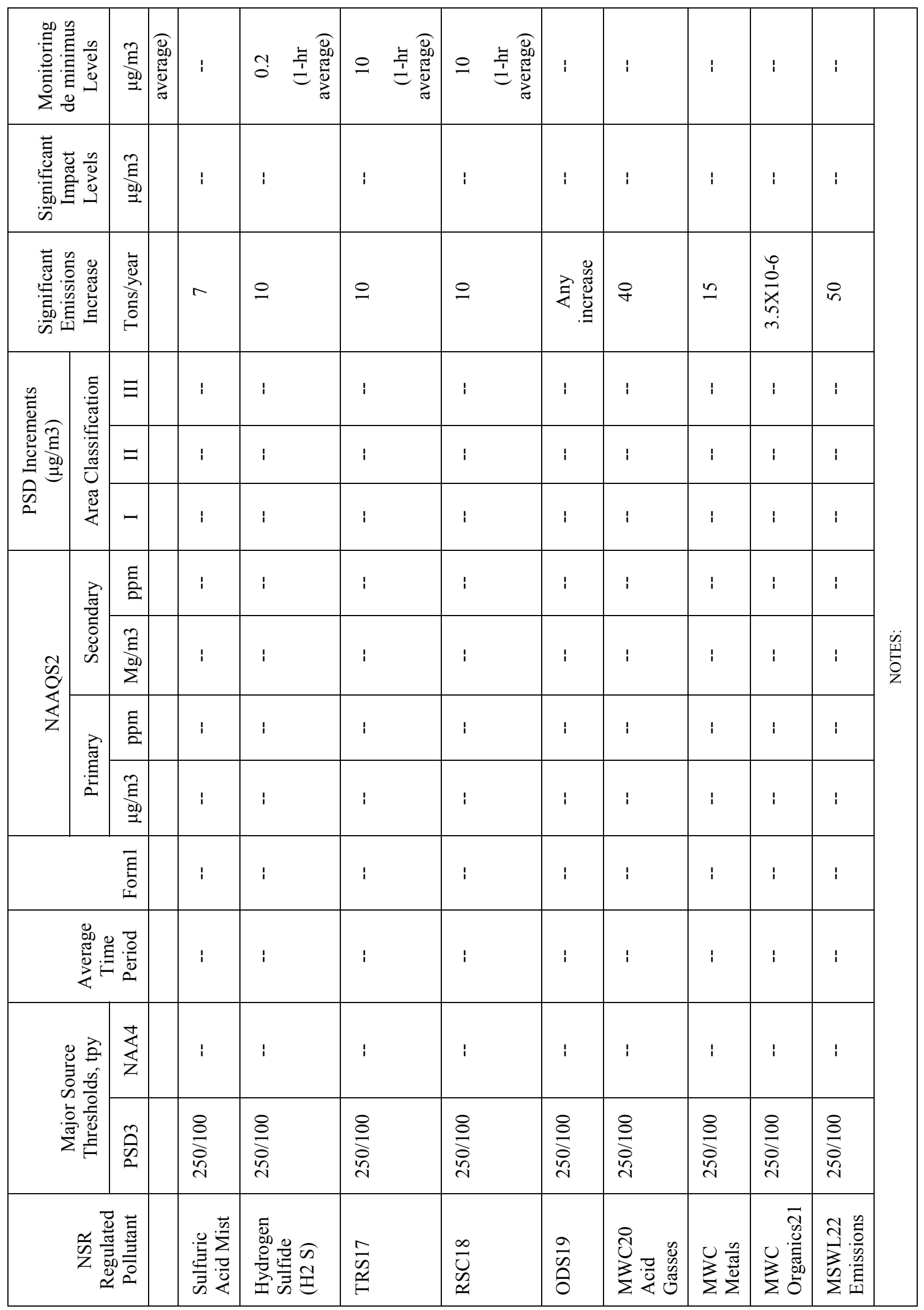




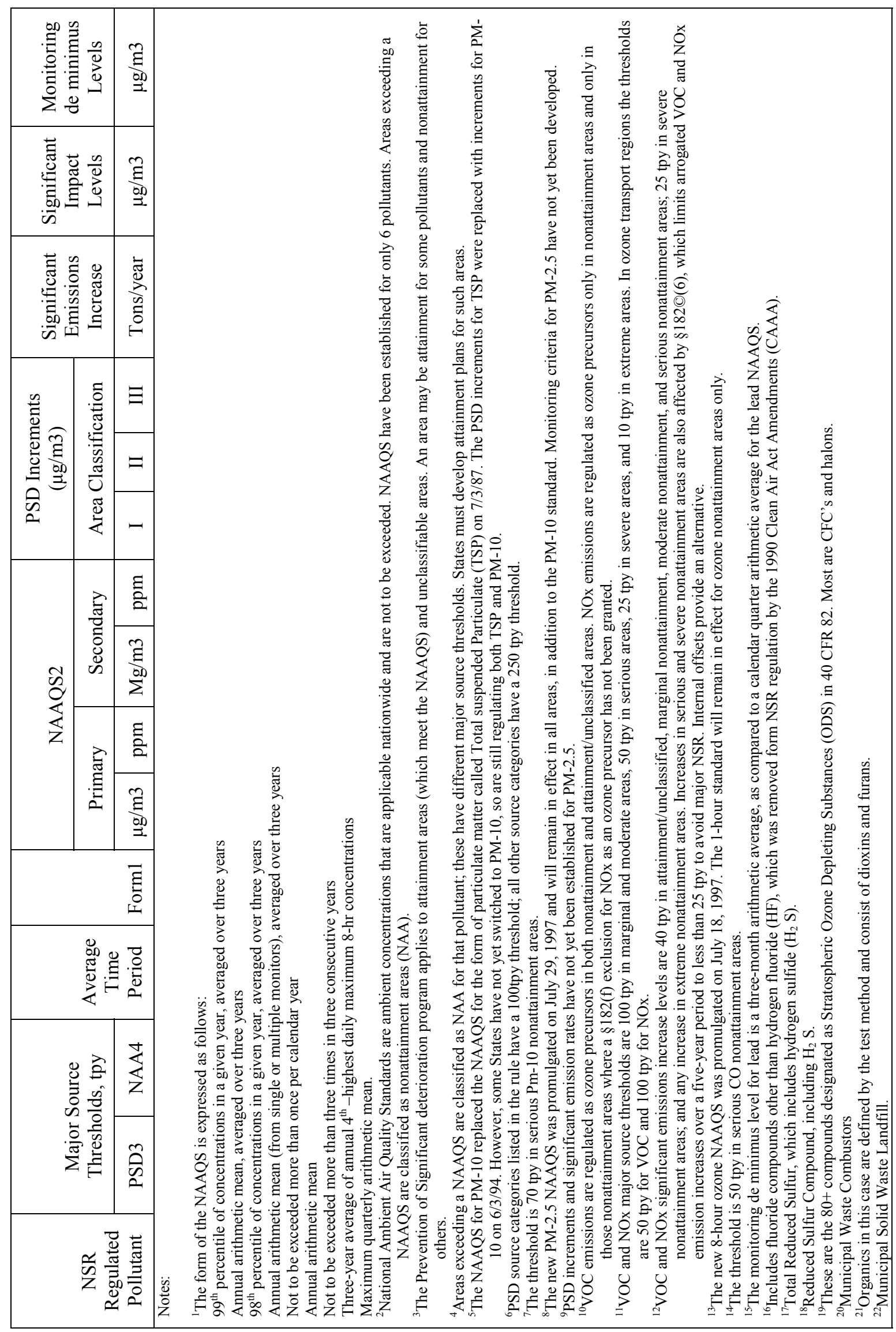




\subsection{Schedule and Related}

The overall schedule for the DV SBW treatment alternative cannot achieve the 2012 milestones (late by at least 50 months) primarily due to the time required to design and construct the DV treatment facility and to treat the SBW in an aggressive, but realistic, time span.

\subsubsection{Capital Project Schedule (February 2005 to December 2013)}

5.3.1.1 Preliminary Design (February 2005 to July 2006). It will require a very aggressive effort to conclude DV Preliminary Design by July 2006, in only an eighteen-month period, starting in February 2005.

The assumed start for the capital project is February 1, 2005, the first day of the new ICP contractor. Preliminary (Title I) Design could possibly start on this date but aggressive work and significant progress could not be made until further process development test work was performed to define the process. Direct vitrification is the least developed of the five down-selected SBW treatment alternatives, while utilizing the most complex process and involving by far the largest and most costly capital project system. Technical development test work would have to start immediately and be pursued aggressively before significant progress could be made in the Preliminary Design phase. Depending on what assurances the Government wanted, Critical Decision 0, CD-0, "Approve Mission Need," and CD-1 "Approve Alternative Selection and Cost Range" would either be approved early or prior to February 1, 2005 , or wait for at least the most important test work to be done to develop more confidence in the process and the volume of waste it would produce. (Waste loading varied significantly in the last test work done in 2001, and was going down, at last report doubling the waste volume from that assumed initially.)

Two previous studies (Bates, 2001 and Adams, 2001) concluded that Preliminary Design (Title I Design) would take from 22 to 30 months, even after having been preceded with a two year Conceptual / Advanced Conceptual Design period and with it an assumed test program run in parallel. The current scenario does not allow time for either of these activities. Assuming that both technical development test work and Preliminary Design were to start on February 1, 2005, and be aggressively pursued, the best effort would be no less than 18 months. During this period, the issues/problems addressed in Section V.i must be resolved such that the process definition can be finalized and P\&IDs can be developed. Related to this, the following must also be done: (1) remote mock-up testing must be started and iterated with design to develop and prove the concepts; (2) safety analysis work must be started and proceed through the fundamental assessment stage to define any safety driven requirements to be included in the design; and (3) the draft environmental permit applications must be written. Both the technical development test work and the mock-up testing would be difficult to achieve in such a short time frame, and they could be schedule limiting or, most likely, require design work to proceed at risk based on the best concepts and assumptions available. All this must be coordinated to finalize the P\&IDs such that facility design and mechanical layout work can be performed in sufficient detail to support submittal of the RCRA Part B and Air permit applications. This is considered to be a "Title I Plus" design; that is, a level of detail beyond what is normally developed in a Preliminary / Title I Design effort. The following would be required:

\section{HWMA/RCRA Permitting}

\section{Process}

- $\quad$ Final process flow diagrams (PFDs), material and energy balances, and process and instrument diagrams (P\&IDs) 
- $\quad$ Process descriptions

- $\quad$ Equipment descriptions

- $\quad$ Operating limits

- $\quad$ Operating procedures (at least draft).

\section{Building}

- $\quad$ Site location

- $\quad$ Facility layouts

- $\quad$ Floor plan drawings

- $\quad$ Equipment and piping layouts

- Materials of construction used

- $\quad$ Secondary containment details (at least typical).

\section{Waste}

- $\quad$ Characterization of feed waste (SBW in tank farm)

- Waste acceptance requirements for the treatment facility

- $\quad$ Process control requirements

- Description of final waste

- Characterization (typical) of final waste

- $\quad$ Sampling and analytical methods used.

\section{Air Permitting}

\section{MACT}

\section{Air emission modeling}

- Identify sources of emission

- Identify constituents of concern

- $\quad$ Model emissions.

\section{Trial burn or emission testing plans}

- $\quad$ Sampling planned

- $\quad$ Analysis to be performed

- Monitoring equipment to be used

- $\quad$ Surrogate runs planned 
- $\quad$ Spiking to be performed (if any).

\section{NESHAPs}

- $\quad$ Estimated emissions of radionuclides.

\section{PSD}

- $\quad$ Estimated NOx emissions

- $\quad$ Estimated visible emissions.

\section{Title V}

- $\quad$ Estimate emission of hazardous constituents.

At the end of Preliminary Design, the details of the design would be fed into the environmental permit applications and 60 days later, after final reviews, revisions, and approvals, the permit applications would be submitted to the Idaho Department of Environmental Quality (IDEQ) for the assumed minimum two-year review and approval process (reduced from the 31 months requested by IDEQ by taking time from the Contractor's schedule only) before permission would be given to start of construction.

Additionally, during Preliminary Design, equipment needs will be examined and detailed specifications will be prepared and finalized, either at this stage or in the early days of Final Design for equipment that is: (1) critical to facility detailed design, (2) needed for the mock-up testing program, or (3) otherwise long-lead and schedule critical. (This equipment is normally referred to as "government furnished equipment, GFE".) Some examples of this are the melter, the NOxidizer ${ }^{\circledR}$, the canister loading assembly, the continuous grout mixer and associated assembly, the decon/transfer cart, the canister handling machine, and the tank mixing pumps.

\subsubsection{Issues related to design and construction of the Vitrification Plant-} Advantages could be realized if the vitrification plant were to be designed for both processing SBW glass for disposal at WIPP and the existing HLW calcine for disposal at Yucca Mountain. A summary of these benefits to the SBW and HLW programs are: significant cost savings and overall schedule savings for HLW, with some net detriment to the SBW schedule, especially in the design phase. Designing for both SBW glass and HLW calcine converted to glass would add to the design and construction complexity and schedule inside the SBW Treatment Project, while early design and construction of a vitrification plant for HLW calcine would be advantageous for the HLW program and should enable significantly earlier disposition of the HLW calcine.

When previously studied (Bates 2001), it was planned that the Idaho Waste Vitrification Facilities (IWVF) project would be built in two major phases. Phase I would design for SBW and NGLW treatment with wet feed to the melter, and Phase II would design for HLW calcine treatment with dry fed to the melter. (Direct vitrification of calcine was assumed versus that of a smaller liquid high activity concentrate from a chemical separations process.) The Phase I SBW direct vitrification facility would be initially designed to accommodate future HLW calcine vitrification in a cost-effective manner consistent with as low as reasonably achievable (ALARA) radiation exposure practices. The Phase II modifications would design and construct the calcine retrieval, receipt, and handling and transport systems; the calcinespecific feed additive and pre-treatment systems; off-gas treatment system modifications; additional glass storage; and change-out the melter. 
Design considerations in the initial Phase I IWVF plant design for ultimate feasible (life-cycle cost minimization, ALARA minimization, access) retrofit / upgrade for direct vitrification of HLW calcine would include:

1. Additional shielding for calcine processing

2. A larger melter to process all of the calcine on schedule

3. Additions to the IWFV for receiving calcine and preparing the calcine for feed to the melter, such as calcine grinders, glass additive equipment, weigh bins, blenders, etc.

4. Equipment and basic provisions (such as enlarged access) for melter change-out for calcine campaigns. (It is assumed that liquid SBW processing over two years might not require a melter change-out, while calcine processing over 15-18 years will require 2 or 3 melter change-outs.)

5. Land set aside and interfaces sized and provided for future expansion of the glass storage facility

6. If desired, land set aside and interfaces sized and provided for future addition of new evaporators to the IWVF plant to serve INTEC until complete closure

7. If desired, land set aside and interfaces sized and provided for addition of a decon facility to the IWVF plant to serve INTEC until complete closure.

All this would not only add to the complexity and schedule of the design effort, but these questions would have to be answered early in Preliminary Design so that design concepts could be developed for the environmental permits to be submitted.

It should be noted that Preliminary Design, feeding into the environmental permit applications, and the application review process by Idaho DEQ leading to approval to construct, is the first of three critical paths on the project. The second one, discussed later, is construction, testing, and startup of the vitrification facility. The third one, also discussed later, is treatment (vitrification) of the SBW, which is a direct function of the throughput of the treatment system.

\subsubsection{Final Design (August 2006 to July 2008).}

The DV Final Design schedule, differing from the other SBW treatment alternatives, is on the critical path. It will require at least $\mathbf{2 4}$ months of aggressive effort to complete Final Design by July 2008.

Final Design (Title II Design) will start immediately following Preliminary Design in early August 2006. It is assumed that there will be no hold period for CD-2, Approve Performance Baseline (authority to commence Final Design). It is also assumed that an early and partial CD-3 (Approval to Start Construction) consent would be given at CD-2 to procure the GFE equipment cited above in the Preliminary Design write-up, which would involve a relatively significant expenditure of capital funds.

All technical development test work and remote mock-up testing must be completed by mid-Final Design in order to be factored into the detailed design.

Two previous studies (Bates, 2001 and Adams, 2001) concluded that Final (Title II) Design would take from 31 to 36 months, even after having Preliminary Design preceded with a two year Conceptual / Advanced Conceptual Design period and a process development test program run in parallel. As previously mentioned, this did not happen in the current scenario. Assuming that both technical development test work and remote mock-up work were to be aggressively pursued in support of Final Design, the best effort would be no less than 24 months. 
Detailed design would iterate with procurement on GFE items to minimize the overall schedule, as well as cost. Design would proceed to the point of preparation of numerous bid packages of equipment specifications and drawings for issuance for competitive bid by either the ICP contractor or his design agency. (The latter is preferred for better communication and control, as well as lower cost.) Vendor bids would be received, analyzed, and awarded. Vendor drawings would be produced, reviewed, revised as necessary, and approved, after which the equipment layouts and facility designs would be completed by the design agency to reflect these details in the bid packages for general construction. Vendor material purchases, fabrication, testing, and ultimate delivery to the construction site would be delayed in order to postpone these costs of fabrication without impacting construction, as well as to wait until the construction contractor is chosen and on-site to receive delivery of these items. This approach will reduce both costs and schedule by not only initiating early procurement, but alsoby providing actual equipment details in the detailed design drawings, thus avoiding numerous design-related questions and delays during construction.

Final Design, bid and award of the construction contract (normally a 3-4 month process for a project of this size), and notice to proceed and mobilization of the construction contractor on the site to be poised for the start of construction (approximately 1 month) will extend 3 months beyond the 26 month permit cycle period (minimum 24 months after submittal, plus 2 months after Preliminary Design for final submittal preparation) before authorization to proceed with construction is obtained from IDEQ. Final Design must complete by July 31, 2008 over a 24-month time frame. This will be an aggressive effort for such a large and complex system as this.

\subsubsection{Construction (January 2009 to December 2012).}

Construction of the DV treatment facility is the second critical path activity on the overall schedule, requiring 48 months if aggressively pursued; 60 months including the testing and readiness review stage leading to hot startup. (NWCF took 71 months, 48 months to construct and 23 months to test and start up.).

Work to obtain Critical Decision-3, Approval to Start Construction, will begin at the end of Final Design. It is assumed that CD-3 approval will be obtained by July 2008, authorizing the start of the bid and award process. It is also assumed that CD-3 will release and provide funding support for the construction contractor to start procurement for construction. Fabrication of the GFE procurement items mentioned above in the Final Design section will be released at this time, and those contracts will be completed by the originating organization (either the design agency or the ICP contractor) and be provided to the construction contractor as GFE for installation. (Schedule analysis will be performed during design, and those GFE items that may be schedule limiting, if any, will be released for fabrication earlier during the late stages of Final Design so that no construction delays are encountered due to these items.)

Two previous studies (Bates, 2001 and Adams, 2001) concluded that it would require 84 to 88 months from the start of construction to the start of operation on hot feed, including the testing, readiness review, and startup period. Assuming that all work was to be aggressively pursued, the best effort is estimated to be no less than 60 months.

Construction will start in January 2009 (in the middle of winter, not a particularly good time) after approval of the RCRA permit is obtained from IDEQ and the construction contractor is competitively selected. Construction will follow a logical installation sequence from site preparation and required demolition, through earthwork, concrete, steel, piping, to completion of instrumentation and electrical installation and construction component checkout (CC Testing). 


\subsubsection{Testing and Startup (January 2012 to December 2013).}

Testing and startup, overlapping with the final stages of construction, are also on the critical path.

During the late stages of construction, after construction forces have completed rudimentary component testing (CC Testing), the ICP contractor, with support from the design agency as necessary, will perform system operation (SO) tests and cold tests (CT) on the treatment system and its supporting facility and equipment. After this, an in-house readiness review will be performed leading to a formal operational readiness review (ORR) by DOE and others. Usual participants in an ORR are DOE-ID and DOE-HQ and sometimes the Defense Nuclear Facilities Safety Board (DNFSB). However, in this case the following applies: (1) final waste treatment is to be performed using a high temperature thermal process requiring compliance with the new MACT regulations, (2) RCRA waste is being treated and stored and the system is to be fully compliant and Part B permitted, and (3) the intent is to dispose of the treated waste in a major federal repository (WIPP). As such, the Federal EPA, Idaho DEQ, and WIPP and New Mexico Environmental Department will also be involved, at least informally or in an audit mode, in the final ORR and hot startup/trial burn, and the waste form qualification and process/program validation leading to program certification for the WIPP repository.

Parallel with the final stages of the ORR, Critical Decision-4, Approval to Start Operations will be conducted, and at the conclusion of both, approval will be given for hot startup of the treatment system.

It is planned that pilot-scale work, along with process knowledge work such as off-gas modeling, will be performed during the construction phase to qualify the waste form and preliminarily validate the process to the satisfaction of WIPP and the National TRU Waste Management Program. It is through this test work that the waste form will be proven and the "macro-batch" (tank farm tank quantities of feed) approach to sampling and characterization, supported by process knowledge, will be validated. (The intent is to physically sample and characterize the feed from the tank farm tanks and not the final waste forms or any intermediate treatment streams.) However, the overall process and program validation still must be proven in the full-scale production system using trained operators and procedures.

A trial burn using actual hot feed (potentially with the need to add (spike) certain species to worstcase levels) is also required to prove to IDEQ and the Federal EPA that off-gas emissions are within acceptable MACT limits.

Discussions with WIPP in 2002 and 2003 resulted in the baseline premise that WIPP could not and would not certify the SBW treatment process/program and its final waste or authorize shipments until 6 months after start of hot operations. The SBWT project assumes that, primarily for milestone schedule reasons, waste treatment must continue and final treated waste must be formed, packaged, and stored "at risk." It is also assumed that a shutdown will be imposed by WIPP, as is historically the case, if anything, to resolve minor procedural, training, or other "paperwork" problems. (Note that it is also assumed that the final SBW glass will not have to be physically reworked in any way, not only due to the assumed success of the prior waste form qualification work, but also because little alteration of it could be performed in any case.) It is also expected that, regardless of what might happen with the WIPP program, a shutdown would most likely be required by the environmental regulators to assess the MACT trial burn results (off-gas sample analytical work, some from special samples to be collected only for the trial burn, and analysis of this data and data from process control instrumentation).

The plan is to operate on hot feed for 4 months and shutdown for 2 months for the WIPP and RCRA/Air Program reviews. It is assumed that at the end of this short shutdown, program certification would be given by WIPP, along with approval to make the first shipment from Idaho to New Mexico. It is 
also assumed that the trial burn review would prove positive, and a re-start would be authorized without the need for a second trial burn. Note that historically this is a risky assumption and that at least one repeat of the trial burn may be necessary.

\subsubsection{Treatment Operations Schedule (January 2014 to February 2017)}

SBW treatment by direct vitrification plus off-gas treatment to meet the new MACT standards and DV glass and scrub solution packaging is the third critical path activity on the overall schedule, assumed to require at least 3 years. Improvements to a 3-year operating schedule are possible, but not certain even with added expenditures. And there are risks that even a 3-year schedule may not be achieved given the complexity of the process system.

Two previous studies (Bates, 2001 and Adams, 2001) concluded that it would require 31 to 36 months to treat the SBW by direct vitrification. However, these estimates do not include a major turnaround for system maintenance which, most likely, would be needed. Recent mass balances have assumed a 2.5-year treatment schedule (Barnes 2004a) but, again, no major maintenance turnaround is assumed. Considering that this process is the most complex of the five SBW treatment alternatives, at least one major maintenance turnaround of 6 months should be assumed to be required (two such turnarounds are assumed for CMACT).

Shorter treatment schedules are technically feasible by increasing equipment sizes or using multiple processing lines, but this would increase the capital cost of the facility since these costs are a function of throughput. Also, pilot-scale testing clearly indicated the potential for off-normal conditions that could result in a longer startup or more frequent shutdowns of the process, extending the treatment schedule. While the treatment schedule could possibly be reduced from 2.5 years, the rate at which WIPP can receive $\mathrm{RH}$-waste is limited, and this would only aggravate the interim storage problem, requiring more storage locations, and also adding to the capital cost of the facility.

\subsubsection{Waste Shipment Schedule (January 2014 to February 2017)}

\section{Remote handled (RH) waste shipments are receipt-rate limited at WIPP and cannot keep pace with treatment nor be completed by the 2012 milestone.}

Idaho's SBW treatment production rate exceeds WIPP's receipt rate. This would result in net accumulation that drives the need for lag storage in Idaho and is a direct function of the treatment rate. Lag storage would be required, as follows.

SBW treatment by direct vitrification would produce about $778 \mathrm{RH}$ canisters with dose rates of 65 $\mathrm{R} / \mathrm{hr}$ on contact. The treatment generation rate could vary from as little as 1.6 canisters per operating day for a 500 day operating campaign (assumed to cover 2.5 years) to 3.9 canisters per operating day for a 200 day campaign ( 1 year), both calculated using a 7-day week with 24-hour-per-day operation. The WIPP overall RH receipt rate/capacity is 12 canisters per week over a 50 -week year; one canister per cask and one cask per truck shipment. This receipt rate is physically limited by the receipt, off-loading, and handling system on the surface at WIPP and not by transportation or placement in the repository. This compares to the DV glass production rate of 10.9 to 27.3 canisters per week; 1.6 to 3.9 per day).

WIPP committed to DOE-ID in 2003 to take 6 RH canisters per week (300 per year) in the 2009 to 2012 time frame. RH capacity currently claimed by others in this time period is 3 canisters per week, such that $75 \%$ of the total is currently claimed while Idaho claims half of that total. The difference between the generation rate in Idaho by direct vitrification and the take-away rate by WIPP is 4.9 canisters per week for a 2.5 year treatment period to 21.3 canisters per week for one year, resulting in net accumulation. With 
the assumption (validated by WIPP) that shipments would not be authorized until 6 months after start of hot operations and the need to continue to treat and generate waste at risk, primarily to minimize schedule, calculations have been done that show that net peak accumulation would range from 114 canisters ( $15 \%$ of the 778 total) for a 2.5 -year campaign to $478(61 \%)$ for a 1-year campaign, given a WIPP RH receipt rate limitation of 6 canisters per week. It would take 2.7 years for WIPP to take all the DV RH glass at a rate of 6 canisters/week, 300/year. For a 2.5-year campaign it would take an additional 1-month, until March 31, 2017, to complete shipment of this accumulated inventory to WIPP with a project start date of February 1, 2005 and an end of treatment date of February 28, 2017. For a one-year campaign it would take an additional 19 months to January 31, 2017 after an end of treatment date of June 30, 2015.

In the 2.5-year campaign scenario (38 months total, 2 months for a WIPP imposed shutdown, plus 6 months for a major maintenance turnaround) the December 2012 milestone is missed by 50 months for treatment and 51 months for shipment to WIPP. In the 1-year campaign scenario (18 months total, 6 months for a major maintenance turnaround with the 2 month WIPP-imposed shutdown inside this) the December 2012 milestone is still missed by 30 months for treatment and 49 months for shipment to WIPP.

As can be seen above, even the 1-year treatment scenario, which would be very aggressive, is not attractive since the 2012 milestones are still missed by many months. It should be considered that the overall DV schedule is more aggressive and hence less realistic than that for the other similar large, complex, high temperature thermal treatment alternatives - CMACT and SR. The Preliminary Design schedule is particularly aggressive - significant technical development work would be necessary in order to define the process, develop and fix the P\&IDs, and detail out the equipment and facility designs to the extent necessary to support completion and submittal of the environmental permit applications, which are critical path on the front end of the schedule. Also, operationally, striving for an aggressive one-year treatment period for direct vitrification, being new, complex, and significantly different than calcination, for example, with which INTEC has many years of operating experience, would be quite risky. As pointed out earlier in this report, the potential for off-normal conditions exists such that operational problems could result in a longer startup or more frequent shutdowns of the process, extending the treatment schedule. The 2.5-year treatment schedule is recommended even though it misses the 2012 treatment milestone by an additional 20 months, but the 2012 shipment milestone by only an additional 2 months.

Shorter SBW treatment operating periods (faster throughput), such as the 1-year period cited above, may be possible (but risky) with the DV process, if necessary, in an attempt to minimize schedule and get closer to the 2012 treatment milestone. However, besides being quite aggressive itself, this would aggravate the lag storage situation even further and significantly add to the capital project cost to provide for an additional 364 canister storage positions.

\subsubsection{Schedule - Summary}

\section{The 2012 milestone schedule cannot be achieved with the direct vitrification SBW treatment alternative. Schedule risks have been identified and include:}

- $\quad$ Beginning Preliminary (Title I) Design activities on February 1, 2005. Any delay releasing this work will impact project completion.

- Completing sufficient technical development test work to support process definition and Preliminary (Title I) Design activities so that environmental permits can be prepared and submitted 
by October 1, 2006. Any delays in this set of activities, being on the critical path schedule, will impact project completion.

- An environmental permitting timeframe of 24 months, especially in light of opposition to thermal treatment by various stakeholders.

- $\quad$ DOE funding, reviews, and approvals. The schedule assumes funding will be available in a timely manner and will not impact design, procurement, or construction.

- $\quad$ Technical development (process testing) as this information iterates with Final (detailed) as well as Preliminary Design.

- $\quad$ Mock-up testing of glass packaging system equipment as this information iterates with detailed design.

- $\quad$ GFE procurement as it feeds into mock-up testing and design.

- $\quad$ Testing, operational readiness reviews (ORRs), startup, WIPP certification, and Trial Burn.

- $\quad$ Treatment over a 3-year period.

In addition to the risks listed above, normal risks associated with a project of this size and complexity can be expected, including availability of skilled craftsmen, weather impacts, and timely delivery of equipment and materials. 


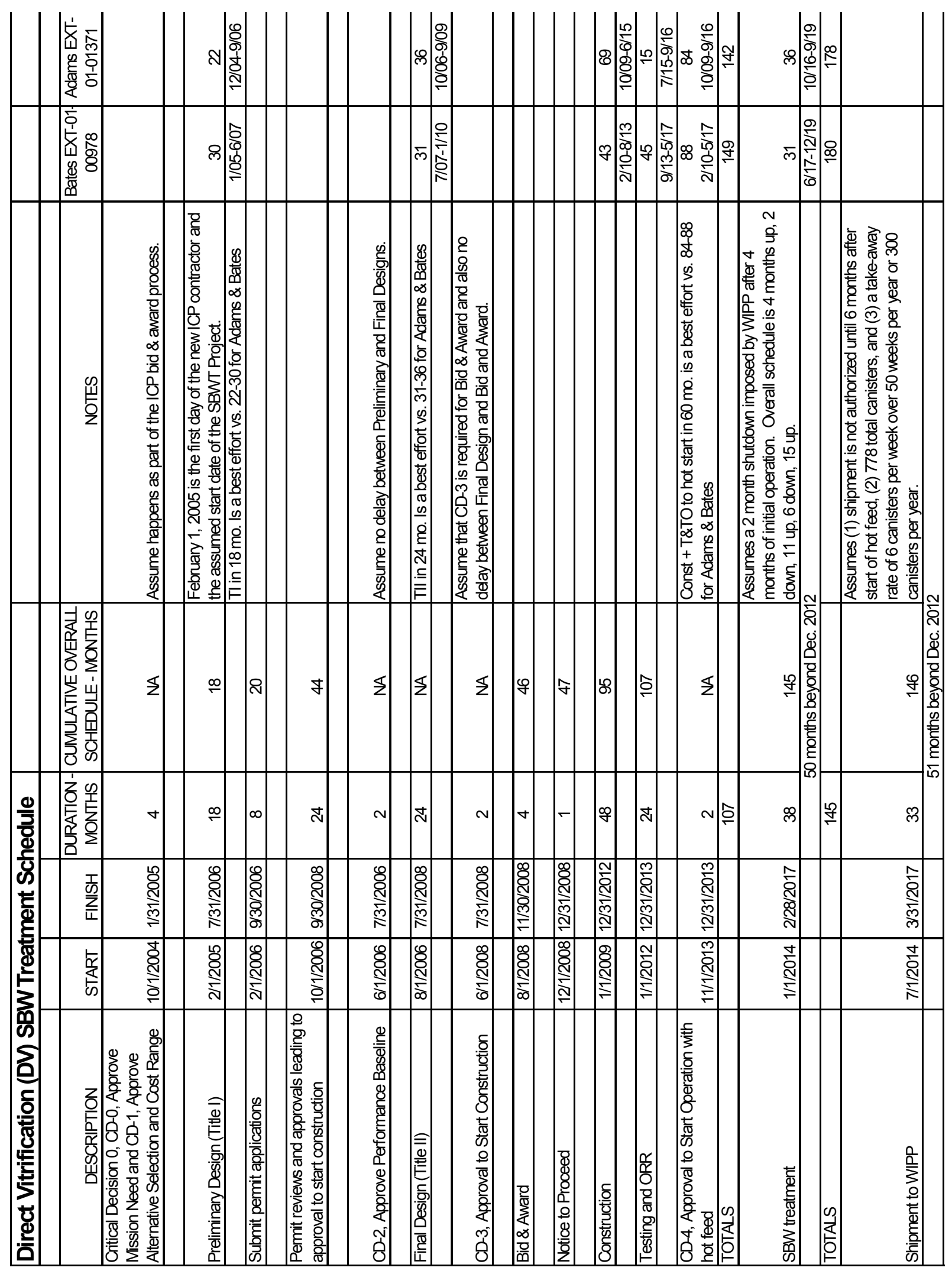




\section{DV product generation and storage}

Based on detailed discussions between WIPP, DOE-ID, \& DOE-HQ in 2002/03, assume 300 RH shipments (1 canister/shipment) to WIPP per year ( $\sim 6 /$ week).

\begin{tabular}{|l|l|l|l|}
\hline & & & \\
\hline Assume 2.5 years of operation over a 3.2 year (38.0 month) span producing 778 total canisters.
\end{tabular}

Assumes a 2 month shutdown imposed by WIPP after 4 months of initial operation, adding 2 months to the overall schedule. Overall schedule is 4 months up, 2 down, 11 up, 6 down, 15 up for 38 months total.

\begin{tabular}{r|r|}
\hline & \\
\hline & \\
\hline & \\
\hline 122 & days (4 months) up w/o shipment - produce \\
\hline 61 & days (2 months) down w/o shipment - produce \\
\hline 335 & days (11 months) up w/shipment - produce \\
\hline 183 & days (6 months) down w/shipment - produce \\
\hline & \\
\hline 456 & days (15 months) up w/shipment - produce \\
\hline & \\
\hline 1156 & TOTAL = 38 months (3.2 years) \\
\hline & \\
\hline & \\
\hline Asume & \\
\hline &
\end{tabular}

\begin{tabular}{l|l|r|l}
\hline & & \\
& & & \\
canisters & $\begin{array}{c}\text { Calendar days } \\
\text { "up" }\end{array}$ & $\begin{array}{l}\text { canisters/ } \\
\text { operating day }\end{array}$ \\
\hline 778 & 913 & 0.8526 \\
\hline & 2.5 years & \\
\hline 104 & ship & 0 \\
\hline & ship & 0 \\
\hline 0 & ship & 275 \\
\hline 285 & ship & 114 \\
\hline & ship & 375 \\
\hline 0 & & \\
\hline 389 & & \\
\hline 778 & & \\
\hline & & &
\end{tabular}

Assume 1.0 year of operation over a 1.5 year (18.0 month) span producing 778 total canisters.

Assumes a 2 month shutdown imposed by WIPP after 4 months of initial operation, not adding time to the overall schedule (see next assumption).

\begin{tabular}{|l|l|l}
\hline Assume that during the WIPP induced shutdown a major maintenance turnaround occurs (the only one) of six months total. \\
\hline
\end{tabular}

Assume that 2 months into the shutdown WIPP authorizes shipment, which can be done without out reducing rate during the maintenance turnaround.

Overall schedule is 4 months up, 6 down, 8 up for 18 months total.

\begin{tabular}{|c|c|c|c|c|c|c|c|}
\hline & & canisters & $\begin{array}{c}\text { Calendar days } \\
\text { "up" }\end{array}$ & \begin{tabular}{|l|} 
canisters/ \\
operating day
\end{tabular} & $\begin{array}{c}\text { canister per } 7 \\
\text { day week }\end{array}$ & $\begin{array}{c}\text { Idaho net } \\
\text { accumulation/day }\end{array}$ & $\begin{array}{c}\text { Idaho net } \\
\text { accumulation/week }\end{array}$ \\
\hline & & 778 & 365 & 2.1315 & 14.92 & 1.27 & 8.92 \\
\hline & & & 1.0 year & & & & \\
\hline 122 & days (4 months) up w/o shipment - produce & 259 & ship & 0 & store & 259 & \\
\hline & & & & & & & \\
\hline 61 & days (2 months) down w/o shipment - produce & 0 & ship & 0 & store & 259 & \\
\hline 122 & days (4 months) down w/shipment - produce & 0 & ship & 100 & store & 159 & \\
\hline & & & & & & & \\
\hline 243 & days (8 months) up w/shipment - produce & 519 & ship & 200 & store & 478 & peak storage need \\
\hline & & & & & Ship the $478 \mathrm{c}$ & nisters off to WIPP & over another \\
\hline 548 & TOTAL $=18$ months ( 1.5 years $)$ & 778 & & & 19 months $(1.6$ & years) & \\
\hline & & & & & & & \\
\hline & & & & & & & \\
\hline Assume & treatment rate matched to the shippi & rate to V & PP to minimiz & e lag storage & & & \\
\hline Calculates & out to be 2.6 years of operation over 42.1 month & 3.5 years) $p$ & ducing 778 total c & canisters. & & & \\
\hline Assumes a & a 5 month shutdown imposed by WIPP after $1 \mathrm{~m}$ & of initial o & ration, adding $5 \mathrm{n}$ & nonths to the ove & rall schedule. & & \\
\hline$\overline{\text { Overall sch }}$ & hedule is 1 month up (for minimal production $\& h$ & e storage), & down, $17 \mathrm{up}, 6 \mathrm{dc}$ & own, 13.1 up for & 42.1 months tot & & \\
\hline & & & & & & & \\
\hline & & canisters & $\begin{array}{l}\text { Calendar days } \\
\text { "up" }\end{array}$ & $\begin{array}{l}\text { canisters/ } \\
\text { operating day }\end{array}$ & $\begin{array}{c}\text { canister per } 7 \\
\text { day week }\end{array}$ & $\begin{array}{c}\text { Idaho net } \\
\text { accumulation/day }\end{array}$ & $\begin{array}{c}\text { Idaho net } \\
\text { accumulation/week }\end{array}$ \\
\hline & & 778 & 947 & 0.8219 & 5.75 & 0.00 & 0.00 \\
\hline & & & 2.6 years & & & & \\
\hline 30 & days (1 month) up w/o shipment - produce & 25 & ship & 0 & store & 25 & peak storage need \\
\hline 152 & 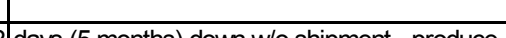 & O & chin & 0 & ctore & 25 & monk ctoramenond \\
\hline & jaays (5 montns) down W/o snipment - proauce & 0 & Snip & 0 & Store & 25 & peak storage need \\
\hline 517 & days (17 months) up w/shipment - produce & 425 & ship & 425 & store & 25 & peak storage need \\
\hline 183 & days (6 months) down w/shipment - produce & 0 & shin & 25 & store & 0 & \\
\hline
\end{tabular}




\subsection{Major Options}

An option within the baseline concept would be to slow down treatment to match the RH receipt/disposal rate at WIPP in order to minimize the size of lag storage in Idaho or eliminate it all together. In conjunction with this, a decision could be made not to proceed with treatment while WIPP reviews the overall process/program prior to authorizing initial shipment. This would additionally save the assumed four months of lag storage of waste produced "at risk" in the early stage of treatment. The two steps combined would save approximately $\$ 30 \mathrm{M}$ in capital project costs, but add 10 months to the 2.5-year schedule and 30 months to the 1-year schedule, both well beyond 2012 .

\subsection{References}

Adams, et al, (2001), Idaho Waste Vitrification Facilities project Preliminary Schedule Report, INEEL/EXT-01-01371, November 2001.

Barnes C. M., A. L. Olson, D. D. Taylor, (2004a), Sodium-Bearing Waste Treatment Technology Evaluation Report, INEEL/EXT-04-01692, February 2004.

Barnes C. M., C. B. Millet, (2004b), Feed Composition for the Sodium-Bearing Waste Treatment Process, INEEL/EXT-2000-01378, Revision 4, June 2004.

Barnes C. M., (2001), "Evaluation of SBW Vitrification Process Alternatives," INEEL Interoffice Memorandum CMB-11-01 to T. T. Nichols, November 5, 2001.

Batcheller, T. A., D. D. Taylor, (2003), Characterization of Tank WM-189 Sodium-Bearing Waste at the Idaho Nuclear Technology and Engineering Center, INEEL/EXT-02-01171 Rev. 1, July 2003.

Bates, S. O., B. D. Raivo, J. J. Quigley, S. M. Berry, W. H. Landman, S. L. Palmer, and T. M. Hipp, (2001), Feasibility Study for Vitrification of Calcine in the Idaho Waste Vitrification Facility, INEEL/EXT-01-00978, Vol. I \& II, September 2001.

Boardman, R. D., B. H. O’Brien, N. R. Soelberg, S. O. Bates, R. A. Wood, and C. St. Michael, (2004), High Temperature Calcination - MACT Upgrade Pilot Plant Tests, INEEL/EXT-04-01625, February, 2004.

Childs, K., B. Lilburn, (2000), Customer Requirements of INEEL Sample Analysis Services, INEEL/INT-2000-01393, November 2000.

Darab, J. G., D. D. Graham, B. D. MacIsaac, R. L. Russell, H. D. Smith, J. D. Vienna, D. K. Peeler, (2001), Sulfur Partitioning During Vitrification of INEEL Sodium Bearing Waste: Status Report, PNNL-13588, July 2001.

Del Debbio, J. A., T. L. Watson, J. B. Heintzelman, (2003), Long-Term Performance of SulfurImpregnated, Granulated Activated Carbon (GAC) for Mercury Removal From NWCF Off-Gas, INEEL/EXT-03-01102, September, 2003.

DOE, (1999) "Advance Notice of Proposed Rulemaking; Potential Revisions to the Land Disposal Restrictions Mercury Treatment Standards," United State Government Memorandum, June 7, 1999. 
Envirocare, (2000), "Envirocare Successfully Treats NFS Mercury Waste," http://envirocareutah.com/pages/ecnews/ec successfully NFS.html.

Goles, R. W., J. A. Del Debbio, R. J. Kirkham, B. D. MacIsaac, J. A. McCray, D. D. Siemer, N. R. Soelberg, (2002), Test Summary Report INEEL Sodium-Bearing Waste Vitrification Demonstration RSM-01-2, PNNL-13869, May, 2002.

Groshner, M. S. (1996), "Update of Safety Concerns for the NWCF Sodium Bearing Waste Project Options," Lockheed Martin Idaho Technologies Company Interdepartmental Communications MSG-43-96, November 26, 1996; included as Appendix C5 in Henry Welland, NWCF Process Modification for Sodium-Bearing Waste Project Conceptual Design, INEL/INT-97-00075, April 1997.

Grunewald, W., G. Roth, W. Tobie, S. Weisenburger, K. Weiss, M. Elliott, L. L. Eyler, (1996), Vitrification of Noble Metals Containing NCAW Simulant with an Engineering Scale Melter (ESM): Campaign Report, PNNL-11010, March 1996.

Herbst, A. K., J. A. Del Debbio, R. J. Kirkham, B. A. Scholes, T. L. Watson, (2002), Idaho Nuclear Engineering Center Sodium-Bearing Waste Treatment Research and Development FY-2002 Status Report, INEEL/EXT-02-00985, September, 2002.

Hulet, G. A., V. C. Maio, M. I. Morris, "Demonstrations to Support Change to the $>260$ ppm Mercury Treatment Regulations," WM'01 Conference, February 25-March 1, Arizona.

Olsen, L. G., (2001), Radioactive Crucible Scale Melts Using INTEC Tank WM-180 Sodium-Bearing Waste, INEEL/EXT-01-01020, September 2001.

Peeler, D. K., T. B. Edwards, I. A. Reamer, R. J. Workman, J. D. Vieea, J. V. Crum, M. J. Schweiger, (2001), Glass Formulation Development For INEEL Sodium-Bearing Waste (FY2001 WM-180), WSRC-TR-2001-00295, Rev. 0, July 2001.

Perry, K. J., R. R. Kimmitt, N. R. Soelberg, R. D. Tillotson, A. N. Olson, (2001), Test Results from SBW-FY-01-PS-01 Vitrification Demonstration of Sodium Bearing Waste Simulant Using WM180 Surrogate, INEEL/EXT-01-01073, August 2001.

Quigley, J. J., (2001), “Material Balance for Vitrification of SBW Liquids and Solids,” Engineering Design File EDF-1680, Rev. 3, June 29, 2001.

Quigley, J. J., B. D. Raivo, S. O. Bates, S. M. Berry, D. N. Nishioka, P. J. Bunnell, (2000), Feasibility Study for Vitrification of Sodium-Bearing Waste, INEEL/EXT-2000-00952, September 2000.

Taylor, D. D., C. M. Barnes Review of FY2001 Development Work for Vitrification of Sodium Bearing Waste, INEEL/EXT-02-00194, September 2002.

Taylor, D., C. Barnes L. Lauerhass, (2001), INEEL SBW Vitrification Process, INEEL/EXT-01-01139, September 2001.

Vienna, J. D. and D. K. Peeler to A. L. Olson and C. A. Musick, (1999), "Waste Loading Estimates for INEEL HAW," April 22, 1999. 


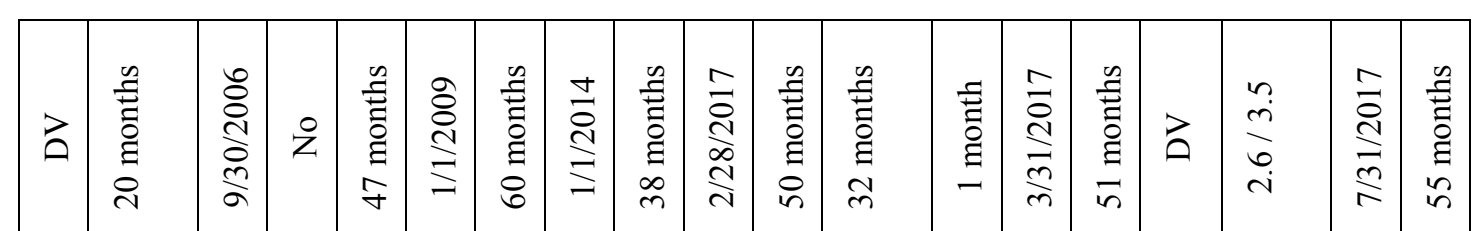

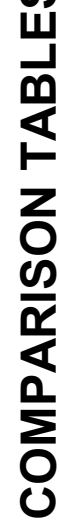

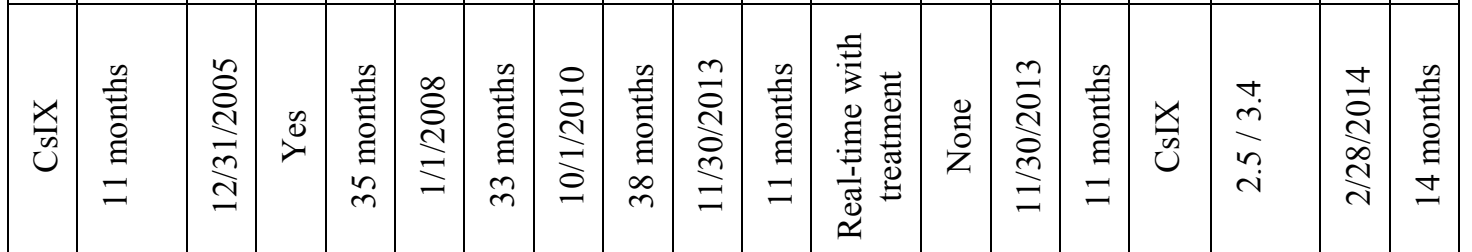

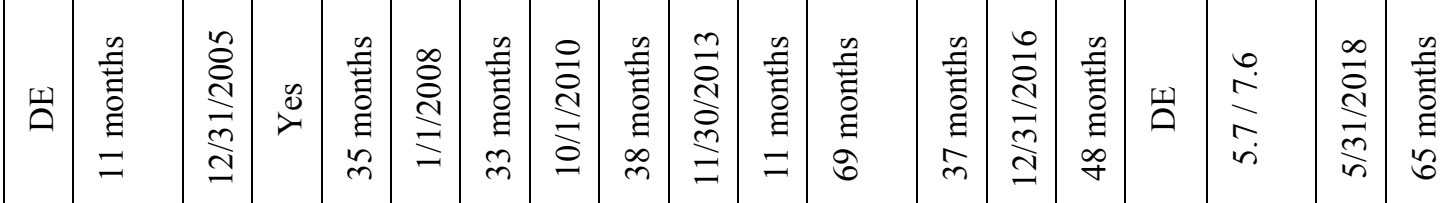

岁

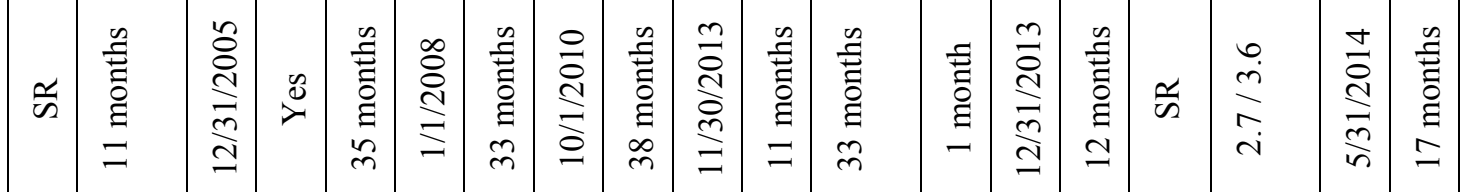

\section{盖}

山

点

只

崖窎

1 它

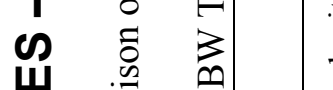

$\sum \begin{array}{ll}\text { Z } & \text { n } \\ & n\end{array}$

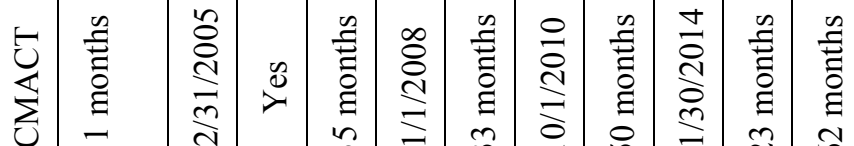

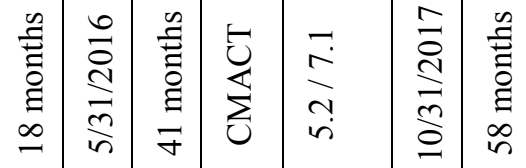






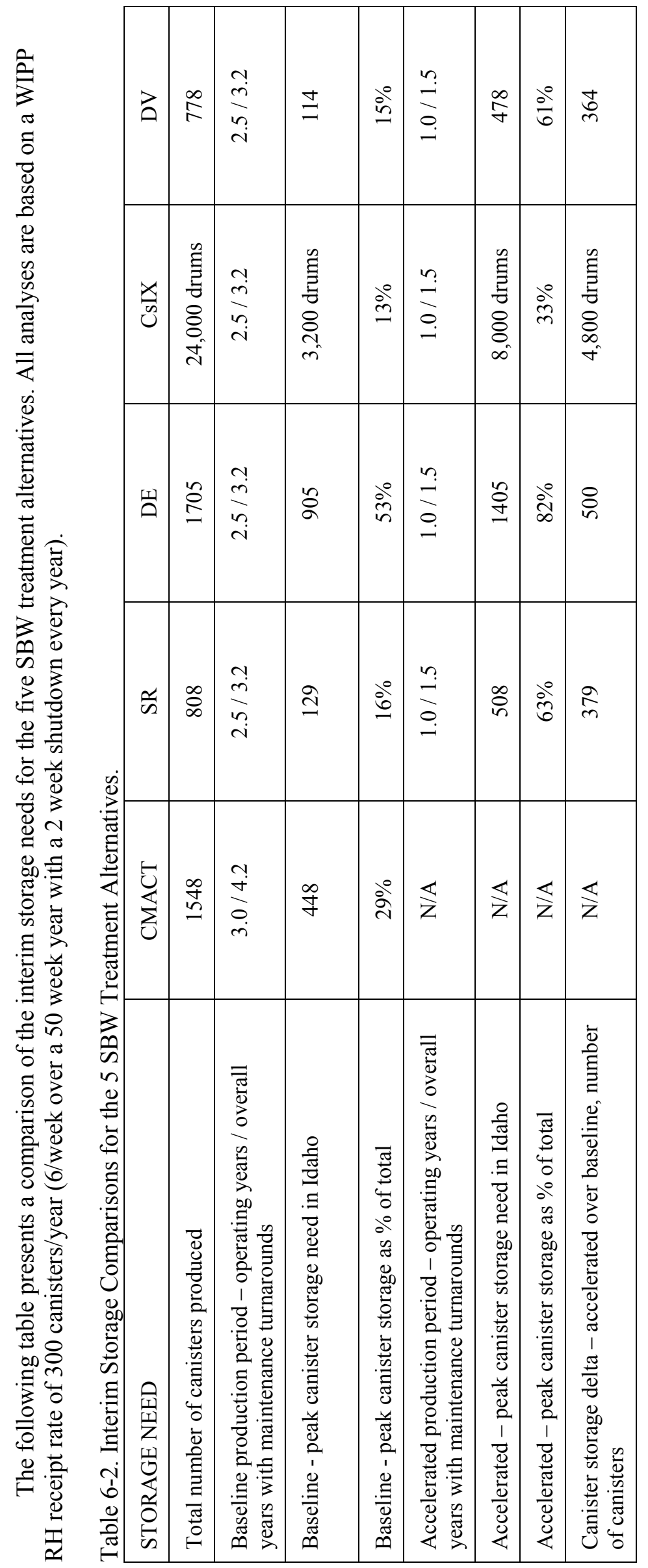

